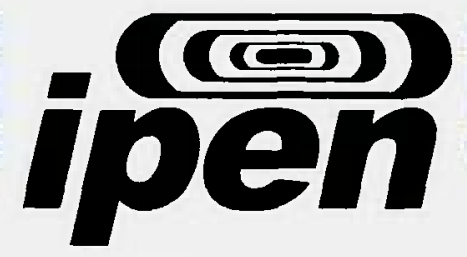

AUTARQUIA ASSOCIADA A UNIVERSIDADE DE SÃO PAULO

\title{
ESTUDOS ARQUEOMÉTRICOS DE SÍTIOS ARQUEOLÓGICOS DO BAIXO SÃO FRANCISCO
}

\author{
JOSÉ OSMAN DOS SANTOS
}

Tese apresentada como parte dos requisitos para obtenção do Grau de Doutor em Ciências na Área de Tecnologia Nuclear - Aplicações.

Orientador:

Dr. Casimiro Sepúlveda Munita 


\section{INSTITUTO DE PESQUISAS ENERGÉTICAS E NUCLEARES}

Autarquia associada à Universidade de São Paulo

ESTUDOS ARQUEOMÉTRICOS DE SÍTIOS ARQUEOLÓGICOS DO BAIXO SÃO FRANCISCO

JOSÉ OSMAN DOS SANTOS

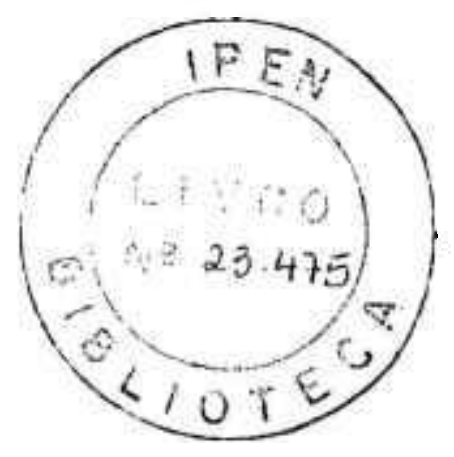

Tese apresentada como parte dos requisitos para obtenção do Grau de Doutor em Ciências na Árè de Tecnologia Nuclear - Aplicações

Orientador:

Dr. Casimiro Sepúlveda Munita

\section{SÃo PAULO}

2007 


\section{INSTITUTO DE PESQUISAS ENERGÉTICAS E NUCLEARES}

Autarquia associada à Universidade de São Paulo

\section{ESTUDOS ARQUEOMÉTRICOS DE SÍTIOS ARQUEOLÓGICOS DO BAIXO SÃO FRANCISCO}

JOSÉ OSMAN DOS SANTOS

Tese apresentada como parte dos requisitos para obtenção do Grau de Doutor em Ciências na Área de Tecnologia Nuclear - Aplicações

Orientador:

Dr. Casimiro Sepúlveda Munita

\section{SĀO PAULO}


Aos Meus pais, Sr. João Cipó e Sra. Maria Aparecida, pelo apoio, força, por ensinar a lutar pelos meus objetivos e, acima de tudo, ser uma pessoa digna.

Aos meus irmãos, Ângela Cristina, Patrícia, Alberto, Oscimar e Wagner; aos cunhados (Zé sebo e Vânia) e sobrinhos (Anne, Wallace e Laís) pelo carinho, amor e pela linda família que formamos.

Aos meus sogros, Sr. Manuel e Sra. Helenita, pela confiança e pelo apoio nos momentos que precisei estar ausente.

\section{OFEREÇO}

À Adriana pelo amor, paciência e pela Sarah Gabrielle, que tem irradiado nossas vidas com muita luz e alegria. 


\section{AGRADECIMENTOS}

À Deus e as forças que iluminam nossos caminhos.

Ao Prof. Dr. Casimiro Sepúlveda Munita pela orientação, pela confiança depositada, estímulo e pela amizade.

À Coordenação de Aperfeiçoamento de Pessoal de Nível Superior (CAPES) e ao Conselho Nacional de Desenvolvimento Científico e Tecnológico (CNPq) pela concessão da bolsa de estudo.

Aos Professores Dr. Mario Ernesto Giroldo Valerio e Dra. Linda Caldas pela confiança na minha inclusão no projeto PROCAD - UFS/IPEN, o qual viabilizou a execução deste trabalho, e pela amizade.

À todos os funcionários do Museu de Arqueologia de Xingó, em especial, ao Dr. José Alexandre Felizola Diniz, à Dra. Cleonice Vergne e à Econ. Maria Luzia Menezes Vieira, pela atenção, amizade e auxilio que tanto contribuíram na execução do trabalho.

Ao Dr. Jorge Sarkis pelas valiosas contribuições ao longo de todo trabalho.

À Dra. Marina Vasconcellos e a todos os funcionários e companheiros da Divisão de Radioquímica do IPEN.

À Dra. Mitiko Saiki pelos auxílios e orientações indispensáveis nos laboratórios da Radioquímica do IPEN.

As amigas, agora irmãs, Andreza e Luciana, que compartilharam todos os momentos agradáveis e desagradáveis no período de execução de trabalho. Juntos conseguimos transpor todas as barreiras, o que tornou prazerosa a convivência em São Paulo.

À Tia Elza por acolher-me em teu lar em momentos dificeis desta jornada.

Ao Dr. Emerson que, mesmo longe, foi uma fonte de inspiração para a pesquisa. 
À todos aqueles que compartilharam, direta ou indiretamente, na concretização desté trabalho.

À minha família que, apesar da distância, contribuíram decididamente para que pudesse transpor mais etapa da minha vida. 
"Tupi or not Tupi, that is the question" (Oswald de Andrade) 


\title{
ESTUDOS ARQUEOMÉTRICOS DE SITIOS ARQUEOLÓGICOS DO BAIXO SÃO FRANCISCO
}

\author{
José Osman dos Santos
}

\begin{abstract}
RESUMO
O estudo minucioso das características físicas e químicas dos artefatos cerâmicos, associado com as pesquisas históricas e arqueológicas tem permitido a reconstituição dos costumes culturais e modos de vida das comunidades antigas. O presente estudo objetivou estudar composição química elementar e mineralógica de cerâmicas arqueológicas coletadas nos sítios Justino, São José, Curituba, Saco da Onça, Porto Belo e Vitória Régia, localizados na região do Baixo São Francisco, Sergipe, Brasil. Por meio da análise por ativação com nêutrons instrumental (AANI) e difratometria de raios - X (DRX), permitiuse definir grupos composicionais de cerâmicas conforme a similaridade química da pastas cerâmica, a qual reflete a composição da matéria-prima utilizada em sua manufatura pelo homem pré-histórico, e inferir a atmosfera e temperatura de queima da cerâmica. As amostras aberrantes foram identificadas por meio das distâncias Mahalanobis clássica e robusta. O efeito do tempero na pasta cerâmica foi estudado por meio do filtro de Mảhalanobis modificado. Os resultados foram interpretados por meio da análise de agrupamento, análise das componentes principais e análise discriminante. O horizonte temporal das cerâmicas foi verificàdò por meio de técnicas de datação termoluminescência (TL). Os resultados obtidos neste trabalho, em asşociação com informações oriundas da Arqueologia, permitiram a identificação dos grupos cerâmicos correspondentes às ocupações ceramistas no sítio Justino e a definição de grupos cerâmicos de referência conforme o comportamento químico. A tecnologia de queima foi estabelecida para alguns vasos cerâmicos, bem como a contemporancidade dos grupos composicionais segundo as datações determinadas por TL. Dessa forma, o trabalho contribui para a reconstituição da pré-história das comunidades que habitaram a região do Baixo Rio São Francisco e para remontagem do quadro geral das populações ceramistas do Nordeste brasileiro.
\end{abstract}




\title{
ARCHAEOMETRICS STUDIES OF ARCHAEOLOGICAL SITES FROM BAIXO SÃO FRANCISCO
}

\author{
José Osman dos Santos
}

\begin{abstract}
The study of the physical and chemical characteristics of the ceramics crafts, in association with historical and archaeological research, has allowed for the reconstruction of the cultural habits from ancient communities. The goal of this work was to study the chemical and mineralogical compositions of archaeological potteries collected from Justino, São José, Curituba, Saco da Onça, Porto Belo and Vitória Régia sites, located in Baixo São Francisco region, Sergipe state, Brazil. The use of the instrumental neutron activation analysis (INAA) and X-ray diffractometry (XRD), allowed the definition of compositional groups of potteries according to the chemical similarities of the ceramic paste, which reveals the composition of the raw materials utilized in the manufacturing process by prehistoric man, and the inference of the atmosphere and temperatures in which the potteries were burned. The outliers were identified by means of classic and robust Mahalanobis distance. The temper effect in the ceramic paste was studied by means of modified Mahalanobis filter. The results were interpreted by means of cluster analysis, principal components analysis and discriminant analysis. The ages of some potteries were determined by means of the thermoluminescence techniques. The results obtained in this work, in association with archaeological information, allowed for the identification of the ceramic groups relative to ceramist occupations at Justino Site and for the definition of the reference groups according to the chemical composition. The burning technology was established for some potteries and the relative ages among the compositional groups were determined by means of TL. Thus, this work provides contributions to the reconstruction of the prehistory of the communities which lived in the Baixo São Francisco region, and to the reconstitution of the general frame of the ceramist population from Brazilian Northeast.
\end{abstract}




\section{SUMÁRIO}



2 OBJETIVOS

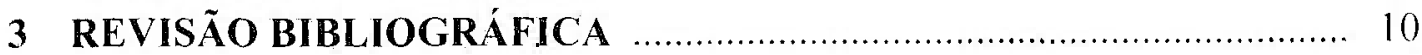

3.1 Pesquisas realizadas no Nordeste brasileiro ..................................... 10

3.2 Comentários sobre as pesquisas arqueológicas de Xingó $\quad \ldots \ldots \ldots \ldots \ldots \ldots \ldots \ldots \ldots \ldots \ldots$

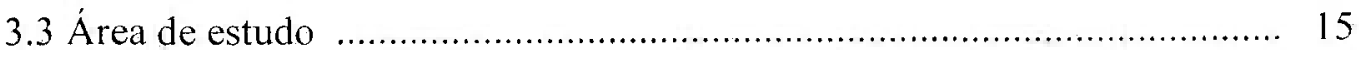

3.3.1 Considerações sobre a cerâmica pré-histórica de Xingó …............ 18

3.3.2 Breve descrição dos sítios arqueológicos estudados f.................. 21

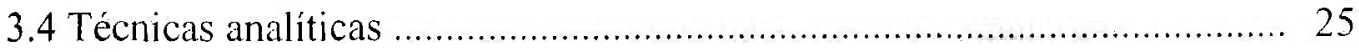

3.4.1 Análise por ativação com nêutrons …......................................... 25

3.4.2 Difratometria de raios-X f.................................................... 29

3.4.3 Datação por termoluminescência ............................................... 31

3.5 As argilas e os estudos arqueométricos f......................................... 35

3.6 Técnicas estatísticas multivariadas utilizadas ................................... 38

3.6.1 Amostras aberrantes ...................................................... 38

3.6.2 Normalização e padronização dos dados ................................ 42



3.6.4 Análise por componentes principais ........................................ 45



3.6.6 Fator de diluição ............................................................... 49

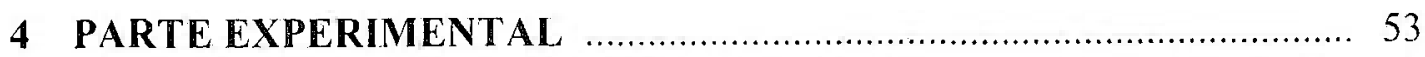

4.1 Preparação das amostras para AANI .............................................. 53

4.2 Preparação das amostras para DRX .................................................. 54 
4.3 Preparação das amostras para TL

4.4 Composição química elementar por AANI .......................................... 55

4.5 Composição mineralógica por DRX .................................................. 57

4.6 Datação por TL ............................................................................. 57

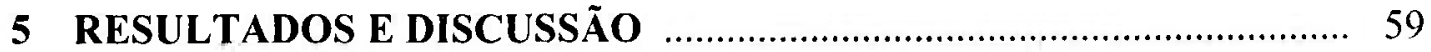



5.2 Normalização e padronização dos dados ...................................................6. 64

5.3 Identificação das amostras aberrantes .................................................... 67

5.4 Definição dos grupos composicionais …......................................... 81

5.4.1 Sítio Justino: Comparação entre os Cemitérios B e C ................... 81

5.4.2 Comparação entre os sítios São José, Saco da Onça e Curituba .... 89

5.4.3 Ocupações antigas: Comparação entre o Cemitério B e o sítio São José

5.4.4 Ocupações recentes: Comparação entre os sítios Porto Belo, Saco da Onça Vitória Régia e Curituba

5.4.5 Sítios de cronologias diferenciadas: Comparação entre os sítios Porto Belo, Justino (B) e Curituba 100

5.5 Datação termoluminescente 102

5.6 Temperatura de queima e composição mineralógica 109

6 CONCLUSÕES 113

SUGESTÕES PARA TRABALHOS FUTUROS. 115 REFERÊNCIAS BIBLIOGRÁFICAS 


\section{LISTA DE TABELAS}

Tabela 4.1 Radioisótopos utilizados para análise química das cerâmicas e seus principais parâmetros nucleares

Tabela 5.1 Resultados para os materiais de referências Soil-7 e Brick Clay....

Tabela 5.2 Resultados das concentrações e distâncias Mahalanobis para amostras do sítio Justino (Superficie).

Tabela 5.3 Resultados das concentrações e distâncias Mahalanobis para amostras do sítio Justino (Cemitério A) 68

Tabela 5.4 Resultados das concentrações e distâncias Mahalanobis para amostras do sítio Justino (Cemitério B)

Tabela 5.5 Resultados das concentrações e distâncias Mahalanobis para amostras do sítio Justino (Cemitério C)

Tabela 5.6 Resultados das concentrações e distâncias Mahalanobis para amostras do Curituba

Tabela 5.7 Resultados das concentrações e distâncias Mahalanobis para amostras do sítio São José

Tabela 5.8 Resultados das concentrações e distâncias Mahalanobis para amostras do sítio Vitória Régia.

Tabela 5.9 Resultados das concentrações e distâncias Mahalanobis para amostras do sítio Saco da Onça 74

Tabela 5.10 Resultados das concentrações e distâncias Mahalanobis para amostras do sítio Porto Belo 75

Tabela 5.11 Tabela com número de amostras e o número total de amostras após eliminação das aberrantes

Tabela 5.12 Composição química média para os cemitérios B e C do Justino 87 
Tabela 5.13 Composição química média para os sítios São José, Saco da Onça e Curituba. 92

Tabela 5.14 Composição química média para os sítios Porto Belo e Vitória Régia 99

Tabela 5.15 Valores das paleodoses determinadas por TL 107

Tabela 5.16 Concentrações de ${ }^{238} \mathrm{U},{ }^{232} \mathrm{Th}$ e ${ }^{4(1)} \mathrm{K}$ nas amostras datadas neste trabalho e a taxa anual de radiação 108

Tabela 5.17 Idades calculadas para os fragmentos cerâmicos estudados 108 


\section{LISTA DE FIGURAS}

Figura 3.1 Mapa da área estudada

Figura 3.2 Vista aérea da Unidade Hidrelétrica de Xingó.

Figura 3.3 Vista do sítio Jerimum escavado na segunda etapa do PAX.

Figura 3.4 Alagamento parcial do Sítio Justino. 16

Figura 3.5 Mapa de localização dos sítios estudados.

Figura 3.6 Alguns aspectos da característica geoambiental da área estudada.....

Figura 3.7 Cerâmicas dos sítios de Xingó.

Figura 3.8 Enterramentos e adornos do sítio Justino 24

Figura 3.9 Fenômenos envolvidos na ativação de um núcleo. 27

Figura 3.10 Representação dos planos cristalinos 31

Figura 3.11 Esquema dos processos envolvido na termoluminescência. 34

Figura 3.12 Gráfico da altura do pico em função da dose (idade). 34

Figura 3.13 Estrutura da caulinita 36

Figura 3.14 Gráfico das variáveis em função das componentes principais. 46

Figura 4.1 Etapas da preparação da amostras para análise por ativação. 54

Figura 4.2 Espectrômetro de raios gama 57

Figura 5.1 Gráfico dos $Z_{\text {escoies }}$ para o material Brick Clay - NIST-SRM-679...

Figura 5.2 Gráfico dos $Z_{\text {escores }}$ para o material IAEA - Soil7.

Figura 5.3 Comparação das concentrações com as obtidas por Kullef.

Figura 5.4 Comparação das concentrações com as obtidas por Bishop. 
Figura 5.5 Distribuição de Cs e Eu de amostras do sítio Porto Belo 66

Figura 5.6 Identificação de amostras aberrantes do sítio Jusțino (Superficial) por meio da distância Mahalanobis robusta. 76

Figura 5.7 Identificação de amostras aberrantes do sítio Justino (Cemitério A) por meio da distância Mahalanobis robusta 76

Figura 5.8 Identificação de amostras aberrantes do sítio Justino (Cemitério B) por meio da distância Mahalanobis robusta 77

Figura 5.9 Identificação de amostras aberrantes do sítio Justino (Cemitério C) por meio da distância Mahalanobis robusta 77

Figura 5.10 Identificação de amostras aberrantes do sítio Curituba por meio da distância Mahalanobis robusta 78

Figura 5.11 Identificação de amostras aberrantes do sítio São José por meio da distância Mahalanobis robusta 78

Figura 5.12 Identificação de amostras aberrantes do sítio Vitória Régia por meio da distância Mahalanobis robusta 79

Figura 5.13 Identificação de amostras aberrantes do sítio Saco da Onça por meio da distância Mahalanobis robusta.. 79

Figura 5.14 Identificação de amostras aberrantes do sítio Porto Belo por meio da distância Mahalanobis robusta.

Figura 5.15 Scree Plot para identificação dos componentes do Sítio Justino.....

Figura 5.16 Biplot para amostras do Justino (Cemitério A), Cemitério B e C..... 
Figura 5.17 Dendrograma para amostras dos Cemitérios B e C do sítio Justino

Figura 5.18 Funções discriminantes para cerâmicas dos Cemitérios B e C do sítio Justino

Figura 5.19 Funções discriminantes para cerâmicas dos Cemitérios B e C do

Sítio Justino, após eliminação de Th e Cr.

Figura 5.20 Funções discriminantes para cerâmicas dos Cemitérios B e C do sítio Justino, após correção com os fatores de diluição.

Figura 5.21 Diferença padronizada das composições médias das cerâmicas dos Cemitérios B e C do sítio Justino

Figura 5.22 Scree Plot para identificação das componentes dos sítios São José, Saco da Onça e Curituba

Figura 5.23 Biplot para amostras dos sítios São José, Saco da Onça e Curituba... 90

Figura 5.24 Funções discriminantes para cerâmicas dos sítios São José, Saco da

Onça e Curituba

Figura 5.25 Funções discriminantes para cerâmicas dos sítios São José, Saco da Onça e Curituba, após eliminação de Lu, Yb, La e Hf.

Figura 5.26 Funções discriminantes para cerâmicas dos sítios São José, Saco da Onça e Curituba, após correção com os fatores de diluição.

Figura 5.27 Diferença padronizada das composições médias das cerâmicas dos sítios Saco da Onça e São José. 
Figura 5.28 Diferença padronizada das composições médias das cerâmicas dos sítios Saco da Onça e Curituba.

Figura 5.29 Diferença padronizada das composições médias das cerâmicas dos sítios São José e Curituba

Figura 5.30 Funções discriminantes para cerâmicas do sítio Justino (Cemitério B) e do sítio São José. 96

Figura 5.31 Funções discriminantes para cerâmicas do sítio Justino (Cemitério B) e do sítio São José, após correção com fatores de diluição. 96

Figura 5.32 Diferença padronizada das composições químicas das cerâmicas dos Sítios São José e Cemitério B

Figura 5.33 Funções discriminantes para cerâmicas dos sítios Saco da Onça, Curituba, Porto Belo e Vitória Régia 98

Figura 5.34 Funções discriminantes para cerâmicas dos sítios Saco da Onça, Curituba, Porto Belo e Vitória Régia, após correção com fatores de diluição. 99

Figura 5.35 Funções discriminantes para cerâmicas do sítio Justino

(Cemitério B) Porto Belo e Curituba 100

Figura 5.36 Diferença padronizada das composições das cerâmicas do sítio Justino (Cemitério B) e Curituba 101

Figura 5.37 Diferença padronizada das composições das cerâmicas do sítio Justino (Cemitério B) e Porto Belo 
Figura 5.38 Diferença padronizada das composições das cerâmicas dos sítios

Curituba e Porto Belo

Figura 5.39 Curvas de emissões TL típicas de amostras do sítio Justino, natural e irradiada com fonte ${ }^{90} \mathrm{Sr} /{ }^{90} \mathrm{Y}$, doses de 10, 20, 30 e 40 Gy.. 103

Figura 5.40 Curvas de emissões TL típicas de amostras do sítio Porto Belo, natural e irradiada com fonte ${ }^{90} \mathrm{Sr} /{ }^{90} \mathrm{Y}$, doses de 3, 6, 9, 12 e 15 Gy. 103

Figura 5.41 Teste do platô para quartzo de Xingó. 104

Figura 5.42 Resposta do pico $320^{\circ} \mathrm{C}$ TL para o sítio Justino (Cemitério C).... 104

Figura 5.43 Resposta do pico $280^{\circ} \mathrm{C}$ TL para o sítio Saco da Onça (Fase 06).. 105

Figura 5.44 Resposta do pico $280^{\circ} \mathrm{C}$ TL para o sítio Porto Belo (Fase 01)........ 105

Figura 5.45 Resposta do pico $280^{\circ} \mathrm{C}$ TL para o sítio Curituba (Fase 09).......... 106

Figura 5.46 Difratograma da cerâmica do sítio Justino (Cemitério B)................ 110

Figura 5.47 Difratograma da cerâmica do sítio Justino (Cemitério C)................ 110

Figura 5.48 Difratograma da cerâmica do sítio São José.................................. 111

Figura 5.49 Difratograma da cerâmica do sítio Curituba................................... 111 


\section{INTRODUÇÃO}

A reconstrução da cultura e História das sociedades antigas constitui um dos principais objetivos das Ciências Arqueológicas, sobretudo quando as fontes de informações são pobres ou escassas. De uma forma geral, o termo Arqueologia é designado como uma parte especial das Ciências Históricas que estuda o passado da humanidade por meio da cultura material (Jones, 2004).

Um dos primeiros registros da aplicação das técnicas analíticas para estudo de materiais de origem arqueológica, foi realizado por Martin Klaproth, em 1800, tendo como objetivo a caracterização química de vidros e moedas (Leute, 1987).

Há registros que Gobel, em 1840, citou que a Química poderia estar a serviço da Arqueologia e da pré-história. Ele analisou diversos objetos metálicos resgatados em escavações nas províncias bálticas da Rússia, e por meio da comparação das composições químicas com outros objetos da pré-história européia, concluiu que aqueles objetos da região báltica tinham origem romana. Nesse trabalho, Gobel analisou um número considerável de amostras, assim ele pode ser considerado um dos pioneiros na caracterização química de materiais arqueológicos (Harbottle, 1982).

Em 1867, os químicos Berzelius e Fresenius também analisaram bronze antigo. Neste mesmo período, Michael Faraday examinou uma amostra de cerâmica romana e vidros (Leute, 1987).

Um dos primeiros trabalhos sobre análises mineralógicas de materiais arqueológicos foi realizado pelo mineralogista francês Damour, quem esteve interessado no estudo da origem do material lítico encontrado em monumentos célticos (Leute, 1987). Nessa época, 1805, Damour assinalou que os arqueólogos deveriam recorrer ao auxílio de Geólogos, Zoólogos e Paleontólogos para dar significado maior a seus estudos. Nessa época, o mesmo autor determinou a composição química e mineralógica de jades encontrados no norte da França (Leute, 1987).

Assim, pode-se perceber que a aplicação de técnicas de caracterização provenientes da Física e da Química para análise de vestígios arqueológicos é bastante antiga. Embora, seja citado que o mais importante trabalho em Arqueometria foi o desen - 
-volvimento do método de datação por carbono - 14, em 1940. Na atualidade diversas técnicas têm sido utilizadas em estudos arqueológicos. Esse avanço tem sido estimulado, principalmente, pelo desenvolvimento da instrumentação científica, do uso da microeletrônica e do crescimento da microinformática (Mazzocchin et al., 2003; Papadopoulou et al., 2006; Hedley, 2001; Fitzpatrick et al., 2003; Tite, 1999).

$\mathrm{Na}$ atualidade, a Arqueologia tem utilizado uma série de métodos e técnicas para reconstruir o passado, tais como, aplicações de técnicas eletromagnéticas na prospecção dos sítios, análise ambiental por meio dos registros glaciais, paleobotânica e paleogeologia, métodos de datação relativos e absolutos, modelos de desenvolvimento oriundos de abordagens sociológicas e etnográticas, análise material dos artefatos para caracterização das tecnologias utilizadas, etc (Gebhard, 2003). Atualmente, a análise material dos artefatos tem sido fundamental para construir a representação de uma cultura antiga, uma vez que estas análises permitem realizar a sua caracterização, conhecer as tecnologias de manufatura e usos (Vandiver, 2001).

Nos últimos anos, é crescente o número de publicações que associam técnicas de caracterização físico-químicas a estudos de materiais arqueológicos. Guasch-Jané et al. (2006), por exemplo, estudou resíduos orgânicos contidos em ânforas encontradas junto ao túmulo de Tutancamon, com objetivo de verificar a presença do ácido siringico, o qual é característico da uva vermelha e, portanto, do vinho tinto. Entretanto, em algumas ânforas não foi encontrado este marcador, o que levou os autores a propor que os vasilhames guardavam vinho branco. Aylon et al. (2004) estudaram a autenticidade de um ossuário atribuído a James, suposto irmão de Jesus. Por intermédio da associação da análise petrográfica com a análise da composição isotópica do oxigênio, presente no material, os pesquisadores verificaram que o ossuário era autêntico da região e da época em que Jesus viveu, mas as letras grafadas são recentes. Estes são alguns exemplos de trabalhos onde as Ciências Exatas têm contribuído com a Arqueologia.

De uma forma geral, os principais aspectos estudados em Arqueometria são as composições químicas. as técnicas de manufatura $\mathrm{e}$ as cronologias dos vestígios resgatados. Este último aspecto permite localizar, temporalmente, o objeto com uma cultura, enquanto que o primeiro permite determinar a proveniência da matéria-prima, intercâmbios comerciais e sistemas econômicos. As técnicas antigas de manufatura de uma cultura podem ser a base para a discussão do nível de desenvolvimento de uma comunidade. Na maioria dos casos, uma técnica de manufatura altamente desenvolvida 
surge, apenas, em sistemas sociais complexos, uma vez que experimentos e comunicações entre diferentes artesões resultam em progressos tecnológicos (Schortman \& Urban, 2004).

Tendo em vista que os materiais cerâmicos representam um sofisticado acúmulo das experiências e conhecimentos humanos em relação aos recursos naturais disponíveis, além de serem os vestígios mais comumente encontrados em escavações arqueológicas, estes vestígios são, conseqüentemente, os mais estudados pelos arqueólogos. Por sua abundância e durabilidade, a cerâmica possui diversas características macroscópicas de interesse arqueológico. As características macroscópicas tais como decoração da superfície e forma são utilizadas, freqüentemente, como indicadores culturais e cronológicos. As propriedades microscópicas tais como textura, composição química e mineralogia podem ser usadas para estudo da tecnologia de fabricação e proveniência dos materiais envolvidos no processo (Velde \& Druc, 1999). Sob esta perspectiva, dois métodos são freqüentemente empregados nos estudos de cerâmicas antigas, em uma abordagem denominada integral: análise química da composição elementar e análise mineralógica (Mommsen, 2004).

Sob uma óptica estritamente geológica, a cerâmica pode ser vista como uma rocha sedimentar que sofreu alguns processos metamórficos, cujos principais componentes são argilas e diversos materiais não-plásticos encontrados naturalmente ou adicionados intencionalmente pelo homem. As argilas são formadas a partir da fragmentação das rochas como conseqüência direta do intemperismo. Logo, as argilas guardam sua história geológica de maneira que as fontes argilosas podem variar amplamente em sua composição química elementar. Associando a variabilidade natural das argilas com a interferência antrópica na preparação da pasta cerâmica, é esperado que a composição química e mineralógica das cerâmicas de um determinado local tenham uma variabilidade menor que a variabilidade entre estas composições química e a de objetos cerâmicos provenientes de outros locais. Esta última afirmação constitui um postulado denominado de "postulado da proveniência" (Bishop et al., 1982). De acordo como este postulado, o estudo da composição química elementar permite determinar a origem do artefato cerâmico e, conseqüentemente, podem ser testadas as hipóteses de interações sociais e econômicas entre culturas ceramistas.

Para estudos de proveniência, por meio da composição química elementar das cerâmicas, têm sido utilizadas técnicas tais como XRF (Klein et al., 2004), PIXE (Roumié et al., 2006; Pappalardo et al., 2003), ICP-MS (Magee et al., 2005; Kennett et al., 2004), PIGE (Felicíssimo et al., 2005), etc. Há várias décadas, a AANI tem sido a principal 
técnica para estudo de proveniência de cerâmicas arqueológicas, uma vez que é capaz de produzir análise multielementar com limites de deteç̧ão ao nível de elementos traços. com exatidão e precisão adequadas a este tipo de estudo (Glascock, 2000). Atualmente. tem sido intensificada a utilização de outras técnicas analíticas para estudo de materiais arqueológicos, tais como PIXE e ICP-MS, as que têm produzido resultados com boa qualidade, comparáveis aos produzidos por AANI.

Com relação à análise mineralógica, os principais trabalhos e técnicas têm sido direcionados para o estudo da temperatura de queima da cerâmica e seu processo de confecção (Goulart, 2004; Legodi \& de Wall, 2007; Spassov \& Hus, 2006). As tecnologias antigas de manufatura têm sido estudadas, freqüentemente, por meio das técnicas de microscopia óptica e microscopia eletrônica de varredura (Felicíssimo, 2001; Goulart, 2004; Broekmans et al., 2004), e as características da queima, tais como tempo de queima, temperatura máxima, taxa de aquecimento e atmosfera da queima, têm sido estudadas, principalmente, por DRX, EPR, SEM e espectroscopia Mössbauer (Wagner \& Kyek, 2004; Hausler, 2004; Froh, 2004; Felicíssimo et al., 2004c). Todas essas técnicas buscam a caracterização das alterações microestruturais sofridas pela pasta cerâmica durante a queima, as quais resultam em mudanças da mineralogia do material (Dooryhee et al., 2006; Pavia, 2006; Chen, 2006).

No Brasil a inserção da Física e da Química na análise de materiais de origem arqueológica ocorreu, juntamente, com o desenvolvimento das pesquisas arqueológicas. Um dos primeiros trabalhos foi desenvolvido na década de 60, por Watanabe, realizando datações por termoluminescência de fragmentos cerâmicos de vasos e urnas funerárias, encontradas no interior do estado de São Paulo (Belisário, 2003). Por um longo periodo, os estudos arqueométricos no país restringiram-se às datações. A partir da década de 90 diversos laboratórios têm desenvolvido projetos aplicados ao estudo da composição química e mineralógica de diversos materiais dè origem arqueológica e de objetos de arte. Atualmente, várias técnicas analíticas estão disponiveis para esse tipo de estudo, tais como análise por ativação com nêutrons (Munita et al., 2006; Munita et al., 2004; Munita et al., 2001a; Munita et al, 2000; Santos et al., 2006), fluorescência de raios-X (Silva et al., 2005; Silva et al, 2002), difratometria de raios-X (Goulart et al., 2006; Goulart et al., 2005), XPS (Felicíssimo et al., 2004a), espectroscopia Raman (Faria et al., 2004; Faria et al., 2003), microscopia eletrônica de varredura (Felicíssimo et al., 2004b), emissão de raios-X induzida por prótons (Rizzutto et al., 2005), ICP-MS (Bona et al., 2005), entre outras técnicas. 
Os principais objetivos das pesquisas arqueométricas, realizadas no Brasil, têm sido direcionados para estudos de proveniência (Munita et al., 2006; Felicíssimo, 2005), identificação de pigmentos (Calza et al., 2005), datações (Baffa et al., 2006; Sastry et al., 2004; Tatumi et al., 1998; ), estudos para conservação de obras de arte (Neiva et al., 2006; Hernandez et al., 2004), etc.

Tendo em vista o crescente avanço das técnicas analíticas multielementares nos estudos arqueométricos, a quantidade de dados gerados em estudos composicionais tem aumentado significativamente. A AANI, por exemplo, é capaz de determinar mais de 30 elementos químicos, com precisão necessária para estudos de proveniência. A interpretação dos resultados obtidos por meio das técnicas analíticas modernas, faz-se necessário o uso de métodos estatísticos cada vez mais sofisticados, tais como as técnicas estatísticas multivariadas. Estas técnicas, de uma forma geral, consideram que cada amostra analisada pode ser representada como um ponto no espaço multidimensional, onde, cada dimensão desse hiperespaço corresponde a eixos determinados pelas composições químicas das amostras. Com objetivo de agrupar as amostras, conforme suas similaridades químicas, devem ser localizadas nuvens de pontos de acordo com algum critério estatístico. Para esse fim, diversos métodos têm sido utilizados, tais como análise de componentes principais (PCA), análise discriminante (DA), análise de conglomerados (CA) e diversos filtros baseados na distância Mahalanobis (Mommsen, 2001; Ma et al, 2000; Baxter, 1994).

Cada método estatístico utilizado para interpretação dos dados compósicionais, apresentam vantagens e desvantagens em relação ao tipo de padronização, aos valores perdidos e às amostras aberrantes. Para contornar as dificuldades enfrentadas durante os processos de agrupamentos das amostras é de extrema importância uma análise exploratória dos dados, de forma que o método escolhido para agrupamento seja robusto.

Outra parte importante dos estudos arqueométricos das cerâmicas está relacionada à cronologia. Da mesma forma que as caracterizações química e mineralógica, as técnicas de datação têm papel de destaque nos estudos arqueológicos, pois permitem a localização temporal do material em estudo. Atualmente, diversas técnicas têm sido empregadas com esse objetivo, utilizando-se da diversidade das materiais encontrados. Entre as técnicas de datação é reconhecida a importância da datação por carbono-14 (Santos et al., 1999). Entretanto, quando não é possivel a coleta de material orgânico, ou alternativamente à técnica de datação por carbono-14, têm sido aplicadas técnicas de datação para materiais inorgânicos. Uma das técnicas mais utilizadas com esse propósito é 
a técnica de datação por termoluminescência (Aitken, 1985). A capitalização do potencial destas técnicas de datação, associadas com as técnicas de caracterização química e mineralógica tem permitido o estabelecimento dos horizontes temporais e espaciais das diversas culturas ceramistas (Borone et al., 2002; Bertelle et al., 2000; Nícoli, 2000).

Uma vez que o estudo de cerâmicas arqueológicas é essencial no processo de reconstrução da pré-história humana, especialmente para o estabelecimento das relações culturais entre as comunidades, diversas pesquisas referentes aos grupos ceramistas têm sido realizadas no Nordeste do Brasil (Martin, 2005; Martin, 1998; Luna, 2005; Carvalho \& Queiroz, 2005; Vergne \& Fagundes, 2004; Vergne et al., 2002; Guidon et al., 2002; Lage \& Moraes, 2005). Estes estudos têm como objetivo a remontagem de um quadro que possibilite a compreensão da dinâmica de ocupação da região no passado, bem como entender os modos de vida das comunidades, as relações entre os grupos pré-históricos que habitaram a região e seu desenvolvimento tecnológico.

Neste contexto, diversos estudos foram e estão sendo realizados na região Nordeste, principalmente, em virtude da construção de obras de engenharia, o que obriga às instituições a realizarem trabalhos de salvamento arqueológico. Um dos principais projetos de salvamento arqueológico, recentemente realizado no Nordeste, foi o Projeto Arqueológico de Xingó - PAX, o qual foi motivado pela construção da última barragem no rio São Francisco, para formação do lago da hidrelétrica de Xingó, localizada entre os estados de Sergipe e Alagoas. Esse projeto permitiu a localização de 56 sítios arqueológicos e o resgate de uma expressiva quantidade de vestígios cerâmicos, líticos, da fauna e da flora, assim como diversos esqueletos humanos (Vergne, 1998).

Frente à riqueza arqueológica dos achados de Xingó, diversos trabalhos têm sido executados na região com o propósito de compreender a ocupação da área (Luna, 2001; Luna, 2006; Santos et al., 2006; Santos, 2002; Vergne \& Fagundes, 2006; Vieira Junior \& Palmeira; 2006; Silva, 2005; Dantas, 2005). Segundo Luna (2001), essas pesquisas àrqueológicas no Baixo São Francisco apresentam grandes lacunas a serem preenchidas, de forma que possibilite uma compreensão, mais geral, a respeito da préhistória do Nordeste brasileiro. Assim, o estudo dos vestígios coletados na região de Xingó, durante o PAX, tem dado uma contribuição importante para o preenchimento destas lacunas. Os estudos a respeito do Sítio Justino, por exemplo, tem fornecido informações valiosas em relação à ocupação do Baixo São Francisco, visto a quantidade e complexidade do material resgatado. Nesse sítio foi resgatada uma quantidade apreciável 
de vestígios cerâmicos associados com enterramentos, pois corresponde a uma das maiores necrópoles indigenas escavadas no Brasil.

O conjunto cerâmico de Xingó tem grande expressão, pois corresponde a um dos maiores acervos de cerâmicas arqueológicas associadas a sítios de enterramento do Nordeste. As datações realizadas, juntamente com as análises técnicas das cerâmicas, sugerem que os grupos que habitaram a região de Xingó são anteriores à expansão dos grupos ceramistas Tupiguarani e Aratu naquela região. Esta inferência indica que, provavelmente, diversos grupos ceramistas que habitaram a região de Xingó são oriundos de uma cultura arqueológica ainda não determinada (Luna, 2001).

Sob uma perspectiva arqueométrica, neste trabalho foram estudados vestígios cerâmicos provenientes de seis sítios arqueológicos de Xingó (Justino, Curituba, São José, Saco da Onça, Porto Belo e Vitória Régia), localizados em Sergipe, Nordeste. Uma abordagem integral, associada com o método de datação por termoluminescência, praticamente inédita no Nordeste, foi aplicado ao estudo destes vestígios cerâmico visando contribuir e testar algumas hipóteses relacionadas à ocupação da região, bem como estudar sua dinâmica neste espaço, sua localização temporal em relação a outras comunidades ceramistas no Nordeste e o grau de desenvolvimento tecnológico das comunidades antigas que habitaram esta região. 


\section{OBJETIVOS}

As hipóteses de penetração, ocupação antiga e dinâmica do homem na área de Xingó, localizada no estado de Sergipe aindạ são desconhecidas. Diversos estudos têm sido realizados com objetivo de montar um quadro que possibilite verificar estas hipóteses, tais como estudos antropológicos, sociológicos, iconográficos, paleopatológicos, geológicos, estudos da cultura material, entre outros. Assim, este trabalho, tem o objetivo geral de contribuir no resgate da cultura dos povos que habitaram a região de Xingó por meio de uma abordagem arqueométrica integral à cerâmica. Estes vestígios cerâmicos foram coletados durante escavações realizadas no período correspondente ao resgate arqueológico, em um período que antecedeu a inundação do lago que constituiria a Hidrelétrica de Xingó. Desta forma, este trabalho possui os seguintes objetivos específicos:

1. Determinar a composição química elementar e mineralógica dos fragmentos cerâmicos e argilas de seis sítios arqueológicos da região de Xingó (Justino, Saco da Onça, Curituba, São José, Porto Belo e Vitória Régia), no vale do Baixo São Francisco, para determinação da origem da matéria - prima e inferência sobre a interação sócio-cultural e econômica entre os grupos que habitaram essa região;

2. Identificar os argilominerais e materiais denominados de "temperos" presentes nas peças cerâmicas analisadas por difratometria de raios - X, para estimar a temperatura de queima e a tecnologia de manufatura;

3. Estabelecer a contemporaneidade, por meio de datação termoluminescente, entre os grupos ceramistas que habitaram a região no passado e, entre estas comunidades e outras comunidades ceramistas da região;

4. Aplicar técnicas estatísticas multivariadas para interpretação de dados: análise de agrupamento, análise de componentes principais, análise discriminante, agrupamento por meio de filtros baseados na distância Mahalanobis modificada, detecção de amostras 
aberrantes por meio da utilização da distância Mahalanobis clássica e da distância Mahalanobis robusta e estabelecimento de técnica de seleção de variáveis por meio da técnica de analises discriminante do tipo "forward Stepwise discriminant". 


\section{REVISÄO BIBLIOGRẢFICA}

\subsection{Pesquisas realizadas no Nordeste brasileiro}

Apesar das pesquisas arqueológicas científicas no Brasil terem seu início por volta dos anos 40 e 50 nas regiões Sul, Sudeste e Amazônia brasileira, estas pesquisas iniciaram-se no Nordeste, de maneira sistemática, na década de 60 , principalmente, em virtude do Programa Nacional de Pesquisas Arqueológicas - PRONAPA (Martin, 1996). As pesquisas arqueológicas realizadas nas regiões Sul e Sudeste se concentraram nas questões relacionadas às origens e à antiguidade do homem americano, a origem e cronologia dos grupos pré-históricos dos sambaquis, à produção de cerâmicas em sítios de origem Tupi-Guarani, enquanto que na Amazônia brasileira, os estudos focalizaram-se na origem e dispersão da cerâmica, sobretudo as cerâmicas marajoaras. No entanto, no Nordeste, até a década de 60, período que antecede ao PRONAPA, não havia uma preocupação científica com o estudo dos achados arqueológicos da região. Dessa forma, as primeiras informações arqueológicas sobre as populações pré-históricas do Nordeste, assim como em todo o país, são produtos de achados fortuitos ou de salvamentos superficiais, os quais foram publicados em jornais ou em revistas não especializadas.

Verifica-se que no Nordeste do Brasil, distintamente das regiões Sul, Sudeste e Amazônia, a maior parte das pesquisas arqueológicas estiverem relacionadas, inicialmente, às pinturas e gravuras rupestres, as que foram identificadas desde a chegada dos portugueses no território brasileiro. Embora os primeiros registros arqueológicos tenham sido interpretados de forma incipiente, têm fornecido subsídios para localização de novos sítios arqueológicos e de pesquisas na região (Oliveira, 2001). Pode-se citar, como exemplo desta afirmação, as informações referentes aos grafismos rupestres relatados por José Azevedo Dantas, em Indicios de uma civilizaçaio antiquïissima, sobre a regiâo do Serindó, nos estados da Paraíba e Rio Grande do Norte (Oliveira, 2001).

Com o desenvolvimento das pesquisas arqueológicas no Nordeste, em virtude da implantação do PRONAPA, somente Bahia e Rio Grandes do Norte tiveram representantes, e as investigações concentravam-se em algumas áreas restritas (Vergne, 1998). Neste período foram identificadas várias Tradições ceramistas regionais baseadas, 
principalmente, nos atributos técnicos, sem, porém ficarem claras as características sócioeconômicas dos autores dessa cerâmica e sua filiação étnica. Como conseqüência direta desses estudos localizados, foram definidas as tradições ceramistas Tupiguarani e Aratu, amplamente dispersas na região. Praticamente todas as cerâmicas encontradas em sítios arqueológicos no Nordeste eram quase que, de forma automática, relacionadas a uma dessas tradições, situação que perdurou por muitos anos. Segundo Martin (2000), essas divisões estão atualmente sendo contestadas e admite-se a existência de grupos ceramistas independentes, não filiados a nenhuma dessas duas tradições, com cerâmicas locais que devem ser estudadas a partir dos seus atributos técnicos e utilitários, sem filiações apriorísticas.

A tradição ceramista Tupiguarani, representada por diversas fases, foi identificada, inicialmente, em sítios arqueológicos ao longo da costa e da zona da Mata Atlântica do Nordeste. Posteriormente, com a intensificação das pesquisas arqueológicas no Nordeste Brasileiro, verificou-se a presença dessa tradição em áreas de caatingas. Acredita-se que a tradição Tupiguarani teve seu início e consolidação em torno de 500 AD, seguindo por vários períodos até os dias atuais (Vergne, 1998). Embora seja uma tradição amplamente estudada, poucos sítios foram escavados no Nordeste e há pouca publicação a respeito desses trabalhos de campo.

A tradição Aratu é outra tradição amplamente estabelecida no Nordeste, a qual é caracterizada não somente pela localização de um tipo de cerâmica, mas também por tratar-se de uma cultura de agricultores ceramistas. Apesar das poucas datações dessa tradição, sugere-se que a cronologia da mesma situa-se entre 870 a 1360 AD. Tem sido apontado na literatura que a influência dessa tradição no Nordeste se estende ao longo da costa, desde o estado de Sergipe até o Espírito Santo, e no interior da Bahia até a região do rio Grande (Vergne, 1998).

Embora as tradições Tupiguarani e Aratu estejam amplamente disseminadas no Nordeste, tem sido observada a presença de diversos sítios arqueológicos com tipos de cerâmicas distintas e, portanto, há necessidade de estudos arqueológicos mais extensos para possibilitar a formação de um quadro de caracterização geral dos grupos ceramistas da região. Observando-se as cronologias presentes nos diversos estudos arqueológicos realizados no Nordeste, por exemplo, pode-se constatar que a presença de grupos ceramistas na região é mais antiga que as tradições ceramistas estabelecidas, tratando-se, portanto, de grupos ceramistas independentes, os quais requerem pesquisas adicionais para inseri-los em todo o contexto arqueológico regional. 
Diante dessa necessidade de expansão das pesquisas arqueológicas no Nordeste, desde da década de 70, esses trabalhos vêm sendo intensificados, com a criação de novos grupos de pesquisas e instituições, os que têm desenvolvido suas atividades em diversas áreas da região (Oliveira, 2001). Na atualidade, essas instituições, a exemplo da Fundação do Museu do Homem Americano (FUNDAHAM) e do Museu de Arqueologia de Xingó (MAX), têm mudado o panorama da Arqueologia nordestina com a execução de extensos projetos de escavações arqueológicas e publicando os resultados das pesquisas em periódicos especializados. Em especial, as pesquisas arqueológicas nos sítios de Xingó têm oferecido novos dados para o entendimento da ocupação humana pré-histórica da região do vale do rio São Francisco, como será descrito a seguir.

\subsection{Comentários sobre as pesquisas arqueológicas de Xingó}

Os primeiros registros referentes às pesquisas arqueológicas em Xingó datam de 1985, quando um grupo formado por pesquisadores da Universidade Federal de Sergipe (UFS) desenvolveu um projeto cujo objetivo era localizar e mapear sítios arqueológicos às margens do rio São Francisco (Vergne, 1998). Nessa ocasião, a equipe encontrou e catalogou quatro sítios gráficos no município de Canindé do São Francisco (SE). Esses achados tiveram conseqüências futuras, a partir do momento que a Companhia Hidro elétrica do São Francisco (CHESF) decidira construir uma nova unidade hidrelétrica no rio São Francisco, na região de Xingó (Figura 3.1), visto que o lago inundaria sítios arqueológicos já identificados e outros a serem descobertos. Dessa forma, com base na lei 3.924, de 21 de junho de 1961, a qual estabelece a obrigatoriedade do salvamento arqueológico em áreas a serem descaracterizadas por obras de engenharia, em 1988 foi firmado um convênio entre a CHESF e UFS com objetivo de realizar os trabalhos de salvamento arqueológico da área, inaugurando a sistematização das pesquisas arqueológicas na região do Baixo São Francisco (Vergne, 1998). 


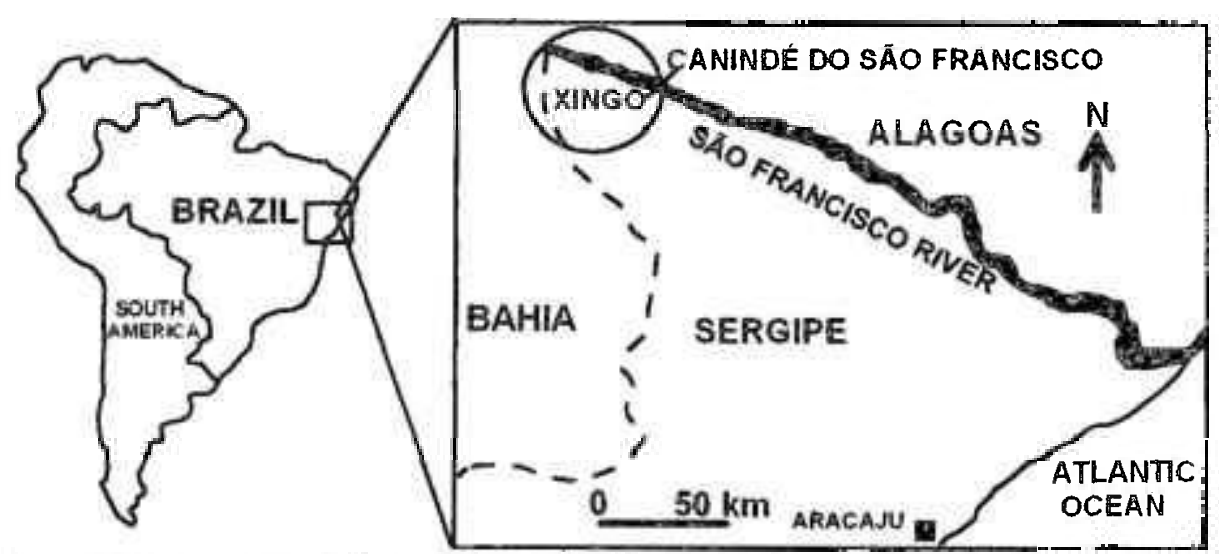

Figura 3.1 -.t áreo estudada corresponde a parte circulado no mapa noroeste to estado de Sergipes.

Durante esse primeiro período do convênio, que se estendeu de 1988 a 1994, o Projeto Arqueológico de Xingó (PAX) identificou e sondou 56 sítios arqueológicos na área diretamente afetada pela Unidade Hidrelétrica de Xingo (UHE - Xingó) (Figura 3.2), sendo 41 assentamentos pré-históricos a céu aberto e 15 sítios de registros rupestres. No total foram resgatados mais de 50.000 achados arqueológicos, incluindo artefatos líticos, cerâmicos, ósseos, malacológicos, estruturas de fogueiras e esqueletos humanos (Vergne, 1998). De acordo com as pesquisas arqueológicas realizadas na área, os esqueletos humanos estão associados a complexos rituais funerários, os quais se referem a 9.000 anos de ocupação da região de Xingó (Vergne, 2004).

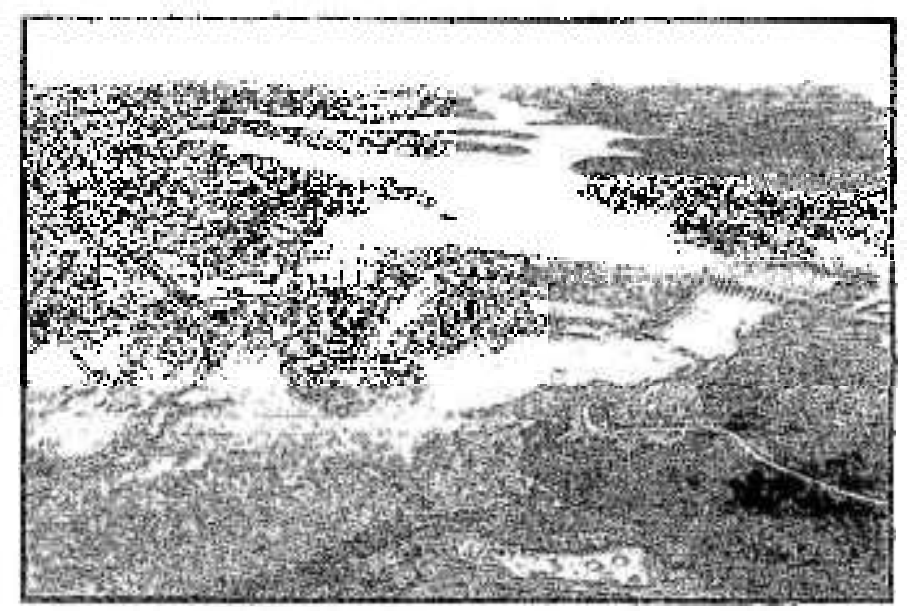

Figara 3.2 - Fista cérea da Lindode Hidreletrica de Yingo f Fonte-1 finisterio des transportess.

Após esta primeira etapa, um novo convênio foi firmado em 1995, contando agora com o apoio da PETROBRAS, visando uma maior compreensão da organização social e da vida cotidiana dos grupos humanos pré-históricos estabelecidos em todo o Baixo São Francisco e suas interações com esse meio geográfico regional (Vergne, 1998). 
Esta nova etapa das pesquisas arqueológicas foi estimulada, entre diversos fatores, pela riqueza arqueológica existente em Xingó e pelos resultados das pesquisas obtidos na primeira etapa do PAX. Nessa fase foram prospectadas áreas dos terraços e ilhas fluviais do São Francisco (Figura 3.3), localizados a jusante da UHE de Xingó, permitindo a descoberta de 214 novos sítios arqueológicos a jusante da UHE de Xingó, e assinalados 218 sítios de registros rupestres no platô do "canyon" desse rio em afluentes situados a montante da UHE de Xingó.

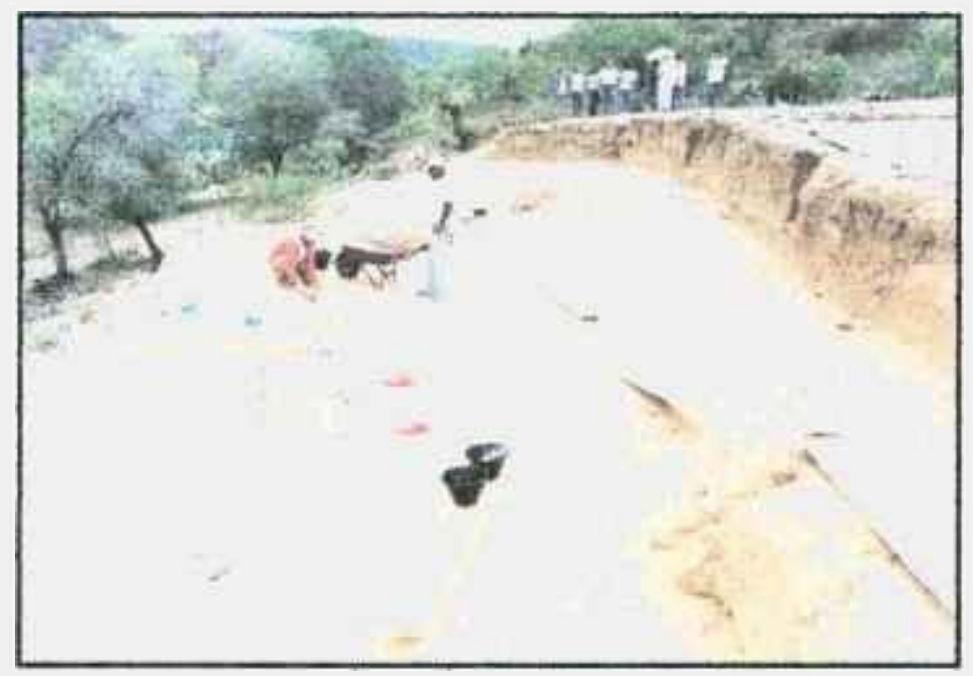

Figura 3.3 - lista do sitio Jerimum escavado na segunda etapa do P.LY (Fonte - .LAX).

Atualmente, diversas pesquisas arqueológicas tem sido realizadas no sentido de compreender a dinâmica cultural dos povos pré-históricos de Xingó, bem como entender a dinâmica de ocupação da área do Baixo São Francisco, as quais podem contribuir para a reconstituição do passado do homem em todo o Nordeste brasileiro (Luna, 2001; Luna, 2006; Santos et al., 2006; Santos, 2002; Vergne \& Fagundes, 2006; Vieira Junior \& Palmeira; 2006; Silva et al., 2005; Dantas, 2005). Tendo em vista o grande volume de material resgatado durante as escavações, será necessário mais tempo para montar um quadro mais geral a respeito da presença humana em Xingó. Entretanto, já é possível inferir alguns aspectos dos grupos pré-históricos viventes no Baixo São Francisco, tais como (Luna, 2006):

i) as datações por carbono-14 evidenciaram que a área foi explorada por grupos de caçadores - coletores e ceramistas em períodos distintos; 
ii) evidências de ocupação da região por grupos pré-históricos em uma faixa cronológica que se estende de $8950 \mathrm{AP}$ a $1280 \mathrm{AP}$;

iii) as áreas dos terraços foram utilizadas, preferencialmente, pelos povos préhistóricos de Xingó, uma vez que as mesmas eram ricas em recursos faunistícos e ambientais;

iv) presença de industrias líticas não filiadas às tradições culturais do Nordeste, a exemplo da tradição Itaparica, localizada no Médio São Francisco;

v) detecção de culturas ceramistas filiadas às tradições Tupiguarani e Aratu, assim como outras não associadas a nenhuma tradição cultural já estabelecida;

vi) identificação de tradição rupestre não filiada às existentes no Nordeste;

vii) variabilidade nas formas de enterramento humanos e presença de rituais funerários altamente complexos;

viii) localização do sítio arqueológico que apresenta o maior número de esqueletos humanos em um único sítio do Nordeste, o que corresponde ao sítio Justino, com cerca de 196 indivíduos dos sexos masculino e feminino, e de diversas faixas etárias.

Um ponto de destaque encontrado nas pesquisas arqueológicas de Xingó é que a ocupação ceramista na área distribui-se em uma larga faixa cronológica. Logo, os estudos sistematizados das cerâmicas dessa região vêm contribuindo decididamente para remontar o passado do homem do São Francisco, principalmente, em virtude da associação dessas cerâmicas com os enterramentos (Luna, 2001). Portanto, a intensificação dos estudos ao material cerâmico de Xingó, por pesquisadores de diversas áreas, inclusive uma abordagem arqueométrica, se faz necessária para a reconstituição da pré-história do homem no vale sanfranciscano.

\section{3 Área de estudo}

A área de estudo compreende parte do pediplano sertanejo, caracterizado pela presença de uma superficie pediplanizada e relevos em colinas e interflúvios tabulares. $O$ trabalho de salvamento de Xingó foi desenvolvido ao longo do rio São Francisco, nos terraços fluviais, os quais foram inundados com a formação do lago da UHE - Xingó (Figura 3.4). Especificamente, a prospeç̧ão foi realizada no eixo do rio São Francisco a, aproximadamente, $8 \mathrm{~km}$ a jusante da cachoeira dos Veados, área situada entre $37^{\circ} 46^{\prime} / 38^{\circ} 14^{\prime}$ de longitude oeste e $9^{\circ} 30^{\prime} / 9^{\circ} 40^{\prime}$ de latitude sul, totalizando uma área de $81,40 \mathrm{~km}^{2}$ (Vergne, 1998). 


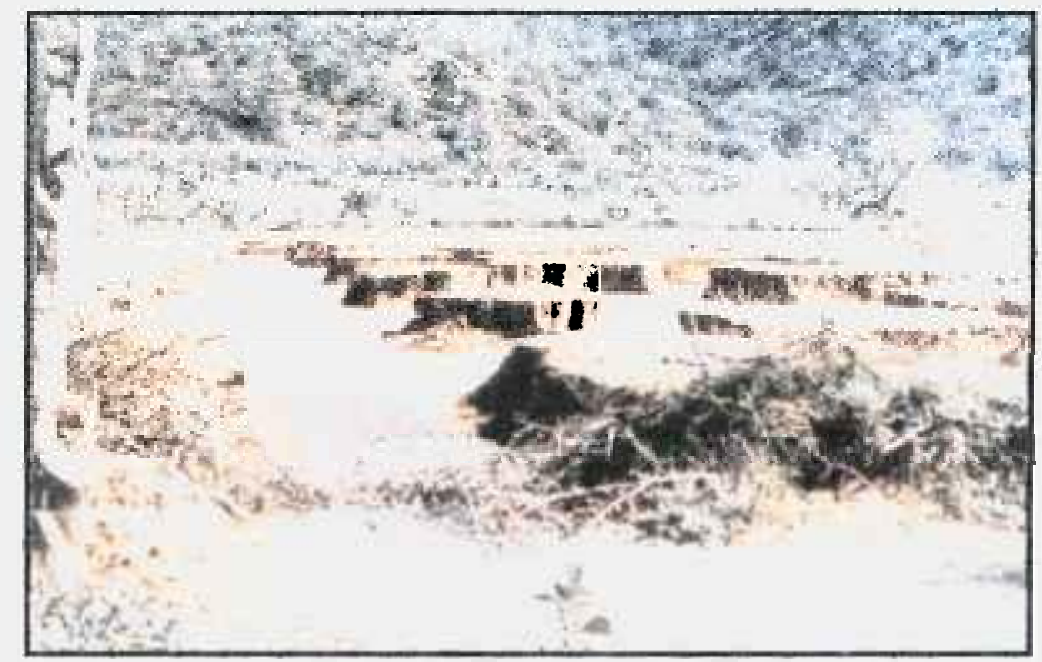

Figura 3.4-A figura mostra o enchimento parcial do Sitio. Justino (Fonte-MAX).

De acordo com as características geomorfológicas, a área foi dividida em três setores conforme a Figura 3.5. Nessa área, ao longo do canal, localizam-se terraços, dispostos descontinuamente ao longo do mesmo, e são constituidos basicamente de $60 \%$ de sedimentos finos $(0,125-0,0062 \mathrm{~mm})$ e $40 \%$ de lama (com predomínio de fração silte e com pouca argila). Muito desses terraços foram utilizados pelos homens pré-históricos que habitaram a região de Xingó, uma vez que nesses espaços o homem dispunha de recursos ambientais para sua sobrevivência.

O clima da área é do tipo semi-árido mediano, com, aproximadamente oito meses de estiagem, perfazendo um precipitação pluviométrica inferior a $500 \mathrm{~mm}$ anuais (Ab'Saber, 1997). De acordo com essas condições climáticas, a vegetação da região era composta, principalmente nas proximidades da calha do rio, de uma caatinga arbustiva arbórea, sobre solos arenosos e rasos, com ou sem afloramento rochoso (Figura 3.6). Contudo, a ação antrópica sobre o ambiente reduziu, significativamente, essa vegetação, a qual esta localizada atualmente em pequenas áreas (Vergne, 1998). 




Figura 3.5 - Mapa de localização dos sitios estudados neste trabalho.



Figura 3.6 - Alguns aspectos das caracteristicas geoambiental da área estudada (Fonte-MAX).

Considerando-se as datações obtidas em diversos estudos arqueológicos realizados na área Sanfranciscana (Luna, 2006), sugere-se que a ocupação pré-histórica do vale do São Francisco remonta há pelo menos 10000 anos AP. Sugere-se, ainda, que os primeiros paleoindios teriam chegado ao vale a partir do planalto goiano, das cabeceiras do alto São Francisco, e dos afluentes que convergem em direção ao São Francisco no sudoeste da Bahia. Algumas pesquisas apontam que as ocupações do Alto e Médio São Francisco são superiores a $7000 \mathrm{AP}$, com ocupações muito antigas de grupos de caçadores - coletores (Calderón, 1974; Etchevarne, 1991; Martin \& Aguiar, 1984), as quais foram classificadas conforme o material lítico, como pertencentes à tradição Itaparica. Entretanto, nessa área os vestígios cerâmicos encontrados datam de, aproximadamente, 2000 AP 
(Luna, 2006), uma vez que maioria dos sítios estudados trata-se de ocupações não ceramistas, ou de ocupações ceramistas recentes, a exemplo das ocupações nas ilhas do Médio São Francisco, ocupadas no início da colonização portuguesa no final do século XVI e início do século XVII (Luna, 2006).

Tendo em vista que a maiorià dos dados referentes às ocupações ceramistas da região referem-se, basicamente, às tradições Tupiguarani ou Aratu, as pesquisas arqueológicas de Xingó têm fornecido novas perspectivas em relação ao estudo da penetração, da ocupação e da adaptação dos grupos ceramistas nas margens do São Francisco, uma vez que as cronologias dos sítios ceramistas de Xingó são mais antigas. Acredita-se que os grupos Tupiguaranis influenciaram outros grupos, no mínimo em relação às técnicas para confecção de cerâmica, e que a ocupação interiorana foi realizada no século XVI. Entretanto, as datações das cerâmicas de xingó mostram uma influencia mais tardia da cerâmica Tupiguarani, ocorrendo sua presença nas últimas ocupações de alguns sítios arqueológicos (Luna, 2001). Em um artigo recente, Luna (2006) propõe que a hipótese da tradição Tupiguarani ter influenciado de forma direta e decisiva na formação de outras tradições ceramistas no Nordeste do Brasil não tem respaldo no contexto arqueológico atual. Nessa mesma publicação, a autora assinala que a prática de confeccionar cerâmica é muito mais antiga que as datações da tradição Tupiguarani, e que outras tradições ceramistas pré-históricas tiveram seu próprio desenvolvimento na técnica da fabricação da cerâmica.

\subsubsection{Considerações sobre a cerâmica pré-histórica de Xingó}

A maior parte dos dados arqueológicos da região do São Francisco, é proveniente da realização de projetos de salvamentos arqueológicos efetuados durante a construção das barragens das hidrelétricas de Sobradinho (década de 70), Itaparica (década de 80) e Xingó (década 90), além de pesquisas anteriores efetuadas por Etchevarne, na Gruta do Padre, nos anos 30, e na década de 60 por Calderón. O conhecimento com relação às formas de assentamento, a caracterização de sua cultura, bem como os caminhos de chegada desses povos à região ainda não estão bem explicados.

Os estudos realizados nos últimos anos na área de Xingó, no baixo São Francisco, vêm auxiliando na reconstituição desse quadro histórico, denotando que os grupos ceramistas habitantes desta parte do vale, já tinham um bom conhecimento da cerâmica em torno de quatro mil anos antes do presente. Essas pesquisas vêm dando 
subsídios para a formulação de novas hipóteses sobre a penetração dos grupos préhistóricos na região sanfranciscana.

Dentro deste contexto, o estudo da cerâmica do vale do São Francisco, vai de encontro ao que se postulava em relação à chegada de povos ceramistas na região, como também das origens étnicas dos mesmos. As cronologias obtidas nos remetem a ocupações cẹramistas desde $5570 \pm 70$ (Beta 86744) a $1280 \pm 45$ (Lyon) anos AP no sítio Justino, e as duas datações oriundas do sítio São José II, $3500 \pm 110$ e $4140 \pm 90$ AP, colocando esse conjunto dentro de um período cronológico fora da suposta influência resultante da expansão dos grupos Tupiguarani e Aratu (Vergne, 1998). Essas cronologias sugerem que os grupo instalados na área de Xingó tenham penetrado por algum ponto na região do Baixo São Francisco e, seguindo o rio, foram se adaptando às condições ribeirinhas, onde encontraram os meio necessários ao seu desenvolvimento. Seriam, portanto, conhecedores de técnicas para manufaturas de cerâmicas (Luna, 2005).

Uma análise comparativa das caracteristicas técnicas das cerâmicas dos sítios de Xingó em relação a outras do vale do São Francisco, sobretudo com aquelas localizadas em escavações nas zonas dunares do sub-médio São Francisco, permitiu apontar algumas conclusões a respeito da cultura ceramista da área de Xingó, constituindo uma nova cultura ceramista ainda não determinada. Entre essas conclusões vale destacar que (Luna, 2005):

i) a cronologia da cerâmica de Xingó é colocada como uma das mais antigas da região;

ii) de acordo com perfil técnico, as cerâmicas apresentam uma diversificação em relação aos tipos de aditivos e tratamento de superficie;

iii) os aditivos compostos por cerâmicas trituradas e tratamento de superficies mais elaborados, tais como o brunido e grafitado, aparecem, somente, na última ocupação da área de Xingó, indicando, possivelmente, chegada de outras populações ceramistas e/ou contatos entre elas;

iv) em Xingó, não se verifica uma grande variabilidade de formas, e na sua maioria os recipientes cerâmicos são destinados ao uso pessoal (Figura 3.7). Dessa forma, os vasos para fins de preparo de alimentos e para armazenamento de líquidos são pouco representativos, diferentemente, de outros sítios no São Francisco;

v) no sítio Justino, em Xingó, verifica-se uma grande variedade nos padrões dos enterramentos, que estão relacionados à posição social, sexo e idade do morto (Vergne, 2004);

vi) há uma ampla variabilidade de objetos no enxoval funerário que acompanhava alguns dos enterramentos no sítio Justino. 


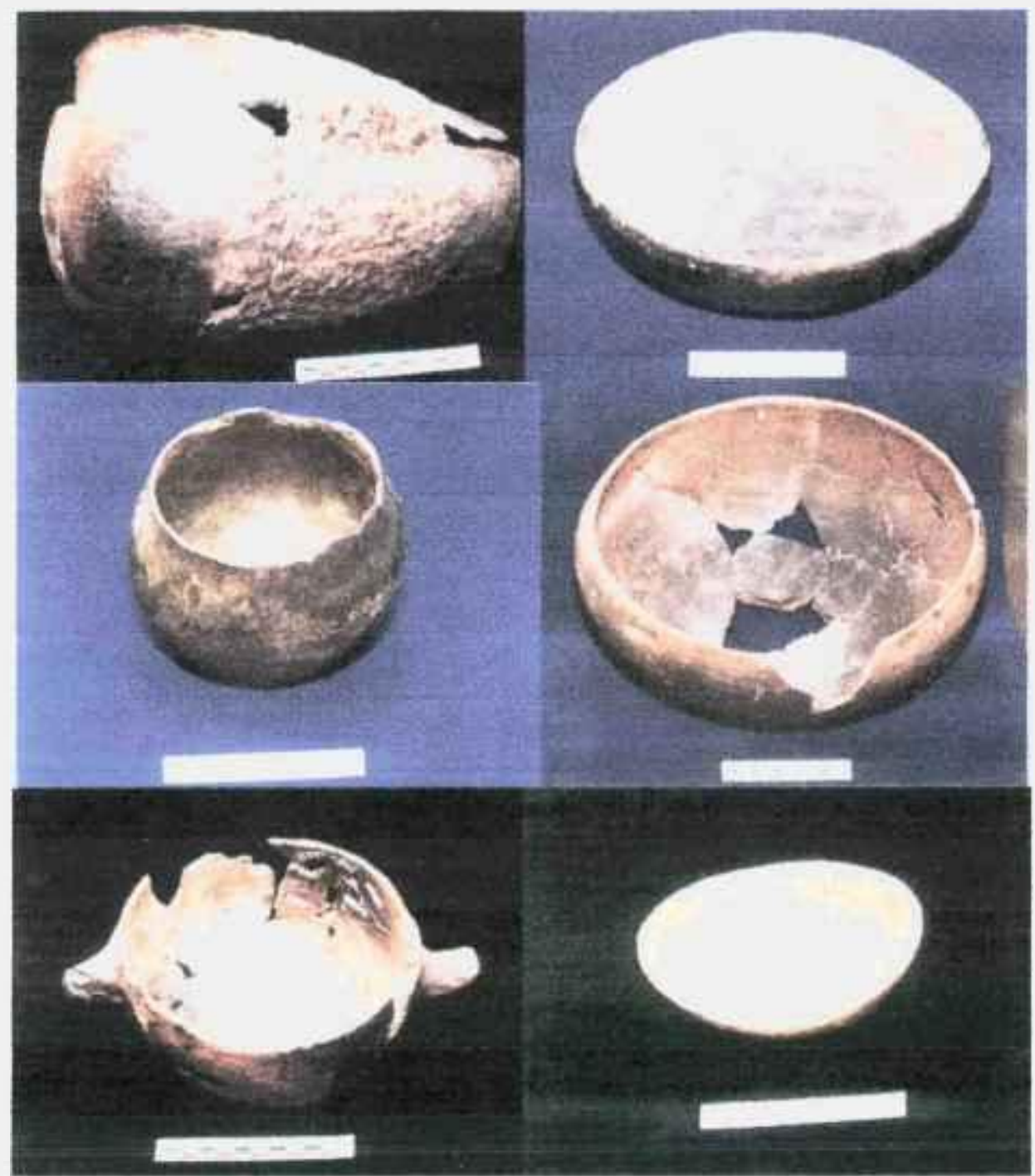

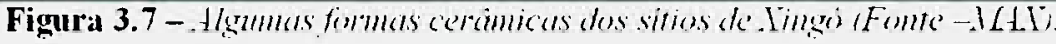

De acordo com essas conclusões, observam-se algumas similaridades entre algumas das características dos vestígios arqueológicos, bem como das suas inter-relações, em diversas ocupações de Xingó, quando comparando com outros sítios da região do São Francisco. É importante ressaltar, de acordo com as pesquisas já realizadas na área, que todas as tradiçòes ceramistas do São Francisco estão representadas nos sítios de Xingó.

Com relação à ocupação da área, sugere-se que a ocupação ceramista da região de Xingó iniciou-se com a fundação da aldeia do Justino (5.570 \pm 70 anos AP), e após 1.400 anos surgiu à aldeia de São José, indicando, provavelmente, o primeiro crescimento populacional da região de Xingó. Em seguida, a aldeia Porto belo foi estabelecida, a cerca de 1.600 anos depois da aldeia São José e, somente, 1.280 anos AP, do estabelecimento da aldeia Porto Belo foram instaladas outras aldeias, a exemplo das aldeias Vitória Régia e Curituba. É nesse periodo que se observa a ampliação das áreas de cultivo. A ampliação das pesquisas arqueológicas ao longo do rio São Francisco, por meio de novas abordagens, 
ampliará a quantidade de dados que, contextualizados, permitirão entender com mais precisão a dinâmica de ocupação da região no passado (Luna, 2006).

\subsubsection{Breve descrição dos sítios arqueológicos estudados}

O conjunto cerâmico de Xingó tem grande expressão, pois possui um dos maiores acervos de cerâmica associados a ritos funerários do Nordeste, que correspondem aos sítios arqueológicos Porto Belo 1 e 2, Vitória Régia 1 e 2, Saco da Onça ,Onça, São José 1, Justino e Curitiba. No sítio Justino, por exemplo, pode-se acompanhar a evolução de todo um contexto arqueológico, relacionado a cerâmicas, durante pelo menos 2000 anos. Os outros sítios pesquisados nos possibilitam a compreensão da ocupação dos espaços (Luna, 2001).

Considerando-se a importância do ponto de vista arqueológico, a abundância do material resgatado e a posição espacial e temporal do sítio, neste trabalho foram estudadas cerâmicas resgatadas cm 6 sítios arqueológicos de Xingó (Figura 3.5): Porto Belo (27), Saco da Onça (25), Curituba (24), Vitória Régia (50), São José (25) e Justino (94). Além do material cerâmico, 4 amostras de argilas, coletadas nas proximidades dos sítios São José e Justino, totalizam um universo amostral de 245 amostras.

Tendo em vista a vasta amplitude cronológica, a profundidade à qual foram coletadas as cerâmicas e considerações arqueológicas, as amostra do sítio Justino foram subdivididas em quatro classes: Amostras Superficiais (até $40 \mathrm{~cm}$ ), Justino A $(40-80 \mathrm{~cm}$ ), Justino B $(90-140 \mathrm{~cm})$ e Justino C $(150-280 \mathrm{~cm})$. As amostras do Justino B e C correspondem às amostras dos Cemitérios B e C, classificadas por Vergne em sua tese de doutorado (Vergne, 2004).

\section{i) Sítio Porto Belo 1}

Localizado na fazenda Porto Belo, município de Canindé do São Francisco (SE), nas coordenadas $8.940 .680,010 \mathrm{~N}$ e $626.800,381 \mathrm{E}$, situado num terraço elevado à altura de 7,24 m na confluência do rio São Francisco com o riacho Fechado (Lucu). Apresenta característica de terraço aluvial, constituida de areia, seixos e silte. Neste sítio foram encontrados 465 fragmentos cerâmicos, vestígios líticos, restos ósseos e fogueira.

\section{ii) Sítio Porto Belo 2}

Localizado na fazenda Porto Belo, município de Canindé do São Francisco (SE), nas coordenadas $8.941 .000,730 \mathrm{~N}$ e $626.260,230 \mathrm{E}$, situado num terraço elevado à 
altura de 7,24 m no encontro do rio São Francisco com o riacho Fechado, sendo seu sedimento constituído de areia e silte. Neste sítio foram encontrados 411 fragmentos cerâmicos, vestígios líticos, restos ósseos, carvão e fogueira.

\section{iii) Sítio Vitória Régia 1}

Sítio localizado na Fazenda Vitória Régia, município de Canindé de São Francisco (SE), nas coordenadas 8.942.160,215 N e 624.280,193 E. Está situado em um amplo terraço, elevado à altura de $8,24 \mathrm{~m}$, na confluência do rio São Francisco com o riacho Portão, sendo seu sedimento formado por areia e silte. Não há registros de datações para este sítios. Foram encontrados 1.619 fragmentos de origem cerâmica, além de diversos vestígios líticos, ósseos, conchas, fogueiras, carvão, etc.

\section{iv) Sítio Vitória Régia 2}

Sítio localizado na Fazenda Vitória Régia, município de Canindé de São Francisco (SE), nas coordenadas 8.942.000,091 N e 624.720,420 E. Está situado em um terraço elevado, à altura de $8,24 \mathrm{~m}$, na confluência do rio São Francisco com o riacho Portão. A superfície desse terraço é plana, apresentando-se parcialmente erodida em conseqüência da ação das águas pluviais que escorriam das vertentes da serra, sendo seu sedimento formado por areia, seixos e silte. Foram encontrados 602 fragmentos de origem cerâmica, além de diversos vestígios líticos, ósseos, fogueiras, carvão, etc.

\section{v) Sítio Saco da Onça}

Localizado na fazenda São Francisco, município de Canindé de São Francisco (SE), nas coordenadas $8.941 .800,125 \mathrm{~N}$ e $625.480,420 \mathrm{E}$, situado em um terraço recuado e elevado, à altura de 5,40 m em relação ao rio São Francisco, fazendo parte de uma única formação geológica, formada em dois momentos, e está localizado no terraço mais baixo, sendo seu sedimento constituído de areia e silte. Foram encontrados 601 fragmentos cerâmicos, diversos vestígios líticos, bem como restos ósseos e blocos. Um ponto importante a respeito desse sítio é que o mesmo se trata de um sítio de acampamento.

\section{vi) Sítio São José 1}

Sítio localizado na fazenda São José, município de Delmiro Golveia (AL), nas coordenadas $8.945 .600,730 \mathrm{~N}$ e $621.000,150$ E. Está situado num terraço, elevado à altura de $12,57 \mathrm{~m}$, na confluência do rio São Francisco com o riacho Talhado. Foram 
encontrando-se 437 fragmentos cerâmicos, diversos vestígios líticos, carvão, restos ósseos, entre outros vestígios.

\section{vii) Sítio Justino}

Localizado na fazenda Cabeça de Nego, município de Canindé de São Francisco, nas coordenadas $8.938 .880,360 \mathrm{~N}$ e $627.560,186 \mathrm{E}$, é considerado a maior necrópole indígena escavada no Brasil (Martin, 1996). Ocupa um terraço elevado à altura de $6,80 \mathrm{~m}$, na confluência do rio São Francisco com o rio Curituba. Neste sítio forma delimitados 60 níveis no setor 1 e 17 níveis no setor 2, apresentado um grande número de peças liticas, cerâmicas (13.862 peças), ossos, esqueletos e fogueiras. Em todo o projeto de salvamento arqueológico de Xingó, este sítio é o que apresenta maior número de datações. Estas datações que vão de 5.570 AP na fase 30 até $1.280 \pm 45 \mathrm{AP}$, as quais foram efetuadas por radiocarbono, além destas datações radiocarbonicas há mais algumas datações realizadas por termoluminescência.

De acordo com as análises laboratoriais, adicionadas às datações absolutas, foram identificadas quatro fases de ocupação distintas para os enterramentos. Três dessas fases correspondem a grupos de agricultores ceramistas e uma associada a um grupo préhistórico de caçadores - coletores. Essas ocupações foram classificadas como cemitérios A, B, C e D: Cemitério A (decapagem $04-08$ ) ocupado no período $1280 \pm 45-2530 \pm 70$ AP; Cemitério B (decapagem 09 - 14) ocupado no período $2650 \pm 150-3270 \pm 135$ AP; Cemitério C (decapagem 16 - 28) ocupado no período $4790 \pm 80-5570 \pm 70 \mathrm{AP}$; e o Cemitério D (decapagem 43 - 52) ocupado há aproximadamente $8950 \pm 70 \mathrm{AP}$.

Segundo Vergne (2004), a análise do sítio Justino permitiu reconhecer que os grupos de Xingó praticavam rituais funerários em áreas previamente estabelecidas, sendo que para cada individuo era escolhido uma modalidade e um tipo de complemento mortuário com finalidade simbólica de definir a estrutura social do grupo (Figura 3.8). Na Tese de doutorado, Vergne (2004) apontou a categorização de hierarquias sociais, distinção de gêneros e idadès nos tipo de enterramentos dos cemitérios A, B e C, sobretudo no B. Sendo que o Cemitério D não foi possivel observar distinções visíveis, pelo menos de acordo com a análise dos vestígios materiais associados aos enterramentos. 


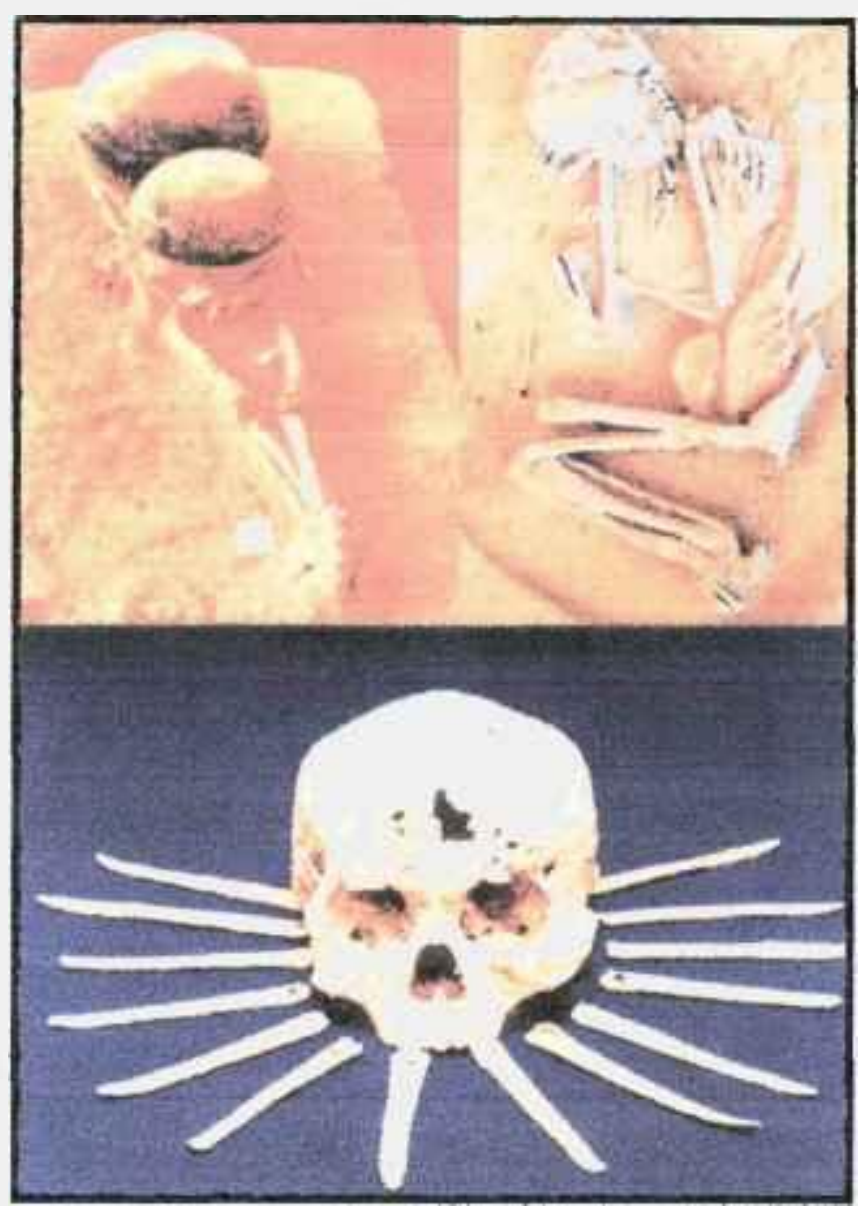

Figura 3.8 - ffgums tipess de enterranento do. Justino facimal e cadornos encontrodos jumtos ao escuneleto (Fonte-ILLI).

Vergne (2004) ainda aponta que no Cemitério $C$ as associações entre os vestígios e os enterramentos trazem características de grupos de caçadores - coletores em transição para uma cultura ceramista, e que no Cemitério B são observadas as maiores distinções dos enterramentos conforme gênero, idade e status social. Já no Cemitério A, essas distinções é observada com mais nitidez para os indivíduos mais velhos

\section{viii) Sítio Curituba 1}

Localizado na fazenda Maringá, municipio de Canindé de São Francisco (SE), nas coordenadas 8.938.600,200 N e 628.00,430 E. Ocupa um terraço elevado à altura de $4,90 \mathrm{~m}$ na confluência do rio São Francisco e o riacho Curituba, constituido de areia e silte. Foram resgatados 1.582 fragmentos cerâmicos, além de diversos vestigios líticos, ossos de fauna, carvão, entre outros. Recentemente, uma análise sobre a cerâmica desse sítio mostrou que a técnica de manufatura da cerâmica foi acordelada e que o antiplástico não foi adicionado à cerâmica pelo ceramista, uma vez que a matéria-prima da área é composta por uma fração significativa de areia, tornando a adição do antiplástico desnecessária (Vergne \& Fagundes, 2006). 


\subsection{Técnicas analíticas}

Para estudo das cerâmicas dos sítios arqueológicos estudados, foram utilizadas as seguintes técnicas analíticas: Análise por ativação com nêutrons instrumental (AANI), difratometria de raios-X (DRX) e datação por termoluminescência (TL):

\subsubsection{Análise por ativação com nêutrons}

Os princípios da análise por ativação com nêutrons foram estabelecidos por volta de 1936, por Hevesy e Levi, apenas quatro anos após a descoberta dos nêutrons (Hevesy \& Levi, 1936). Os autores determinaram a concentração de disprósio em amostras de ítrio, por meio da utilização de uma fonte de nêutrons composta de $\mathrm{Ra}-\mathrm{Be}$ e um contador Geiger - Müller, e identificando o elemento de acordo com sua meia-vida (Balla, 2005). Tendo em vista a dificuldade de obtenção de fontes de nêutrons de alto fluxo e equipamentos para espectrometria gama, o método teve um lento desenvolvimento até os $\operatorname{anos} 40$.

A construção e a rápida distribuição de reatores nucleares de pesquisa após a Segunda Guerra Mundial foram os propulsores do desenvolvimento da análise por ativação com nêutrons. Até a década de 50, a separação radioquímica, assim como os contadores Geiger ou proporcionais, foram essenciais para a aplicação da técnica. Entretanto, o desenvolvimento dos detectores de cintilação em 1950, acoplado com o aparecimento dos analisadores de alta resolução, e a revolução da eletrônica estabeleceram as bases para o progresso da espectrometria gama e, portanto, da análise por ativação neutrônica.

No início dos anos 60 , foram construídos os detectores semicondutores compostos de Ge dopados com Li, o que resultou na melhoria na resolução na análise, em cerća de 30 vezes, em relação ao que era possível por meio da utilização dos detectores de $\mathrm{Nal}(\mathrm{Tl})$. Por volta de 1970, já estavam disponíveis, comercialmente, detectores de Ge(Li) com $1000 \mathrm{~cm}^{3}$ de volume sensível, além de analisadores multicanais de 4096 canais. Neste período, o progresso no campo da espectrometria gama fez possível a aplicação da AANI para análise multielementar de diversas matrizes.

Os anos 80 foram marcados pela substituição dos detectores de Ge(Li) pelos detectores de germânio hiperpuros, pelo desenvolvimento da eletrônica nuclear, pela disseminaç̃ão dos computares pessoais (PC) e pela utilização dos programas computacionais para processaimento dos espectros, o que resultou em um progresso dinâmico constante na análise por ativação com nêutrons (Glascock, 2000). De fato, após os anos 70, a análise por ativação passou a ser uma das técnicas mais sensíveis para análise 
química quantitativa multielèmentar, e, ainda, ocupa uma posição sólida no rol das técnicas analíticas mais sensíveis e versáteis para análise de amostras de diversos tipos de matrizes.

A AANI tem sido utilizada para análise de materiais arqueológicos desde os anos 50. Um dos primeiros trabalhos foi desenvolvido por Ambrosimo \& Pindrus (1953), o qual estava relacionado ao estudo de moedas da coleção do museu do Louvre. Em 1956, Oppenheimer sugeriu que o uso de técnicas analíticas nucleares poderia auxiliar na solução de questões arqueológicas. Como resultado desta declaração, a qual ocorreu durante um congresso em Princeton, diversos projetos de pesquisas foram iniciados no Laboratório Nacional de Brookhaven e no Laboratório de Pesquisas Arqueológicas de Oxford. Já em 1957, Sayre \& Dodson (1957), desenvolveu um trabalho relacionado ao estudo de cerâmicas mediterrâneas, por meio da utilização da AANI, e concluiu que os resultados eram satisfatórios para resolução de questões específicas da Arqueologia, assim como tinha sido proposto por R. Oppenheimer.

As primeiras aplicações da análise por ativação com nêutrons na Arqueometria foram, inicialmente, de natureza metodológica. Mas, em virtude do desenvolvimento da instrumentação científica, o número de elementos determinados com boa precisão aumentou consideravelmente. Por mais de duas décadas, os dois principais laboratórios envolvidos nas aplicações da INAA no estudo de material arqueológicos foram os laboratórios "Brookhaven laboratory" e "Lawrence Berkeley laboratory". Todavia, um trabalho que marcou o período inicial da AANI, tanto experimental como teórico no estudo de cerâmicas arqueológicas, foi desenvolvido por Perman \& Asaro (1969). Nesse trabalho foi desenvolvido o procedimento analítico para determinação de vários elementos com desvio padrão relativo menor que $1 \%$. Os autores assinalaram que a exatidão da análise é menos importante que a precisão nos estudos composicionais de cerâmicas. $\mathrm{Na}$ atualidade, os laboratórios especializados em estudos de proveniência cerâmica, por meio da composição química determinada por AANI, contam com procedimentos similares àqueles estabelecidos no trabalho de Perman e Asaro (1969).

Por, pelo menos duas décadas, pode ser mencionado que o método analítico padrão para determinação multielementar da composição química das cerâmicas arqueológicas, ao nível de ppm, foi a AANI. Mesmo com as dificuldades resultantes do declínio da aceitação da energia nuclear, a análise por ativação com nêutrons é uma das técnicas mais utilizadas em estudos composicionais, juntamente com as técnicas PIXE e ICP - MS. 
No Brasil, a aplicação da análise por ativação com nêutrons ao estudo de materiais de origem arqueológica tem sido praticada, basicamente, por dois grupos de pesquisa, um estabelecido no Centro de Desenvolvimento de Tecnologia Nuclear - CDTN (Belo Horizonte - MG) e outro no Instituto de Pesquisas Energéticas e Nucleares - IPEN. Desde o fim da década de 90, o grupo de Arqueometria do IPEN, um dos grupos mais ativo no Brasil na aplicação da INAA na Arqueologia, tem desenvolvido projetos de pesquisa voltados ao estudo de proveniência de cerâmicas arqueológicas. Este grupo tem analisado cerâmicas de diversas regiões, tais como cerâmicas Marajoaras e cerâmicas do Amazonas, e tem liderado diversas pesquisas relacionadas à interpretação de dados em Arqueometria (Munita et al., 2006; Munita et al., 2004; Munita et al., 200la).

A principal reação nuclear envolvida com a técnica da análise por ativação com nêutrons é denominada de captura radiativa de nêutrons (Figura 3.9). Esta reação tem origem na interação do nêutron com um núcleo alvo, por meio de uma colisão inelástica ou captura, resultando na formação de um núcleo composto em um estado excitado. $\mathrm{Na}$ maioria dos casos, esta nova configuração resulta em um nuclídeo radiativo com emissão de raios gamas característicos, com taxa de decaimento governada pela meia - vida $\left(T_{122}\right)$ própria do nuclídeo (IAEA-TECDOC-564, 1990). A identificação e quantificação das concentrações elementares são realizadas através de espectroscopia gama, a qual utiliza a energia e intensidade da radiação emitida para identificar o elemento e sua concentração.

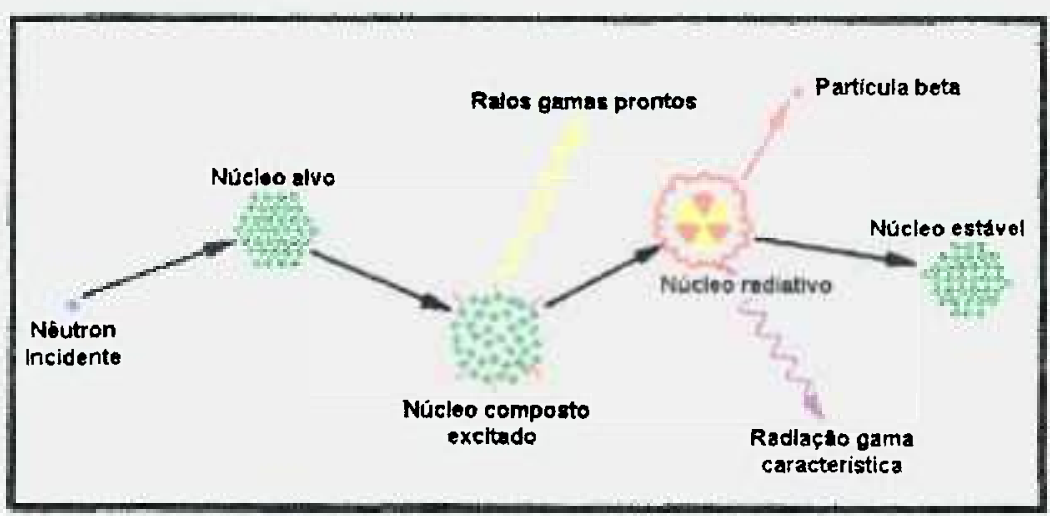

Figura 3.9 - Representaçöo dos fenômenos embolvidos na ativuçăo de um micleo.

A determinação das concentrações elementares das amostras analisadas pode ser realizada por meio da medida direta das energias e intensidades da radiação emitida (método absoluto), ou por comparação com um material cuja composição química elementar é conhecida previamente (método relativo). No primeiro caso o método é 
denominado de método absoluto e no segundo caso o método é chamado de método relativo.

Pode ser mostrado que a atividade radiativa $\left(A_{\iota}\right)$ de uma amostra que foi exposta a um fluxo de nêutrons, e sofreu capturas radiativas, é dada pela Equação 3.1 (Kuleff \& Djingova, 1990; Alamin \& Spyrou, 1997)

$$
A_{t_{c}}=\frac{N_{0} \varphi \sigma \theta m}{M}\left\{\left[1-\exp \left(-\lambda_{B} t\right)\right] \exp \left(-\lambda_{B} t_{c}\right)\right\},
$$

onde,
$\mathrm{N}_{0}$ é o número de Avogadro
$\varphi$ é o fluxo de nêutrons
$\sigma$ é a seção de choque para captura radiativa
$\theta$ é fração isotópica do elemento
m é a massa da amostra
M é a massa atômica do elemento a ser determinado
$\lambda_{B}$ é a constante de decaimento do elemento
$t_{c} o$ tempo de resfriamento

Por meio da Equação 3.1 podemos determinar a massa (m) de um dado elemento contido na amostra. Neste caso, a sensibilidade e precisão da determinação irão depender da energia da radiação detectada e das condições da medida. No método absoluto de análise por ativação é necessário determinar a atividade absoluta da amostra, sendo, assim, extremamente sensível à eficiência de contagem (geometria, absorção de fótons, espalhamentos, tempo morto, etc.) (Alamin \& Spyrou, 1997).

O método relativo de análise por ativação é baseado na comparação da atividade da amostra em estudo $\left(\mathrm{A}_{\mathrm{x}}\right)$, a qual é proporcional a área do pico correspondente, com a atividade de um material cuja concentração elementạr é conhecida, denominado de padrão $\left(A_{p}\right)$. A amostra e padrão são irradiados (ativados) em condições bastante próximas e de forma simultânea. Neste método o padrão deve ser colocado o mais próximo possível da amostra para evitar erros devido à heterogeneidade do fluxo de nêutrons. Da mesma forma, as medidas das atividades devem ser realizada em condições idênticas para que a precisão do método não seja afetada (Balla, et al., 2004). 
A concentração de um elemento numa amostra pode ser determinada por meio da equação

$$
C_{x}=\frac{\left(\mathrm{A}_{\mathrm{x}} m_{p} C_{p}\right) \mathrm{e}^{\lambda\left(t_{\mathrm{n}}-t_{r}\right)}}{A_{p} \mathbf{m}_{\mathfrak{a}}}
$$

onde,

$\mathrm{C}_{\mathrm{x}}$ - concentração do elemento na amostra

$\mathrm{C}_{\mathrm{p}}$ - concentração do elemento no padrão

$\mathrm{A}_{\mathrm{x}}$ - atividade da amostra

$A_{p}$ - Atividade do padrão

$m_{a}-$ massa da amostra

$m_{p}-$ massa do padrão

$\lambda$ - constante de decaimento do elemento

$\left(t_{a}-t_{p}\right)-$ tempo de resfriamento

Pode-se observar a partir da Equação 3.2 que todos os parâmetros que podem influenciar nas atividades do material em estudo e padrão se cancelam, tonnando a análise independente destes fatores.

Apesar de que a aplicação do método relativo torna a determinação das concentrações elementares mais precisas, deve ser ressaltado que os procedimentos envolvidos nas análises multielementares apresentam algumas dificuldades (Heydorn, 1990). Estas dificuldades podem ser contornadas, parcialmente, através do uso de padrões multielementares, sintéticos e padrões de materiais de referência. Padrões multielementares devem conter, de preferência, todos os elementos a serem determinados, em quantidades conhecidas. $\mathrm{Na}$ atualidade, há disponibilidade de padrões multielementares homogêneos e confiáveis para análise por ativação com nêutrons (Suzuki \& Hirai, 1992).

\subsubsection{Difratometria de raios-X}

Após a descoberta dos raios - X no final do século XIX. por Röntgen, observaram-se, rapidamente, as potencialidades da sua aplicação em diversos campos do conhecimento (Cullity, 1978). As primeiras e principais aplicações dos raios -X estiveram relacionadas à geração de imagens (radiografia), e, mais tarde, no setor industrial.

As tecnologias ligadas à aplicação dos raios - $\mathrm{X}$ difundiram-se rapidamente e, já no ano de 1912, o físico Max Von Laue observando que o comprimento de onda dessa 
Observa-se que as ondas espalhadas, coerentemente, interferem-se construtivamente, dando origem a regiões de máxima intensidade, se é obedecida a Lei de Bragg (Figura 3.10), a qual pode ser expressa matematicamente como:

$$
n \lambda=2 \cdot \mathrm{d} \cdot \operatorname{sen} \theta
$$

onde,

$\lambda$ - comprimento de onda dos raios - $\mathrm{X}$;

$\mathrm{d}$ - distância interplanar;

$\theta$ - ângulo de incidência.

Os raios - X que satisfazem à condição de Bragg darão origem aos picos característicos das figuras de difração, os quais são úteis para determinação das estruturas cristalinas, visto que cada estrutura cristalográfica apresenta padrões distintos, permitindo que a espécie cristalina (mineral, "temperos", etc) sejam identificada.

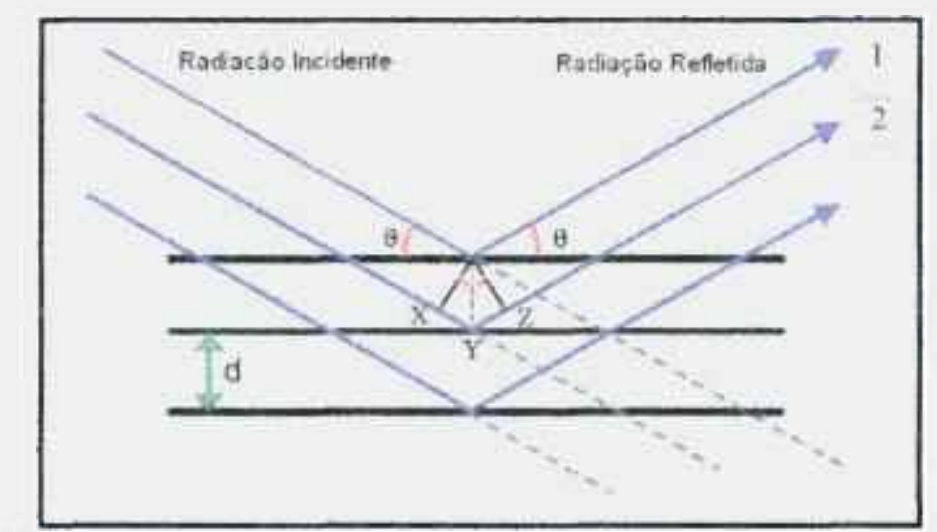

Figura 3.11 - As linhas horizontais representame os plames cristalimos

\subsubsection{Datação por termoluminescência}

A termoluminescência é caracterizada pela emissão de luz a partir de um material semicondutor ou isolante aquecido, quando é submetido, previamente, à radiação ionizante, armazenando a energia da radiação incidente.

UnI dos primeiro relatos, de caráter cientifico, do fenômeno da termoluminescència (TL) foi apresentado, em 1663, por Robert Boyle, após observar uma "emissão estranha de luz" transitória, quando um cristal de diamante era submetido a um processo de aquecimento. Contudo, até 1940, ano em que foi obtida a fotomultiplicadora, o fenômeno da TL era utilizado, apenas, como ferramenta na identificação de minerais. A partir de 1950, a TL passou a ser usada para realizar medidas da exposição à radiação 
nuclear, além de outras aplicações (Daniel et al., 1953). Randall e Wilkins, 1945, estudaram o mecanismo envolvido com a TL, e formularam um modelo teórico para a curva de emissão (Randal \& Wilkins, 1945).

A possibilidade do uso da TL para datação arqueológica e geológica foi sugerida por Daniels et al. (1953) e, em 1960, Kennedy e Knopf já relataram os resultados de datação por TL de amostras arqueológicas e de lava (Kennedy \& Knopff, 1960). Grögler et al. (1960) levantou a possibilidade de usar a TL para datação de cerâmicas.

Em 1961, os trabalhos de datação de amostras geológicas por termoluminescência, tomou um grande pulso com os trabalhos de Johnson (Aitken; 1985), datando rochas presentes nas proximidades da intrusão da lava, a fim de determinar a época em que a mesma flui pela região. Porém, nesta época, os pesquisadores encontravam diversas dificuldades na utilização da termoluminescência para datação arqueológica e geológica, pois a quantidade de impurezas presentes nas amostras já era um fato bastante conhecido, mas não havia sido feito um estudo do papel das impurezas na TL.

Posteriormente, com o estudo do mecanismo e do efeito das impurezas na TL (Medlin, 1968), a termoluminèscência passou a ser utilizada para datação arqueológica em diversos laboratórios (Aitken et al., 1964; Aitken et al., 1968; Ichkawa, 1965; Mazess \& Zimmerman, 1966; Ralph \& Han, 1966; Mejdahl, 1969). Atualmente, existem mais de 40 laboratórios envolvidos na aplicação da termoluminescência em datação arqueológica e geológica, ou na realização de testes de autenticidade de vasos cerâmicos.

Imediatamente, após o início da década de 70, surgiram extensões do uso da datação por Termoluminescência para diversos materiais, a exemplo da argila queimada, a qual apresentou-se como uma ferramenta para estudos paleontológicos, onde o método do carbono 14 apresentava algumas limitações; a calcita para datação de estalagmite e lava vulcânica para estudo em geologia, etc.(Tatumi et al., 1986).

No Brasil, as primeiras datações por TL foram feitas por Szmuk \& Watabe, em 1971, quando dataram vasos cerâmicos e urnas funerárias encontradas no interior do estado de São Paulo (Szmuk \& Watabe, 1971) e, em seguida, foram realizados diversos trabalhos relacionados a vários sítios arqueológico (Miyamoto, 1973; Matsuoka et al., 1984). Atualmente, têm sido feitas diversas datações por TL de materiais provenientes de vários locais do Brasil, realizadas, principalmente, pelo Laboratório de Vidros da FATEC/SP (Tatumi et al., 2006; Tatumi et al., 2003; Watanabe, et al., 2005; Watanabe et al., 2003; Watanabe et al., 1997). 
Em Sergipe, o potencial para datação arqueológica foi levantado, após a implantação do Laboratório de Caracterização de Materiais, posteriormente, denominado, em 1992, Laboratório de Preparação e Caracterização de Materiais (LPCM), no Departamento de Física da Universidade Federal de Sergipe (UFS). Com a implantação do Projeto Arqueológico de Xingó levantou-se a possibilidade de formação de um grupo de datação Arqueológica por TL no LPCM, o qual está em atividade na atualidade (Santos, 2002; Souza et al., 2006; Oliveira et al., 2006).

A termoluminescência é o fenômeno caracterizado pela emissão de luz a partir de um isolante ou semicondutor quando este é aquecido, porém, esta emissão de luz não pode ser confundida com a emissão de luz de uma substância quando aquecida até a incandescência (McKever, 1985). A termoluminescência é a emissão termicamente estimulada de luz seguida, previamente, de absorção de energia a partir das radiações ionizantes.

A emissão termoluminescente pode ser explicada da seguinte forma: quando a radiação ionizante incide sobre o material, transfere elétrons da banda de valência para banda de condução, em virtude do efeito fotoelétrico ou Compton. Na tentativa de retornar para a banda de valência, uma parte dos elétrons pode ficar retida em níveis de energia denominados de armadilhas. Estes níveis de energia presentes no material é um resultado dos defeitos na estrutura cristalina do material, tais como impureza substitucionais, vacância, entre outros defeitos (Agullo-Lopez et al., 1998). Com a saida do elétron da banda de valência, produz-se um buraco que, como o elétron na banda de condução tornase móvel, e se não se recombinar com um elétron, pode ser capturado por uma armadilha de buracos. Se as profundidades das armadilhas de elétrons ou de buracos forem pequenas, o elétron ou buraco aprisionado, tem uma probabilidade considerável de escapar, à temperatura ambiente, mas se a profundidade é relativamente grande, a meia-vida da carga armadilhada torna-se suficientemente grande para manter a carga presa por um longo tempo. Com a excitação térmica, o elétron recebe suficientemente energia para ser desarmadilhado, e pode recombinar-se com um buraco armadilhado em um centro de recombinação, emitindo luz TL (Figura 3.11). 




Figura 3.11- ( i) A radiaçào ionizante retira elétrons da handa dé valéncia o qual difiundi-sé pelo cristal banda de condeça ) até ser armadilhado e'm $T$ ( armadilhas de elétrons ), da mesma forma os buracos irào difundir-se pela banda de valencia, ate ficar armadilhado em $L$ (armadilha de baracos ). $($ ii ) A meia-vida dos eletrons (buracos) depende da profiundidade E das armadilhas. (iii) Quando a amostra è aquecida ate: uma certa temperatura a qual a vibraçào térmica é suficiente para que os elétrons escapem da armadilhas 7 .

haverá difusào do elètron até a banda de conduçaio e poderá haver recombinaçào en am centro de' luminescência L com emissäo de luz TL Apud Aitken. 198.5).

O princípio básico da datação por termoluminescência está fundamentado no fato que a curva da intensidade luminosa em função da temperatura (Figura 3.12) é proporcional ao tempo em que esta amostra esteve exposta à radiação ambiente, e por conseguinte, a paleodose absorvida pela amostra. Este comportamento é resultado do acréscimo da quantidade de radiação absorvida pela amostra, aumentando o número de elétrons armadilhados e, conseqüentemente, maior liberação de luz na etapa de recombinação.

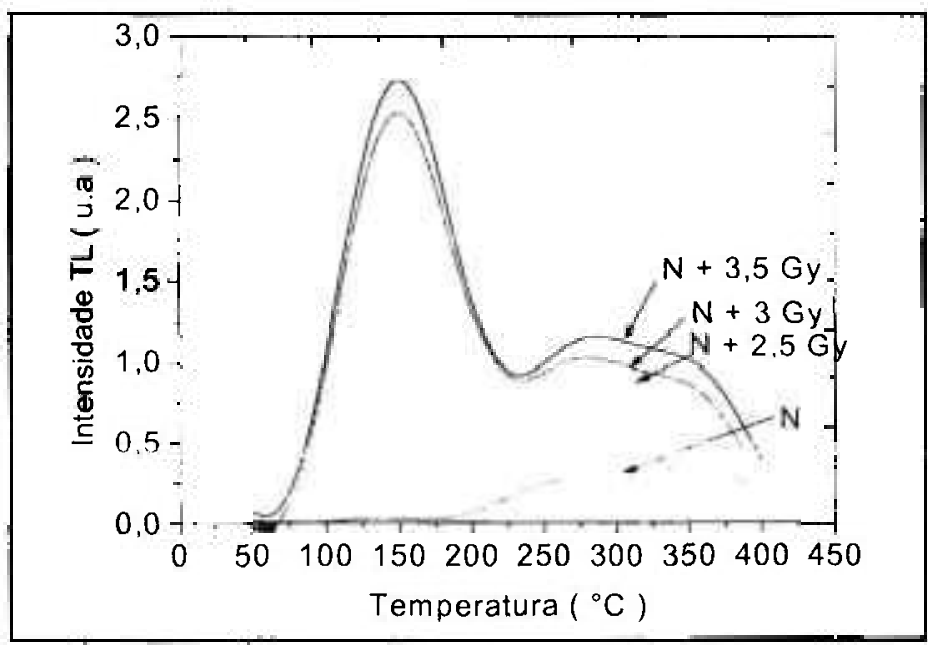

Figura 3.12 - curvas arbitrarias mostrando que a altura do pico cresece com a idade Arquesoligica da amostra. 
Na datação por TL dos vestígios cerâmicos o zero cronológico corresponde ao momento da última queima sofrida pelo artefato cerâmico. Com o aquecimento a energia absorvida pelo material até aquele momento é liberada e, a partir desse momento, a peça começa a absorver a radiação dó ambiente. Assim, os métodos de datação por TL buscam determinar as doses de radiação absorvida pela amostra ao longo dos anos (paleodose) e conhecendo-se a taxa à qual o material foi irradiado obtém-se diretamente a idade da amostra. A irradiação da amostra no ambiente é um resultado do decaimento espontâneo dos radionuclideos (Th, $\mathrm{U}$ e K) presentes no solo e na própria pasta cerâmica.

Há diversos métodos para determinação da paleodose absorvida pela amostras (Aitken, 1985). Os mais conhecidos são os métodos da curva calibração, método da dose adicional, método da pré-dose e o método da fototransferência (Aitken, 1985). Os dois primeiros métodos são baseados na proporcionalidade entre a intensidade de um pico estável com a dose absorvida. Os dois últimos estão relacionados à sensibilização de picos em baixas temperaturas, geralmente em $110^{\circ} \mathrm{C}$, que crescem com a dose absorvida. Conhecendo-se a paleodose e a taxa de dose, a idade pode ser determinada de acordo com a equação

$$
I=\frac{D_{A}}{D^{\prime}}
$$

onde,

$\mathrm{D}_{\mathrm{A}}$ é a paleodose

D' é a taxa de dose de radiação

Neste trabalho, utilizou-se o método da dose adicional, com objetivo de obter resultados com maiores precisão e exatidão.

\subsection{As argilas e os estudos Arqueométricos}

A principal fonte de matéria-prima para produção de artefatos cerâmicos é a argila, que é formada basicamente pelos argilominerais, podendo conter minerais que não são argilominerais (calcita, dolomita, quartzo, pirita, etc.), matéria orgânica e outras impurezas. Por ser constituida basicamente de argilominerais, a argila apresenta: estrutura cristalina definida; diâmetro inferior a $2 \mu \mathrm{m}$; boa plasticidade quando umedecida; quando seca adquire alta resistência mecânicẩ e possui alta capacidade de trocas catiônicas (Santos, 1975).

A classificação mineralógica das argilas pode ser feita em função das suas propriedades estruturais, tais como distância interplanar basal, grau de substituição na 
camada octaédrica, expansibilidade pela introdução de moléculas polares entre camadas basais e o tipo de arranjo ao longo dos eixos cristalográficos, que definem as espécies de um mesmo grupo mineralógico. Em especial, o grupo das caulinitas é de fundamental importância para a determinação da temperatura de queima dos produtos manufaturados a partir das argilas.

Os argilominerais da caulinita (Figura 3.13) englobam quatro variedades politípicas polimórficas, a Nacrita, Diquita, Caulinita e Haloisita, todos com a fórmula $\mathrm{Al}_{2} \mathrm{Si}_{2} \mathrm{O}_{2}(\mathrm{OH})_{4}$. De acordo com sua gênese, a caulinita pode apresentar ordenações estruturais diferentes ao longo do eixo "b" da estrutura triclínica (ou monoclínica), sendo baixo o teor de substituintes isomórficos (Gardolinski et al., 2003), sendo eletricamente neutra. Os minerais do grupo da caulinita e outros minerais são formados pela decomposição de feldspatos por processos geológicos, tendo sericita como intermediário (Equação 3.5) (Montes et al., 2002).

$$
2 \mathrm{KAISi}_{3} \mathrm{O}_{8}+3 \mathrm{H}_{2} \mathrm{O} \rightarrow \mathrm{Al}_{2} \mathrm{Si}_{2} \mathrm{O}_{5}(\mathrm{OH})_{4}+4 \mathrm{SiO}_{2}+2 \mathrm{KOH}
$$



Figura $3.13-$ Estrutura dar collimita

Na estrutura da gibbsita os átomos de aluminio estão posicionados nos centros dos octaedros e, nos vértices, estão posicionadas as hidroxilas. Somente $2 / 3$ dos octaedros são ocupados, com os octaedros ligados pelas arestas, o que caracteriza a caulinita como dioctraédrica (Frost, 1997; Grim, 1953) . Na estrutura da sílica, os átomos de silicio estão posicionados nos centros dos tetraedros, nos quais os vértices estão sitiados por átomos de oxigênio. Devido à forma como os tetraedros estão coordenados, origina-se um buraco na lamela o qual expõe a hidroxila para eventuais reações. Estas intercalações podem ser ocupadas, por exemplo, por pequenas moléculas polares, polímeros ou moléculas de água 
(caulinita hidratada). A ocupação destas intercalações por água é de grande importância no processo de manufatura da cerâmica, visto que a presença de água entre os planos torna as argilas plásticas.

Durante o processo de queima da cerâmica os argilominerais apresentam transformações múltiplas em suas estruturas cristalinas. A caulinita, por exemplo, perde a água adsorvida na superfície dos cristais a temperatura abaixo de $100{ }^{\circ} \mathrm{C}$ (desidratação da caulinita), e continuando o aquecimento até $518^{\circ} \mathrm{C}$ ocorre o processo de desidroxilação da matriz (perda de água interbasal), o que transforma a caulinita em metacaulinita (Frost \& Vassallo, 1996; Okada et al., Murad \& Wagner, 1991). Acima de $800^{\circ} \mathrm{C}$ (com pico $970{ }^{\circ} \mathrm{C}$ na curva de DTA) praticamente toda a água é perdida, resultando na nucleação do argilomineral denominado de mulita (Rice, 1987). Através do levantamento da composição mineralógica por DRX é possível estimar a faixa de temperatura que foi processada a queima da cerâmica, tendo em vista a presença ou não de um dado argilomineral.

A seleção da argila para produção cerâmica requer uma avaliação de sua plasticidade para a formação do manufaturado. Em todos os processos de seleção das argilas é necessário encontrar um balanço entre o percentual de argila, que fornece a plasticidade, e o percentual de inclusões não-plásticas, os quais fornecem importantes propriedades mecânicas ao produto final.

A inclusões não-plásticas, denominadas de temperos, podem ser identificadas por diversas técnicas de caracterização mineralógica. De acordo com a distribuição dos tamanhos dos grãos e suas formas pode ser inferido se estas inclusões foram adicionadas intencionalmente ou se são componentes intersticiais da própria matriz argilosa.

A investigação das composições química e mineralógica dos componentes da cerâmica, argilas e temperos, desempenha um papel crucial para o entendimento das culturas que a utilizaram. O conhecimento da organização da produção cerâmica e a extensão da especialização da arte são de interesse em estudos Arqueométricos, em parte por causa das implicações para produção do excedente para sua comercialização e ultimamente pela origem das formas complexas da organização social e política das culturas ceramistas (Tite, 1999). Assim, pode-se afirmar que o estudo da cerâmica é revelador da estrutura das comunidades e de suas interações. 


\subsection{Técnicas estatísticas multivariadas utilizadas}

A classificação das amostras analisadas é facilitada quando suas composições químicas são estatisticạmente distinguíveis de acordo com seus perfis químicos. No estudo composicional de cerâmicas arqueológicas, supõe-se que as características da pasta são determinadas pelas características químicas das argilas, temperos utilizados para manufaturá-las e pelas técnicas de confecção dos artefatos. Uma vez que o comportamento químico das rochas que deram origem aos materiais utilizados para fabricação da cerâmica é um reflexo dos processos geológicos locais, as abundâncias dos elementos são correlacionadas com estes processos. Deste modo, a composição química elementar da cerâmica tem uma relação particular com o local no qual foi coletada a matéria-prima.

Durante os últimos anos a aplicação de técnicas multielementares para estudo composicional, permitiram a geração de uma enorme quantidade de dados. Logo, para estudo multicomposicional da cerâmica tem sido utilizada técnicas estatísticas com o propósito de simplificar a estrutura de dados, ordená-los e agrupá-los, investigar a dependência entre as variáveis, realizar as predições e executar os testes de hipóteses.

A formação de grupos estatisticamente significantes das amostras analisadas e a avaliação de amostras de origens desconhecidas, para alocação em um dos grupos estabelecidos, são objetivos básicos dos estudos composicionais da cerâmica. Para estes fins têm sido aplicadas técnicas multivariadas de agrupamento, análise fatorial, análise discriminante e análise por componentes principais (Mommsen et al., 1988).

A aplicação de tais técnicas requer uma base de dados bem comportada em relação aos valores aberrantes, aos valores perdidos, às condições de normalidade e em relação às diferenças entre as magnitudes das variáveis medidas. De acordo com estas considerações, antes da aplicação das técnicas multivariadas é necessário um estudo sistemático das amostras aberrantes, das condições de normalidade e padronização dos dados, visando diminuir os ruídos nas interpretações finais dos dados.

\subsubsection{Amostras aberrantes}

As amostras aberrantes, também denominadas amostras atipicas ou "outliers", são observações constantes em uma base de dados que diferem significativamente da maioria das observações, ou seja, são observações caracterizadas pela sua discrepância relativa às demais. A distância das amostras aberrantes em relação ao centróide das observações de um dado grupo, é de fundamental importância para identificá-los. 
Estas amostras discrepantes podem ser geradas por diferentes mecanismos, tais como: erros de medição, variabilidade populacional do atributo medido, instrumentos defeituosos, entre outros processos. O estudo das amostras aberrantes é importante tendo em vista que uma base de dados contaminada com os mesmos pode conduzir a falsas estimativas e interpretações equivocadas. Independente de suas causas, o estudo das amostras aberrantes é realizado basicamente em três fases: detecção, testes para confirmação e destino final dos mesmas (Beckman \& Cook, 1983).

A identificação de observações discordantes em amostras univariadas é relativamente simples (Grubbs, 1950). Geralmente, por simples inspeção gráfica ou por meio de alguns testes específicos (teste de Grubbs, teste de Dickson, etc.) é possível confirmar a presença da amostra aberrante. Por outro lado, a identificação de valores aberrantes em amostras multivariadas é de extrema dificuldade, visto que a inspeção de cada variável isolada não é suficiente para identificar uma amostra aberrante.

Na literatura há poucos trabalhos sobre identificação de amostras aberrantes em amostras que envolvem mais de uma variável. A maioria dos métodos propostos na atualidade é subjetiva e rẻsume-se a métodos gráficos, tais como dendograma obtidos por análise de conglomerado. Alguns autores propõem que a distância Mahalanobis $\left(D_{i}^{2}\right)$ é eficiente como método de detecção de amostras discrepantes em dados multivariados (Baxter, 1999). Considerando uma base de dados com $n$ amostras e $p$ variáveis medidas, a distância Mahalanobis é dada por

$$
D_{i}=\sqrt{\left(X_{i}-\overline{\mathrm{X}}\right)^{T} S^{-1}\left(X_{i}-\overline{\mathrm{X}}\right)}
$$

onde $S=\sum_{i=1}^{n}\left(X_{i}-\bar{X}\right)\left(X_{i}-\bar{X}\right)^{T} / n-1$, representa a matriz de variância - covariância amostral, $X_{i}$ é a observação de interesse, e $\bar{X}_{i}$ é o vetor de média, o qual corresponde ao centróide do grupo.

A identificação de valores discrepantes por meio de $D_{i}^{2}$ é feita calculando-se $D_{i}^{2}$ para cada grupo de amostras e efetuando-se teste de hipóteses por meio da comparação deste valor com o valor crítico. Na literatura, tem sido sugerido que a determinação dos valores críticos da distância de Mahalanobis deve ser efetuada por meio da distribuição $F$, especialmente, para amostras de tamanho pequeno (Penny, 1987). Wilks sugeriu que o valor crítico para a distância Mahalanobis pode ser calculada por

$$
\frac{\mathrm{p}(\mathrm{p}-1)^{2} F_{p: n-\mathrm{p}-1 ; \alpha ; \mathrm{n}}}{n\left(n-\mathrm{p}-1+\mathrm{pF}_{n: \mathrm{n}-\mathrm{p}-1: \alpha ; \mathrm{n}}\right)}
$$


onde,

$n$ é o número de amostras

p é o número de variáveis

F é o F da distribuição de Fisher.

caso $D_{i}^{2}$ seja maior que este valor crítico a amoștra é considerada aberrante (Wilks, 1963).

Apesar da simplicidade do método descrito anteriormente, o mesmo apresenta alguns problemas relacionados à própria determinação dả distância de Mahalanobis, quando na presença de uma amostra aberrante ou um grupo de amostras aberrantes (Hardir \& Rocke, 2004). Estes problemas são originados da sensibilidade apresentada pela distância Mahalanobis à presença de amostras discrepantes. Este comportamento aparenta ser anômalo, uma vez que a distância Mahalanobis deve ser capaz de detectar as amostras aberrantes, mas, simultaneamente, esta distância pode ser afetada pela presença de uma anomalia amostral.

A principal razão da falta de robustez da distância de Mahalanobis diante de amostras aberrantes está relacionada à sensibilidade do vetor de média e da matriz de covariância, presentes na Equação 3.6. Uma solução para este problema é obtida por meio da utilização de estatísticas robustas. Para obtenção de uma distância de Mahalanobis robusta à presença de observações atípicas, $\bar{X}$ e $S$ na Equação 3.6 devem ser estimadas de forma resistentes à influência das observações aberrantes. $\mathrm{Na}$ literatura podem ser encontrados diversos estimadores robustos para os vetores de média e para a matriz de covariância (Hardir \& Rocke, 2004), mas aqueles baseados na subamostragem dos dados, e que apresentam menor determinante para a matriz de covariância (MCD - Minimum Covariance Determinant), tem sido, provavelmente, os mais utilizados (Filzmoser et al., 2005).

Por definição, os estimadores MCD são determinados de forma que o subconjunto das observações escolhido, de tamanho $h$, minimize o determinante da matriz de covariância amostral, calculados a partir das $h$ amostras. Os estimadores de tendência central e dispersão são os vetores de média e matriz de covariância desses $h$ pontos, considerando que o estimadores de dispersão é proporcional a sua matriz de covariância. A escolha do tamanho $h$ do subconjunto dos dados para estimativa de $\bar{X}$ e $S$, baseado no MCD, deve ser obtida de acordo com o compromisso entre a robustez e a eficiência da 
estimativa. $\mathrm{Na}$ literatura, tem sido apontado que $h \approx 0,75 n$, onde $n$ é o tamanho da amostra, pode ser empregado com este compromisso (Filzmoser et al., 2005).

De uma forma geral, os estimadores MCD correspondem aos vetores de média $\left(\overline{X^{*}}\right)$ e matriz de covariância $\left(S_{j}^{*}\right)$ baseados na subamostragem de tamanho $h(h \leq n)$ (Filzmoser et al., 2005). Matematicamente, podemos expressá-los como $\operatorname{MCD}=\left(\bar{X}^{*}, S_{j}^{*}\right)$, onde

$$
\begin{aligned}
& \mathrm{J}=\left\{\text { conjunto de } \mathrm{h} \text { pontos }:\left|\mathrm{S}_{\mathrm{j}}^{*}\right| \leq\left|\mathrm{S}_{\mathrm{k}}^{*}\right| \forall \text { conjunto } \mathrm{K},|\mathrm{K}|=\mathrm{h}\right\}, \text { tal que } \\
& X_{j}^{*}=\frac{1}{h} \sum_{i \in j} X_{i} \text { e } S_{j}^{*}=\frac{1}{h} \sum_{i \in j}\left(X_{i}-\overline{X_{j}^{*}}\right)\left(X_{i}-X_{j}^{*}\right)^{t} .
\end{aligned}
$$

Nas expressões acima, o valor de $h$ determina a robustez dos estimadores, $h \approx 0,75 n$ é a fração do número de amostras, que quando excedida, deixa os estimadores, completamente, enviesados.

Usando-se os estimadores obtidos por meio das Equações 3.9, é possível a determinação das distâncias de Mahalanobis robustas, as quais apresentam uma distribuição, aproximadamente, $\chi^{2}$ (Filzmoser et al., 2005). Amostras com mesmas distâncias de Mahalanobis robustas em relação ao centróide do grupo, a um certo quantil da $\chi^{2}$, por exemplo, estão dispostas na superficie de uma hiperelipsóide. Assim, pontos exteriores ao hiperelipsóide, correspondente a um nível crítico, são considerados aberrantes em relação ao grupo de amostras considerado. Na literatura é citado que se a distância de Mahalanobis robusta é superior ao quantil $\chi_{2:(1) .98}^{2}$, a amostra é considerada aberrante (Filzmoser et al., 2005).

Deste modo, o procedimento gráfico para determinação das amostras atípicas por meio da distância de Mahalanobis robusta é composta das seguintes etapas: cálculo das distâncias de Mahalanobis robusta, usando $h \approx 0,75 n$; determinação das componentes principais, para permitir a projeção dos pontos amostrais em um plano; construção da elipse correspondente a $\chi_{2: 1198}^{2}$ no plano das componentes principais; verificação das amostras externas à elipse $\chi_{2: 0,98}^{2}$ (Filzmoser et al., 2005).

Neste trabalho, a deteç̧ão de observações aberrantes foi efetuada por meio da distância de Mahalanobis clássica, com valor crítico obtido por meio do critério lambda Wilks e, simultaneamente, por meio da distância de Mahalanobis robusta. A obtenção das amostras aberrantes de acordo com os dois procedimentos descritos nessa secção, 
possibilitou a obtenção do método mais restritivo para esse objetivo. A identificação destas observações é importante para eliminar a possibilidade de erros nas interpretações referentes ao estudo composicional das peças cerâmicas analisadas.

\subsubsection{Normalização e padronização dos dados}

As inferências estatísticas consistem em generalizar informações obtidas a partir dos espaços amostrais para uma ou mais populações. Nos procedimentos inferências. nas estimativas e na obtenção dos intervalos de confiança admite-se, geralmente, que as médias amostrais são normalmente distribuídas, independente da forma da distribuição original da população (Magalhães \& Lima, 2004).

A normalidade multivariada dos dados é requerida, em muitos casos, visto que muito dos métodos estatísticos multivariados, incluindo análise de variância, análise fatorial com extração por função de verossimilhança, correlação canônica entre outros métodos, assumem que os dados seguem este tipo de distribuição (Baxter, 1999).

Segundo Mecklin \& Mundfrom (2004), a identificação da normalidade multivariada pode ser obtida por meio de gráficos e coeficientes de correlação. Dentro deste ponto de vista o gráfico dos percentis (Q-Q plot) tem sido utilizado com bastante freqüência (Hair et al., 2005). O procedimento gráfico consiste em construir o gráfico dos percentis amostrais em função dos percentis da distribuição normal padronizada. A normalidade é verificada por meio da avaliação da qualidade do ajuste da reta dos mínimos quadrados aos pontos do gráfico. Apesar da praticidade do método, o mesmo não constitui um teste formal para verificar desvio de normalidade multivariada. Para contornar esta limitação, diversos autores têm proposto métodos formais para verificação de normalidade por meio de estatisticas que utilizam o vetor de média, coeficiente de assimetria e curtose (Mardia, 1974).

Um dos testes proposto por Mardia, baseado na assimetria e curtose multivariada definidos como

$$
b_{1, f}=\frac{1}{n^{2}} \sum_{i=1}^{n} \sum_{j=1}^{n}\left[(x,-\bar{X}) S^{\prime}\left|(\lambda,-\bar{Y})^{\}}\right|\right.
$$

L

$$
b_{2, p}=\frac{1}{n} \sum_{i=1}^{n} \sum_{i=1}^{n}\left[\left(X_{i}-\bar{X}\right)^{\prime} S^{-1}\left(X_{j}-\bar{X}\right)^{2}{ }_{j}^{-}\right.
$$

respectivamente, onde, 
$\mathrm{p}=2,3$ para pequenas amostras

$\mathrm{X}_{\mathrm{i}}$ e $\mathrm{X}_{\mathrm{i}}$ são observações

$\bar{X}$ é o vetor de média

S é a matriz de variância-covariância

pode ser utilizado para realizar testes formais de normalidade. Estas estatísticas são calculadas e comparadas com seus respectivos valores críticos para verificação de desvio da distribuição normal multivariada (Mardia \& Kent, 1991). Outro teste para normalidade multivariada dos dados, o que é uma extensão do teste de Shapiro-Wilks para o caso univariado, implementado no programa estatístico $R$, tem sido utilizado com bastante freqüência (Royston, 1995; Royston, 1982).

No estudo da composição química da cerâmica tem sido observado que os elementos analisados se distribuem log - normalmente (Glascock, 1992). Isto é preferível por duas razões básicas: primeiro, porque tem sido observado que diversas concentrações elementares são normalizadas quando tomado os seus valores logarítmicos. A segunda razão é que a transformação dos dados de concentração em uma escala logarítmica compensa as diferenças de magnitudes das variáveis medidas (padronização).

Visando a padronização e normalização dos dados, neste trabalho a interpretação dos dados foi efetuada em uma escala logarítmica. Esta transformação viabilizou a aplicação das técnicas de agrupamentos das amostras de forma mais segura. A verificação da normalidade univariada dos dados foi verificada por meio do teste de Shapiro-Wilks (Hair et al., 2005) e para teste de normalidade multivariada foi aplicado a extensão desse teste, o qual está implementado no programa $\mathrm{R}$.

\subsubsection{Análise de agrupamento}

A análise de agrupamento ("Cltuster Analysis") é uma técnica estatística multivariada utilizada para produzir padrões de comportamento em bancos de dados por meio da formação de grupos homogêneos de casos. O objetivo principal da técnica é agrupar objetos semelhantes de acordo com suas características.

Para formação dos grupos, conforme esse método de agrupamento, é necessário adotar critérios bem definidos. Um critério razoável para formação dos grupos é considerar a proximidade entre os pontos, visto que pontos que estão próximos têm valores de coordenadas próximas, ou seja, as variáveis para cada caso assumem valores similares. 
Logo, esta técnica exige a definição de um coeficiente de parecença para indicar a proximidade entre os individuos.

$\mathrm{Na}$ literatura estatística são citadas duas medidas de parecença: medidas de similaridades (quanto maiores os valores mais similares são os objetos) e medidas de dissimilaridades (quanto maior, menor a similaridade entre os objetos) (Johnson \& Wichern, 1992). A partir da definição do critério de parecença é construída uma matriz de parecença como ponto de partida do método de agrupamento.

Os elementos da matriz de similaridade ou dissimilaridades são determinados, geralmente, a partir das diversas medidas de distância (Massart \& Kaufiman, 1983). Entre as medidas de distância a mais utilizada é a distância Euclidiana. Em um espaço pdimensional, a distância Euclidiana é dada pela equação

$d\left(X_{A}, X_{B}\right)=\sqrt{\left(X_{A 1}-X_{B 1}\right)^{2}+\left(X_{A 2}-X_{B 2}\right)^{2}+\ldots+\left(X_{s p}-X_{B p}\right)^{2}}=\sqrt{\left(\tilde{X}_{X}-\tilde{X}_{B}\right)^{\gamma}\left(\tilde{X}_{A}-\widehat{X}_{n}\right)}$

onde,

$\widetilde{X}_{b}$ e $\widetilde{X}_{B}$ representam os vetores de observações.

Após construção da matriz de parecença o próximo passo da técnica é optar por um algoritmo de agrupamento. Há diversos algoritmos para formação dos grupos, os quais de forma geral podem ser classificados em métodos hierárquicos e de partição ou nãohierárquicos (Jolliffe et al., 1995).

Nos métodos hierárquicos, os agrupamentos são formados a partir da matriz de parecença de acordo com a seqüência: inicialmente os n objetos formam n classes; Em seguida as observações mais semelhantes são agrupadas em uma mesma classe, resultando em n-1 classes; Este processo continua até que todos os indivíduos pertençam a uma única classe.

As regras de reconstrução da matriz de parecença a cada formação de classe determinam a homogeneidade dos grupos formados. Entre os métodos mais comuns para este fim estão o método do vizinho mais próximo, método do vizinho mais longe, método das médias das distâncias, métodos dos centróides e método de Ward (Johnson \& Wichern, 1992).

Os métodos de agrupamentos não-hierárquicos buscam definir partições de $n$ objetos em $k$ grupos de acordo com algum critério estabelecido previamente. A prefixação dos critérios está associada à produção de medidas referentes à qualidade da partição 
produzida. Entre os métodos de partição os mais conhecidos são o método das k-médias e método dos k-medóides (Kaufman \& Rousseeuw, 1990).

A principal vantagem dos métodos hierárquicos em relação aos métodos nãohierárquico é que os mesmos não requerem o conhecimento a priori do número de grupos que serão formados. As introduções dos métodos não-hierárquicos permitem uma verificação da significância da alocação de um dado objeto em um grupo. Assim, em muitos casos remenda-se a adoção de um método hierárquico para a determinação do número inicial de grupos e posteriormente aplicar um dos métodos não-hierárquico.

Nas fases finais de aplicação da técnica de conglomerado os agrupamentos podem ser representados graficamente por meio dos dendrogramas. Os dendrogramas apresentam os elementos e os respectivos pontos de fusão ou divisão dos grupos formados em cada estágio. A inspeção visual dos dendrogramas permite a identificação dos grupos. Apesar de sua simplicidade a análise de conglomerado tem sido utilizada com bastante sucesso como ponto de partida para outras técnicas estatísticas mais refinadas e que produzam grupos mais homogêneos e de fácil identificação (Jolliffe, 1989).

\subsubsection{Análise por componentes principais}

Uma questão importante na análise composicional da cerâmica está relacionada à representação dos dados, tendo em vista o grande número de variáveis observadas para cada amostra. Uma vez que está dificuldade esta sempre presente em análises composicionais de cerâmicas, em muitos casos é necessário recorrer a técnicas estatísticas multivariadas no sentido de explicar a estrutura de dados em termos de poucas variáveis. Umả das técnicas mais utilizadas com este objetivo é a técnicas de componentes principais. (Vinagre Filho et al., 2005; Hall. 2004; Neff, 1994).

A análise das componentes principais é uma técnica que transforma linearmente um conjunto de $p$ variáveis observadas em um conjunto com um número menor $(k)$ de variáveis não correlacionadas e que explicam uma parcela substancial da estrutura de covariância dos dados (Jolliffe, 1989). As $p$ variáveis transformadas $\left(\mathrm{Y}_{1}, \mathrm{Y}_{2}, \ldots, \mathrm{Y}_{\mathrm{p}}\right)$ a partir das variáveis originais são denominadas de componentes principais. As componentes principais estão ordenadas de forma que a primeira componente $\left(\mathrm{Y}_{1}\right)$ explique a maior parcela da variabilidade. $\left(\mathrm{Y}_{2}\right)$ a segunda maior parcela e assim sucessivamente. Apesar desta transformação gerar um número de componentes igual ao número de variáveis originais, na aplicaçâo da técnica retém-se $k$ componentes $(k<p)$ para explicação de toda variabilidade dos dados. Assim, de uma forma geral a análise das componentes principais 
tem o objetivo de reduzir a dimensionalidade dos dados, obter combinações interpretáveis das variáveis, descrever e entender a estrutura de correlação entre as variáveis observadas.

Algebricamente, as componentes principais são combinações lineares das variáveis originais. Geometricamente, as componentes principais representam as coordenadas dos pontos amostrais em um sistema de eixos ortogonais obtidos pela rotação do sistema de eixos originais em direção da máxima variabilidade (Figura 3.14).

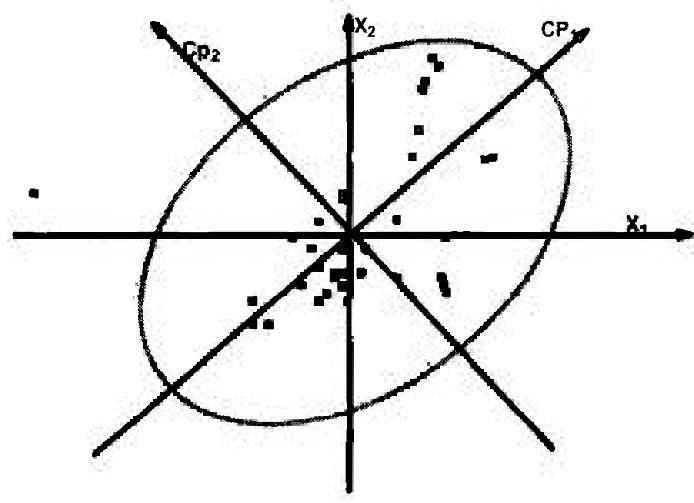

Figura 3.14 - Representaçùo das variáveis em termos de componentes principais $\left(C P_{l}\right.$ e $\left.C P_{2}\right)$

As componentes principais dependem exclusivamente da matriz de covariância $\Sigma$ (ou da matriz de correlação $\rho$ ) e das variáveis $\left(X_{1}, X_{2}, \ldots, X_{p}\right)$. Para $\tilde{X}^{T}=\left(X_{1}, \ldots, X_{p}\right)$, onde $\tilde{X}^{T}$ é o vetor observação das $\mathrm{p}$ variáveis originais, as componentes são as combinações lineares dadas por

$$
\begin{gathered}
Y_{1}=I_{1}^{T} \tilde{X}=I_{11} X_{1}+I_{12} X_{2}+\ldots+I_{1 p} X_{p} \\
Y_{2}=I_{2}^{T} \tilde{X}=I_{21} X_{1}+I_{22} X_{2}+\ldots+I_{2 p} X_{p} \\
Y_{p}=I_{p}^{T} \tilde{X}=I_{p 1} X_{1}+I_{p 2} X_{2}+\ldots+I_{p p} X_{p}
\end{gathered}
$$

A variância da i-ésima componente é dada por $\operatorname{var}\left(Y_{i}\right)=E\left(y_{i}, Y_{i}\right)$, que pode ser escrita como

$$
\operatorname{var}\left(Y_{i}\right)=l_{i}^{T} \Sigma l_{i}
$$

A covariância da componente $Y_{i}$ com a componente $Y_{j}$ pode ser calculada de acordo equação

$$
\operatorname{cov}\left(Y_{i}, Y_{j}\right)=I_{i}^{T} \Sigma I_{j}
$$


Por definição as componentes principais não são correlacionadas e possuem variâncias máximas. Entretanto, devem-se impor restrições à maximização da variância. Geralmente, impõem-se a restrição $I_{j}^{\top} I_{j}=1$. Considerando estas restrições tem-se que a primeira componente é a combinação linear $I_{1}^{\top} \tilde{X}$ que maximiza $\operatorname{var}\left(I_{1}^{\top} \tilde{X}\right)$ e sujeita a restrição de normalização. A i-ésima componente é a combinação linear que maximiza $I_{i}^{T} \tilde{X}$, sujeita a restrição $I_{i}^{T} I_{j}=1 \operatorname{com} \operatorname{cov}\left(I_{i}^{T} \tilde{X}, I_{j}^{T} \tilde{X}\right)=0$. Assim, a soma das variâncias das componentes e das variáveis originais assume os mesmos valores e as componentes não estão correlacionadas.

A transformação da matriz de dados $\tilde{X}$ em função das componentes principais não altera a variância total da estrutura de dados. De acordo com esta consideração a proporção da variância total devido ao i-ésimo componente principal é dada por

$$
\frac{\lambda_{i}}{\lambda_{1}+\lambda_{2}+\ldots+\lambda_{p}}, \quad i=1,2, \ldots, p .
$$

onde $\lambda_{j}$ é o autovalor associado ao componente i.

Em diversas situações a aplicação da análise das componentes principais permite que $70 \%$ ou mais da variância total seja explicada pelas primeiras $k$ componentes. Dessa forma, estas primeiras $k$ componentes podem substituir as $p$ variáveis originais sem perda significativa de informação.

Em análise de componentes principais uma questão freqüente é saber o número de componentes que devem ser retidas para explicar toda estrutura de dados. Os aspectos que devem ser considerados são as quantidades de variâncias explicadas, os tamanhos relativos dos autovalores e a interpretação subjetiva das componentes. Alguns critérios tais como critério de Kaiser, "screen plot", entre outros critérios podem auxiliar na escolha do número de componentes que devem ser retidos (Kaiser, 1958).

No estudo composicional da cerâmica a técnica de componentes principais é extremamente útil, visto que as modernas técnicas de análise fornecem um grande número de variáveis para as amostras, e na maioria dos casos estas estão correlacionadas. A composição de cada espécie original pode ser convertida em seus escores principais tornando-se mais facilmente interpretáveis. Vários pesquisadores descrevem que no estudo da cerâmica cerca de $70 \%$ ou mais da variância total dos dados é explicada em termos das três primeiras componentes principais. Desta forma, por meio das componentes principais 
é possível realizar os agrupamentos das amostras de uma forma mais simples em virtude da redução da dimensionalidade dos dados.

\subsubsection{Análise discriminante}

A análise discriminante é uma técnica estatística multivariada utilizada com o objetivo de discriminar populações e/ou classificar objetos em populações previamente definidas. Os principais objetivos da técnica são encontrar funções das variáveis originais (funções discriminantes) que expliquem as diferenças entre as populaçôes e que permitam alocar novos objetos em uma das populações envolvidas na análise.

Diferentemente da análise de agrupamento, a análise discriminante é uma técnica supervisionada, pois neste tipo de análise há necessidade do conhecimento a priori das populações às quais pertencem os objetos. Para aplicação da análise discriminante as $n$ populações devem ser bem definidas. Estas características diferem da análise de agrupamento visto que nesta técnica não se conhecem a priori quais as populações envolvidas.

Para determinação das funções discriminantes é utilizado com muita freqüência o método de Fisher (Poston \& Marchette, 1998). Este método consiste em obter novos eixos a partir de combinações lineares das variáveis originais que permitam diferenciar significativamente as populações. Com este propósito, busca-se a combinação linear $\tilde{Y}=\tilde{I}^{\top} \tilde{X}$ (onde $\tilde{X}$ é o vetor de observação) que maximize as distâncias entre os vetores de média de cada população $\left(\tilde{\mu}_{i}\right)$ e minimize as variâncias internas.

Considerando que as matrizes de covariâncias das populações $\left(\tau_{1}, \tau_{2}, \ldots, \tau_{n}\right)$ são iguais, ou seja $\Sigma_{1}=\Sigma_{2}=\ldots=\Sigma_{n}=\Sigma$, a combinação linear para discriminação das populações segundo o método Fisher implica na maximização de $\frac{\tilde{l}^{\top} B_{0} \tilde{I}}{\tilde{l}^{T} \Sigma \tilde{l}}$, onde $B_{0}=\sum\left(\tilde{\mu}_{i}-\bar{\mu}_{i}\right)\left(\tilde{\mu}_{i}-\bar{\mu}_{i}\right)^{T}$ e $\bar{\mu}$ é o vetor de média das médias.

Os coeficientes $\left(\tilde{l}_{i}\right)$ da primeira função descriminante são os elementos do autovetor padronizado de $\Sigma^{-1} B_{0}$, associado ao maior autovalor dessa matriz. O vetor $(\tilde{l})$ que maximiza a razão referida no parágrafo anterior, sujeita à restrição $\operatorname{cov}\left(I_{1}^{T} \tilde{X}, I_{2}^{T} \tilde{X}\right)=0$, é o vetor padronizado associado ao segundo maior autovalor de 
$\Sigma^{-1} B_{0}$, sendo que a combinação linear resultante é chamada de segunda função discriminante. Assim, a k-ésima função discriminante é $\tilde{l}_{k}^{T} \tilde{X}$, onde $\tilde{l}_{k}$ é o correspondente $k$-ésimo autovalor padronizado sujeito à condição $\operatorname{cov}\left(I_{k}^{T} \tilde{X}, I_{i}^{T} \tilde{X}\right)=0 . \operatorname{com} \mathrm{i}<\mathrm{k}$. Como $\mu_{\mathrm{i}}$ e $\Sigma$ são, em geral, desconhecidos estes são substituídos por suas estimativas na análise discriminante.

Nos estudos Arqueométricos a análise discriminante tem sido aplicada intensamente para estudos de proveniência das fontes de matérias-primas e agrupamentos de vestígios cerâmicos conforme suas similaridades (Munita et al., 2003). Outra finalidade onde a análise discriminante tem sido utilizada com bastante freqüência está relacionada á seleção do melhor conjunto de variáveis que discriminam os grupos definidos a priori. A análise discriminante utilizada com esse objetivo é denominada discriminante "stepwise", e têm encontrado bastantes aplicações em Arqueometria (Baxter \& Jackson, 2001).

\subsubsection{Fator de diluição}

Freqüentemente, diversos problemas surgem na interpretação dos resultados obtidos em estudos composicionais de cerâmicas arqueológicas, uma vez que os dados obtidos pelas várias técnicas analíticas estão sujeitas aos efeitos de diluição (Perlman \& Asaro, 1971; Harbottle, 1976; Gunneweg et al., 1987). Os efeitos de diluição podem ser causados naturalmente, pela adição de diferentes quantidades de componentes na argila, ou em virtude de praticas ceramistas, resultando em diferentes quantidades de temperos nas cerâmicas fabricadas a partir da mesma argila. Na análise multielementar isto resulta, simplesmente, no decréscimo simultâneo de todas as concentrações medidas. O efeito de diluição pode, também, ser um resultado técnico da análise (Beier \& Mommsen, 1994; Mommsen et al., 1988), por exemplo, uma pesagem errada, diferentes quantidades de água nas amostras ou pequenas flutuações no fluxo de nêutrons, raios-x ou gás na AANI, FRX ou ICP, respectivamente.

Em geral, as diluições não podem ser reconhecidas sem a devida atenção. Os valores de concentração das amostras, os quais estão intensamente diluídos comparados aos seus grupos, diferem a partir dos valores deste grupo apenas por um fator. As técnicas multivariadas para interpretação dos dados composicionais, tais como análise das componentes principais, análise discriminante e análise de agrupamento, não levam em consideração os efeitos de diluição. Assim, algumas amostras podem ser consideradas aberrantes em relação ao grupo, visto que está diluída em relação ao centro do grupo. 
Uma diluição ou uma alteração (natural ou artificial), matematicamente, é uma transformação no vetor dos dados originais $\vec{X}_{0}$, o qual é simplesmente dado pela multiplicação de cada componente do vetor pela mesma constante $\phi$, transformando os dados originais nos valores medidos $\vec{X}$ de acordo com

$$
\vec{X}_{0} \rightarrow \vec{X}=D_{\text {alil }}(\phi) \vec{X}_{0},
$$

onde a 'matriz das distorções de diluição' $D_{\text {alil }}$ é dado por $D_{\text {till }}(\phi)=\phi 1$, I sendo uma matriz identidade $m \times m$. Quando comparamos dois pontos $\vec{X}$ e $\vec{Y}$, no hiperespaço, eles podem estar diluídos em relação a diferentes fatores. Estudos de proveniência por meio de análise multielementar, contudo, são baseados na suposição que os valores medidos resultarão em um mesmo padrão químico para uma mesma rede de produção, e não estão distorcidos, ou são igualmente distorcidos para todas as amostras. Desta forma, se as distorções de vários tamanhos e tipos estão presentes nos dados, os resultados obtidos, possivelmente, estarão alterados em relação aos valores originais. Assim, os valores medidos devem ser transformados em seus valores originais. Isto é feito pela aplicação da inversa da matriz de diluição $D_{d i l}^{-1}\left(\phi_{X}\right)$ e $D_{d i l}^{-1}\left(\phi_{Y}\right)$ para $\vec{X}$ e $\vec{Y}$, respectivamente. O termo 'valor original' é usado, exclusivamente, por razões matemáticas, uma vez que as diluições podem ser naturais e, portanto, pode não existir o valor original no sentido lato da palavra.

Como foi citado na seção referente ao estudo de amostras aberrantes, a distância de Mahalanobis pode ser utilizada para identificar se uma dada amostra pertence a um determinado grupo composicional. Uma modificação da distância de Mahalanobis clássica (Equação 3.1), a qual inclui as incertezas experimentais foi proposta por Beier \& Mommsen (1994). Esta distância apresenta uma distribuição $\chi^{2}$, e da mesma forma que a distância de Mahalanobis clássica, pode ser utilizada para decidir se uma amostras pertence a um dado grupo. Assim, a distância de Mahalanobis modificada pode ser entendida como uma medida da similaridade química entre uma dada amostra e o centróide do grupo, o que dá a assinatura química do grupo cerâmico considerado.

$$
d_{M}^{2}(\vec{X}, \vec{Y})=\frac{1_{1}}{m}(\vec{X}-\vec{Y})\left(S_{X}+S_{Y}\right)^{-1}(\bar{X}-\bar{Y})
$$

onde,

$d_{M}^{2}(\bar{X}, \vec{Y})$ é a distância Mahalanobis modificada;

$\mathrm{S}_{\mathrm{X}}$ é a matriz das incertezas experimentais;

$\mathrm{S}_{Y}$ é a matriz de covariância. 
Incluindo as correções dos efeitos de diluição na equação anterior, como proposto por Beier \& Mommsen (1994), as concentrações medidas serão alteradas para seus valores originais, e $d_{M}^{2}(\vec{X}, \vec{Y})$ resultará em

$$
\begin{aligned}
& d_{M}^{2}(\vec{X}, \vec{Y})=\frac{1}{m}\left(\vec{X}_{0}-\vec{Y}_{0}\right)\left(S_{X O}+S_{Y_{0}}\right)^{-1}\left(\vec{X}_{0}-\vec{Y}_{0}\right) \\
& =\frac{1}{m}\left(D_{d i l}^{-1}\left(\phi_{X}\right) \vec{X}-D_{d i l}^{-1}\left(\phi_{Y}\right) \vec{Y}\right)\left(D_{d i l}^{-1}\left(\phi_{X}\right) S_{X}^{\prime} D_{d i l}^{-1}\left(\phi_{X}\right)+\right. \\
& \left.+D_{d i l}^{-1}\left(\phi_{Y}\right) S_{Y}^{\prime} D_{d i l}^{-1}\left(\phi_{Y}\right)\right)^{-1}\left(D_{d i l}^{-1}\left(\phi_{X}\right) \vec{X}-D_{d i l}^{-1}\left(\phi_{Y}\right) \vec{Y}\right) \\
& =\frac{1}{m}(f \vec{X}-\vec{Y})\left(f^{2} S_{X}+S_{Y}\right)^{-1}(f \vec{X}-\vec{Y}),
\end{aligned}
$$

onde $f=\phi_{Y} / \phi_{X}$ foi introduzida de forma a simplificar o formalismo matricial. Multiplicando-se $\vec{X}$ por $f$, uma correção em virtude da diluição é efetuada. Todavia, $f$ não é, normalmente, conhecido a priori.

Sob a suposição que as correções, em virtude das diluições, devem aproximar o máximo possível $\vec{X}$ e $\vec{Y}$, onde $\vec{X}$ representa uma dada amostra no hiperespaço e $\vec{Y}$ o centróide do grupo, $f$ é a solução $f_{0}$ da equação

$$
\partial f^{[}\left[(f \bar{X}-\bar{Y})\left(f^{2} S_{X}+S_{Y}\right)^{-1}(f \bar{X}-\bar{Y})\right]=0 .
$$

Assim, por meio destes últimos argumentos o conceito de diluição é adicionado de forma natural na distância de Mahalanobis modificada, por substituição direta da solução $f_{\text {n }}$ na Equação 3.16.

A introdução do fator de diluição como uma correção das 'distorções' nos dados pode, também, ser usado para introduzir outras correções. Se a correção de uma distorção para dois pontos amostrais $\bar{X}$ e $\bar{Y}$ pode ser descrito por operadores lineares, $M_{\text {dist } . X}(\vec{\psi})$ e $M_{\text {disst.Y }}(\vec{\psi})$, dependente do vetor de parâmetros $k$-dimensional (inicialmente conhecido) $\vec{\psi}=\left(\psi_{1}, \ldots, \psi_{k}\right), \mathrm{k}$ menor que $\mathrm{m}, M_{\text {dis } \omega_{\psi} X} \neq M_{\text {dis } \kappa_{k},}$ (caso contrário nenhuma correção é necessária), então a distância de Mahalanobis entre $\vec{X}$ e $\vec{Y}$, corrigida de acordo com as distorções, é dada por

$$
\begin{aligned}
& d_{M: A l s t-c a m}^{2}(\vec{X}, \vec{Y}) \\
& =\frac{1}{m-k}{ }^{\prime}\left[M_{\text {dist. } . Y}\left(\vec{\psi}_{0}\right) \overrightarrow{\mathbf{X}}-M_{\text {dist. } .}\left(\vec{\psi}_{0}\right) \vec{Y}\right] \\
& \times\left[M_{d i s t . X}\left(\vec{\psi}_{0}\right) S_{X}^{t} M_{\text {dist } . X}\left(\vec{\psi}_{0}\right)-M_{\text {dist. } . Y}\left(\vec{\psi}_{0}\right) S_{Y}^{t} M_{d i s t . Y}\left(\vec{\psi}_{0}\right)\right]
\end{aligned}
$$




$$
\times\left[M_{\text {dist } . X}\left(\vec{\psi}_{0}\right) \overrightarrow{\mathbf{X}}-M_{\text {dist..Y }}\left(\vec{\psi}_{0}\right) \vec{Y}\right]
$$

onde $\vec{\psi}_{0}$ é a solução do sistema de equação a seguir

$$
\bar{\nabla}_{\dot{\psi}} d_{\text {si dist-crorr }}(\bar{X}, \bar{Y})=0 \text {. }
$$

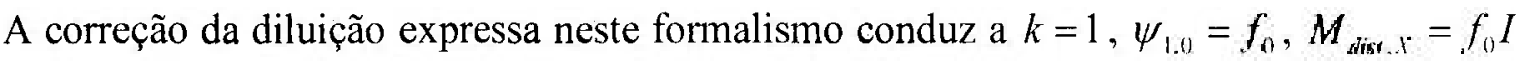
e $M_{\text {dist. } Y}=I$, uma vez que $\vec{Y}$ não é corrigido. O método geral pode ser de enorme potencialidade, especialmente, no estudo de materiais cerâmicos com composições que sofrem alterações pós-deposicionais em estudos arqueométricos.

Tendo em vista que as correções dos efeitos de diluição alteram as concentrações medidas para as concentrações mais prováveis, para uma dada fonte de matéria-prima, uma melhor resolução nos grupos é obtida se os efeitos de diluição natural e técnica são considerados, antes da aplicação dos métodos de agrupamentos multivariados. Dentro desta perspectiva, neste trabalho, as concentrações obtidas por análise por ativação com nêutrons, também, foram corrigidas a fĩm de melhorar a resolução espacial dos grupos cerâmicos. 


\section{PARTE EXPERIMENTAL}

\subsection{Preparação das amostras para AANI}

Inicialmente, cerca de $2-3 \mathrm{~mm}$ das superfícies laterais dos fragmentos cerâmicos foram extraídos com uma lima rotativa, constituída de carbeto de tungstênio, adaptada a uma furadeira, cuja velocidade de rotação é regulável por meio de um potenciômetro. A seguir, extraíram-se cerca de $500 \mathrm{mg}$ de amostra, na forma de pó, por meio da perfuração de orifícios transversais, com broca de carbeto de tungstênio. $O$ pó obtido foi secado em estufa a temperatura de $105^{\circ} \mathrm{C}$ por $24 \mathrm{~h}$ e armazenado em dessecador (Munita et al., 2004). O material de referência Constituent Elements Coal Fly Ash (NIST SRM - 1633b) foi utilizado como padrão e os materiais Brick Clay (NIST - SRM-679) e Trace Elements in Soil (IAEA - Soil - 7) foram utilizados para verificar a qualidade analítica dos resultados. Estes materiais de referências foram secados a $105^{\circ} \mathrm{C}$ por 2 horas e postos em dessecador até a pesagem.

Cerca de $100 \mathrm{mg}$ de amostras e padrões, na forma de pó, foram pesados em envelopes de polietileno. Cada envelope contendo as amostras e o padrão foram envolvidos em folha de alumínio e, grupos constituidos de três materiais de referência e seis amostras foram colocados em um cilindro de alumínio, denominado "coelho". O "coelho", contendo as amostras e os materiais de referência foram irradiados sob um fluxo de nêutrons térmicos da ordem de $10^{12} \mathrm{n} . \mathrm{cm}^{-2} \cdot \mathrm{s}^{-1}$, durante $8 \mathrm{~h}$, no reator IEA-R $1 \mathrm{~m}$ do IPEN-CNEN/SP. A Figura 4.1 mostra a representação da preparação seqüencial das amostras para análise por ativação com nêutrons. 

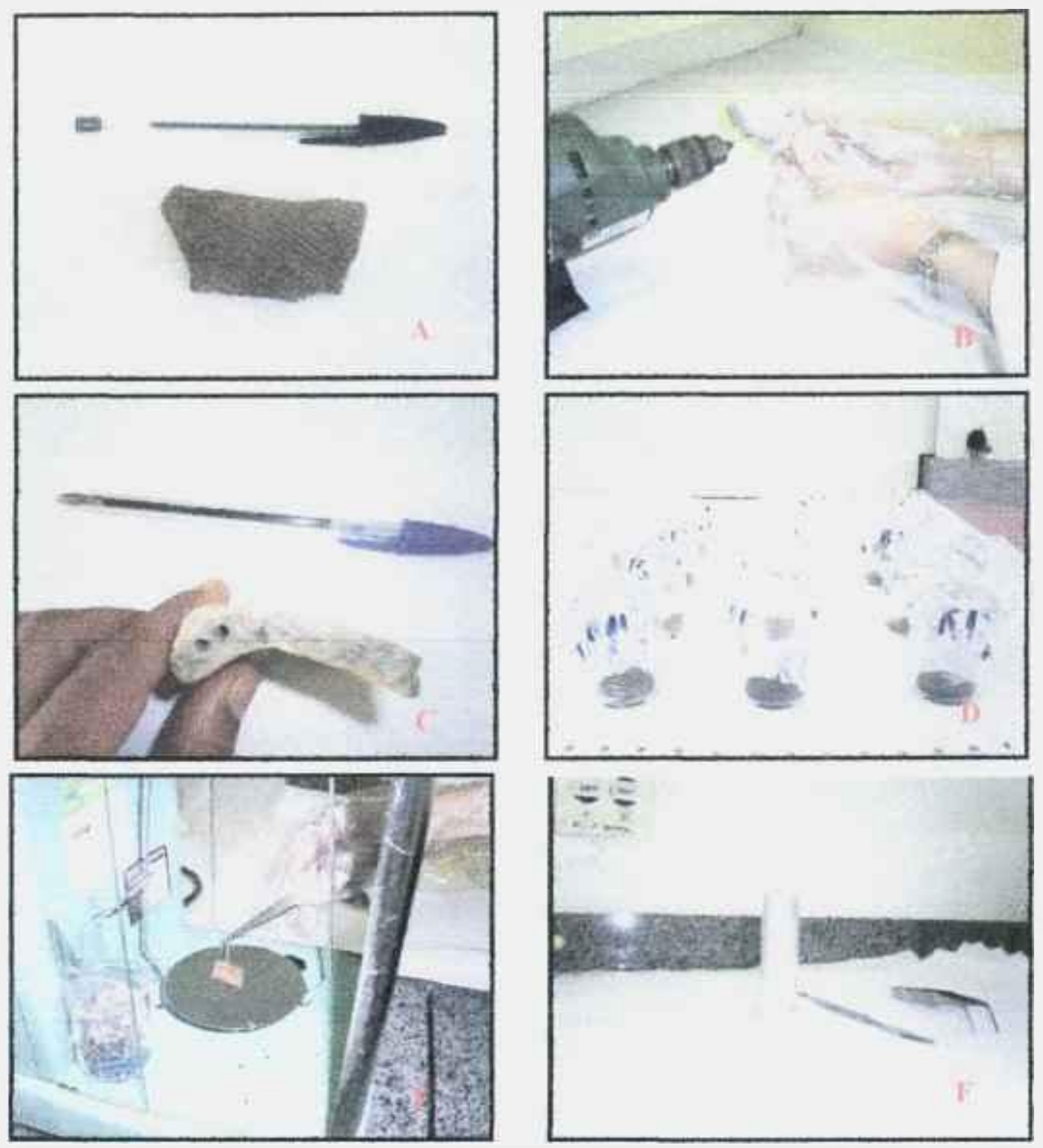

Figura 4.1. Etapas da preparação da amostras para análise por ativação: (A) peça a ser analisada: (B) Peça ceràmica sendo furada: (C) Visão de uma cerâmica furada: (D) Pó coletado a partir da cerâmica e pronto para secar: (E) Pesagem de amostras e padrões; (F) "Coelho "usado para irradiação das amostras no reator nuclear.

\subsection{Preparação das amostras para DRX}

O pó obtido a partir das amostras preparadas para análise por ativação com nêutrons foi peneirado para uniformizar o tamanho dos grãos (abertura de $74 \mu \mathrm{m}$ ), e em seguida foram preparadas as lâminas para os ensaios de difração. As lâminas de vidro foram preparadas pela distribuição uniforme do pó na área que seria iluminada pelos raios$X$. A distribuição do pó na superficie da lâmina foi realizada criteriosamente para evitar 
efeitos de direções preferências, a qual pode prejudicar a interpretação do difratograma obtido (Albers et al., 2002):

\subsection{Preparação das amostras para TL}

As etapas envolvidas na obtenção do quartzo a partir da cerâmica para determinação da paleodose absorvida foram (Wintle, 1997):

1. Eliminação das impurezas que poderiam estar presas à superfície, com escovas de cerdas de aço;

2. Trituração das peças em almofariz de ágata até obter o material com granulometria entre $75 \mu \mathrm{m}-200 \mu \mathrm{m}$;

3. Retiradas de materiais magnéticos por meio de um ímã;

4. Dissolução da matéria orgânica em $\mathrm{HCl}(6 \mathrm{M})$, durante 24 h, e em seguida o material lavado com água destilada;

5. Após diss̉olução da matéria orgânica em $\mathrm{HCl}$, o material foi submetido a um ataque em meio básico com solução de hidróxido de sódio $(\mathrm{NaOH} 6 \mathrm{M})$ por 6 horas;

6. Após remoção da solução básica com água destilada, o material foi tratado em ácido fluorídrico (HF 50\%) por 1 hora para remoção da superfície dos cristais de quartzo e lavado em água destilada;

7. Em seguida, a amostra foi separada em alíquotas: uma aliquota para medida da emissão natural da amostra e outras alíquotas para medida da emissão após irradiação com diferentes doses.

\subsection{Determinação da composição química elementar por AANI}

As amostras irradiadas foram submetidas à espectrometria gama, após um tempo resfriamento de 7 dias para determinação das concentrações de As, Ba, K, La, Na, $\mathrm{Nd}, \mathrm{Sm}$ e $\mathrm{Yb}$. A segunda medida foi realizada após 30 dias para determinação das concentrações de Co, Cr, Cs, Eu, Fe, Hf, Rb, Sb, Sc, Ta, Tb, Th, U e Zn (Glascock \& Neff, 2003). Na Tabela 4.1, encontram-se alguns dados nucleares dos radioisótopos determinados nesse trabalho, onde são apresentadas a meia-vida, a fração isotópica, a seção de choque e a energia da radiação gama usada na análise. 
Tabela 4.1. Radioisótopos utilizados para análise química das ceraimicas e seus principais parametros nucleares:

\begin{tabular}{|c|c|c|c|c|c|}
\hline Elem. & Radioisótopo & Meia-vida & $\begin{array}{c}\text { Fração } \\
\text { isotópica (\%) }\end{array}$ & $\begin{array}{c}\text { Seção de } \\
\text { choque (barns) }\end{array}$ & $\begin{array}{c}\text { Energia } \\
(\mathrm{keV})\end{array}$ \\
\hline $\mathrm{Na}$ & ${ }^{24} \mathrm{Na}$ & $15,4 \mathrm{~h}$ & 100 & 0,525 & 1368.55 \\
\hline $\mathrm{K}$ & ${ }^{42} \mathrm{~K}$ & $12,5 \mathrm{~h}$ & 6,88 & 1,3 & 1524.58 \\
\hline Sc & ${ }^{46} \mathrm{Sc}$ & $83,9 \mathrm{~d}$ & 100 & 12 & 889,28 \\
\hline $\mathrm{Cr}$ & ${ }^{51} \mathrm{Cr}$ & $27,8 \mathrm{~d}$ & 4,31 & 15,9 & 320,08 \\
\hline $\mathrm{Fe}$ & ${ }^{59} \mathrm{Fe}$ & $45,1 \mathrm{~d}$ & 0,33 & 1,01 & 1099,25 \\
\hline $\mathrm{Co}$ & ${ }^{60} \mathrm{Co}$ & $5,24 \mathrm{a}$ & 100 & 20 & 1332,50 \\
\hline $\mathrm{Zn}$ & ${ }^{65} \mathrm{Zn}$ & $245 \mathrm{~d}$ & 48,89 & 0,47 & 1115,55 \\
\hline As & ${ }^{76} \mathrm{As}$ & $26,3 \mathrm{~h}$ & 100 & 5,4 & 559,10 \\
\hline $\mathrm{Rb}$ & ${ }^{86} \mathrm{Rb}$ & $18,66 \mathrm{~d}$ & 72,15 & 0,91 & 1077,00 \\
\hline $\mathrm{Sb}$ & ${ }^{124} \mathrm{Sb}$ & $60,2 \mathrm{~d}$ & 42,75 & 2,5 & 1690.98 \\
\hline $\mathrm{Ba}$ & ${ }^{131} \mathrm{Ba}$ & $11,5 \mathrm{~d}$ & 0,10 & & 496,28 \\
\hline $\mathrm{Cs}$ & ${ }^{1.44} \mathrm{Cs}$ & $2,7 \mathrm{a}$ & 100 & 30 & 795,84 \\
\hline $\mathrm{La}$ & ${ }^{141} \mathrm{La}$ & $47,27 \mathrm{~h}$ & 99,91 & 8,7 & 1596.21 \\
\hline $\mathrm{Ce}$ & ${ }^{141} \mathrm{Ce}$ & $32,5 \mathrm{~d}$ & 88,5 & 0,31 & 145,44 \\
\hline $\mathrm{Nd}$ & ${ }^{149} \mathrm{Nd}$ & $11,1 \mathrm{~d}$ & 17,22 & 1,8 & 531,02 \\
\hline $\mathrm{Eu}$ & ${ }^{152} \mathrm{Eu}$ & $12,2 \mathrm{a}$ & 47,8 & 1500 & 1408,01 \\
\hline $\mathrm{Sm}$ & ${ }^{15.3} \mathrm{Sm}$ & $47,1 \mathrm{~h}$ & 26,8 & 140 & 103,18 \\
\hline $\mathrm{Tb}$ & ${ }^{160} \mathrm{~Tb}$ & $73 \mathrm{~d}$ & 100 & 45 & 879,38 \\
\hline $\mathrm{Yb}$ & ${ }^{175} \mathrm{Yb}$ & $101 \mathrm{~h}$ & 31,84 & 60 & 396,32 \\
\hline $\mathrm{Lu}$ & ${ }^{177} \mathrm{Lu}$ & $6,75 \mathrm{~d}$ & 2,6 & 4000 & 208,36 \\
\hline Hf & ${ }^{181} \mathrm{Hf}$ & $44,6 \mathrm{~d}$ & 35,24 & 10 & 482,18 \\
\hline Ta & ${ }^{182} \mathrm{Ta}$ & $115,1 \mathrm{~d}$ & 99,98 & 19 & 1221,41 \\
\hline $\mathrm{Th}^{*}$ & ${ }^{23} \mathrm{~Pa}$ & $27 \mathrm{~d}$ & 36,00 & & 312,17 \\
\hline $\mathrm{U}^{* *}$ & ${ }^{279} \mathrm{~Np}$ & $2,35 \mathrm{~d}$ & 10,79 & & 228,18 \\
\hline
\end{tabular}

As medidas da emissão gama das amostras foram realizadas no espectrômetro de raios gama, constituído por um detector de Ge hiperpuro, modelo GX 2519, da Canberra, com resolução de $1,90 \mathrm{keV}$ no pico de $1332 \mathrm{keV}$ do ${ }^{60} \mathrm{Co}$, acoplado a um analisador multicanal, constituído de 8192 canais. A Figura 4.2 mostra uma amostra irradiada, colocada em um disco, bem como do espectrômetro utilizado para determinação 
das atividades nas amostras. As determinações das concentrações elementares foram realizadas por meio do programas Genie -2000 Neutron Activation Analysis Processing Procedure da Canberra
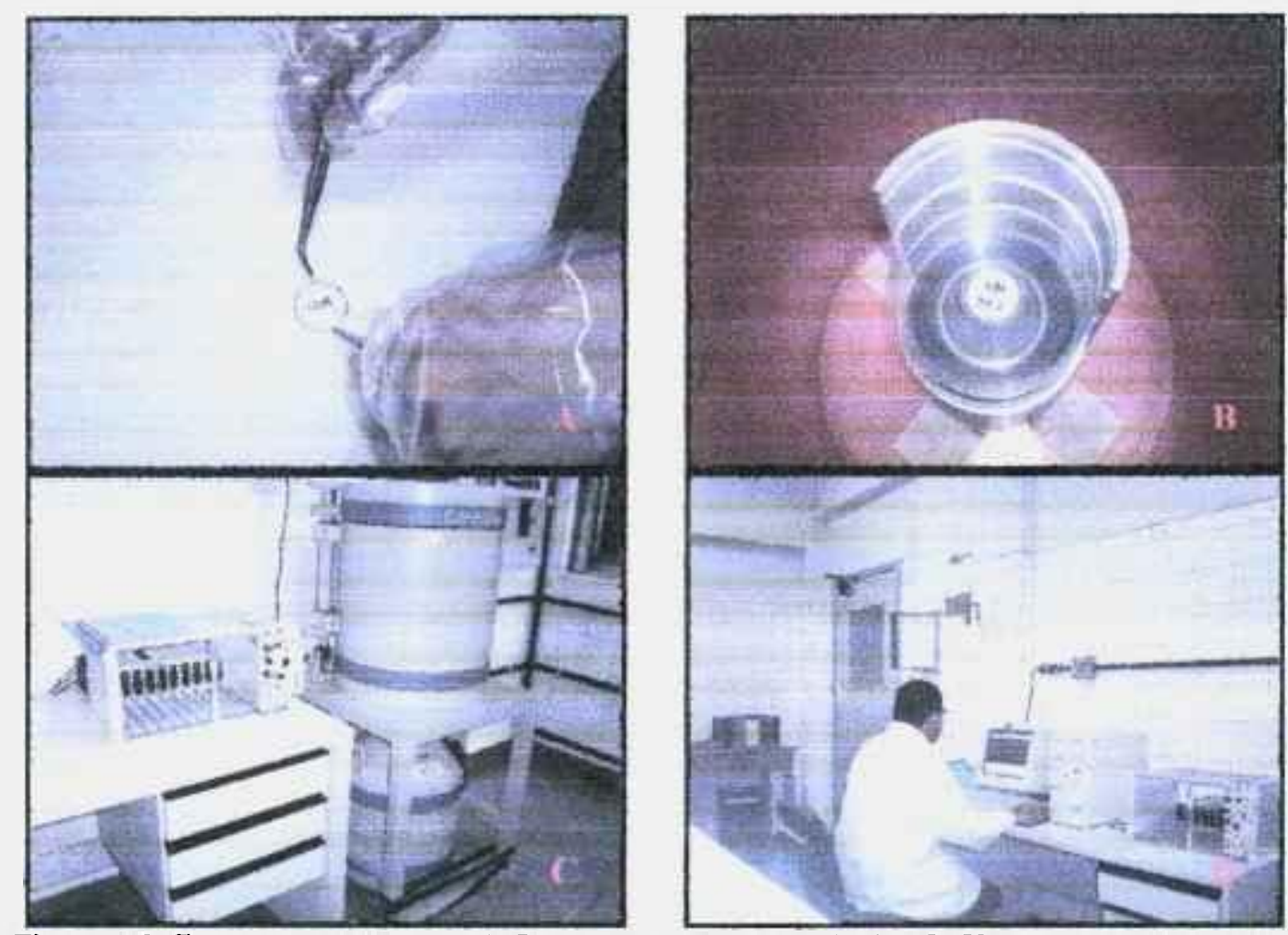

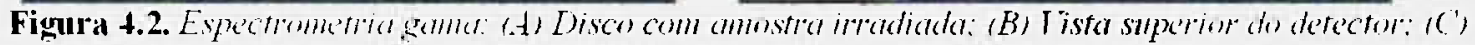
Vista lateral do espectrômetro; (D) Análise do espectro.

\subsection{Composição mineralógica por DRX}

Os difratogramas foram obtidos com um espectrômetro DRX do tipo RIGAKU equipado com fonte de $\mathrm{Cu}-\mathrm{k}_{\alpha}$, pertencente ao Laboratório de Preparação e Caracterização de Materiais da Universidade Federal de Sergipe. A varredura de $2 \theta$ foi realizada em uma faixa de $2^{\circ}$ a $30^{\circ} \mathrm{com}$ velocidade de $1 \% \mathrm{~min}$, a temperatura ambiente. Durante a varredura, a lâmina permaneceu em movimento circular uniforme para reduzir os efeitos das direções preferenciais dos cristalinos.

\subsection{Dataç̃o por TL}

Neste trabalho as paleodoses, e conseqüentemente as idades das amostras, foram obtidas pelo método das doses adicionais. Todas as medidas foram efetuadas sob um taxa de aquecimento de $10^{\circ} \mathrm{C} / \mathrm{s}$ a partir da temperatura ambiente até $400^{\circ} \mathrm{C}$. 
O sistema para leitura do sinal TL é composto de uma placa de platina, com dimensões de $1 \mathrm{~mm} \times 12 \mathrm{~mm} \times 70 \mathrm{~mm}$, cuja função é armazenar a amostra para o aquecimento (porta amostra). Esta placa está contida dentro de uma caixa de madeira de 50 $\mathrm{mm}$ por $40 \mathrm{~mm}$ por $230 \mathrm{~mm}$, de forma que a amostra fica isenta da presença de luz externa.

A placa para aquecimento está conectada à saída de um transformador, que está ligado a um módulo de potência. Esse módulo de potência está conectado a um conversor de sinais, com dois canais, duas entradas $\mathrm{AD}$ e uma DA, assim o sinal é enviado a um PC. Com o auxílio de um software controla-se a corrente enviada para a placa de platina, definindo, por efeito Joule, uma taxa de aquecimento constante durante a medida TL.

Sob taxa de aquecimento controlada, constante e monitorada através de um termopar de Chromel - Alumel, que envia o sinal de tensão ao computador, via conversor de sinal, o material emite luz que é captada por uma fotomultiplicadora EMI 9789 - B. Esta fotomultiplicadora é alimentada por uma fonte de alta tensão variável $(0-3000 \mathrm{KV})$. O sinal enviado pela fotomultiplicadora é captado e amplificado por um eletrômetro que opera na faixa de $10^{-7}$ a $10^{-11}$ A. Após amplificar o sinal elétrico, este é enviado ao conversor de sinais e, finalmente, enviado para um computador.

O software utilizado nas rotinas de aquisição e controle de dados do sistema conversor de sinais/computador foi elaborado em linguagem Basic.

A fonte de radiação beta utilizada é formada pelos radioisótopos ${ }^{9(1} \mathrm{Sr} /{ }^{90} \mathrm{Y}$, apresentando uma taxa de $0,4518 \mathrm{~Gy} / \mathrm{min}$ com carga radioativa diretamente sobre $o$ material a ser irradiado.

Para a determinação da dose anual de radiação, as concentrações de $\mathrm{U}$, Th e $\mathrm{K}$, nas amostras e sedimentos, foram determinadas por meio da análise por ativação com nêutrons (Hossain et al., 2003). 


\section{RESULTADOS E DISCUSSÃO}

\subsection{Controle de qualidade analítico}

Em estudos de proveniência de cerâmicas arqueológicas é fundamental que a técnica analítica empregada para a determinação da composição química elementar apresente uma boa precisão. Elementos que são determinados com baixa precisão podem interferir, significativamente, na interpretação dos resultados. Em estudos composicionais de cerâmicas arqueológicas considera-se que uma determinação com coeficiente de variação (CV) maior que 10\% tem baixa precisão (IAEA-TRS416, 2003). Estas imprecisões analíticas reduzem, na maioria dos casos, os efeitos discriminantes da composição química da pasta cerâmica utilizada na manufatura das peças analisadas, uma vez que a variabilidade total da assinatura química das amostras será fortemente influenciada pela variabilidade analítica (Munita et al., 2001b).

Para verificação da precisão e exatidão da metodologia empregada neste trabalho, foram analisados por análise por ativação com nêutrons, juntamente com as amostras, dois materiais de referência: Brick Clay (NIST-SRM-679 e Trace Elements in Soil (IAEA - Soil - 7). Para o primeiro material de referência foram realizadas 22 determinações e para o segundo 19.

Para avaliar a qualidade analítica, os resultados das concentrações elementares dos materiais de referência foram estatisticamente comparadas com os valores certificados (Gouveia \& Prudêncio, 2000). De acordo com esta análise estatística, obteve-se que diversos elementos apresentaram CV menor de 5\% para os materiais de referência analisados (Tabela 5.1), concordando com valores obtidos por outros autores (Ni et al., 1995). Alguns elementos apresentaram CV maior que 10\%, valores similares aos obtidos por outros autores (Kuleff \& Dingova, 1990). Obteve-se, ainda. que a interlerência da

fissão do ${ }^{235} \mathrm{U}$ na determinação de $\mathrm{La}, \mathrm{Ce}$ e $\mathrm{Nd}$ foi desprezível em virtude que as concentrações de $U$ não excederam 5 ppm, e as concentrações dos terras raras não foram muito baixas (Glascock et al., 1986). 
O coeficiente de variação para os elementos $\mathrm{Ba}, \mathrm{K}, \mathrm{Nd}, \mathrm{Sm}, \mathrm{Tb}$ e $\mathrm{U}$ no material de referência Brick Clay (NIST - SRM-679) foram maiores que 10\%. Estes mesmo elementos, mais o $\mathrm{Rb}$, apresentaram o mesmo comportamento na determinação para o material IAEA - Soil - 7. Para os elementos Ba, K, Sm e Nd este comportamento pode ter sido provocado pelo grande número de "valores perdidos" nas análises, que pode ser reduzido pela otimização do tempo de resfriamento. O elemento tântalo apresenta-se em concentrações muito baixas e possui uma interferência importante no pico de $1221,3 \mathrm{keV}$ com o pico de $1120,5 \mathrm{keV}$ do Sc, resultando na redução de sua precisão. Finalmente, as determinações do $U$ e Tb são prejudicadas em virtude da baixa concentração destes nos materiais de referência.

Tabela 5.1 - Resultados para os materiais de rẹferências IAEA-Soil7 e Brick Clay (valores em ppm a nào ser quando indicádo).

\begin{tabular}{|c|c|c|c|c|c|c|}
\hline \multirow[b]{2}{*}{ Elem. } & \multicolumn{3}{|c|}{ IAEA - Soil - 7} & \multicolumn{3}{|c|}{ Brick Clay (NIST - SRM-679) } \\
\hline & V. Det*. & V. Certif. & $\mathrm{CV}(\%)$ & V. Det $* *$. & V. Certif. & $\mathrm{CV}(\%)$ \\
\hline $\mathrm{Ba}$ & $207,2 \pm 48,4$ & $(159 \pm 32.5)$ & 23,4 & $545,11 \pm 148.05$ & $432.2 \pm 9.8$ & 27.2 \\
\hline $\mathrm{Ce}$ & $59,92 \pm 1,53$ & $61 \pm 6.5$ & 2,6 & $105.95 \pm 4,11$ & $(105)$ & 3.9 \\
\hline Co & $9.02 \pm 0.28$ & $8.9 \pm 0.85$ & 3,1 & $26,70 \pm 0.98$ & (26) & 3.7 \\
\hline $\mathrm{Cr}$ & $69,73 \pm 3,15$ & $60 \pm 12.5$ & 4,5 & $106,33 \pm 5,01$ & $109.7 \pm 4.9$ & 4.7 \\
\hline Cs & $5.78 \pm 0.27$ & $5.4 \pm 0.75$ & 4.7 & $9.99 \pm 0.55$ & $(9,6)$ & 5.5 \\
\hline Eu & $1,05 \pm 0,05$ & $1,0 \pm 0,2$ & 4,8 & $1.82 \pm 0.09$ & $(1,9)$ & 4.9 \\
\hline $\mathrm{Fe}, \%$ & $2,63 \pm 0,08$ & $(2,57 \pm 0,06)$ & 3,0 & $9.10 \pm 0.23$ & $9,05 \pm 0,21$ & 2.5 \\
\hline Hf & $5,01 \pm 0,36$ & $5.1 \pm 0.35$ & 7,2 & $4,55 \pm 0.40$ & $(4.6)$ & 8.8 \\
\hline $\mathrm{K}, \%$ & $1.43 \pm 0.15$ & $(1.21 \pm 0.07)$ & 10,5 & $2.4 \pm 0.3$ & $2.433 \pm 0,047$ & 12.5 \\
\hline La & $30,91 \pm 0,77$ & $28 \pm 1$ & 2.5 & $55.31 \pm 2.24$ & - & 4.0 \\
\hline Lu & $0.37 \pm 0,02$ & $(0,3 \pm 0.2)$ & 5,4 & $0,59 \pm 0,04$ & - & 0.78 \\
\hline $\mathrm{Na}, \%$ & $0,23 \pm 0,01$ & $(0,24 \pm 0,01)$ & 4,3 & $0.13 \pm 0,01$ & $0.1304 \pm 0.0038$ & 7,7 \\
\hline Nd & $22.08 \pm 5.43$ & $30 \pm 6$ & 24,6 & $43,59 \pm 9.83$ & - & 22.6 \\
\hline $\mathbf{R b}$ & $47.40 \pm 5.54$ & $51 \pm 5$ & 11.7 & $199.23 \pm 17.84$ & $(190)$ & 9.0 \\
\hline Sc & $8,66 \pm 0.22$ & $8.3 \pm 1,1$ & 2.5 & $23.26 \pm 0.66$ & $(22.5)$ & 2.8 \\
\hline Sm & $4.11 \pm 0.71$ & $5,1 \pm 0.4$ & 17,3 & $8.81 \pm 2.54$ & - & 28.8 \\
\hline $\mathbf{T a}$ & $0.70 \pm 0,06$ & $0,8 \pm 0,2$ & 8,6 & $1,23 \pm 0,12$ & - & 9.8 \\
\hline $\mathrm{Tb}$ & $0,59 \pm 0,09$ & $0.6 \pm 0.2$ & 15.3 & $1,30 \pm 0,23$ & $(-)$ & 17.7 \\
\hline Th & $8.28 \pm 0.29$ & $8.2 \pm 1,1$ & 3.5 & 14.24 上0.50 & (14) & 3.5 \\
\hline $\mathbf{U}$ & $2,29 \pm 0,29$ & $2.6 \pm 0.6$ & 12,7 & $2.59 \pm 0.31$ & - & 12.0 \\
\hline $\mathbf{Y b}$ & $2,29 \pm 0,15$ & $2.4 \pm 0.4$ & 6.5 & $3.91 \pm 0,26$ & - & 6.6 \\
\hline $\mathrm{Zn}$ & $98.08 \pm 6.04$ & $104 \pm 6$ & 6,1 & $123,31 \pm 8,15$ & $(150)$ & 6.6 \\
\hline
\end{tabular}

*desvio padrão para $n=22$.

* desvio padrão para $n=19$. 
Apesar de que o requisito principal na análise composional de ceràmica ser a precisão analítica, as exatidões das determinações químicas elementares foram acompanhadas criteriosamente (Glascock et al., 1986). Nas Figuras 5.1 a 5.2 são apresentados os valores das diferenças padronizadas entre os valores obtidos e os valores certificados, denominados Z-score, para os materiais de referência Brick Clay - NISTSRM-679 e IAEA - Soil -7. Pode ser constatado que todos os elementos determinados para os materiais de referência Brick Clay - NIST-SRM-679 e IAEA - Soil -7 apresentaram $\left|Z_{\text {score }}\right|$ menor que 2, o que é considerado satisfatório. Estes dois resultados para a análise do material de referência mostram que os resultados obtidos por meio da análise por ativação neutrônica são satisfatoriamente exatos.

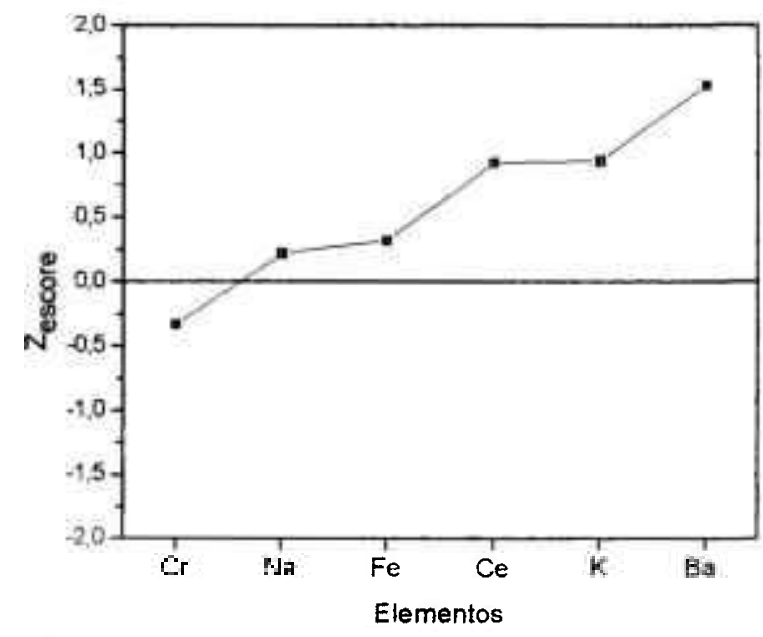

Figura 5.1 - Avaliação dos desvios das concentrações obtidas em relação aos valores certificados para Brick Clay - NIST-SRM-679.

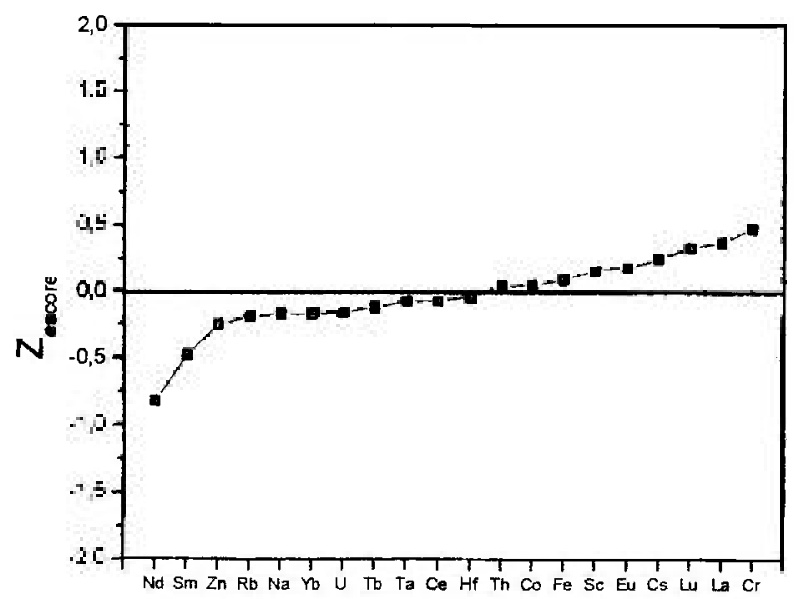

Elementos

Figura 5.2 - Avaliação dos desvios das concentrações obtidas em relação aos valores certificados para IAEA - Soil7. 
Na Figura 5.3 são realizadas comparações diretas entre os valores obtidos para o material de referência IAEA - Soil -7 com os valores publicados por Kullef \& Pernicka (2002), onde é possivel observar que a qualidade analítica dos resultados obtidos são da mesma ordem das obtidas por Kullef \& Pernicka (2002), com maiores discordâncias em relação a $\mathrm{Sb}, \mathrm{Sm}, \mathrm{Ba}$ e $\mathrm{Nd}$.
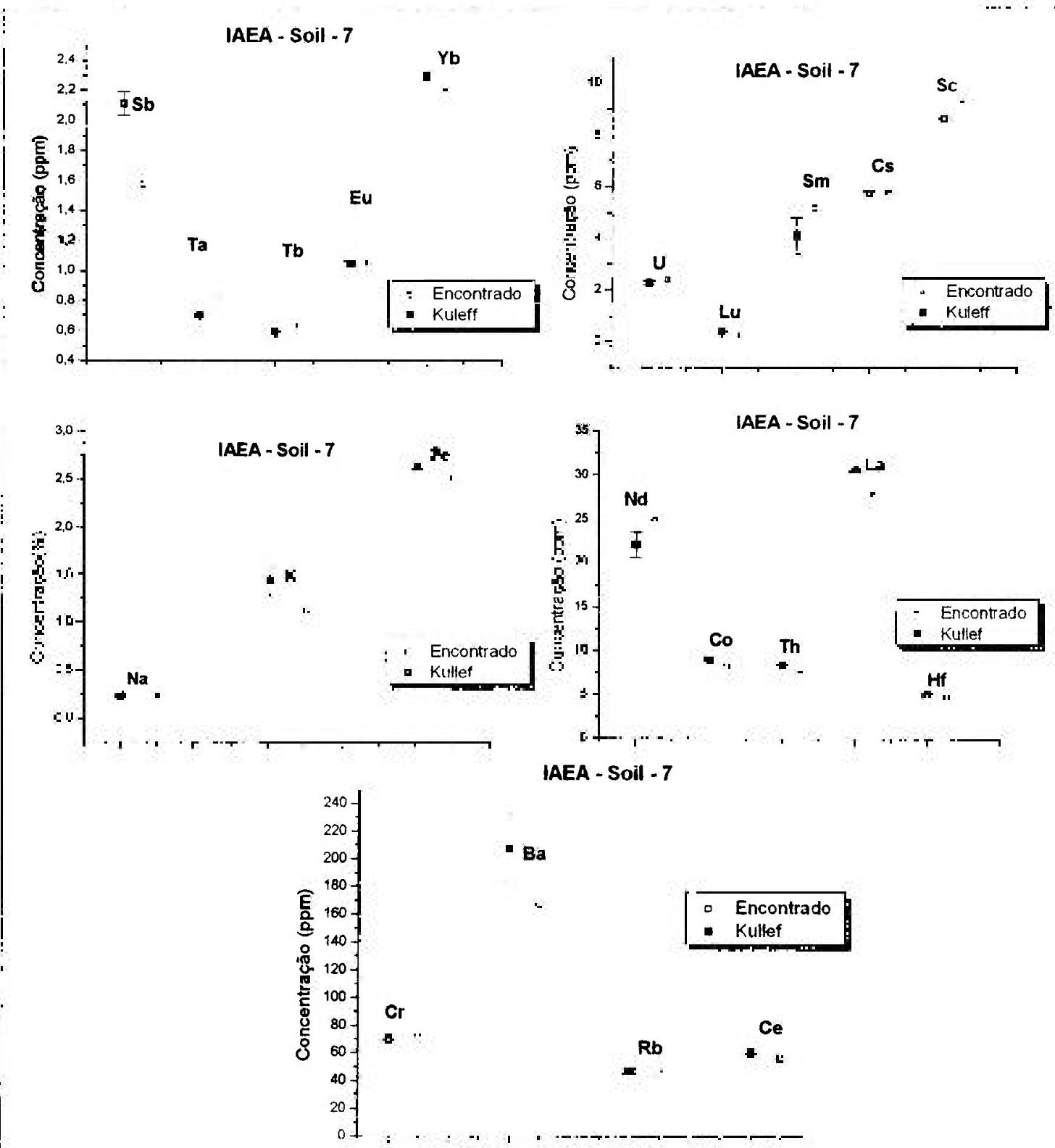

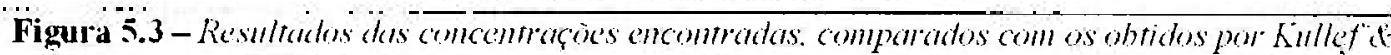
Pernicka para LAEt-Soil t. ts baras de erro indicam o intenalo de confiança no nivel de $95^{\circ} \%$.

Na Figura 5.4 são realizadas comparações diretas entre os valores obtidos para o material de referência Brick Clay - NIST-SRM-679 com os valores publicados por Bishop \& Blackman (2002), relativo à 311 determinações desse material de referência, 
onde é possivel observar que a qualidade analítica dos resultados obtidos são da mesma ordem das obtidas por Bishop, com maiores discordâncias em relação a $\mathrm{Sm}$ e Nd.



Figura 5.4 - Resultados des concentraçoes encontradas comparatos com os obtides por Bishop d Blackman para Brick (lan. As harras de erro indicam o imten alo de confiança no nivel de $95 \%$.

Uma vez que o procedimento analitico adotado para a determinação da composição elementar das cerâmicas é utilizado, rotineiramente, pelo Grupo de Arqueometria da Divisão de Radioquímica do IPEN, a qualidade analítica dos resultados pôde ser testada de acordo com o teste de proficiência que o grupo do IPEN participou recentemente. Este teste de proficiência foi realizado dentro do projeto coordenado pela Agência Internacional de Energia Atômica (IAEA - CRPF 2.30.23 - "Applications of 
nuclear analytical techniques to investigate the authenticity of art objects"), do qual o Grupo de Arqueometria da Divisão de Radioquímica é participante (IAEA/AL/168, 2006). $O$ teste de proficiência foi realizado por meio da determinação dos elementos maiores, menores e traços, em um material de cerậmico, preparado e caracterizado pelo Instituto de Física de Alta Energia da Academia Chinesa de Ciências (IAEA/AL/168, 2006). Ao todo, 24 laboratórios participaram do teste de proficiência, utilizando diversas técnicas analíticas, sendo que $83 \%$ do total foram considerados proficientes ao final da análise estatística dos dados. Todos os elementos determinados e enviados pelo grupo do IPEN foram considerados proficientes neste teste.

De posse destes controles analíticos foi possível detectar os elementos que poderiam ser utilizados para identificação de grupos cerâmicos, de acordo com as suas composições químicas elementares. Uma vez que os sítios estudados estão em uma mesma bacia geológica, visto as proximidades geográficas entre os mesmos, a habilidade para observar diferenças nas composições químicas seria difícil, se não impossível sem a aplicação de uma técnica de alta precisão. Para interpretação estatística dos resultados, as determinações dos elementos $\mathrm{Ba}, \mathrm{K}, \mathrm{Nd}, \mathrm{Rb}, \mathrm{Sm}, \mathrm{Ta}, \mathrm{Tb}$ e $\mathrm{U}$ foram eliminadas da matriz de dados. Apesar dos elementos Ce, Zn e Co apresentarem coeficiente de variação menor que $10 \%$ estes elementos não foram considerados para determinação dos grupos composicionais. As concentrações de Co foram eliminadas em virtude das possíveis contaminações da amostra durante sua preparação. O elemento Ce foi retirado em virtude de sua alta variabilidade nas amostras, o que possivelmente esta relacionada às características de troca iônica com alguns elementos presentes nos argilominerais (Nyakairu et al., 2001). As concentrações de $\mathrm{Zn}$ foram eliminadas em virtude que sua determinação sofre forte interferência com o pico de $1120 \mathrm{keV}$ do ${ }^{46} \mathrm{Sc}$, e a intensidade deste último é da ordem de duas vezes maior que a intensidade do pico do Zn (Perlman \& Asaro, 1969). Desta forma, 11 elementos constaram na base de dados para questões de interpretação (Cr, Cs, Eu, Fe, Hf, La, Lu, Na, Sc, Th e Yb).

\subsection{Normalização e padronização dos dados}

Em análise estatística multivariada faz-se necessário a verificação da normalidade dos dados, devido, principalmente, ao uso de um grande número de variáveis, o qual torna as distorções potenciais e vieses mais significativos quando as suposições são violadas. Além disso, a complexidade das análises e dos resultados pode mascarar os sinais de violações de suposições aparentes nas análises univariadas simples. Entretanto, em 
quase todos os métodos multivariados, as estimativas e predições realizadas de acordo com um determinado modelo multivariado podem ser obtidas, mesmo se a normalidade multivariada for violada, visto a robustez dos métodos. Nestes casos, deve-se estar ciente das implicações da violação no processo de estimação e nas interpretações dos resultados.

Tendo em vista estas proposições, neste trabalho estudou-se a normalidade univariada dos elementos analisados e da distribuição conjunta destes elementos. Inicialmente, a normalidade univariada dos elementos foi verificada por meio da observação da simetria das concentrações medidas em torno da média, utilizando-se da construção dos histogramas dos elementos para cada sítio estudado e, em seguida, realizouse um teste formal de normalidade por meio do teste de Shapiro-Wilks (Royston, 1982). Para verificação da normalidade multivariada foi realizado um teste formal de normalidade multivariada, o qual corresponde a uma generalização do teste de Shapiro-Wilks para o caso multivariado, e que está implementado no programa estatístico R (Jarek, 2005).

Os testes de normalidade foram realizados para os dados brutos e para os dados transformados de acordo com o logaritmo das concentrações. Testar a normalidade dos dados após transformação logarítmica é de interesse em estudo composicionais de cerâmicas visto que tem sido observado por diversos autores que vários dos elementos analisados se distribuem log - normalmente (Glascock, 1992). A segunda razão é que a transformação dos dados de concentração em escala logarítmica compensa as diferenças de magnitudes das variáveis medidas, promovendo a padronização da matriz de dados.

A observação da forma dos histogramas para os dados brutos não apresentou assimetrias visivelmente acentuadas para nenhum dos elementos determinados com $\mathrm{CV}$ menor $10 \%$ (Figura 5.5). Entretanto, após testar a normalidade univariada por meio do teste de Shapiro-Wilks, verificou-se que os elementos $\mathrm{Cr}, \mathrm{Cs}$, Sc, Eu e Hf não apresentaram uma distribuição significativamente normal $(\mathrm{p}<0,05)$. Por outra parte, por meio da transformação logarítmica dos dados, observou-se que as concentrações elementares das amostras, para cada sítio estudado, ajustaram-se satisfatoriamente à distribuição normal (Figura 5.5) e os testes de normalidade indicaram que a hipótese de normalidade univariada dos dados após transformação logarítmica é significante $(p>0,1)$. 



Figura 5.5 - Histogramas para as distribuições de Cs e Eu nas amostras do sitio Porto Belo, para os dados brutos (esquerda) e para $\log _{10}$ da concentração do elemento (direita).

Una vez que a transformação logarítmica teve um efeito de normalização e padronização dos dados, como mostrado na Figura 5.5 e na avaliação da significância do teste de Shapiro-Wilks, realizou-se o teste de normalidade da distribuição conjunta das concentrações elementares transformadas logaritmicamente. A extensão do teste de Shapiro-Wilks para o caso multivariado indicou que nenhum dos sítios tem suas amostras cerâmicas distribuidas normalmente no espaço $p$-variado $(p<0,05)$. O fato das variáveis individuais se distribuirem normalmente, mas a conjunta não se distribui normalmente no hiperespaço, não é surpreendente em estudos envolvendo muitas variáveis. Este resultado obedece a um teorema que determina que se a distribuição das amostras é normal no hiperespaço, as variáveis individuais ou uma combinação linear das mesmas também serão normais, mas a reciproca não é verdadeira (Hair et al., 2005).

Assim, apesar de ter sido verificado um desvio da normalidade multivariada dos dados, a interpretação dos grupos composicionais será obtida após transformação logarítmica das concentrações, visto que esta transformação promove a padronização das concentrações dos diversos elementos e a normalização individual das variáveis utilizadas 
para formação dos grupos. Como tem sido apontado por alguns autores, o desvio de normalidade no hiperespaço não é crítica em estudos composicionais, visto que são utilizadas técnicas de agrupamento robustas a estes desvios, tais como Análise das Componentes Principais, Análise Discriminante, Análise de Conglomerados, entre outras (Hair et al., 2005; Beier \& Mommsen, 1994; Barroso \& Artes, 2003).

\subsection{Identificação das amostras aberrantes}

A identificação das amostras aberrantes de cada sítio estudado foi realizada por meio das distâncias de Mahalanobis clássica e da distância de Mahalanobis robusta em relação ao centro do grupo, no hiperespaço das concentrações elementares. Estes dois procedimentos foram utilizados com o objetivo de eliminar as amostras que podem provocar ruidos indesejáveis na matriz de variância-covariância de cada grupo e, conseqüentemente, nos procedimentos de agrupamentos.

O primeiro procedimento para a identificação das amostras aberrantes foi baseado na distância de Mahalanobis clássica, usando-se o lambda Wilks como valor crítico (Wilks, 1963). Nas Tabelas 5.2 a 5.10 são apresentados os resultados dos procedimentos para identificação de amostras atípicas para cada sítio, em relação ao centróide dos grupos composicionais correspondente a cada sítio. A identificação foi realizada por meio do cálculo das distâncias de Mahalanobis clássica e verificação das amostras que ultrapassaram o valor crítico. Após eliminação das amostras aberrantes, um novo centro foi redefinido e o procedimento anterior repetido. $\mathrm{O}$ procedimento foi interrompido no instante que as amostras residuais apresentaram distâncias de Mahalanobis menores que o valor crítico. Por meio deste procedimento foi possível a detecção de 15 amostras aberrantes, distribuidas por sítio arqueológico de acordo com a Tabela 5.11. 
Tabela 5.2 - Resultados das concentraçòes e distâncias Mahalanobis para amostrà do sitio Justino

(superficial). As amostras aberrantes estão destacadas em negrito.

\begin{tabular}{|c|c|c|c|c|c|c|c|c|c|c|c|c|}
\hline & $\mathrm{Na} \%$ & Lu & $\mathbf{Y b}$ & $\mathbf{L a}$ & Th & $\mathrm{Cr}$ & $\mathrm{Cs}$ & Sc & $\mathrm{Fe} \%$ & Eu & Hf & $D_{1}^{2}$ \\
\hline 1 & 2,00 & 0,22 & 2.60 & 16.60 & 32,01 & 82,70 & 3,30 & 10,40 & 3.70 & 5,10 & 10,20 & 14,48 \\
\hline 2 & 1,80 & 0.41 & 2,40 & 58,10 & 47,80 & 101,50 & 4,50 & 12.60 & 4,50 & 5.80 & 11.70 & 11,59 \\
\hline 3 & 1.95 & 0,43 & 3,00 & 33,00 & 11,10 & 21,40 & 3,90 & 9,70 & 3,50 & 1,40 & 6.70 & 7,22 \\
\hline 4 & 1,90 & 0.61 & 4,04 & 72.50 & 7,90 & 16,20 & 3.90 & 16.20 & 4,70 & 2,10 & 3,50 & 8,87 \\
\hline 5 & 2,80 & 0,59 & 4.60 & 76,90 & 7,40 & 35,10 & 5,90 & 25,40 & 6.90 & 3,10 & 5,10 & 7,15 \\
\hline 6 & 2,60 & 0,46 & 2,50 & 58,10 & 17,10 & 8,80 & 6,40 & 9.70 & 5,20 & 2,70 & 6,30 & 11,93 \\
\hline 7 & 2,20 & 0,54 & 3,40 & 92,30 & 12,40 & 37,30 & 5,10 & 15,00 & 5,30 & 2,50 & 5,50 & 5,18 \\
\hline 8 & 1,74 & 0,38 & 2,63 & 43,70 & 8,50 & 26,70 & 3,80 & 8,42 & 3,90 & 1,88 & 7,30 & 6,92 \\
\hline 9 & 2,30 & 0,48 & 3,62 & 59,40 & 8,90 & 18,70 & 3,90 & 18,05 & 6,74 & 2,50 & 11,20 & 11,12 \\
\hline 10 & 0,67 & 0,38 & 3,48 & 87,70 & 21,30 & 48,40 & 4,80 & 9,18 & 2.62 & 2,42 & 5,10 & 7,85 \\
\hline 11 & 0,75 & 0,45 & 3,97 & 34,20 & 13,10 & 126,00 & 9,90 & 21,99 & 6,91 & 1,38 & 6,20 & 13,55 \\
\hline 12 & 1,08 & 0,35 & 2,96 & 53,40 & 10,80 & 74,00 & 3,70 & 13,39 & 2,59 & 2,13 & 5.80 & 10,50 \\
\hline 13 & 0,45 & 0,45 & 3,87 & 78,00 & 25,70 & 92,00 & 10,10 & 14,01 & 3,10 & 2,93 & 6,00 & 10,47 \\
\hline 14 & 2,38 & 0,57 & 4,40 & 70,00 & 2,30 & 26,50 & 4,80 & 15,70 & 5,60 & 2,70 & 10,20 & 13,86 \\
\hline 15 & 2,10 & 0,67 & 4,80 & 49,70 & 12,10 & 32,10 & 3,30 & 19,00 & 5,80 & 2,50 & 12,90 & 11,35 \\
\hline 16 & 2,40 & 0,63 & 3,60 & 58,10 & 6,90 & 18,90 & 3,20 & 16,90 & 6,30 & 2,40 & 8,70 & 3,27 \\
\hline 17 & 2,09 & 0,58 & 3,50 & 51,60 & 6,80 & 16,50 & 3,50 & 20,40 & 6,30 & 2,30 & 8,20 & 4,78 \\
\hline 18 & 1,62 & 0,51 & 2,70 & 44,70 & 11,40 & 81,70 & 7,90 & 19,00 & 5,00 & 2,10 & 8,10 & 9,91 \\
\hline \multicolumn{12}{|c|}{ Valore crítico no nivel de Significância de $5 \%$} & 15,40 \\
\hline
\end{tabular}

Tabela 5.3 - Resultados das concentraçòes e distâncias Mahalanobis para amostras do sítio Justino A. As amostras aberrantes estào destacadas em negrito.

\begin{tabular}{|c|c|c|c|c|c|c|c|c|c|c|c|c|c|}
\hline & $\mathrm{Na} \%$ & Lu & $\mathbf{Y b}$ & La & Th & $\mathrm{Cr}$ & $\overline{\mathrm{Cs}}$ & $\overline{\text { Sc }}$ & $\mathrm{Fe} \%$ & $\overline{\text { Eu }}$ & $\overline{\text { Hf }}$ & $D_{1}^{2}$ & $D_{2}^{2}$ \\
\hline 1 & 1,11 & 0,14 & 0,56 & 22,81 & 20,63 & 23,56 & 6,04 & 4,07 & 1,54 & 0,71 & 5.22 & 16.83 & 16,09 \\
\hline 2 & 1,95 & 0,56 & 3,94 & 55,59 & 12,90 & 17,40 & 2.54 & 8.14 & 3.66 & 1,78 & 7,98 & 6,06 & 12,31 \\
\hline 3 & 1,90 & 0,60 & 3,80 & 50.90 & 8,70 & 27,40 & 2,80 & 17,80 & 5,60 & 1,80 & 5.80 & 3,82 & 4.42 \\
\hline 4 & 2,10 & 0,98 & 6,20 & 66,70 & 11,60 & 18,40 & 5,30 & 16,80 & 5,90 & 2,70 & 10.20 & 3,58 & 6,45 \\
\hline 5 & 1,98 & 0,38 & 2,63 & 31,55 & 8.34 & 35,99 & 3,94 & 17,98 & 4,78 & 1.54 & 4.38 & 4.10 & 4,04 \\
\hline 6 & 2,50 & 0,74 & 4,90 & 91,30 & 9.50 & 20,70 & 3,60 & 18,03 & 6,40 & 3,70 & 9,20 & 3,48 & 4,26 \\
\hline 7 & 1,80 & 0,28 & 1,90 & 17,40 & 7,20 & 48,90 & 3,30 & 11,30 & 3,30 & 0,90 & 7.30 & 11,32 & 10,95 \\
\hline 8 & 1,65 & 0,97 & 6,61 & 104,20 & 15,08 & 21,12 & 2,63 & 10,74 & 3,95 & 3,24 & 8,61 & 10,87 & 10,50 \\
\hline 9 & 2,09 & 0,78 & 4,78 & 68,16 & 7,64 & 92,69 & 2,80 & 22,83 & 6,25 & 2,71 & 5,69 & 9,03 & 9,39 \\
\hline 10 & 1,75 & 0,53 & 3,89 & 49,65 & 13,45 & 32,93 & 3,53 & 24,15 & 6,81 & 2,18 & 5,42 & 7,62 & 7.28 \\
\hline 11 & 2,42 & 0,43 & 2,70 & 94,20 & 11,50 & 23,80 & 5,70 & 10,40 & 4,80 & 2,70 & 7,20 & 3,53 & 4,48 \\
\hline 12 & 2,39 & 0,64 & 4,69 & 84,34 & 14,04 & 9,89 & 4,57 & 14,25 & 5,78 & 2,62 & 8,53 & 8,59 & 8,84 \\
\hline 13 & 1.85 & 0,38 & 1,86 & 60,09 & 12,83 & 20,26 & 3,91 & 6.96 & 2,80 & 1,83 & 8.87 & 6,09 & 6.01 \\
\hline 14 & 2,33 & 0,23 & 1,44 & 97,87 & 12,82 & 80.25 & 4,60 & 11,03 & 4,01 & 3,18 & 8,50 & 10,42 & 10.19 \\
\hline 15 & 1,70 & 0,60 & 3.80 & 33,20 & 10,7 & 32,70 & 4,04 & 12,70 & 3,30 & 1,20 & 4,70 & 10,18 & 11,23 \\
\hline 16 & 1,90 & 0,39 & 2,40 & 54,50 & 7,50 & 11,40 & 5,50 & 7,20 & 3.60 & 2,00 & 6.50 & 5,94 & 7,77 \\
\hline 17 & 2,70 & 0,53 & 3,90 & 54,70 & 5,60 & 18.70 & 3,50 & 16,20 & 6,10 & 2,70 & 12,90 & 10,25 & 10,53 \\
\hline 18 & 1,60 & 0,05 & 0,33 & 6,00 & 2,10 & 3,90 & 0,44 & 0,91 & 3,70 & 0,16 & 0,57 & 22,67 & \\
\hline 19 & 1,19 & 0,31 & 2,48 & 54,60 & 18,30 & 98,00 & 3,60 & 16,47 & 5,02 & 1,59 & 7.60 & & 12.16 \\
\hline 20 & 1,38 & 0,74 & 5.30 & 35,80 & 10,20 & 60,00 & 4,70 & 21,56 & 5.67 & 2,37 & 5,40 & 13,46 & 13,15 \\
\hline 21 & 2,42 & 1,45 & 7,08 & 95,21 & 13,75 & 19,40 & 5,80 & 18,57 & 7,20 & 3,39 & 6,88 & 11,60 & 11,15 \\
\hline 22 & 1,08 & 0,24 & 1,69 & 43,10 & 2,60 & 103,65 & 0,67 & 14,46 & 2,55 & 1,36 & 3,81 & 18,27 & 17,85 \\
\hline 23 & 2,19 & 0,24 & 1,59 & 123,40 & 10,45 & 41,69 & 7,69 & 6,54 & 3,18 & 3,10 & 10,26 & 12,37 & 12,36 \\
\hline 24 & 1,92 & 0,53 & 3,60 & 82,70 & 8.20 & 18,20 & 4,30 & 11,30 & 5,10 & 2.90 & 8,00 & 2,05 & 3,03 \\
\hline 25 & 2,20 & 0,21 & 1,40 & 13,40 & 1,60 & 13,68 & 1,80 & 22,60 & 5,10 & 1,20 & 3,00 & 15,61 & 15.55 \\
\hline & & & & & & & & & & & & 19,10 & 3,70 \\
\hline
\end{tabular}


Tabela 5.4 - Resultados das concentraçòes e distäncias Mahalanobis para amostras do sitio Justino B. As amostras aberrantes estão destacadas em negrito.

\begin{tabular}{|c|c|c|c|c|c|c|c|c|c|c|c|c|c|}
\hline & $\mathrm{Na} \%$ & Lu & $\mathbf{Y b}$ & La & Th & $\mathrm{Cr}$ & Cs & Sc & $\mathrm{Fe} \%$ & $\mathbf{E u}$ & Hf & $D_{1}^{?}$ & $D_{2}^{2}$ \\
\hline 1 & 10 & 0,96 & 7,01 & 94,50 & 7 & 16,9 & 2,70 & 11,00 & 4,20 & 3,20 & 7,60 & 21,04 & \\
\hline 2 & & 42 & 2.2 & & & & & & & & & & 11.95 \\
\hline 3 & 2,20 & 0,68 & 5,50 & 47,55 & 13,70 & 17,90 & 4,88 & 18,60 & 6,90 & 2,80 & 9,90 & 7,54 & 7.22 \\
\hline 4 & 2,20 & 0,40 & 2,20 & 44,40 & 7,40 & 11,40 & 5,90 & 8,50 & 4.10 & 2,20 & 7,48 & 13,30 & 12.89 \\
\hline 5 & 2,40 & 0,39 & 2,50 & 44,50 & 5,40 & 12,80 & 4,10 & 18,30 & 6,30 & 2,10 & 7,50 & & 7,18 \\
\hline 6 & 2,28 & 0,87 & 5,39 & 62,76 & 9,63 & 21,74 & 4,88 & 17,34 & 6,05 & 3.02 & 7,09 & 3,87 & 5,82 \\
\hline 7 & 2,08 & 0,56 & 3,18 & 55,07 & 8,20 & 19,94 & 8,16 & 12,19 & 4,57 & 2,56 & 9,50 & 6 & 6.50 \\
\hline 8 & 1,85 & 0,56 & 3,34 & 68,96 & 10.33 & 61,30 & 4,97 & 11,38 & 4,52 & 2,93 & 5.93 & & 10.08 \\
\hline 9 & 2,10 & 1,06 & 6,45 & 47,55 & 13,26 & 62,43 & 2,23 & 19,46 & 6.60 & 3,40 & 7,48 & 12,15 & 12.65 \\
\hline 10 & 2,46 & 0,80 & 4,80 & 47,55 & 77 & & 8,76 & 12,64 & 4,97 & 2,90 & 9,20 & & 7,08 \\
\hline 11 & 2,03 & 0,66 & 4,32 & 70,68 & 21,86 & 52,10 & 4,46 & 13,32 & 5,22 & 2,07 & 7,16 & & 14,93 \\
\hline 12 & 2.06 & 0,51 & 3,30 & 68,91 & 8,69 & 10,86 & 5,69 & 16,27 & 6,73 & 2,80 & 9,93 & 8. & 7,71 \\
\hline 13 & 2,37 & 0,72 & 5,12 & 47,55 & 14,08 & 14,30 & 4,88 & 17,93 & 6,77 & 2,89 & 8.81 & & 5,33 \\
\hline 14 & 2,45 & 0,55 & 3,19 & 46,87 & 8,02 & 20,70 & 4.28 & 18,99 & 5,53 & 2,17 & 9,64 & 8. & 8,32 \\
\hline 15 & 2,03 & 0,41 & 2,79 & 44,01 & 11,39 & 81,11 & 4,84 & 14,00 & 3,73 & 1,70 & 6,38 & 4 & 4,66 \\
\hline 16 & 2,03 & 0,41 & 3,07 & 46,95 & 11,56 & 87,60 & 6,22 & 14,18 & 3.69 & 2,07 & 6,42 & & 9,60 \\
\hline 17 & & 0,73 & 5,40 & & & 2 & 00 & & 5,80 & 2,22 & 9,10 & 4. & 7,99 \\
\hline 18 & 1,90 & 1,10 & 7.40 & 47,55 & 17,30 & 17,60 & 4,88 & 16,70 & 5,90 & 3,20 & 5.30 & & 9.65 \\
\hline 19 & 1,90 & 0,70 & 4,30 & 47,55 & 15,50 & 44,00 & 2,60 & 11,00 & 4,10 & 3.40 & 6.20 & 10 & 10.79 \\
\hline 20 & 1,74 & 0,99 & 6,35 & 105,52 & 16,16 & 37,90 & 8,81 & 20,22 & 6,40 & 2,94 & 4,60 & 14.65 & 14,03 \\
\hline 21 & 1,90 & 0,54 & 3,30 & 56,50 & 9.60 & 25,90 & 2.90 & 17.70 & 5.80 & 1,60 & 3.70 & 13.21 & 13,25 \\
\hline 22 & 1,90 & 0,56 & 3,40 & & 9.50 & & 4,30 & & 5,50 & 1,70 & 6.30 & & 7.73 \\
\hline 23 & 2,37 & 0,40 & 3,03 & 37,50 & 4,08 & 19,60 & 2,50 & 18,74 & 6,45 & 2.22 & 11,00 & 8.07 & 9,32 \\
\hline 24 & 1,51 & 0,39 & 3,71 & 33,30 & 4,90 & 19,00 & 3,30 & 22,64 & 6,81 & 1,77 & 4,90 & 13,91 & 13,37 \\
\hline 25 & 1,82 & 0,43 & 3,81 & 22,50 & 5,10 & 91,00 & 5,10 & 22,40 & 5,59 & 1,17 & 11,30 & & 17,34 \\
\hline 26 & 2,03 & 0,51 & 3,40 & 47,55 & 12,79 & 87.44 & 5,42 & 14,61 & 3,87 & 1,89 & 7,45 & 4.29 & 4.59 \\
\hline
\end{tabular}


Tabela 5.5 - Resultados das concentraçòes e distâncias Mahalanobis para amostras do sítio Justino C. As amostras aberrantes estào destacadas em negrito.

\begin{tabular}{|c|c|c|c|c|c|c|c|c|c|c|c|c|c|}
\hline & $\mathrm{Na} \%$ & Lu & $\mathbf{Y b}$ & La & Th & $\mathrm{Cr}$ & Cs & Sc & $\mathrm{Fe} \%$ & $\mathbf{E u}$ & Hf & $D_{1}^{2}$ & $D_{2}^{2}$ \\
\hline 1 & 1.50 & 0,21 & 1,16 & 19.30 & 10.70 & 23,80 & 12,30 & 5,36 & 2,30 & 0,80 & 5,70 & 11.42 & 11,05 \\
\hline 2 & 2,30 & 0,18 & 1,20 & 81,30 & 12,50 & 49.30 & 2,70 & 7,30 & 2,80 & 1,90 & 6.10 & 11,43 & 11.92 \\
\hline 3 & 2.13 & 0,33 & 2,42 & 60,33 & 13.92 & 15,82 & 1,06 & 8,59 & 3,93 & 2,40 & 5,45 & 12,95 & 14,05 \\
\hline 4 & 2.04 & 0,58 & 4.34 & 26,44 & 6,57 & 19.40 & 1,33 & 12,38 & 3.90 & 1.76 & 8,67 & 13,60 & 13.04 \\
\hline 5 & 2,41 & 0,53 & 4,02 & 63,54 & 0,44 & 15,17 & 2,42 & 16,30 & 6,05 & 2,72 & 10,19 & 6,84 & 6,86 \\
\hline 6 & 1.04 & 0,15 & 1.11 & 15,54 & 7,92 & 20,20 & 4,90 & 5,56 & 1,71 & 0,73 & 2.71 & 11.30 & 10,89 \\
\hline 7 & 1,53 & 0,75 & 5,29 & 61,30 & 15,19 & 23,55 & 5,51 & 11,57 & 4,18 & 2,60 & 8,80 & 6,65 & 6,38 \\
\hline 8 & 2,26 & 0,40 & 2,60 & 59.34 & 9,16 & 28,96 & 4,93 & 9,80 & 4.00 & 1,89 & 7,05 & 2.67 & 5,58 \\
\hline 9 & 2,05 & 0,52 & 4,12 & 44,60 & 17,40 & 16,63 & 1,20 & 9,32 & 4,14 & 3,93 & 9,55 & 11,43 & 15,72 \\
\hline 10 & 1,82 & 0,64 & 4,56 & 60,32 & 6,18 & 20,09 & 6,73 & 15,62 & 6.06 & 2,88 & 13,65 & 8,65 & 8,27 \\
\hline 11 & 1,68 & 0,47 & 2,76 & 38,31 & 4,37 & 52,12 & 4,23 & 21,80 & 6.70 & 1,97 & 4,96 & 11,32 & 11.05 \\
\hline 12 & 1,93 & 0,58 & 4,25 & 44,17 & 30,14 & 52,72 & 3,90 & 19,10 & 5.13 & 0,96 & 6.35 & 13,26 & 13.56 \\
\hline 13 & 1,93 & 0,46 & 3,11 & 40,50 & 10,83 & 35,11 & 4.07 & 17,34 & 5.59 & 1,90 & 8,23 & 1,81 & 6,16 \\
\hline 14 & 1,93 & 0,46 & 3,16 & 44,60 & 35,84 & 72,74 & 2,24 & 20,55 & 6,99 & 3,48 & 14,12 & 19,65 & \\
\hline 15 & 1,60 & 0,46 & 3,20 & 35,20 & 7,80 & 48,11 & 3,90 & 20,10 & 6.10 & 1,50 & 4,80 & 5,44 & 5,31 \\
\hline 16 & 0,92 & 0,26 & 1,70 & 24,80 & 16,80 & 15,80 & 7,50 & 5,60 & 2,00 & 0.82 & 5.00 & 5.04 & 4.81 \\
\hline 17 & 2,90 & 0,33 & 1,60 & 115,00 & 10,82 & 54,20 & 2,90 & 7,90 & 3,94 & 2,90 & 12,60 & 14.39 & 14,09 \\
\hline 18 & 2,10 & 0,86 & 4,90 & 78,80 & 22,10 & 38,10 & 9,90 & 16,60 & 5,50 & 2,20 & 6,70 & 11,37 & 10,92 \\
\hline 19 & 1,68 & 0,54 & 3,87 & 59,30 & 17,50 & 63,00 & 4,10 & 14,24 & 4,85 & 1,97 & 6,20 & 6.14 & 5,88 \\
\hline 20 & 1,81 & 0,26 & 1,63 & 29,50 & 17,60 & 22,20 & 4,70 & 5,79 & 2,28 & 0,78 & 6,40 & 6,46 & 6,29 \\
\hline 21 & 1,97 & 0,56 & 5,20 & 44,60 & 4,3 & 25,60 & 2,60 & 16,27 & 5,08 & 2,23 & 11,60 & 8,64 & 8.54 \\
\hline 22 & 1,93 & 0,37 & 3,32 & 44,60 & 10,62 & 32,80 & 3,90 & 8,98 & 2,23 & 1,26 & 5,95 & 13,60 & 13,15 \\
\hline 23 & 1,23 & 0,36 & 1.54 & 47,64 & 28,10 & 11,94 & 3,71 & 6,67 & 2,37 & 0,78 & 6,91 & 17.27 & 16.67 \\
\hline 24 & 1,94 & 0,54 & 4.30 & 53,30 & 5,46 & 27,20 & 3,00 & 23,51 & 6.99 & 2,73 & 7,60 & 5.67 & 5.57 \\
\hline 25 & 1,44 & 0,41 & 2,65 & 32,20 & 10,80 & 25,70 & 3,70 & 17,00 & 4,97 & 1,27 & 6.00 & 4,46 & 5,23 \\
\hline & & & & & & & & & & & & 19,10 & 18,70 \\
\hline
\end{tabular}


Tabela 5.6 - Concentraçoes ohtidas e distancias Mahalanobis para amostras do Curituha. As amostras identificadas como aberrantes estào destacadas em negrito.

\begin{tabular}{|c|c|c|c|c|c|c|c|c|c|c|c|c|c|}
\hline & $\mathrm{Na} \%$ & Lu & $\mathbf{Y b}$ & La & Th & $\mathrm{Cr}$ & Cs & Sc & $\mathrm{Fe} \%$ & $\mathbf{E u}$ & Hf & $D_{1}^{2}$ & $D_{2}^{2}$ \\
\hline 1 & 2,23 & 0,54 & 3.90 & 38,76 & 4,71 & 40,85 & 3,31 & 22,51 & 6.64 & 2,27 & 6.85 & 3.98 & 3,71 \\
\hline 2 & 2,26 & 0,54 & 3,70 & 44,19 & 11,91 & 37,35 & 3,19 & 22,51 & 5,36 & 1,95 & 8,08 & 12,97 & 11,89 \\
\hline 3 & 1,78 & 0,43 & 2.56 & 25,13 & 4,60 & 28,04 & 3,62 & 18,87 & 5,36 & 1,49 & 5,61 & 6,62 & 6,29 \\
\hline 4 & 2,35 & 0,53 & 3,37 & 48,37 & 5,61 & 35,31 & 6,01 & 23,87 & 7,50 & 2,48 & 6,07 & 11,98 & 12.14 \\
\hline 5 & 1,89 & 0.55 & 4,28 & 45,24 & 10,78 & 55,71 & 5,99 & 18,79 & 5,28 & 1,93 & 6,93 & 4,62 & 4.19 \\
\hline 6 & 1,13 & 0.38 & 2,23 & 67,74 & 19,05 & 80,24 & 5,47 & 12.10 & 3.42 & 2,12 & 8,07 & 12,86 & 12,34 \\
\hline 7 & 1,66 & 0,84 & 5,84 & 87.81 & 17,75 & 37,35 & 6,66 & 17.54 & 5,98 & 2,81 & 10,78 & 7,95 & 7,19 \\
\hline 8 & 1,75 & 0,79 & 5,71 & 44,19 & 11,11 & 19,45 & 3,80 & 9,59 & 3,01 & 4,02 & 8,92 & 18,93 & \\
\hline 9 & 1,54 & 0,66 & 4,67 & 98,00 & 10,30 & 23,37 & 3,77 & 8,93 & 2,76 & 3,30 & 7,11 & 19,20 & \\
\hline 10 & 1,98 & 0,62 & 4,26 & 67,93 & 14,29 & 35,35 & 5.14 & 13,30 & 4.46 & 2.10 & 10.23 & 5,61 & 7,07 \\
\hline 11 & 1,29 & 0,48 & 2,75 & 35,04 & 7.83 & 61,85 & 5,06 & 15,05 & 4,04 & 1.92 & 4.39 & 8,92 & 13.65 \\
\hline 12 & 2,26 & 0,59 & 4,82 & 89,20 & 13,11 & 35,53 & 4,19 & 14,86 & 5,74 & 2,83 & 8,51 & 9,23 & 8,78 \\
\hline 13 & 1,92 & 0,82 & 6.06 & 60,12 & 17,82 & 91,64 & 5,16 & 20.81 & 5,58 & 2,17 & 6,23 & 10,21 & 9,62 \\
\hline 14 & 1,47 & 0,42 & 3,13 & 40.19 & 10,34 & 88.68 & 2.95 & 17,56 & 4,51 & 1,80 & 6,02 & 7,43 & 7.01 \\
\hline 15 & 2,12 & 0,63 & 4,07 & 37,95 & 8.45 & 36,43 & 2,92 & 20,44 & 6,01 & 2,12 & 7,08 & 4.33 & 5.91 \\
\hline 16 & 2,19 & 0,34 & 2,15 & 29,01 & 7,13 & 14,49 & 3,28 & 16,21 & 5,14 & 1,64 & 5.13 & 12,78 & 12,82 \\
\hline 17 & 2,03 & 0,56 & 3,85 & 92,23 & 10,32 & 24.74 & 1,72 & 10.88 & 4.59 & 3,45 & 11,89 & 14.53 & 14.88 \\
\hline 18 & 2.10 & 0.59 & 3,84 & 53,16 & 13,85 & 42.54 & 4,53 & 17,70 & 6,01 & 2.15 & 6.83 & 4,16 & 5.89 \\
\hline 19 & 2.24 & 0,56 & 4.67 & 40,37 & 3,63 & 37.22 & 1,81 & 25,21 & 7,16 & 2,60 & 9,67 & 11,97 & 11,19 \\
\hline 20 & 1,94 & 0,38 & 2,72 & 34,17 & 5,57 & 39,15 & 3,09 & 17.74 & 5.36 & 1,63 & 4,61 & 6.47 & 7,27 \\
\hline 21 & 1,60 & 0,38 & 2,72 & 36,42 & 11,16 & 40.69 & 8.04 & 10.07 & 3,47 & 1.59 & 10,26 & 14.64 & 15.75 \\
\hline 22 & 1,30 & 0,38 & 2,46 & 32,14 & 9,74 & 79,22 & 3,46 & 14,91 & 4,10 & 1,30 & 6,94 & 7,30 & 8,98 \\
\hline 23 & 0,98 & 0,48 & 3,48 & 75.03 & 10,32 & 83,63 & 5,26 & 12,77 & 3.50 & 2,48 & 10,44 & 9,10 & 11,33 \\
\hline 24 & 1.65 & 0,43 & 2,46 & 40,26 & 7,62 & 33.34 & 3,62 & 17,14 & 5,87 & 1,44 & 5,22 & 7,78 & 12,10 \\
\hline & & & & & & & & & & & & 18,70 & 17,70 \\
\hline
\end{tabular}


Tabela 5.7 - Resultados das concentraçòes e distâncias Mahalanobis para amostras do sítio Säo José. As amostras aberrantes estão destacadas em negrito.

\begin{tabular}{|c|c|c|c|c|c|c|c|c|c|c|c|c|c|c|}
\hline & $\mathrm{Na} \%$ & $\overline{L u}$ & $\overline{Y b}$ & $\overline{L a}$ & $\overline{T h}$ & $\overline{\mathrm{Cr}}$ & $\overline{C s}$ & $\overline{\text { Sc }}$ & $\mathrm{Fe} \%$ & $\overline{\mathbf{E u}}$ & $\overline{H f}$ & $D_{1}^{2}$ & $D_{2}^{2}$ & $D_{3}^{2}$ \\
\hline 1 & 2.10 & 0,57 & 4,10 & 52.5 & 4,70 & 54,40 & 3,30 & 22.40 & 6.90 & 2.80 & 8.80 & 5.48 & 7.42 & 11.09 \\
\hline 2 & 1,60 & 0,25 & 2,00 & 66,7 & 14,02 & 85,10 & 4,00 & 9,30 & 3,10 & 2,40 & 8,50 & 9,24 & 9.14 & 8.68 \\
\hline 3 & 1,53 & 0,35 & 2,64 & 32,45 & 6,07 & 53,15 & 4,19 & 22,38 & 5,19 & 1,21 & 2,95 & 16,03 & 18,23 & \\
\hline 4 & 1,60 & 0.66 & 4,03 & 47,90 & 11,10 & 51,90 & 3,30 & 13.10 & 4,10 & 1,80 & 8.80 & 3.37 & 4,07 & 3,84 \\
\hline 5 & 2,10 & 0,40 & 2.50 & 47.00 & 8,90 & 71.50 & 7,40 & 10,50 & 4.30 & 1,90 & 7,94 & 7,18 & 6.75 & 6.85 \\
\hline 6 & 2.22 & 0.39 & 2,65 & 27,26 & 5,03 & 32,85 & 4.18 & 10,06 & 4,00 & 1,38 & 5.75 & 9,09 & 8,46 & 13,22 \\
\hline 7 & 1,36 & 0,51 & 3,11 & 42,06 & 11,06 & 58,45 & 4,34 & 13,17 & 4.18 & 1,65 & 7,94 & 2.89 & 2,66 & 2,67 \\
\hline 8 & 1,39 & 0.53 & 3,30 & 43,09 & 10,89 & 46,71 & 3,75 & 13,20 & 4,15 & 1,73 & 8,62 & 2.49 & 2.64 & 2.50 \\
\hline 9 & 1.44 & 0.54 & 3,05 & 42,09 & 10.53 & 47,89 & 3,63 & 12,56 & 3,92 & 1,68 & 9,93 & 5,93 & 6,57 & 6.71 \\
\hline 10 & 1.64 & 0,33 & 3,14 & 52,39 & 15,22 & 163.91 & 6.20 & 13,32 & 4,90 & 3,95 & 7,78 & 11,98 & 11.58 & 11.02 \\
\hline 11 & 2,10 & 0,34 & 2,44 & 52,65 & 18,04 & 88,37 & 3.91 & 15,95 & 5,56 & 2,16 & 8,10 & 7,56 & 7,21 & 6,85 \\
\hline 12 & 1,03 & 0,90 & 5,90 & 36,50 & 8,80 & 17,20 & 3,75 & 11,60 & 4,70 & 2,10 & 7,49 & 10.95 & 11,43 & 12,64 \\
\hline 13 & 2,10 & 0,88 & 6,20 & 110,6 & 5,20 & 119,90 & 0,76 & 22,50 & 6,50 & 2,50 & 7,49 & 19,24 & & \\
\hline 14 & 1,70 & 0,33 & 1,80 & 40,80 & 20,20 & 69,50 & 3,20 & 13,80 & 5.00 & 1,50 & 7,56 & 10.65 & 10,24 & 10.14 \\
\hline 15 & 1,90 & 0.30 & 1,60 & 50,40 & 7,70 & 18.00 & 1.70 & 5,90 & 2.50 & 1,60 & 9,70 & 14.19 & 13,45 & 13.04 \\
\hline 16 & 1,82 & 0,79 & 5,27 & 104,68 & 10,49 & 17,86 & 2,44 & 16,62 & 5,42 & 3,33 & 7.35 & 9,15 & 12,61 & 12.34 \\
\hline 17 & 1,92 & 0,70 & 4,65 & 59,74 & 16,34 & 20.61 & 3,76 & 23,18 & 6,47 & 2,41 & 5.89 & 9,58 & 9,70 & 10.76 \\
\hline 18 & 1,60 & 0,18 & 1,91 & 15,33 & 10,06 & 94,39 & 0,52 & 15,91 & 5,15 & 4,96 & 6,74 & 21,58 & & \\
\hline 19 & 2,54 & 0,52 & 3,97 & 91,87 & 5,43 & 112,02 & 3,75 & 27,02 & 9,15 & 3,19 & 13,38 & 12,96 & 13,63 & 13.57 \\
\hline 20 & 1,91 & 0,17 & 1.92 & 70,21 & 17,00 & 47,20 & 7,01 & 5,92 & 2,70 & 1,87 & 6,25 & 7.52 & 7.73 & 7,36 \\
\hline 21 & 2,83 & 0,42 & 2,65 & 62,26 & 5,99 & 14,32 & 3,68 & 14,32 & 7,02 & 3,33 & 8.65 & 11,97 & 14,40 & 15.10 \\
\hline 22 & 1,71 & 0,14 & 1,88 & 68,77 & 19,89 & 43,86 & 7,20 & 5,79 & 2,70 & 1,70 & 5,27 & 7,15 & 8,17 & 7,77 \\
\hline 23 & 2,88 & 0,48 & 3,69 & 52,28 & 28,02 & 66,57 & 3,75 & 13,02 & 3,81 & 3.82 & 7,92 & 9,84 & 12,67 & 12,15 \\
\hline 24 & 1,86 & 0,17 & 1,04 & 73,70 & 10,71 & 47.51 & 7,30 & 6,22 & 2,83 & 1,79 & 5,88 & 6,64 & 6,45 & 6,56 \\
\hline 25 & 1,52 & 0,32 & 1,59 & 82,33 & 17,51 & 62,99 & 1,86 & 8,26 & 3,70 & 2,42 & 9,79 & 7,83 & 15,90 & 15,17 \\
\hline & $\mathrm{ar}$ & & $d$ & $\therefore$ & d & & & & & & & 19,10 & 18,20 & 17,70 \\
\hline
\end{tabular}


Tabela 5.8 - Resultados das concentraçòes e distâncias Mahalanobis para amostras do sitio Vitörta Régia. As amostras aberrantes estão destacadas em negrito.

\begin{tabular}{|c|c|c|c|c|c|c|c|c|c|c|c|c|c|c|}
\hline & $\mathbf{N a} \%$ & $\mathbf{L u}$ & $\mathbf{Y b}$ & La & Th & $\mathrm{Cr}$ & Cs & Sc & $\mathrm{Fe} \%$ & Eu & Hf & $D^{-}$ & $D_{2}^{2}$ & $D_{3}^{2}$ \\
\hline 1 & 1,73 & 0,66 & 4,16 & 42,50 & 9,82 & 53,34 & 5,08 & 15,25 & 4,57 & 1,56 & 10,18 & 5,36 & 5,45 & 5,48 \\
\hline 2 & 1,62 & 0,52 & 1,75 & 47,19 & 15,92 & 51,87 & 4,37 & 13,08 & 3,89 & 1,82 & 10,21 & 11,97 & 13,21 & 13,86 \\
\hline 3 & 2,18 & 0,51 & 3,08 & 58,24 & 12,64 & 66,23 & 2,00 & 16,08 & 4,61 & 2,18 & 8,94 & 4,52 & 4,67 & 4,45 \\
\hline 4 & 1,56 & 0,82 & 5,08 & 51,46 & 12,10 & 56,73 & 4,24 & 14,73 & 4,36 & 1,85 & 9,23 & 5.89 & 6,06 & 5.85 \\
\hline 5 & 1,64 & 0,67 & 4,34 & 51.51 & 12,47 & 60,79 & 3.91 & 15.20 & 4.47 & 1,77 & 9.04 & 3,09 & 3,03 & 2,89 \\
\hline 6 & 1,58 & 0,70 & 4,50 & 47.99 & 12,26 & 60,49 & 3.82 & 16,01 & 4,62 & 1,83 & 7,12 & 3,04 & 3.57 & 3,35 \\
\hline 7 & 2,16 & 0,57 & 4,05 & 51,05 & 3,88 & 61.54 & 3,17 & 20,63 & 6.35 & 2,36 & 7,06 & 8.60 & 8.57 & 9.80 \\
\hline 8 & 2,02 & 0,58 & 3,68 & 55,48 & 11.32 & 68,13 & 3,07 & 18,55 & 5.58 & 2,45 & 6,04 & 3,00 & 4,95 & 5,94 \\
\hline 9 & 1,80 & 0,56 & 4.17 & 73.74 & 13.58 & 42.27 & 2,02 & 17.43 & 5.82 & 2.79 & 7,04 & 5,46 & 6.92 & 7,52 \\
\hline 10 & 1,67 & 0,58 & 3,38 & 41,26 & 10,16 & 53,80 & 3,73 & 12,55 & 3,79 & 1,55 & 9,26 & 3,81 & 3,66 & 3.43 \\
\hline 11 & 1,65 & 0,54 & 3,17 & 44,31 & 8,52 & 20,87 & 7,63 & 12,51 & 4,46 & 2,30 & 7,50 & 7,00 & 7,49 & 8,54 \\
\hline 12 & 2,02 & 0,25 & 1,54 & 38,93 & 5,89 & 16,54 & 1,78 & 4,66 & 1,98 & 1,48 & 8,70 & 12,79 & 13,41 & 12,66 \\
\hline 13 & 1,70 & 0,67 & 3,84 & 55,52 & 17,10 & 22,98 & 7,81 & 12,93 & 3,85 & 1,90 & 5,81 & 10,83 & 11,64 & 12,33 \\
\hline 14 & 1,83 & 0,56 & 3,28 & 52,30 & 9,86 & 13,53 & 1,64 & 12,44 & 3,86 & 2,03 & 8,98 & 14,74 & 15,63 & 18.55 \\
\hline 15 & 2,03 & 0,27 & 1,56 & 43,50 & 5,48 & 19,89 & 1,56 & 5,03 & 2,01 & 1,55 & 7,62 & 14,83 & 14,86 & 14.18 \\
\hline 16 & 1,84 & 0,81 & 4,35 & 69,06 & 11,51 & 53,02 & 3,63 & 20,98 & 7,32 & 2,92 & 10,46 & 5.49 & 8,30 & 9,88 \\
\hline 17 & 1,65 & 0,31 & 1,49 & 64,60 & 6,97 & 30,72 & 7,14 & 16,99 & 3,01 & 1,43 & 3,99 & 19,24 & 25,67 & \\
\hline 18 & 1,92 & 0,37 & 2,22 & 20,70 & 6,39 & 29,27 & 3.98 & 12,25 & 4,30 & 1,16 & 4,44 & 14,43 & 14.80 & 14.97 \\
\hline 19 & 1,78 & 0,32 & 2,14 & 43,33 & 8,28 & 14,11 & 6,06 & 5,61 & 2,60 & 1,69 & 7,08 & 9,64 & 11,00 & 13,03 \\
\hline 20 & 1,82 & 0,39 & 2,88 & 37,56 & 6,65 & 25,99 & 3,19 & 16,38 & 4,65 & 1,80 & 4,13 & 7.18 & 6,93 & 9,44 \\
\hline 21 & 1,41 & 0,22 & 1,19 & 42,13 & 11,10 & 42,27 & 3.73 & 10,98 & 3,16 & 2,19 & 7,83 & 10.31 & 14.51 & 19.20 \\
\hline 22 & 1,85 & 0,74 & 4,56 & 51,77 & 9,35 & 42,27 & 4,67 & 21,01 & 5,93 & 2,65 & 11,03 & 5,10 & 6.88 & 7.08 \\
\hline 23 & 1,69 & 0.64 & 4,30 & 40,72 & 10,16 & 55,73 & 3.66 & 14,75 & 4,53 & 1,53 & 10,84 & 5.38 & 5.52 & 5,89 \\
\hline 24 & 2,00 & 0,26 & 1,00 & 81,79 & 14,14 & 80,92 & 6,26 & 9,57 & 3,94 & 2,36 & $\mathbf{6 , 3 0}$ & 21,91 & 25,10 & \\
\hline 25 & 1,80 & 0,46 & 2,96 & 24,11 & 6,31 & 26,49 & 4,20 & 10,24 & 3,09 & 1,07 & 5,86 & 7.45 & 7,56 & 8.78 \\
\hline 26 & 2,02 & 0,60 & 3,70 & 56,01 & 11,61 & 66,25 & 3,16 & 18,53 & 5,54 & 2,40 & 9,18 & 2,07 & 2.51 & 2,63 \\
\hline 27 & 1,71 & 0,52 & 5,18 & 47,08 & 12,43 & 34,27 & 3,08 & 17,17 & 5,00 & 1,93 & 7,55 & 3,08 & 3.29 & 3.74 \\
\hline 28 & 1,07 & 0,44 & 3,85 & 55,84 & 15,18 & 85,41 & 4,84 & 15,98 & 3,59 & 1,90 & 7,12 & 10,11 & 12,34 & 13,79 \\
\hline 29 & 1,80 & 0,63 & 6,44 & 59,08 & 4,85 & 37,75 & 2,24 & 22,35 & 6.71 & 2,99 & 8.45 & 9,76 & 9,46 & 9,56 \\
\hline 30 & 1,50 & 0,49 & 4,56 & 45,66 & 11,51 & 30,74 & 2,34 & 10,97 & 4,22 & 1,64 & 7,82 & 4,01 & 5,76 & 8.57 \\
\hline 31 & 1,60 & 0,36 & 2,55 & 57,44 & 19,54 & 58,47 & 2,65 & 11,80 & 3,79 & 1,81 & 9 & & 7.57 & 8,61 \\
\hline 32 & 1,76 & 0,25 & 1,75 & 19,78 & 16,14 & 15,51 & 5,56 & 4,16 & 1,59 & 1,92 & 4,67 & 18,44 & 24,95 & \\
\hline 33 & 2,10 & 0,53 & 4,68 & 55,87 & 9,76 & 43,21 & 4,56 & 20,96 & 6,43 & 2,07 & 5,19 & 5,48 & 6.25 & 7,00 \\
\hline 34 & 2,03 & 0,53 & 4,99 & 27,34 & 4,85 & 68,41 & 3.07 & 21,36 & 5,45 & 1,85 & 6,33 & 7,44 & 7.77 & 8,59 \\
\hline 35 & 1,47 & 0,50 & 5,00 & 51,58 & 7.35 & 92,02 & 2.44 & 23,54 & 6,46 & 2.28 & 4,53 & 9,85 & 10,02 & 10,16 \\
\hline 36 & 1,28 & 0,93 & 3,70 & 47,08 & 19,28 & 42,27 & 4,04 & 19,38 & 6,02 & 4,82 & 6,30 & 27,27 & & \\
\hline 37 & 1,73 & 0,56 & 4,90 & 47,15 & 13,80 & 60,37 & 5,53 & 18,30 & 5,06 & 1,92 & 7,55 & 4,41 & 4,44 & 4.12 \\
\hline 38 & 1,60 & 0,52 & 4,71 & 45,78 & 12,37 & 58,13 & 4,37 & 18,27 & 4,81 & 2,03 & 8,12 & 3,30 & 4.21 & 4,23 \\
\hline 39 & 2,50 & 0,42 & 3,65 & 60,35 & 11,86 & 43,63 & 2,02 & 9,75 & 3,29 & 2,21 & 6,96 & & 7.26 & 7.78 \\
\hline 40 & 1,69 & 0,70 & 6,82 & 27,64 & 6,19 & 40,13 & 1,91 & 17.15 & 5.06 & 1,95 & 6.41 & 8,85 & 9.61 & 13,54 \\
\hline 41 & 1,78 & 0,31 & 2,45 & 39,79 & 20,76 & 33,00 & 2,64 & 11.72 & 3,70 & 1,62 & 6.62 & 9,04 & 8.99 & 8.57 \\
\hline 42 & 1,04 & 0,29 & 1,94 & 33,60 & 17,33 & 14,23 & 5,19 & 4,95 & 1,68 & 0,99 & 5,07 & 12.92 & 13,59 & 13,58 \\
\hline 43 & 1,74 & 0,39 & 3,67 & 15,24 & 6,89 & 22,51 & 3,36 & 11,93 & 4,33 & 1.17 & 5.77 & 17,08 & 16.45 & 16,72 \\
\hline 44 & 1.94 & 0,39 & 3,04 & 50,04 & 20,63 & 23,80 & 2,88 & 16,62 & 4,30 & 1,60 & 4.22 & 15,36 & 14.83 & 15,91 \\
\hline 45 & 2,22 & 0.50 & 4.43 & 46.64 & 12.16 & 85.70 & 1.84 & 17.37 & 5,04 & 2.05 & 7.11 & 5.67 & 5.44 & 5.73 \\
\hline 46 & 2,52 & 0.46 & 4,54 & 51.50 & 8,21 & 13,74 & 3.39 & 17.06 & 6,10 & 2,43 & 11.49 & 15,62 & 16.54 & 16,91 \\
\hline 47 & 2,31 & 0,52 & 4,18 & 77,18 & 12.79 & 14,14 & 6,21 & 14,96 & 5,71 & 2.67 & 8.65 & 13,73 & 13,30 & 12,89 \\
\hline 48 & 1,52 & 0.24 & 1.93 & 22.79 & 14,02 & 15,49 & 4,05 & 4,95 & 1,90 & 1,92 & 5.90 & 11,76 & 12,84 & \\
\hline 49 & 1,76 & 0,18 & 1,36 & 13,97 & 13,34 & 15,86 & 5,49 & 15,25 & 1,61 & 1,92 & 7,12 & 35,82 & & \\
\hline 50 & 1,39 & 0,55 & 4,88 & 44,38 & 9.28 & 63,62 & 4,13 & 18,54 & 5,27 & 2,00 & 8.32 & 3,11 & 3.36 & 3,10 \\
\hline \multicolumn{12}{|c|}{ Valore crítico no nível de Significância de $5 \%$} & 25,20 & 24,90 & 24.40 \\
\hline
\end{tabular}


Tabela 5.9 - Resultados das concentraçòes e distâncias Mahalanobis para amostras do sítio Saco da Onça. As amostras aberrantes estào destacadas em negrito.

\begin{tabular}{|c|c|c|c|c|c|c|c|c|c|c|c|c|c|}
\hline & $\mathrm{Na} \%$ & Lu & $\mathbf{Y b}$ & La & Th & $\mathrm{Cr}$ & Cs & Sc & $\mathrm{Fe} \%$ & $\mathbf{E u}$ & $\overline{\mathbf{H f}}$ & $D_{1}^{2}$ & $\overline{D_{2}^{2}}$ \\
\hline 1 & 1.50 & 0,34 & 1,89 & 48,61 & 27,46 & 11,76 & 3.03 & 7,34 & 2.44 & 0.97 & 6,06 & 8,54 & 7.78 \\
\hline 2 & 2,19 & 0,42 & 2,75 & 53,05 & 9,45 & 12,20 & 4,19 & 12,90 & 4,37 & 1,99 & 7,87 & 6.25 & 7,34 \\
\hline 3 & 2,79 & 0,31 & 1,86 & 32,05 & 12,33 & 30,34 & 3,28 & 7,33 & 3,54 & 1,62 & 8.79 & 5,99 & 10,52 \\
\hline 4 & 1,69 & 1,22 & 8,27 & 193,15 & 13,30 & 37,13 & 2,42 & 11,22 & 3,97 & 3,33 & 7,17 & 12,74 & 14.57 \\
\hline 5 & 1,85 & 0,17 & 1,27 & 59,60 & 13,93 & 39,10 & 4,37 & 5.37 & 2.75 & 1,50 & 6,82 & 7,80 & 9,25 \\
\hline 6 & 1,90 & 0,51 & 3.93 & 57,05 & 13,98 & 14,02 & 2,82 & 11.01 & 4.51 & 1,98 & 5,84 & 8,84 & 9,20 \\
\hline 7 & 2,21 & 0,42 & 2,17 & 3,73 & 9,95 & 7,55 & 4,34 & 10,69 & $\mathbf{3 , 5 7}$ & 0,84 & 9,10 & 19,40 & \\
\hline 8 & 1,89 & 0.46 & 2,72 & 38,34 & 7.24 & 29,36 & 7,56 & 13.16 & 3.78 & 1,35 & 4,09 & 6.37 & 6.71 \\
\hline 9 & 1,91 & 0.18 & 1,00 & 25,32 & 10,49 & 20,69 & 5,31 & 8,98 & 3,52 & 1,12 & 5,84 & 9.01 & 9,63 \\
\hline 10 & 1,62 & 0,24 & 1,98 & 88,73 & 39,87 & 45.65 & 4.80 & 6,49 & 2.80 & 2,37 & 9.74 & 11.81 & 10.80 \\
\hline 11 & 1,86 & 0,64 & 3.69 & 61,21 & 17,17 & 45,04 & 3,20 & 18,83 & 5,64 & 2,42 & 7,44 & 4,54 & 5.47 \\
\hline 12 & 1,29 & 0,43 & 2.43 & 47,29 & 31,32 & 10,44 & 3,09 & 7,27 & 2,32 & 1.05 & 6,04 & 8.05 & 9,20 \\
\hline 13 & 1,78 & 0,43 & $\mathbf{0 , 5 4}$ & 16,20 & 11,82 & 18,48 & 7,36 & 4,42 & 1,69 & 1,99 & 3,44 & 22,26 & \\
\hline 14 & 1,71 & 0,43 & 2,47 & 32,84 & 13,93 & 20.69 & 10,44 & 12,11 & 3,71 & 1,04 & 4,99 & 5.48 & 9.23 \\
\hline 15 & 2,19 & 0,35 & 4,47 & 65,96 & 18.37 & 17,89 & 3,74 & 11,54 & 4.13 & 2,07 & 8.59 & 2,41 & 3,05 \\
\hline 16 & 1,29 & 0,62 & 3,65 & 166,79 & 71,12 & 49.84 & 1,68 & 12,28 & 3,59 & 2,41 & 12,07 & 14,04 & 14,06 \\
\hline 17 & 0,64 & 0,72 & 4,46 & 67,31 & 25,82 & 20,69 & 4.33 & 21,37 & 4,91 & 2.71 & 9.53 & 9,88 & 9.61 \\
\hline 18 & 0.72 & 0.35 & 2,55 & 60.54 & 23.47 & 25.97 & 9.31 & 7,92 & 2.80 & 1.28 & 2.98 & 10,09 & 10.73 \\
\hline 19 & 1,55 & 0,56 & 3,87 & 71,93 & 13,22 & 63,52 & 3,20 & 18,97 & 5,36 & 2.49 & 4,89 & 8,48 & 8.06 \\
\hline 20 & 1,34 & 0,43 & 3,01 & 26,69 & 7,58 & 36,04 & 4.15 & 12,21 & 3,86 & 1,35 & 7.12 & 6,80 & 12,49 \\
\hline 21 & 1,09 & 0.24 & 2,07 & 67,32 & 17,85 & 29.83 & 2,67 & 6,80 & 1,93 & 2,55 & 10,29 & 15.91 & 14,82 \\
\hline 22 & 2,87 & 0,68 & 4,88 & 50,89 & 7.50 & 19,62 & 1,44 & 14,55 & 5,10 & 3,68 & 15,52 & 7,17 & 7,40 \\
\hline 23 & 2,81 & 0.77 & 4,76 & 52,02 & 7,65 & 15,40 & 2,35 & 13,99 & 4,91 & 3.68 & 17,02 & 7,96 & 9,06 \\
\hline 24 & 0,96 & 0,22 & 1,31 & 33,94 & 10,79 & 14,91 & 10,79 & 4,16 & 1,59 & 0.83 & 6,36 & 13,13 & 12.50 \\
\hline 25 & 2,28 & 0,53 & 3,51 & 73,28 & 16,60 & 15,31 & 5,82 & 12,76 & 5,32 & 1,99 & 7.85 & 8,29 & 8.53 \\
\hline & & & & & & & & & & & & 19,10 & 18,2 \\
\hline
\end{tabular}


Tabela 5.10 - Resultados das concentraçòes e distâncias Mahalanobis para amostras do sitio Porto Belo. As amostras aberrantes estào destacadas em negrito.

\begin{tabular}{|c|c|c|c|c|c|c|c|c|c|c|c|c|c|}
\hline & $\mathrm{Na} \%$ & $\mathbf{L u}$ & $\mathbf{Y b}$ & La & Th & $\mathrm{Cr}$ & Cs & $\mathbf{S c}$ & $\mathrm{Fe} \%$ & Eu & Hf & $D_{1}^{?}$ & $D_{2}^{2}$ \\
\hline 1 & 1.53 & 0,35 & 2.48 & 53,06 & 16,26 & 48.55 & 2,70 & 10,54 & 3,57 & 1,86 & 10.01 & 8,27 & 8.08 \\
\hline 2 & 1,18 & 0,25 & 1.67 & 16,29 & 5,72 & 13,18 & 2,95 & 6,43 & 2,35 & 2,03 & 3,65 & 12,66 & 12,60 \\
\hline 3 & 2,16 & 0,76 & 5,24 & 71,13 & 8,28 & 17,64 & 3,79 & 19.81 & 7.07 & 2,65 & 12,49 & 5,22 & 5,00 \\
\hline 4 & 1,92 & 0,65 & 4,12 & 31,76 & 6,50 & 2345 & 3,76 & 11,32 & 3.35 & 1,55 & 6,26 & 8.49 & 13,53 \\
\hline 5 & 2,12 & 0,64 & 3,84 & 52,73 & 12,18 & 29,50 & 2.61 & 19.50 & 4,99 & 1,91 & 6,89 & 3,54 & 3,42 \\
\hline 6 & 1,96 & 0,97 & 6.19 & 52,21 & 10,55 & 25,42 & 2,30 & 11,89 & 4,37 & 2,88 & 11.54 & 8.54 & 8,31 \\
\hline 7 & 1,68 & 0,37 & 2,31 & 22.13 & 10,53 & 21.77 & 3,28 & 18,47 & 5,44 & 1,12 & 7,29 & 11,04 & 11,23 \\
\hline 8 & 2.02 & 0,49 & 3,11 & 36,87 & 5.49 & 36,83 & 4,27 & 21.26 & 6.54 & 2,03 & 6.78 &  & 8,87 \\
\hline 9 & 2,15 & 0,76 & 3,96 & 61,86 & 13.46 & 26,60 & 2,63 & 19.48 & 4,94 & 2,29 & 6,65 & 9,94 & 9.83 \\
\hline 10 & 1.94 & 0.42 & 2.97 & 47,83 & 10,57 & 21,19 & 2,89 & 16,31 & 5,31 & 1,99 & 4,51 & 5.35 & 5.61 \\
\hline 11 & 1,84 & 0,46 & 2.67 & 49.10 & 12.16 & 76,70 & 3,30 & 15,02 & 4,94 & 1,86 & 9,99 & 1.2 & 7,37 \\
\hline 12 & 2,42 & 0,68 & 4,49 & 66.73 & 6,67 & 12.27 & 4,41 & 19.43 & 7,32 & 2,72 & 11,87 & 9,42 & 9.83 \\
\hline 13 & 2,44 & 0,32 & 2.16 & 17,27 & 5.87 & 11,41 & 8,94 & 6,29 & 2.09 & 2,03 & 6.17 & 13.22 & 12.78 \\
\hline 14 & 1,62 & 0,32 & 2,17 & 27.58 & 9,05 & 20,99 & 2,15 & 13,33 & 3,80 & 1,12 & 5.03 & 9,29 & 10.51 \\
\hline 15 & 1,92 & 0,36 & 2,20 & 36,83 & 10,01 & 24,92 & 8,69 & 13.19 & 2,48 & 1,35 & 5,60 & 17,40 & 16,71 \\
\hline 16 & 2,70 & 0,68 & 4,88 & 72,10 & 7,48 & 13,34 & 2,42 & 20,59 & 7,36 & 2,82 & 10,58 & 7.05 & 7.22 \\
\hline 17 & 1,56 & 0,60 & 3,54 & 39,08 & 11,77 & 47,48 & 3,16 & 17.69 & 5,14 & 1,92 & 7,29 & 4,06 & 4.19 \\
\hline 18 & 2,30 & 0,76 & 4,64 & 48.57 & 9,38 & 31,54 & 2,11 & 20,97 & 6,56 & 2,84 & 12.04 & 5,99 & 10,65 \\
\hline 19 & 1,98 & 0,70 & 4,55 & 84,99 & 9.72 & 22,1 & 3,66 & 11,07 & 4,28 & 3,63 & 5.34 & 5.70 & 5.81 \\
\hline 20 & 1,15 & $\mathbf{0 , 9 0}$ & 3,69 & 53,66 & 13,09 & 12,0 & 3,9 & 3 & 1,76 & 1,14 & 4,67 & 22,99 & \\
\hline 21 & 2,38 & 0.81 & 5,05 & 97.97 & 11,03 & 23,11 & 3,59 & 12.56 & 4,81 & 4,06 & 5,86 & 6.39 & 6,23 \\
\hline 22 & 1,89 & 0,62 & 4,32 & 52,21 & 14,18 & 41,79 & 4,38 & 19.79 & 5,95 & 1,78 & 3,66 & 14,99 & 14.56 \\
\hline 23 & 2,01 & 0,71 & 4,67 & 92,08 & 11,63 & 20, & 3,52 & 11,63 & 4,79 & 3,55 & 7,2 & 3.5 & 4,23 \\
\hline 24 & 1,2 & 0 , & 2,1 & 33 & 18 & 21 , & 5, & 5 & 2,04 & 2,03 & 5,82 & 7,54 & 7,41 \\
\hline 25 & 1,87 & 0,83 & 5,99 & 76.36 & 32.23 & 28,58 & 5,42 & 13,06 & 4,25 & 2,38 & 11.60 & 15,14 & 14.71 \\
\hline 26 & 1,71 & 0,21 & 1,25 & 52,21 & 15,89 & 65,74 & 4,23 & 7,44 & 3,99 & 2,61 & 7,23 & 14,97 & 16,14 \\
\hline 27 & 2,23 & 0,14 & 1,16 & 54,4 & 10,35 & 51,71 & 5,71 & 8,13 & 3,44 & 2,02 & 6,42 & 14,14 & 15,17 \\
\hline
\end{tabular}

Valore crítico no nivel de Significância de 5\%

$19.90 \quad 19,50$

O segundo procedimento para identificação das amostras aberrantes, para cada sítio, foi fundamentado na distância Mahalanobis robusta. Os estimadores de tendência central e dispersão para a determinação da distância de Mahalanobis robusta foram determinados por meio de um subconjunto dos dados, com $75 \%$ do total de amostras para cada sítio, o qual apresentou menor determinante para matriz de covariância. Nas Figuras 5.6 a 5.14 estão ilustradas as disposições das composições químicas elementares para o sítio arqueológico estudado, no espaço das componentes principais. Nestas Figuras (5.6 a 5.14), a elipse mais externa correspondente à distância de Mahalanobis igual a $\chi_{2: 1,1,4 \times}^{2}$ 




Figura 5.6. Amostras do sitio Justino (Superficial) no espaço das componentes principais (3 componentes explicaram $77,4 \%$ da variabilidade total). As elipses correspondem aos quantis $25 \%, 50 \%, 75 \%$ e $98 \%$ da distribuição $\chi_{p}^{2}$. As amostras aberrantes estão fora da elipse de tolerância $\chi_{2 ; 0.98}^{2}$..

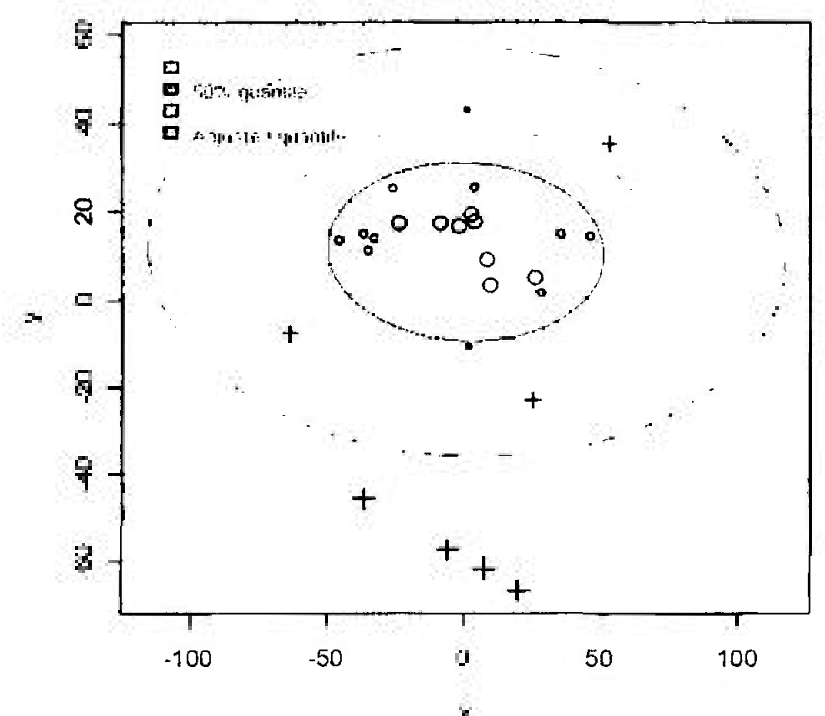

Figura 5.7. Amostras do sitio Justino A no espaço das componentes principais (4 componentes explicaram $82,0 \%$ da variahilidade total). As elipses correspondem aos quantis $25 \%, 50 \%, 75 \%$ e $98 \%$ da distribuição $\chi_{p}^{2}$. As amostras aberrantes estão fora da elipse de toleräncia $\chi_{2 ; 0,98}^{2}$. 


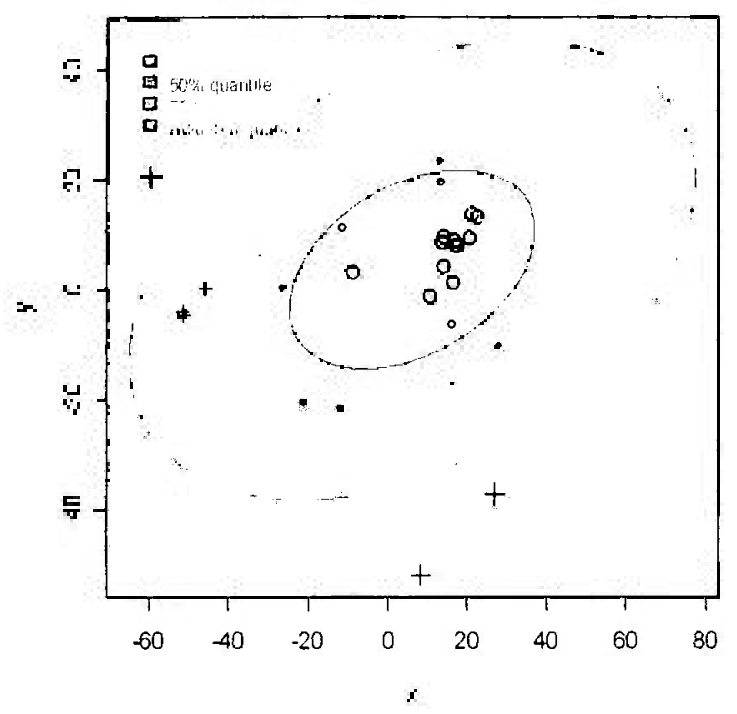

Figura 5.8. Amostras do sitio Justino B no espaço das componentes principais (4 componentes explicaram $77,9 \%$ da variabilidade total). As elipses correspondem aos quantis $25 \%, 50 \%, 75 \%$ e $98 \%$ da distribuição $\chi_{p}^{2}$. As amostras aberrantes estão fora da elipse de tolerância $\chi_{2: 0,98}^{2}$.



Figura 5.9 Amostras do sitio Justino C no espaço das componentes principais (4 componentes explicaram $83,7 \%$ da variabilidade total). As elipses correspondem aos quantis $25 \%, 50 \%, 75 \%$ e $98 \%$ da distribuição $\chi_{p}^{2}$. As amostras aberrantes estão fora da elipse de tolerancia $\chi_{2: 0, \%}^{2}$. 




Figura 5.10 Amostras do sitio Curituba no espaço das componentes principais (3 componentes explicaram $77,6 \%$ da variabilidade total). As elipses correspondem aos quantis $25 \%, 50 \%, 75 \%$ e $98 \%$ da distribuiçco $\chi_{p}^{2}$. As amostras aberrantes estão fora da elipse de tolerância $\chi_{2 ; 0,98}^{2}$.

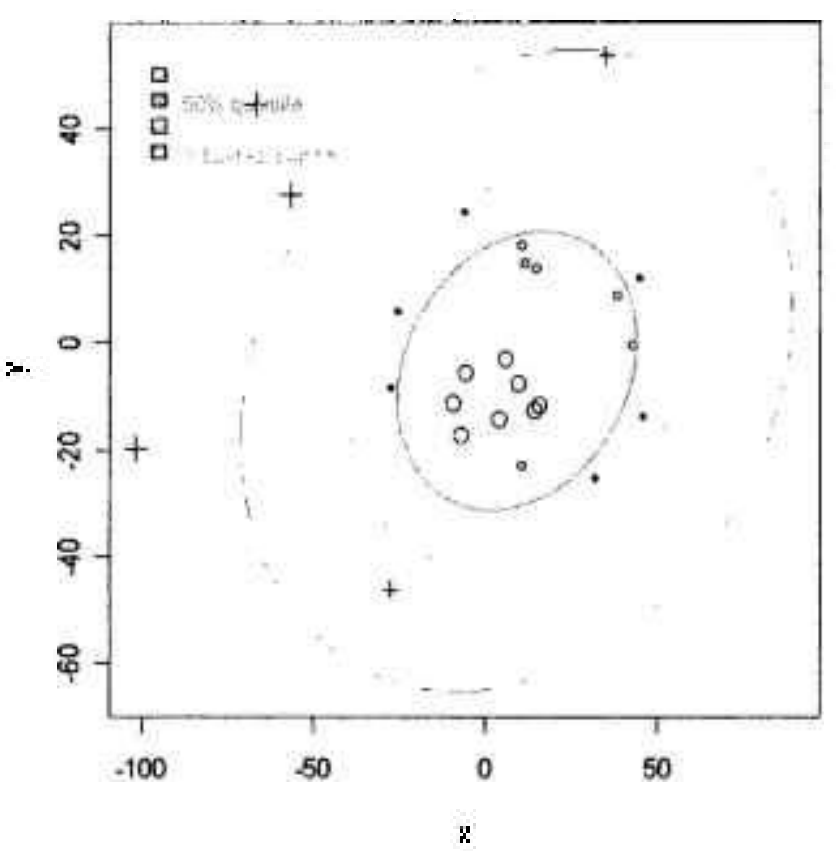

Figura 5.11. Imostras de sitio Sào Jose no espaço das componentes principais a componcentes explicarem $73,8 \%$ da variabilidade total). As elipses correspondem aos quantis $25 \%, 50 \%, 75 \%$ e $98 \%$ da distribuição $\chi_{p}^{2}$. As amostras aberrantes estão fora da elipse de tolerância $\chi_{2 ; 0,98}^{2}$. 


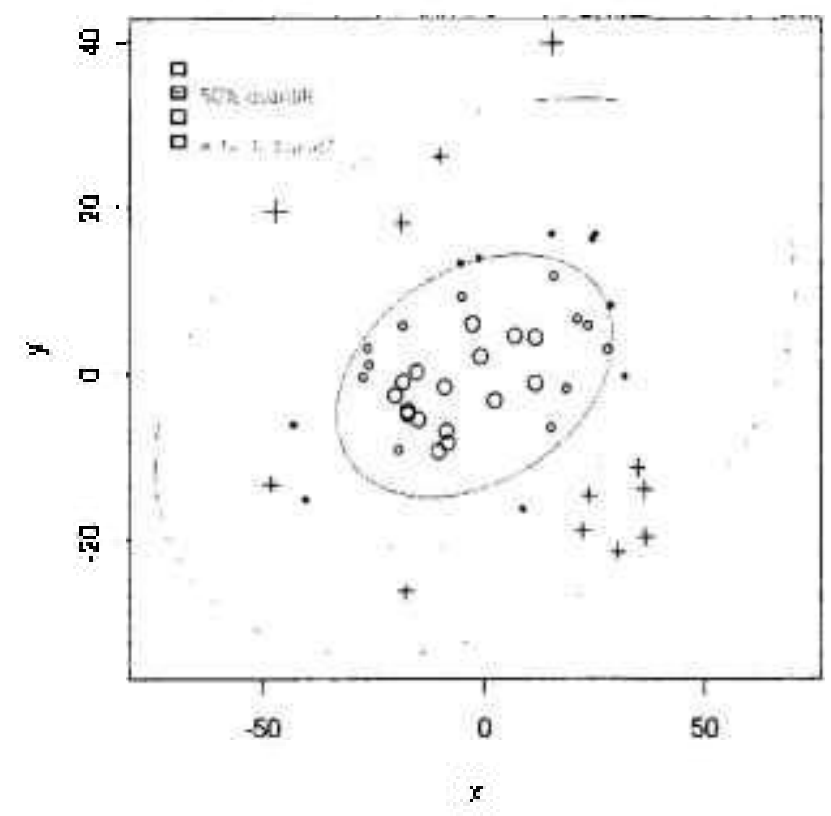

Figura 5.12. Amostras do sítio Vitória Régia no espaço das componentes principais (3 componentes explicaram 66,8\% da variabilidade total). As elipses correspondem aos quantis $25 \%, 50 \%, 75 \%$ e $98 \%$ da distribuição $\chi_{p}^{2}$. As amostras aberrantes estão fora da elipse de tolerância $\chi_{2 ; 0,98}^{2}$

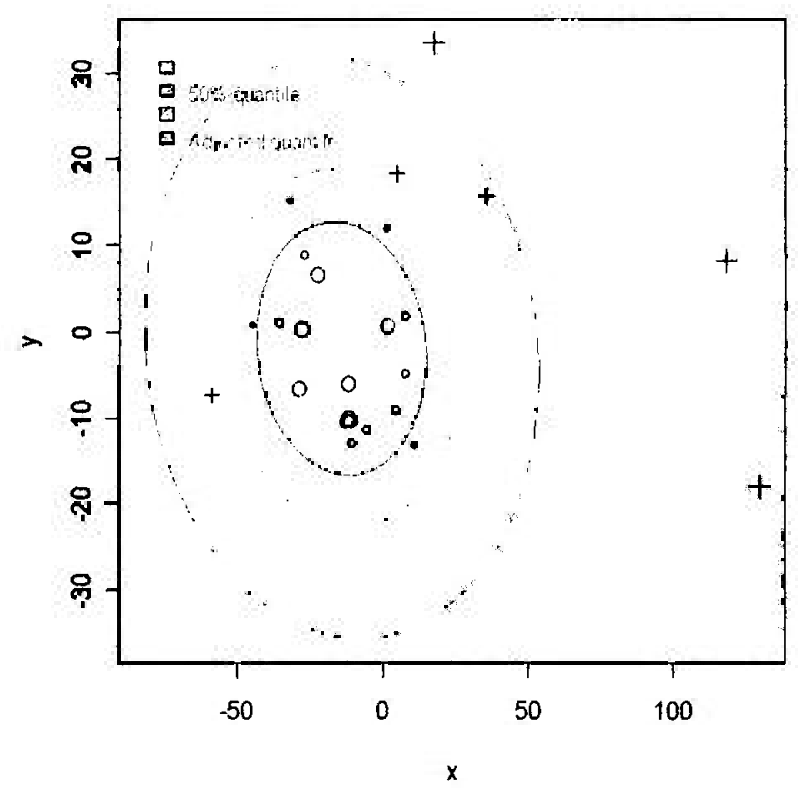

Figura 5.13. Amostras do sitio Saco da Onça no espaço das componentes principais (3 componentes explicaram 74,2\% da variahilidade total). As clipses correspondem aos quantis $25 \% .50 \%, 75 \%$ e $98 \%$ da distribuição $\chi_{p}^{2}$. As amostras aberrantes estão fora da elipse de tolerância $\chi_{2 ; 0,98}^{2}$. 


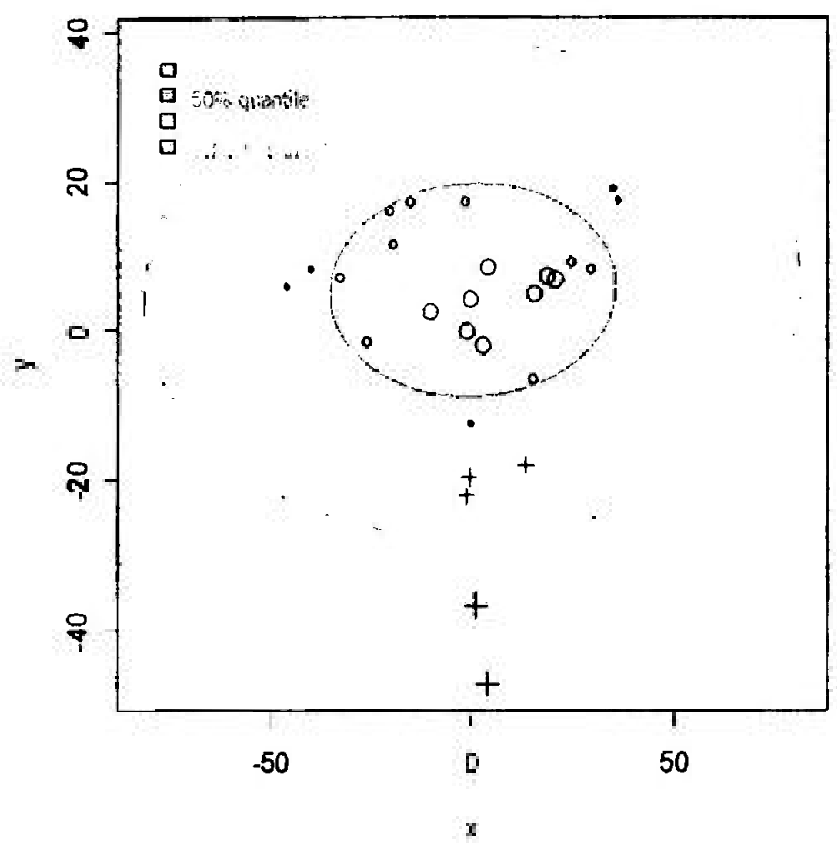

Figura 5.14. Amostras do sitio Porto Belo no espaço das componentes principais ( 3 componentes explicaram $81,1 \%$ da variabilidade total). As elipses correspondem aos quantis $25 \%, 50 \%, 75 \%$ e $98 \%$ da distribuição $\chi_{p}^{2}$. As amostras aherrantes estão fora da elipse de tolerância $\chi_{2: 0.98}^{2}$.

De acordo com as Figura 5.6 a 5.14 é possivel observar a presença de amostras discrepantes em todos os sítios arqueológicos estudados, conforme indicado na Tabela 5.11. Pode ser verificado que o número de amostras consideradas discrepantes pelo segundo método é quase duas vezes maior que o encontrado por meio da utilização da distância de Mahalanobis clássica. Este comportamento resulta da redução da dispersão da matriz de covariância, e conseqüentemente da dispersão das amostras no hiperespaço formado pelos componentes principais, a qual é resultante de uma subamostragem que apresenta um perfil químico mais estreito e significante para o grupo considerado. As amostras superficiais do sítio Justino, por exemplo, apresentam uma composição química bastante dispersa em relação aos outros sítios, e por meio do primeiro procedimento não se identificou amostras atípicas, visto a alta dispersão na matriz de covariância, que resulta na redução dos valores na distância de Mahalanobis clássica em relação ao centro do grupo. Como as distâncias de Mahalanobis neste caso são reduzidas, aumenta-se a probabilidade da inclusão de amostras atipicas neste grupo, as quais foram detectadas por meio da distância de Mahalanobis robusta, com valores críticos dados pela distribuição $\chi_{p}^{2}$.

Assim, de uma forma geral, a utilização da distância de Mahalanobis robusta é mais eficiente para a detecção de amostras aberrantes em estudos composicionais de 
cerâmicas arqueológicas. De acordo com esse estudo das amostras discrepantes, as amostras consideradas aberrantes no segundo procedimento não foram levadas em consideração para interpretação dos grupos composicionais. Na Tabela 5.11 está exposto um resumo das amostras identificadas como atípicas em relação a cada sitio:

Tabela 5.11 - Tabela com os numeros de amostras aberrantes e nimero total do amostras após eliminaçäo das aberiantes.

\begin{tabular}{ccccc}
\hline Sítio & N $^{\mathbf{0}}$ Total de amostras & Método clássico & Método Robusto & N $^{\text {wo }}$ Total sem Outliers \\
\hline Justino Sup. & 18 & 0 & 4 & 14 \\
Justino A & 25 & 1 & 4 & 21 \\
Cemitério B & 26 & 1 & 3 & 23 \\
Cemitério C & 25 & 1 & 2 & 23 \\
São José & 25 & 3 & 3 & 22 \\
Saco da Onça & 25 & 2 & 3 & 22 \\
Curituba & 24 & 2 & 4 & 20 \\
Porto Belo & 27 & 1 & 2 & 25 \\
Vitória Régia & 50 & 5 & 2 & 48 \\
\hline Total & 245 & 16 & 27 & 218 \\
\hline
\end{tabular}

\subsection{Definição dos grupos composicionais}

\subsubsection{Sítio Justino: Comparação entre os Cemitérios B e C do sítio Justino}

A formação dos grupos de cerâmicas arqueológicas coletadas no sítio Justino, conforme a composição química elementar, foi determinada por meio da aplicação de técnicas estatísticas multivariadas. A matriz de dados para estabelecimentos dos grupos foi composta por 81 amostras e 11 elementos químicos (Na, Lu, Yb, La, Th, Cr, Cs, Sc, Fe, Eu e Hf). A definição desta matriz foi realizada após eliminação dos outliers e das variáveis de baixa precisão, conforme o estudo apresentado na seção anterior. As 81 amostras estão distribuídas da seguinte forma: 14 amostras superficiais, 21 amostras Justino A, 23 amostras do Cemitério B e 23 amostras do cemitério $\mathrm{C}$.

Uma análise exploratória dos dados, pela representação de todas as amostras no espaço formado pelas duas primeiras componentes principais, foi observado que as amostras superficiais e do Justino A apresentam uma dispersão elevada em suas composições quimicas elementares, comparativamente à dispersão das amostras coletadas mais profundamente. A dispersão destas amostras, coletadas mais próximo à superfície, pode ser um resultado de interferência antrópica recente, visto que este sítio foi escavado em uma área que apresentava atividade agrícola, e o manejo do solo pode ter combinado amostras cerâmicas de várias profundidades. Por isso, as amostras superficiais foram retiradas da base do sítio Justino com o objetivo de identificar mais claramente os grupos. 
Com base no "Scree Plot" (Figura 5.15) e no critério de Kaiser (Kaiser, 1958), o qual visa a observação do número de componentes significantes na análise, identificou-se que três componentes principais explicam $74 \%$ da variabilidade total da matriz formada pelas amostras do Justino A, Cemitério B e Cemitério C. Na Figura 5.16 é mostrado os escores das amostras no espaço formado pelos dois primeiros eixos principais, onde pode ser visualizado que as amostras do Justino A estão bastantes dispersas em relação às amostras dos Cemitérios B e C. Ainda na Figura 5.16, observa-se que as amostras do Cemitério $\mathrm{B}$ formam um grupo compacto entre os $2^{\circ}$ e $3^{\circ}$ quadrantes nos espaço das componentes principais. As amostras do Cemitério $\mathrm{C}$, apesar de possui maior dispersão que o Cemitério B, forma um grupo com amostras, preferencialmente, dispersas nos $1^{\circ} \mathrm{e} 4^{\circ}$ quadrantes da Figura 5.16.

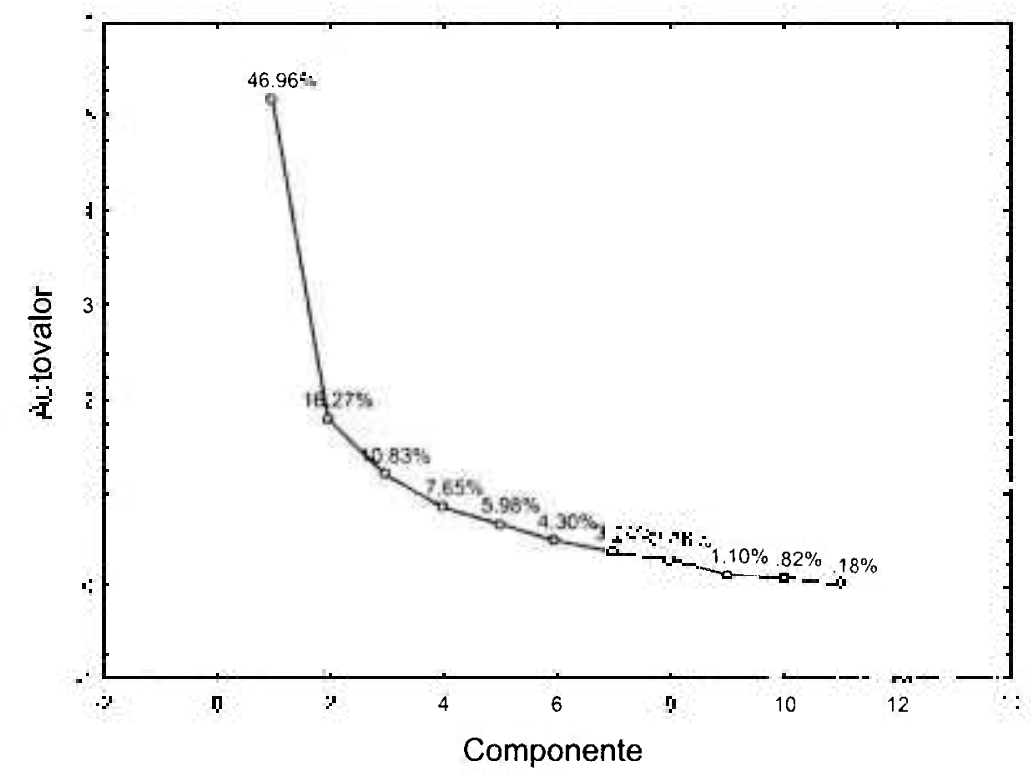

Figura 5.15 - "Scree Plot" para identificaçào do número de componentes para o Sitio Justino. 


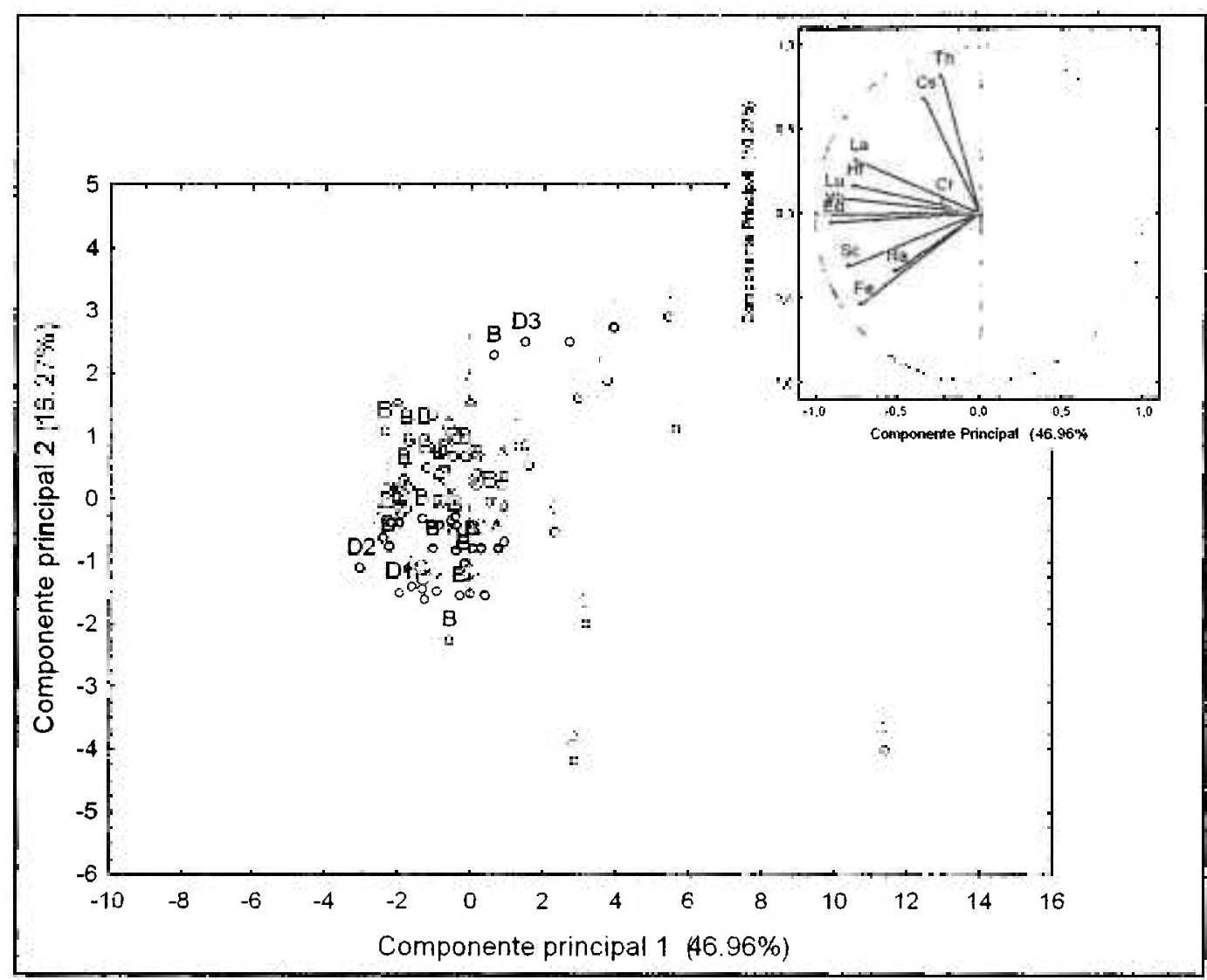

Figura 5.16 - Biplot para amostras do Justino A, Cemitério B e C.

A diferença entre as amostras dos Cemitérios B e C pode ser explicada pela estrutura de correlaçâo entre as variáveis de interesse na interpretação dos resultados aqui apresentados. A estrutura de correlação apresentada no biplot (Figura 5.16), mostra que as principais correlações são entre os elementos terras raras e $\mathrm{Hf}$, entre $\mathrm{Na}, \mathrm{Sc}$ e Fe e terceiro grupo formado por Th e Cs. Pela projeção das cargas fatoriais dos elementos nos dois primeiros eixos principais, é possivel observar que a distinção entre os Cemitérios é provocada pela variabilidade dos elementos traços ( $\mathrm{La}, \mathrm{Hf}, \mathrm{Yb}$ e $\mathrm{Eu}$ ), visto que estes elementos estão em maior concentração e menor variabilidade no Cemitério B. A maior variabilidade na composição química elementar das amostras cerâmicas do Cemitério $\mathrm{C}$ do Justino, relativo ao Cemitério $B$, pode ter sido causada pela interferência do homem no preparo da pasta cerâmica, provocando a diluição. Logo, o processo de evolução tecnológica da manufatura da cerâmica pré-histórica de Xingó, está refletida na variância das composições químicas das cerâmicas, uma vez que o grupo ceramista que ocupou o sítio Justino, em uma faixa cronológica contemporânea ao Cemitério $\mathrm{C}$, se trata do primeiro grupo ceramista que ocupou o Justino, sendo, portanto, detentor de um processo de manufatura cerâmica ainda incipiente. Com o processo de evolução tecnológica, o que 
implica em uma pasta cerâmica mais homogênea, o grupo que ocupou a Cemitério B do Justino já apresentava um processo de manufatura mais elaborado, o que explica a maior homogeneidade da composição química das amostras coletadas nos níveis correspondentes a este Cemitério. Entretanto, as amostras do Cemitério A são mais dispersas que as amostras coletadas nos Cemitérios B e C, o que se deve, provavelmente, a mudanças na tecnologia de fabricação das cerâmicas, em virtude do contato e intercâmbio entre o grupo que ocupou o Justino neste periodo mais recente com outros grupos ceramistas.

Para facilitar a visualização dos grupos composicionais realizou-se uma análise de agrupamento com as amostras dos Cemitérios $\mathrm{B}$ e C, mediante utilização do método de Ward e da distância euclidiana quadrática (Figura 5.17). Apesar da superposição de amostras nos grupos, foi possivel observar três grupos: um grupo central, formado, preferencialmente, por amostras pertencentes ao Cemitério B, um grupo inferior composto por amostras do Cemitério $\mathrm{C}$ e um grupo superior, formado pela superposição das amostras dos cemitérios B e C.

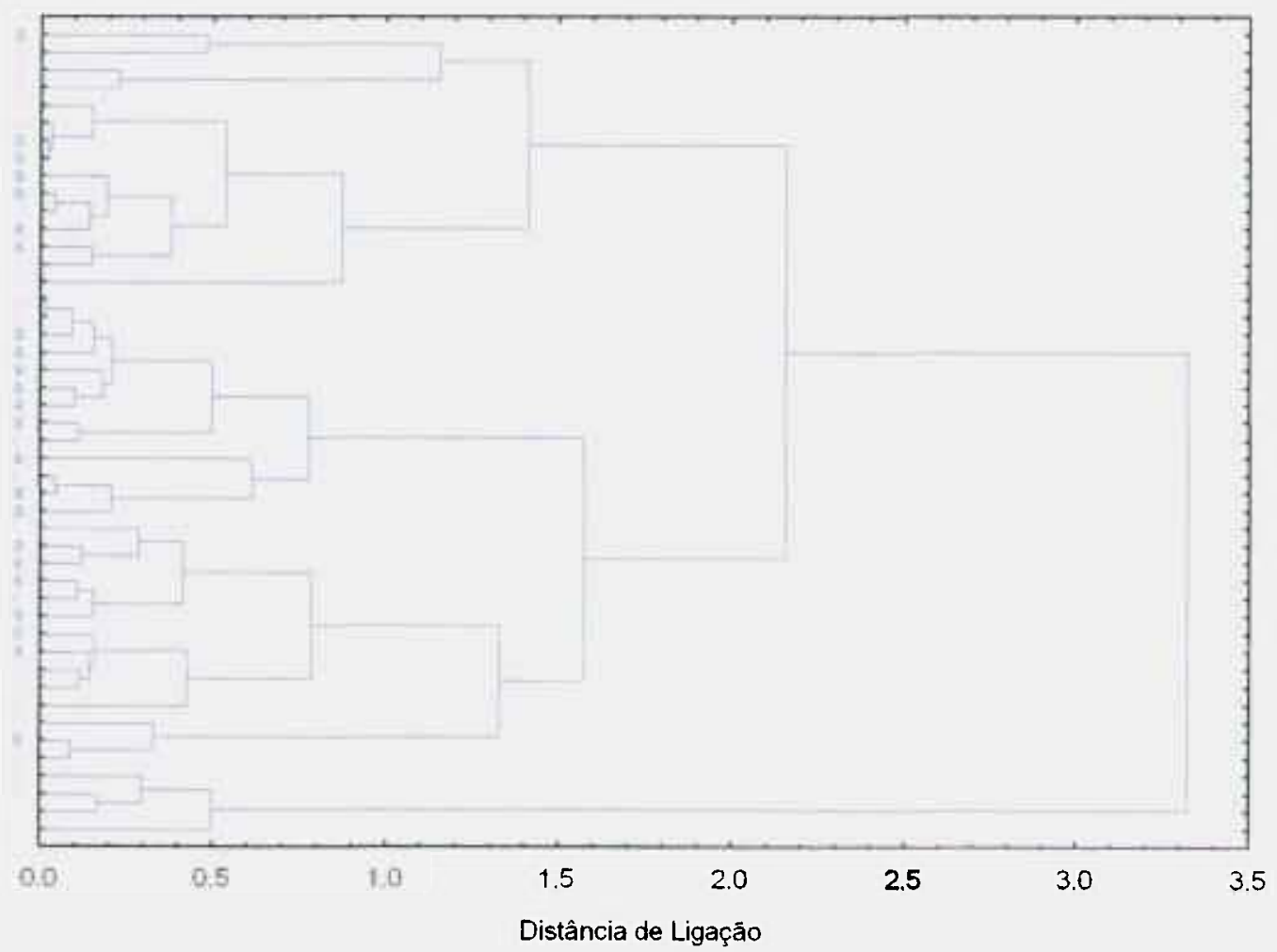

Figura 5.17 - Dendrograma para agrupamento das amostras dos (emitérios $B$ e C do sitio Justino.

Para confirmar os grupos realizou-se análise discriminante linear, para as amostras dos Cemitérios B e C. A análise discriminante apontou que $78 \%$ das amostras do 
Cemitério $\mathrm{B}$ e $83 \%$ das amostras do Cemitério $\mathrm{C}$ foram classificadas corretamente de acordo com a suposição apriorísticas que as amostras destes cemitérios têm diferentes composições químicas. Eliminando-se as amostras classificadas incorretamente foi realizada nova análise discriminante, confirmando-se a classificação obtida anteriormente. Neste caso, a distância de Mahalanobis quadrática observada entre os centróides dos grupos foi de 3,57. Na Figura 5.18 são mostrados os escores das funções discriminantes para as amostras dos Cemitérios $\mathrm{B}$ e $\mathrm{C}$, onde pode ser observada a dispersão das amostras do Cemitério $\mathrm{C}$ relativo ao $\mathrm{B}$, como fora detectado por análise das componentes principais.

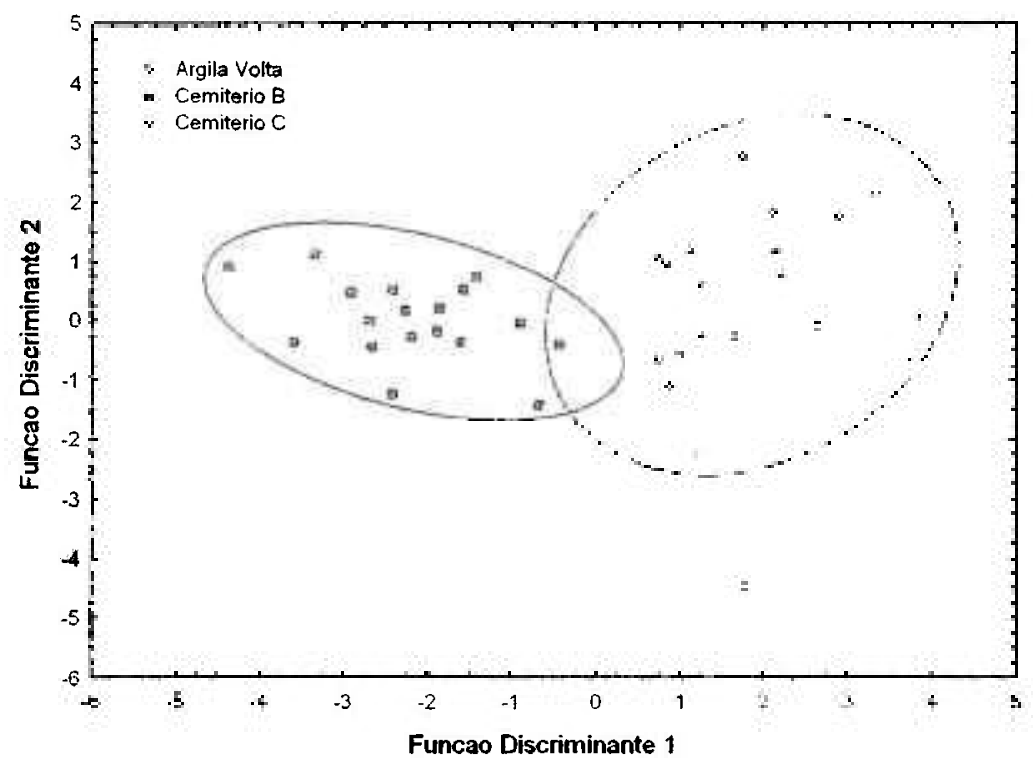

Figura 5.18 - Funções discriminantes para a composição quimica das cerâmicas dos Cemitérios $B$ e $C$ do Justino, e argila. (As elipses representam nivel de confiança de 95\%)

A aplicação da análise discriminante passo-a-passo (Forward Stepwise Discriminant Analysis) nos permite identificar as variáveis discriminantes entre os grupos composicionais (Baxter, 1994; Munita et al., 2006), ou seja, selecionar as variáveis que possibilita a diferenciação dos grupos composicionais. Verificou-se que as concentrações de Th e Cr não são significativas, de acordo com o critério lambda Wilks. Eliminando Th e $\mathrm{Cr}$ da matriz de dados e aplicando-se análise discriminante, verificou-se que as amostras dos Cemitérios B e C foram classificadas corretamente em seus respectivos grupos. $\mathrm{Na}$ Figura 5.19 têm-se os escores nos espaço das funções discriminantes. Aplicando-se análise discriminante, após eliminação das variáveis $\mathrm{Th}$ e $\mathrm{Cr}$, a distância Mahalanobis quadrática observada entre os centróides dos grupos foi de 15,27, assim obteve-se por meio da aplicação desta técnica uma melhor separação entre os grupos composicionais. 




Figura 5.19 - Funções discriminantes para a composição quimica das cerâmicas dos Cemitérios $B$ e $C$ do Justino, e argila, após eliminação de The $C r$. As elipses representam nivel de confiança de 95\%.

Em virtude das práticas ceramistas as concentrações de vários elementos podem sofrer efeitos de diluição (Beier \& Mommsen, 1994), assim neste trabalho foram calculados, para cada amostra, os fatores de diluição por meio da distância Mahalanobis modificada. Em seguida, as concentrações foram corrigidas de acordo com os seus respectivos fatores de diluição. De uma forma geral, estas diluições provocam o aumento da dispersão dos grupos composicionais e, conseqüentemente, nas probabilidades de classificações erradas. Na Tabela 5.12 estão os fatores de diluições médios, as concentrações médias dos elementos utilizados para interpretação e suas dispersões, para as amostras dos Cemitérios B e C. Nesta tabela a redução da dispersão das concentrações de cada sitio é muito clara, o que implica em uma melhor separação entre estes dois grupos. 
Tabela 5.12 - Concentração elementar média (M) para as cerâmicas do sitio Justino (cemitérios B e C). Valores em ppm, exceto quando indicado, e desvio padrão em percentagem da média.

\begin{tabular}{|c|c|c|c|c|}
\hline & \multicolumn{2}{|c|}{ Cemitério B } & \multicolumn{2}{|c|}{ Cemitério C } \\
\hline & $\begin{array}{c}\text { Sem correção } \\
(M \pm C V)\end{array}$ & $\begin{array}{c}\text { Com correção } \\
\left(f=1,(00 \pm 0,03)^{*}\right. \\
(M \pm C V)\end{array}$ & $\begin{array}{l}\text { Sem correção } \\
(\mathrm{M} \pm \mathrm{CV})\end{array}$ & $\begin{array}{c}\text { Com correção } \\
(f=0,90 \pm 0,08)^{*} \\
(M \pm C V)\end{array}$ \\
\hline $\mathrm{Na} \%$ & $1,55 \pm 12,79$ & $1,53 \pm 12,43$ & $1,31 \pm 23,65$ & $1,27 \pm 18,45$ \\
\hline Lu & $0,68 \pm 33,22$ & $0,65 \pm 22,76$ & $0.47 \pm 39,44$ & $0,44 \pm 23,84$ \\
\hline $\mathbf{Y b}$ & $4,54 \pm 34,48$ & $4,32 \pm 24,20$ & $3,44 \pm 47,50$ & $3,16 \pm 30,48$ \\
\hline La & $59,41 \pm 24,18$ & $58,13 \pm 20,28$ & $48,93 \pm 40,44$ & $45,69 \pm 29.52$ \\
\hline Th & $13,53 \pm 37,78$ & $13,55 \pm 37,35$ & $14,68 \pm 53,58$ & $15,27 \pm 51,02$ \\
\hline $\mathrm{Cr}$ & $37,96 \pm 72,31$ & $39,38 \pm 71,44$ & $27,91 \pm 52,29$ & $27,13 \pm 45,41$ \\
\hline Cs & $6,71 \pm 40,17$ & $6,63 \pm 39,91$ & $4,77 \pm 60,89$ & $4,49 \pm 59.23$ \\
\hline Sc & $17,57 \pm 22,81$ & $17,16 \pm 18,68$ & $12,91 \pm 43,44$ & $12,06 \pm 31,58$ \\
\hline $\mathrm{Fe} \%$ & $5,99 \pm 22,88$ & $5,82 \pm 14,29$ & $4,44 \pm 37,88$ & $4,14 \pm 22,82$ \\
\hline Eu & $2,58 \pm 22,03$ & $2,51 \pm 15,04$ & $1,85 \pm 50,61$ & $1,70 \pm 36,97$ \\
\hline Hf & $7,52 \pm 19,88$ & $7,42 \pm 18,86$ & $7,06 \pm 36,18$ & $6,71 \pm 23,42$ \\
\hline
\end{tabular}

*f representa o fator de diluição médio com o desvio padrão

Após correção das concentrações em virtude do efeito de diluição, aplicou-se, novamente, análise discriminante e obteve-se distância Mahalanobis quadrática entre os centróides dos grupos de 34,52, valor da ordem duas vezes maior que a obtida anteriormente. Na Figura 5.20 são mostrados os escores discriminantes para as amostras dos cemitérios B e C, onde é evidente a redução na dispersão de cada grupo.

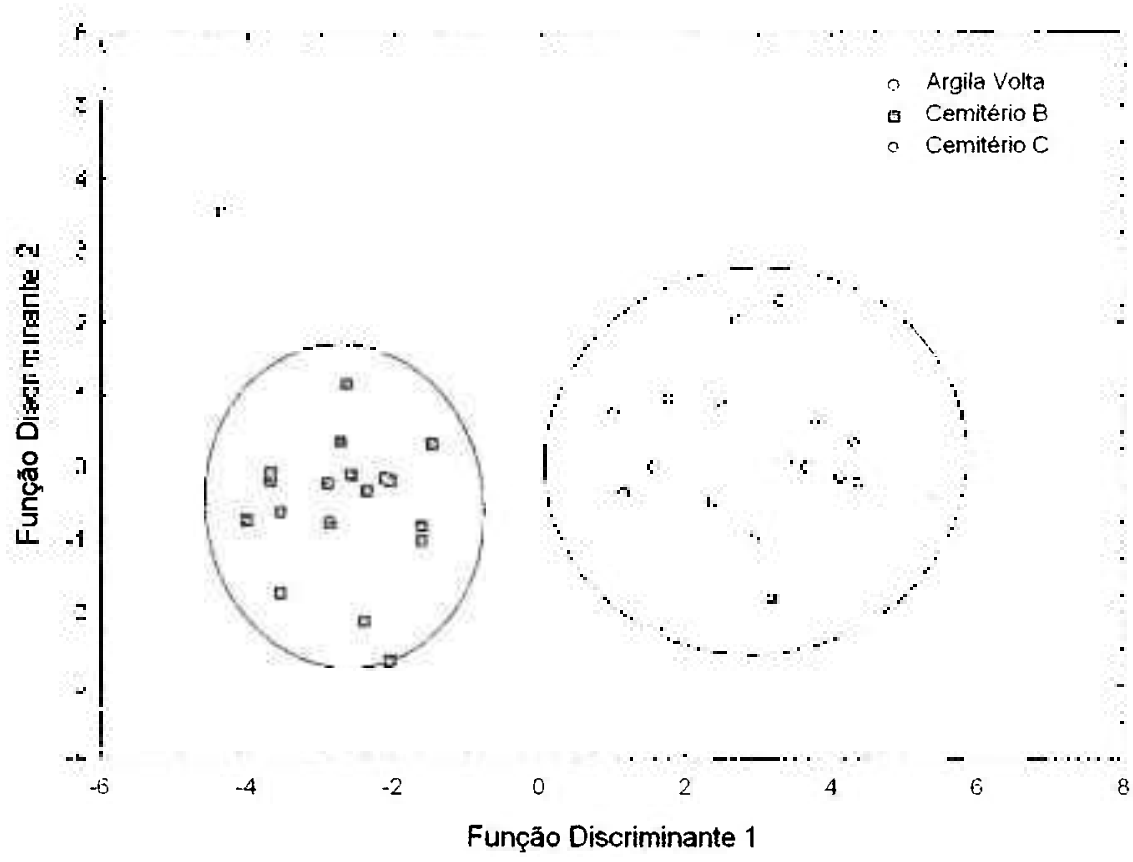

Figura 5.20 - Função discriminante para a composição química das cerâmicas do sitio Justino (Cemitérios $B$ e $C$ do Justino e argila, após correção com os fatores de diluição. As elipses representam nivel de confiança de 95\%. 
Levando-se em consideração os resultados apresentados, é possível inferir que a distinção da composição química elementar das cerâmicas dos Cemitérios B e C do sítio Justino é resultado do processo de fabricação dos objetos. A figura 5.21 mostra a diferença padronizada entre a composição química das ceràmicas dos cemitérios $\mathrm{B}$ e $\mathrm{C}$, de maneira univariada. As diferenças entre as concentrações dos Cemitérios B e C estão normalizadas de acordo com a raiz quadrática da soma das variàncias de cada grupo. Considera-se que diferenças padronizadas em torno de 2, ou superior, são significativas (Montana et al., 2003). De acordo com esse critério, pode ser observado que as cerâmicas do Cemitério B apresentam concentrações significativamente mais elevadas, com exceção dos elementos La, Th, Cr, Cs e Hf.

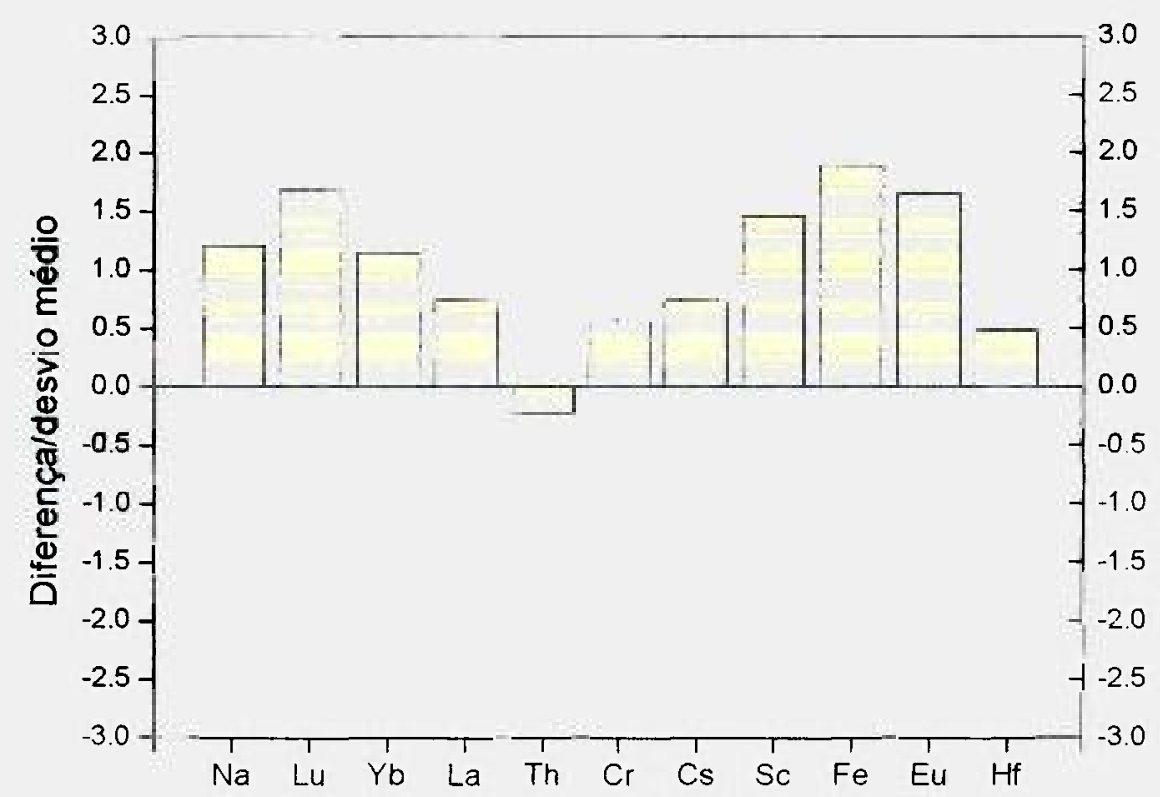

Figura 5.21 - Diferença padronizada entre a composição quimica média das cerâmicas do sitio Justino(Cemitérios $B$ e C).

Esta diferença composicional entre as cerâmicas dos cemitérios $\mathrm{B}$ e $\mathrm{C}$, nos remete à hipótese proposta por Vergne (2004) que estes sítios são oriundos de distintas ocupações, baseando-se na variabilidade das associações do material cerâmico destes Cemitérios com os enterramentos e na distância temporal entre eles,. Mesmo que a fonte de matéria-prima usada pelos grupos que habitaram a região seja a mesma, as evoluções tecnológicas dos sucessivos grupos que habitaram a região implicaram em alterações na manufatura da cerâmica local. Esta evolução pode ser observada, por exemplo, na composição química elementar do Cemitério $\mathrm{B}$, cemitério mais recente que o $\mathrm{C}$, como será 
visto na seção referente à datação por TL, pois este apresenta uma pasta de composição mais homogênea e distinta da composição das amostras do Cemitério C.

\subsubsection{Comparação entre os Sítio São José, Saco da Onça e Curituba}

Segundo as hipóteses de ocupação da região de Xingó, sugeridas por Luna (2003), a primeira ocupação ceramista em Xingó se deu no sítio Justino, por volta de 5570 AP. Como resultado do crescimento populacional desta comunidade, aproximadamente 1400 anos depois foi estabelecida a ocupação do sítio São José, 3000 anos após seu deu a ocupação do sítio Porto Belo e só 4200 após a primeira ocupação ceramista, as regiões correspondentes aos sítios Curituba, Vitória Régia e Saco da Onça foram ocupadas.

Tendo em vista que as formas de produção, consumo e distribuição dos objetos cerâmicos são reflexos das condições sócio-culturais e econômicos da comunidade, esperase que a composição química elementar da pasta cerâmica apresente uma diferenciação com relação à dinâmica de ocupação de Xingó. Os sítios São José e Curituba podem ser considerados na verificação desta hipótese, uma vez que apresentam cronologias e localizações diferenciadas. O sítio Saco da Onça, contemporâneo ao sítio Curituba, foi utilizado com o propósito de verificar evoluções tecnológicas dos grupos que habitaram a região no passado em virtude de se tratar de um sítio de acampamento.

Por meio da das componentes principais, verificou-se que, apenas, quatro componentes principais são significativas para explicar a variabilidade das composições químicas das cerâmicas resgatadas nos sítios São José, Saco da Onça e Curituba (Figura 5.22). Essas componentes explicam $76,81 \%$ da variância total das composições químicas elementares das cerâmicas dos três sítios arqueológicos. Projetando-se os pontos amostrais no espaço formado pelas duas componentes principais (Figura 5.23), observa-se a aglomeração das amostras do sítio São José, as quais estão dispostas, preferencialmente, na região onde os escores são positivos para a $2^{\mathrm{a}}$ componente principal. Ainda na Figura 5.23, verifica-se que as amostras do sítio Curituba estão localizadas na região onde os escores são negativos para a $1^{\mathrm{a}}$ componente principal. As amostras do sítio Saco da Onça, estão dispersas no espaço formado pelas duas primeiras componentes principais. 


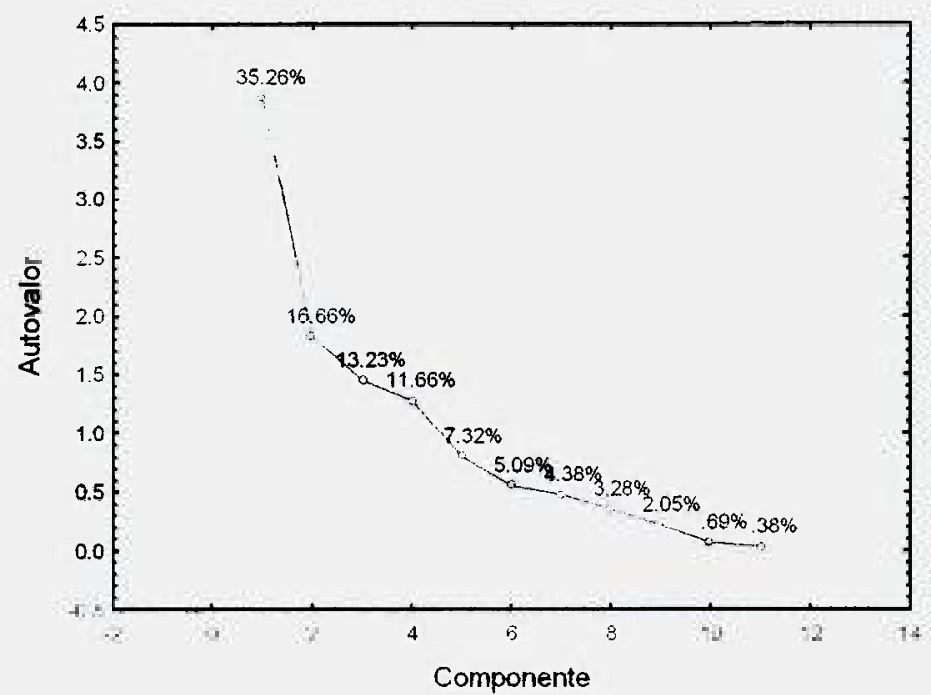

Figura 5.22 - "Scree Plot" para identificação do número de componentes significantes para interpretação dos sitios São José, Saco da Onça e Curituba.

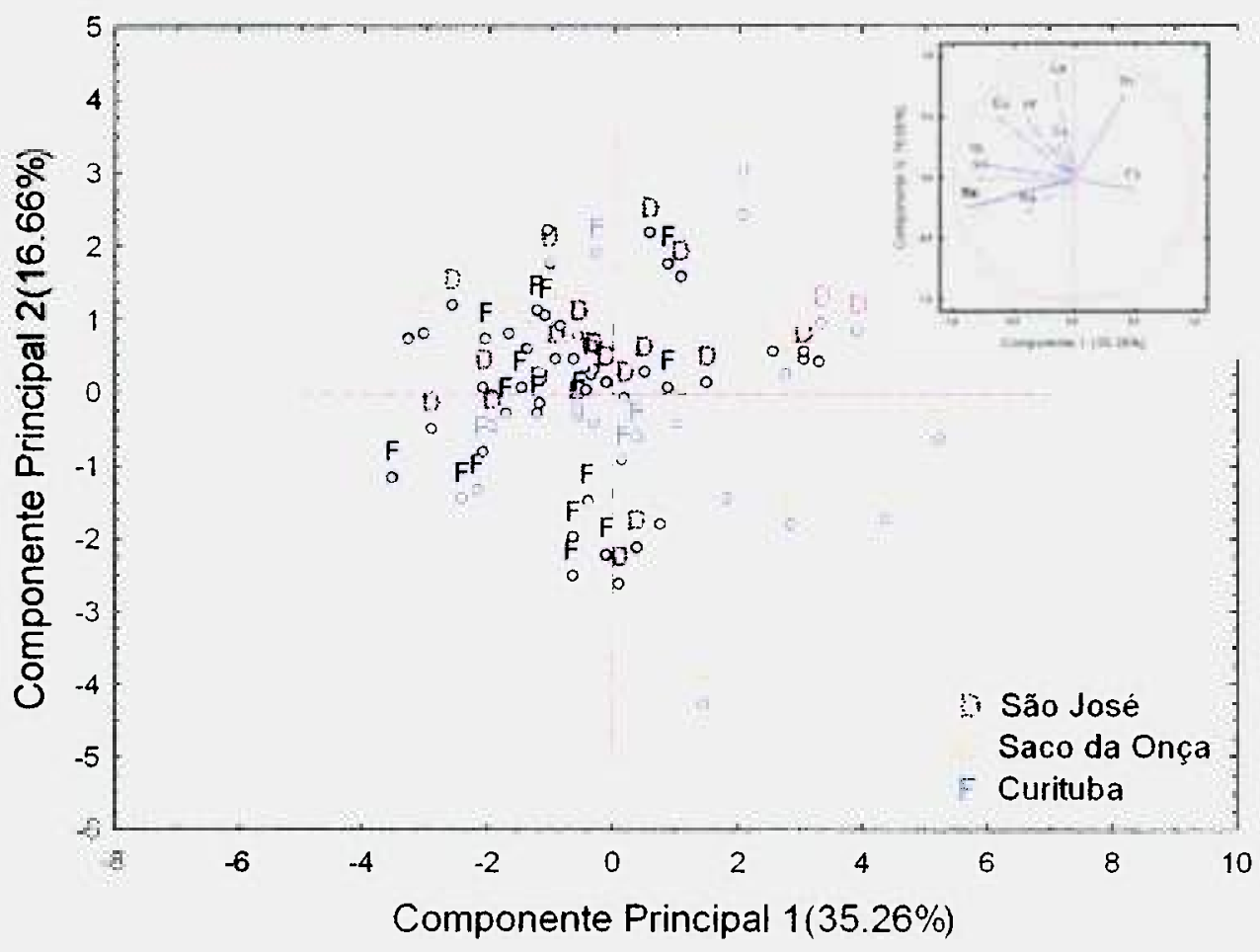

Figura 5.23 - Biplot para amostras dos sítios São José, Saco da Onça e Curituba.

Para confirmar os agrupamentos das amostras dos três sitios foi realizada análise discriminante, que ratificou a hipótese que as amostras de cerâmicas dos sitios São José, Saco da Onça e Curituba formam grupos composicionais distintos. Nessa análise, $86 \%$ das amostras do sítio São José, 100\% das amostras do sítio Curituba e $81 \%$ das amostras do sítio Saco da Onça foram classificados corretamente em seus respectivos 
grupos. Na Figura 5.24 estão dispostas as amostras no espaço formado pelas funções discriminantes, onde é possivel visualizar três grupos, e a dispersão interna, relativamente maior, das amostras do sítio Saco da Onça. A dispersão encontrada para o sítio Saco da Onça leva-nos a inferir, de acordo com o critério da abundância, que diversas amostras são intrusivas neste sítio. Este inferência confirma a hipótese que este sitio se tratava de um sítio de acampamento.



Figura 5.24 - Função discriminamte para a composição quimica das cerâmicas dos sitios São José, Saco da Onça e Curituba. As elipses representam nivel de confiança de $95 \%$.

Por intermédio da análise discriminante passo-a-passo, verificou-se que as variáveis $\mathrm{Lu}, \mathrm{Yb}$, La e Hf não são significativas para discriminação dos três grupos composicionais. Na Figura 5.25 são apresentados os escores discriminantes das amostras cerâmicas dos sítios São José, Saco da Onça e Curituba, após eliminação das variáveis pouco significativas. Mesmo que a distância Mahalanobis entre os centros dos grupos ter decrescido, observa-se uma nítida separação entre os grupos. 


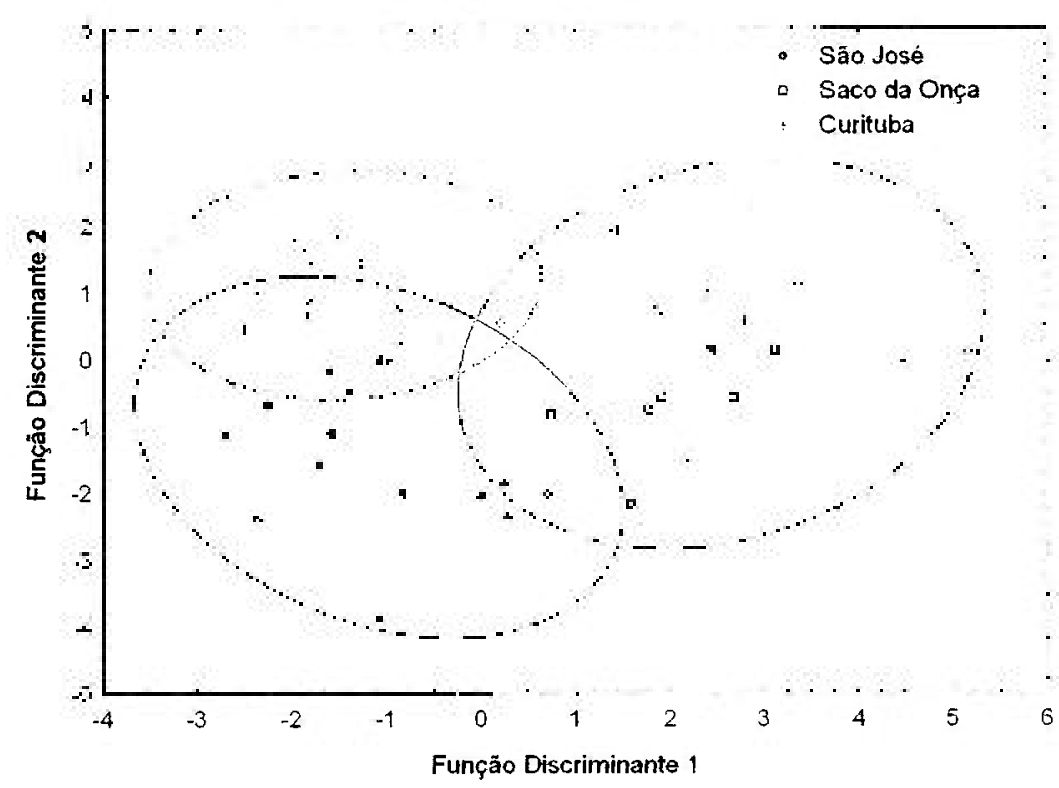

Figura 5.25 - Função discriminante para a composição química das cerâmicas dos sítios São José, Saco da Onça e Curituba, após eliminação de Lu, Yb, La e Hf. As elipses representam nivel de confiança de $95 \%$

Em virtude de algumas práticas ceramistas, tal como a adição de temperos, alguns elementos podem sofrer efeito de diluição. Assim, as concentrações forma corrigidas de acordo com o fator de diluição. Na Tabela 5.13 estão apresentadas as composições químicas médias das cerâmicas de cada sítio, antes e após correção, assim como o fator de diluição médio por sítio. Nessa tabela pode ser observado que dos três sítios arqueológicos, as cerâmicas do Saco da Onça apresentou maior efeito de diluição.

Tabela 5.13 - Concentração elementar média(M) para as cerâmicas dos sítios São José, Saco da Onça e Curituba. Valores médios em ppm, exceto quando indicado, e desvio padrão em percentagem da média.

\begin{tabular}{|c|c|c|c|c|c|c|}
\hline & \multicolumn{2}{|c|}{ Curituba $(n=20)$} & \multicolumn{2}{|c|}{ São José } & \multicolumn{2}{|c|}{ Saco da Onça } \\
\hline & $\begin{array}{c}\text { Sem correção } \\
(\mathbf{M} \pm \mathbf{C V})\end{array}$ & $\begin{array}{c}\text { Com correção } \\
\left(\mathrm{f}=1,01 \pm(1,18)^{\star}\right. \\
(\mathrm{M} \pm \mathrm{CV})\end{array}$ & $\begin{array}{c}\text { Sem correção } \\
(\mathrm{M} \pm \mathrm{CV})\end{array}$ & $\begin{array}{c}\text { Cum correçãu } \\
\left(\mathrm{f}=1,00 \pm(1,19)^{*}\right. \\
(\mathrm{M} \pm \mathrm{CV})\end{array}$ & $\begin{array}{c}\text { Sem correção } \\
(\mathrm{M} \pm \mathrm{CV})\end{array}$ & $\begin{array}{c}\text { Com correção } \\
(f=0,93 \pm 0,21)^{*} \\
(M \pm C V)\end{array}$ \\
\hline $\mathrm{Na} \%$ & $1,81 \pm 0,40$ & $1,32 \pm 0,35$ & $1,82 \pm 0,44$ & $1,31 \pm 0,32$ & $1,80 \pm 0,62$ & $1,28 \pm 0,50$ \\
\hline Lu & $0,51 \pm 0,13$ & $0,54 \pm 0,06$ & $0,43 \pm 0,21$ & $0,42 \pm 0,18$ & $0,44 \pm 0,18$ & $0,42 \pm 0,11$ \\
\hline $\mathbf{Y b}$ & $3,53 \pm 1,10$ & $3,79 \pm 0,54$ & $2,76 \pm 1,42$ & $2,78 \pm 1,19$ & $2,75 \pm 1,27$ & $2,68 \pm 0,86$ \\
\hline La & $44,77 \pm 13,60$ & $49.47+13.09$ & $53.21+19.70$ & $55,1+ \pm 19.21$ & $50,33 \pm 20,33$ & $46,29 \pm 20,73$ \\
\hline Th & $9,78 \pm 4,23$ & $10,92 \pm 4,31$ & $12,41 \pm 5,86$ & $13,95 \pm 8,16$ & $16,37 \pm 8,46$ & $18,70 \pm 12,67$ \\
\hline $\mathrm{Cr}$ & $49,() 6 \pm 23,53$ & $49,32 \pm 24,50$ & $50,47 \pm 23,59$ & $49,66 \pm 21,56$ & $24,02 \pm 13,81$ & $29,46 \pm 28,66$ \\
\hline Cs & $4,29 \pm 1,46$ & $4,72 \pm 1,75$ & $4,01 \pm 1,81$ & $4,86 \pm 2,58$ & $4,88 \pm 2,62$ & $5,45 \pm 4,66$ \\
\hline Sc & $17,36 \pm 4,44$ & $19,54 \pm 5,42$ & $12,87 \pm 5,18$ & $13,15 \pm 4,94$ & $10,82 \pm 4,78$ & $10,59 \pm 3,47$ \\
\hline Fe & $5,09 \pm 1,26$ & $5,74 \pm 0,64$ & $4,43 \pm 1,32$ & $4,54 \pm 1,15$ & $3,66 \pm 1,25$ & $3,64 \pm 1,02$ \\
\hline $\mathbf{E u}$ & $2,06 \pm 0,59$ & $2,07 \pm 0,24$ & $2,25 \pm 0,91$ & $2,09 \pm 0,52$ & $1,89 \pm 0,83$ & $1,62 \pm 0,46$ \\
\hline Hf & $7,18 \pm 1,91$ & $6,78 \pm 1,57$ & $7,54 \pm 1,69$ & $6,95 \pm 2,18$ & $7,69 \pm 3,45$ & $6,58 \pm 2.36$ \\
\hline
\end{tabular}

*f representa o fator de diluição médio com o desvio padrão 
Após correção das concentrações foi realizada análise discriminante e obteve-se que a variância interna de cada grupo sofreu um decréscimo. Um resultado direto da redução da variabilidade de cada grupo pode ser examinado na Figura 5.26, onde se observa que as distâncias entre os centros de cada grupo aumentou, resultando em uma melhor resolução espacial para a discriminação dos grupos composicionais.

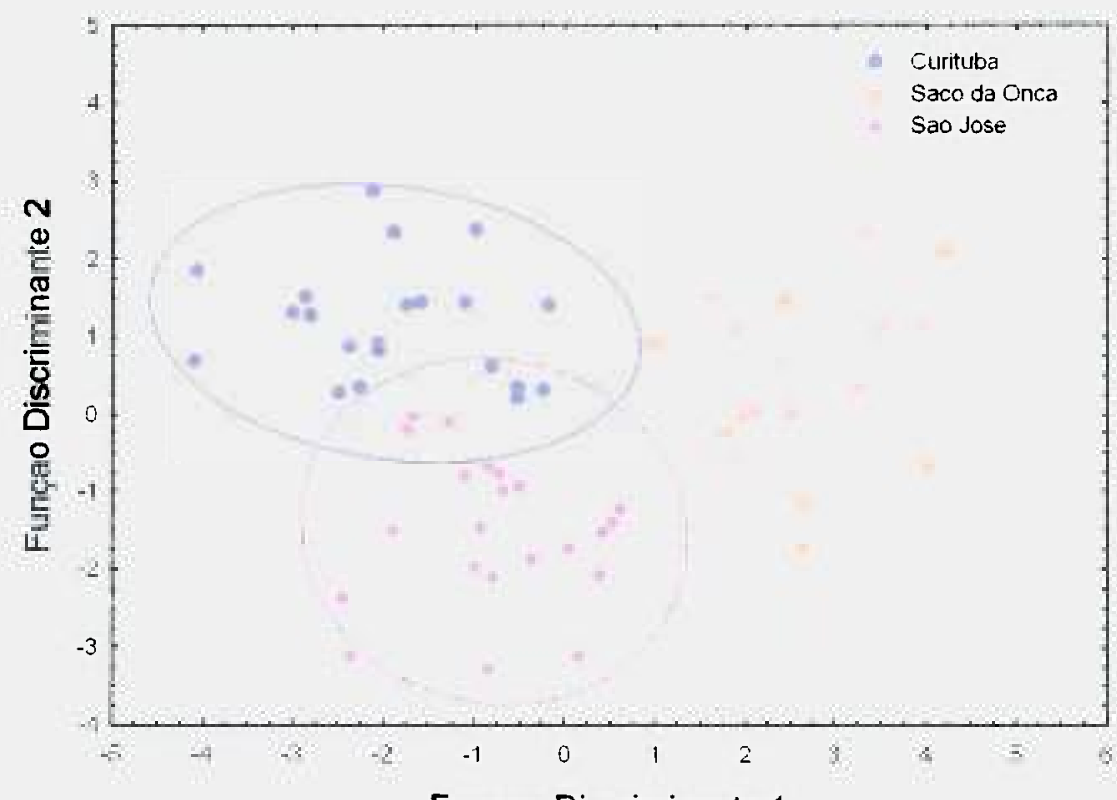

Funcao Discriminante 1

Figura 5.26 - Função discriminante para a composição química das cerâmicas dos sitios. São José, Saco da Onça e ('urituba, após correção com us fatores de diluiçòes. As elipses representam nivel de confiança de $95 \%$

As Figuras 5.27 a 5.29, apresentam as diferenças padronizadas entre as composições químicas média das cerâmicas dos sitios São José, Saco da Onça e Curituba. De acordo com a Figura 5.27, pode-se inferir que as diferenças mais significativas entre a composição química das cerâmicas dos sítios Saco da Onça e São José são para os elementos Fe e Eu, cujas concentrações são maiores no sítio São José. Na Figura 5.28, referente à comparação entre os sítios Saco da Onça e Curituba, foi observada que esta diferença é significativa em relação aos clementos $\mathrm{Lu}, \mathrm{Yb}, \mathrm{Sc}, \mathrm{Fe}$ e Eu. Os elementos Lu, $\mathrm{Yb}$ e Sc são os que apresentam as maiores diferenças entre os sítios São José e Curituba (Figura 5.29).

Assim, considerando-se os resultados apresentados, pode-se inferir que, provavelmente, os grupos ceramistas que habitaram os sitos São José, Saco da Onça e 
Curituba tinham traços diferenciais na tecnologia de produção cerâmica, que estão refletidos na composição química elementar das cerâmicas

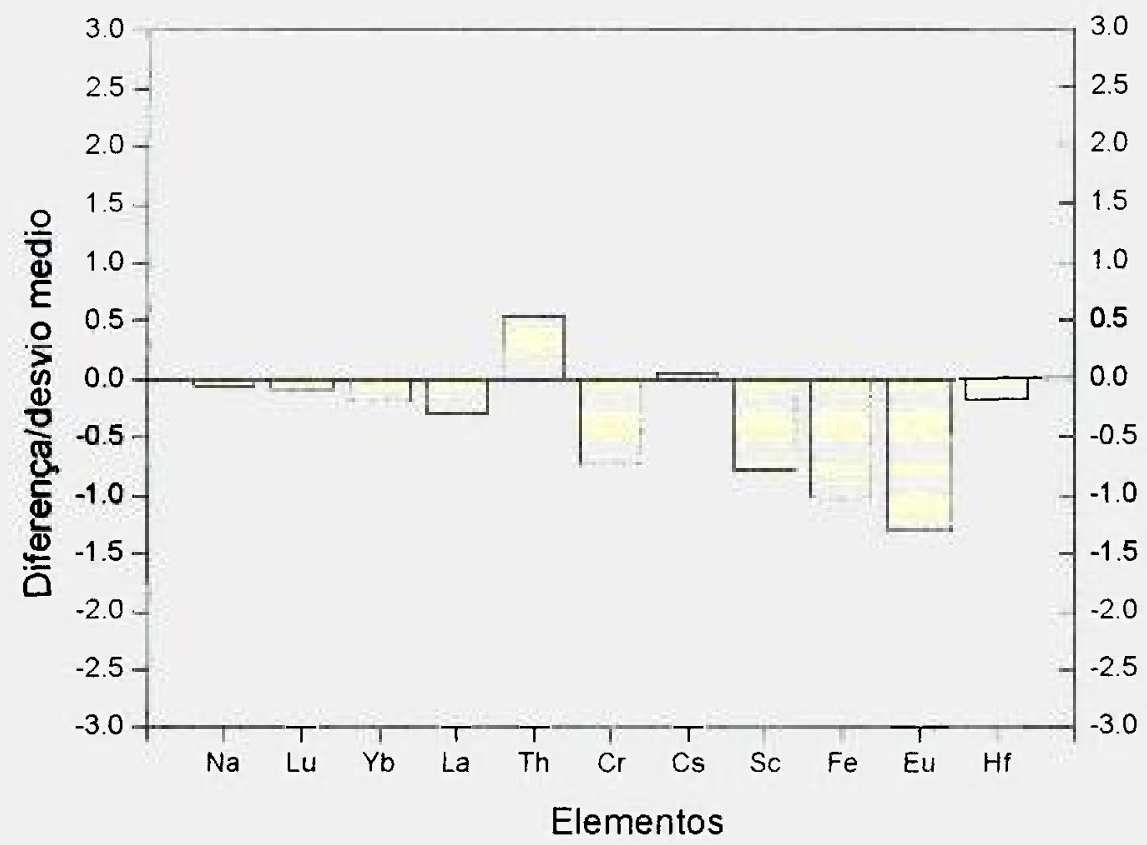

Figura 5.27 - Diferença padronizada entre a composição quimica média das cerâmicas dos sitios Saco da Onça e São José.

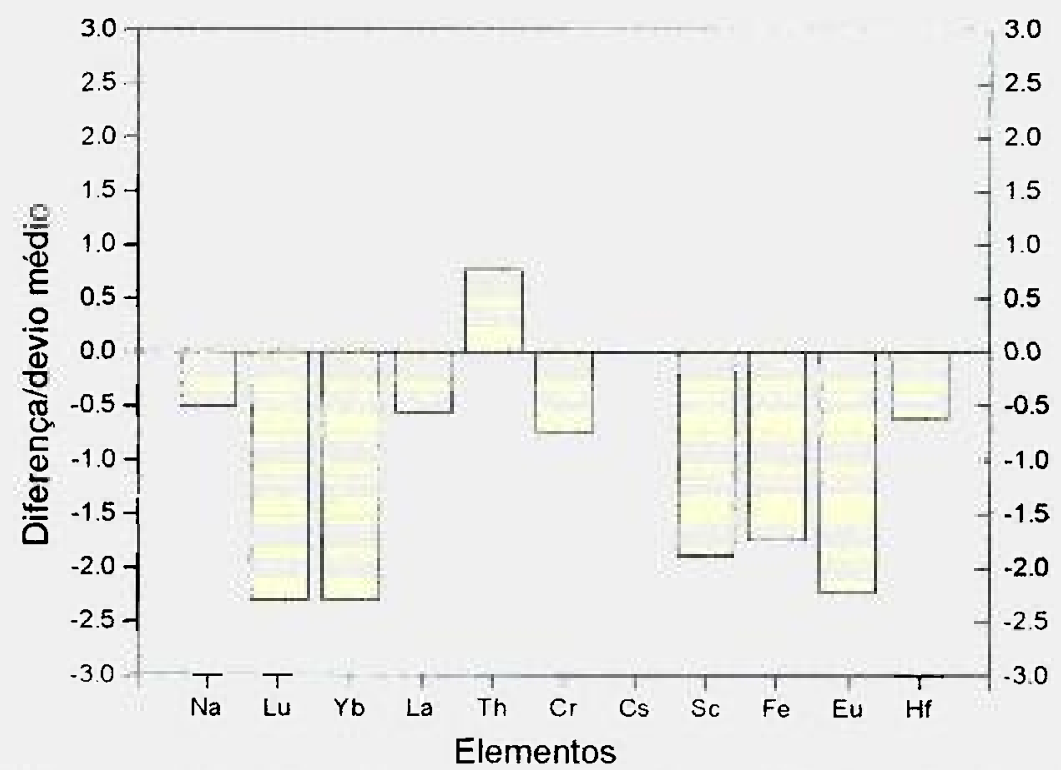

Figura 5.28 - Diferença padronizada entre a composição quimica média das cerâmicas dos sitios Saco da Onça e Curituba. 




Figura 5.29 - Diferença padronizada entre a composição quimica média das cerâmicas dos sitios São José e Curituba.

\subsubsection{Ocupações antigas: Comparação entre Cemitério B do Justino X São José}

Tendo em vista que as cronologias do Cemitério $\mathrm{B}$ e do sítio São José são relativamente próximas, bem como a localização desses sítios, realizou-se uma análise comparativa entre a composição química das cerâmicas. Essa análise teve o objetivo de verificar se os grupos que ocuparam esses sítios mantinham uma produção cerâmica compartilhada, ou se produziam seus proprios utensilios cerâmicos.

Partindo-se da hipótese aprioristica que os dois grupos ceramistas citados mantinham produção local, ou seja, produziam suas próprias cerâmicas, realizou-se uma análise discriminante no sentido de ser testada a hipótese. De acordo com o resultado da análise discriminante, obteve-se que $82 \%$ das amostras do Cemitério B e $76 \%$ das amostras do sitio São José foram classificadas corretamente. A Figura 5.30 mostra as funções discriminantes dos dois sitios, após eliminação das amostras classificadas incorretamente, onde é possivel observar que a composição quimica das cerâmicas dos dois sítios de interesse nessa seção são distintas. 




Figura 5.30 - Função discriminante para a composição quimica elementar das cerâmicas do sitio Justino (C'emitérios B) e do sitio. São José. (As elipses representam regiôes nivel de confiança de 95\%)

Uma vez que as concentrações podem sofrer efeitos de diluição, obtiveram-se concentrações corrigidas de acordo com o fator de diluição para cada sítio. Nas Tabelas 5.12 e 5.13 estão a concentrações médias e fator de diluição médio para cada grupo composicional. Na Figura 5.31, as amostras do Cemitério B e do sitio São José são representadas em termos dos escores discriminantes, obtidos com as concentrações corrigidas, onde é visivel a separação dos grupos composicionais. De acordo como o resultado nessa figura, pode-se inferir que as cerâmicas consumidas pelos grupos que ocuparam os dois sitios produziam suas próprias cerâmicas.

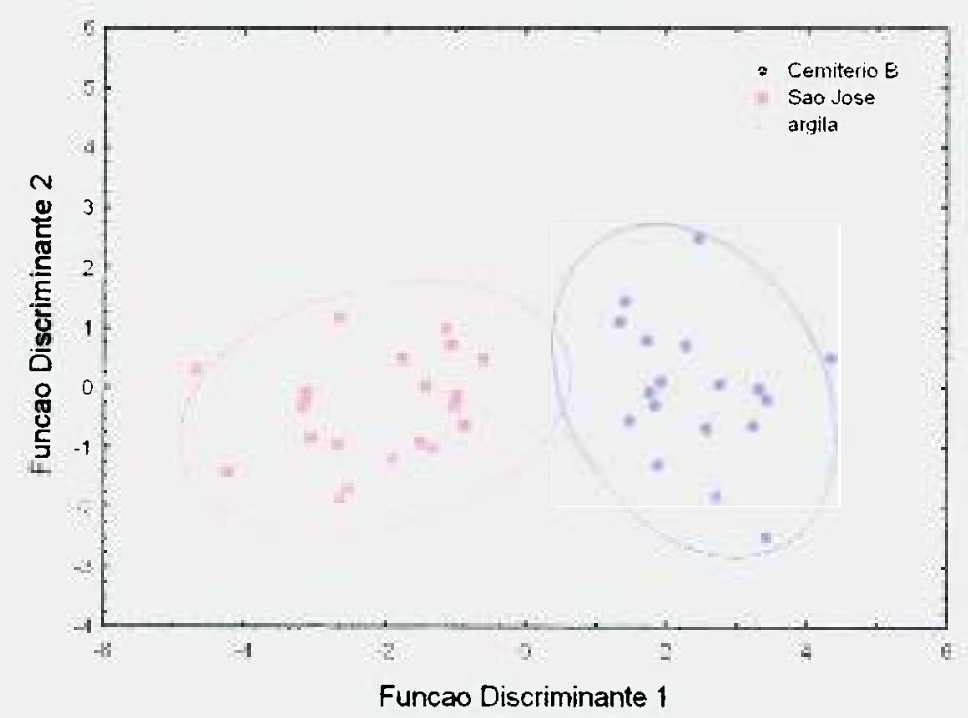

Figura 5.31 - função discriminante para a composição química elementar das cerâmicas do sitio .Justino (Cemitério B) e do sitio São José e argila, após correção com os fatores de diluições. As elipses representam regiōes nivel de confiança de 95\%. 
Realizou-se, também, uma análise discriminante passo-a-passo e obteve-se que todas as variáveis são relevantes para discriminação das cerâmicas do Cemitério $B$ e do sítio São José. Apesar desse resultado, observou-se que as diferenças padronizadas entre as composições quimicas elementares das cerâmicas dos dois sitios, com exceção dos elementos La, Th e Cr, são significativas (Figura 5.32).

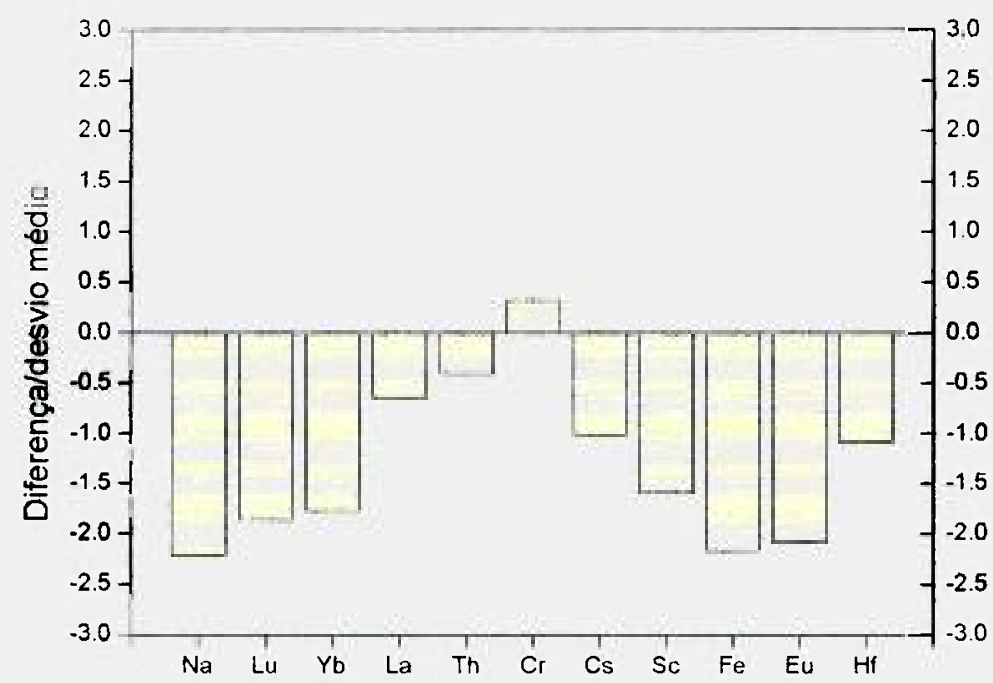

Figura 5.32 - Diferença padronizada entre as composiçõés quimicas médias das cerâmicas dos sitios São Jové e Justino (Cemitério B).

\subsubsection{Ocupações recentes: Comparação entre os sítios Porto Belo, Saco da Onça, Vitória Régia e Curituba}

Conforme citado, as ocupações ceramistas mais recentes em Xingó correspondem àquelas estabelecidas nos sitios Porto Belo, Saco da Onça, Vitória Régia e Curituba. Segundo resultados discutidos anteriormente, foi observado que a composição química das cerâmicas dos sitios Curituba e Saco da Onça são diferentes, apesar da ampla dispersão na concentração elementar das amostras do sitio Curituba. Visando obter um quadro geral em relação à composição quimica das cerâmicas dos quatro sítios mais recentes, a seguir, faz-se uma comparação entre as cerâmicas dessas ocupações.

Considerando a hipótese que as amostras de cerâmica dos quatro sítios de ocupação recente são distintas, em relação à composição quimica elementar, realizou-se uma análise discriminante. Na Figura 5.33, são mostrados os escores das funções discriminantes para os sitios Porto Belo, Saco da Onça, Curituba e Vitória Régia, onde fica evidente a superposição dos quatro grupos composicionais. Assim, não podemos inferir que as cerâmicas dos quatro sítios arqueológicos têm composições quimicas diferentes, 
uma vez que o número de classificações corretas foi baixo. Na Figura 5.33 fica nítida a distinção entre as composições químicas das cerâmicas dos sítios Curituba e Saco da Onça, já discutida anteriormente.

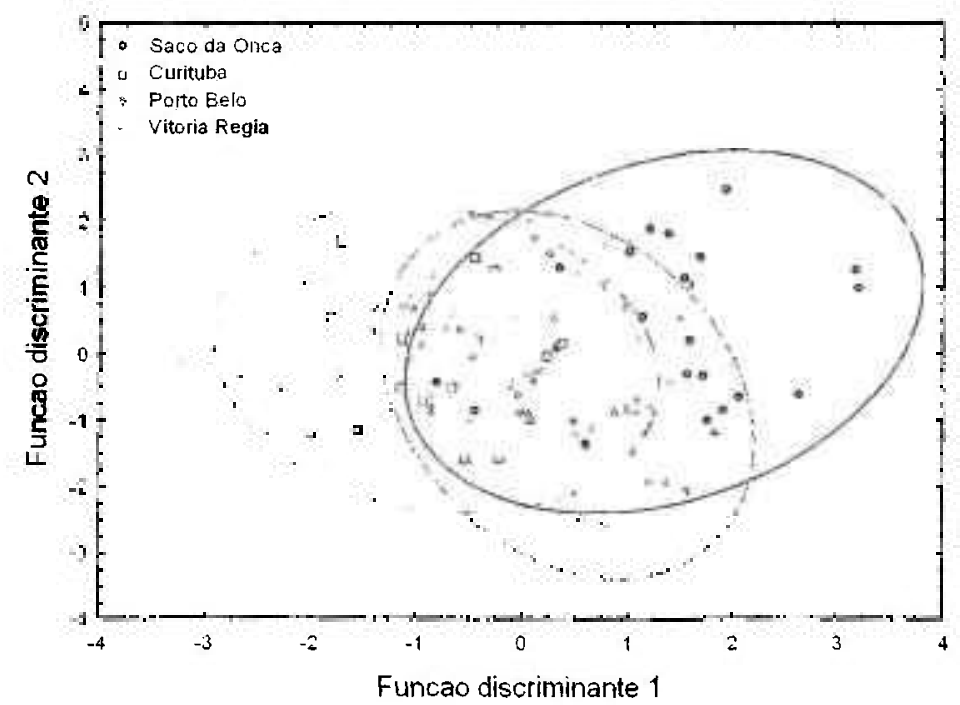


Onça. Curtuba. Porto Belo e Titoria Regia. As elipses representam regiós nivel de confiança de $9.5 " 1$.

Mesmo após correção das concentrações quimicas das amostras cerâmicas de acordo com seus respectivos fatores de diluição (Tabela 5.13 e 5.14), em relação ao centróide de cada sítio arqueológico, a superposição dos grupos composicionais no espaço das funções discriminantes ainda foi significativa (Figura 5.34). Embora seja nítida a superposição dos grupos, pode ser observado na Figura 5.34 que a dispersão do grupo cerâmico Saco da Onça é superior à dos outros grupos e, portanto, corrobora com a hipótese que a área desse sítio arqueológico foi utilizada por grupos ceramistas que estavam de passagem pelo local. Pelo contrário, as amostras dos sítios Curituba estão dispostas, na Figura 5.34, em uma pequena região do plano formado pelos dois eixos discriminantes, e, praticamente, isolada da região ocupada pelas amostras do sítio Saco da Onça. 
Tabela 5.14 - Concentração elementar média (M) das cerâmicas dos sitios Porto Belo e lituria Régia (I alores médios em ppm, exceto quando indicado, e desvio padrão em percentagem da média).

\begin{tabular}{|c|c|c|c|c|}
\hline & \multicolumn{2}{|c|}{ Porto Belo } & \multicolumn{2}{|c|}{ Vitória Régia } \\
\hline & $\begin{array}{l}\text { Sem correção } \\
(M \pm C V)\end{array}$ & $\begin{array}{c}\text { Com corrcção } \\
(f=0,91 \pm 0,16)^{*} \\
(M \pm C V)\end{array}$ & $\begin{array}{c}\text { Sem correção } \\
(M \pm C V)\end{array}$ & $\begin{array}{c}\text { Com correcão } \\
(f=0,96 \pm 0,07)^{*} \\
(M \pm C V)\end{array}$ \\
\hline $\mathrm{Na} \%$ & $1.93 \pm 0.40$ & $1.29 \pm(1.19$ & $1.77 \pm 0.30$ & $1.47 \pm 0.39$ \\
\hline Lu & $0.58 \pm 0.23$ & $0.55 \pm 0.16$ & $0.5(0 \pm 0.17$ & $0.55 \pm 0.42$ \\
\hline Yb & $3.66 \pm 1.37$ & $3.45 \pm 1.06$ & $3.59 \pm 1.34$ & $3.63 \pm 1.26$ \\
\hline $\mathbf{L a}$ & $51.95 \pm 22,25$ & $50.27 \pm 15.97$ & $+4.62 \pm 13.12$ & $+3,17 \pm 12.53$ \\
\hline Th & $11,20 \pm 5,41$ & $13.31 \pm 10.09$ & $11.19 \pm 4.29$ & $11.2+ \pm 4.14$ \\
\hline $\mathrm{Cr}$ & $25.92 \pm 11.51$ & $26.26 \pm 15.96$ & $+2.77 \pm 21.19$ & $+4.12 \pm 28,95$ \\
\hline Cs & $3.95 \pm 1,78$ & $+.13 \pm 2.18$ & $3.77 \pm 21.19$ & $4.03 \pm 2.03$ \\
\hline Sc & $14.08 \pm 5.44$ & $14.23 \pm 5.06$ & $14.67 \pm 5.01$ & $14.76 \pm 4.69$ \\
\hline $\mathrm{Fe} \%$ & $+.56 \pm 1.68$ & $4.57 \pm 1.33$ & $+.37 \pm 1.43$ & $4.42 \pm 1.30$ \\
\hline Eu & $2.23 \pm 0.77$ & $1.90 \pm 0.55$ & $1.98 \pm 0.61$ & $1.93 \pm 0.54$ \\
\hline Hf & $7.45 \pm 2.78$ & $6.37 \pm 1.66$ & $7 .+1+1.94$ & $6.95 \pm 1.67$ \\
\hline
\end{tabular}

${ }^{*} f$ representa o fator de diluição médio com o desvio padrão



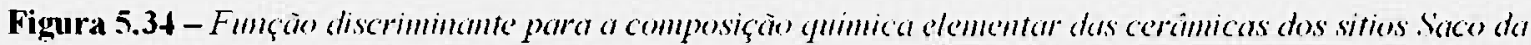


comficmcara $95 \%$.

De acordo com esses resultados, pode-se inferir que a pasta cerâmica dos sítios Porto Belo, Saco da Onça, Vitória Régia e Curituba são similares, quando observadas conjuntamente. Contudo, as amostras dos sitios Saco da Onça e Curituba são diferentes. Esses resultados nos leva a inferir que as fontes de matéria-prima desses sitios são, provavelmente as mesmas, ou/e as comunidades que ocuparam esses sítios compartilhavam a produção cerâmica. 


\subsubsection{Sítios de cronologias diferenciadas: Comparação entre os sítios Porto Belo, Justino (B) e Curituba}

Como já citado anteriormente, esperava-se uma diferenciarão nas composições químicas das cerâmicas de Xingó conforme a cronologia dos sítios arqueológicos, uma vez que a tecnologia de manufatura das cerâmicas sofre alteração no tempo, principalmente, em virtude das interações sócio-culturais e da disponibilidade de matéria-prima no local. Para tornar essa hipótese mais evidente, apresentam-se os resultados da análise comparativa, em relação à composição química elementar, das cerâmicas de três sítios de cronologias bastante diferenciadas: Sítio Justino (Cemitério B), Sítio Porto Belo e sítio Curituba, os quais correspondem às ocupações antiga, intermediária e nova, respectivamente.

$\mathrm{Na}$ Figura 5.35, mostram-se os escores das funções discriminantes, obtidas a partir das concentrações elementares corrigidas, para os três sítios. Observa-se que as amostras cerâmicas dos três sítios arqueológicos formam grupos composicionais distintos, confirmando a hipótese que mesmo sendo sítios localizados em uma mesma região, o processo de manufatura determina a composição química final da pasta cerâmica. Uma vez que o processo de obtenção dos artefatos cerâmicos muda no tempo, a pasta da cerâmica de Xingó sofrera alterações evidenciadas pela análise por ativação com nêutrons.

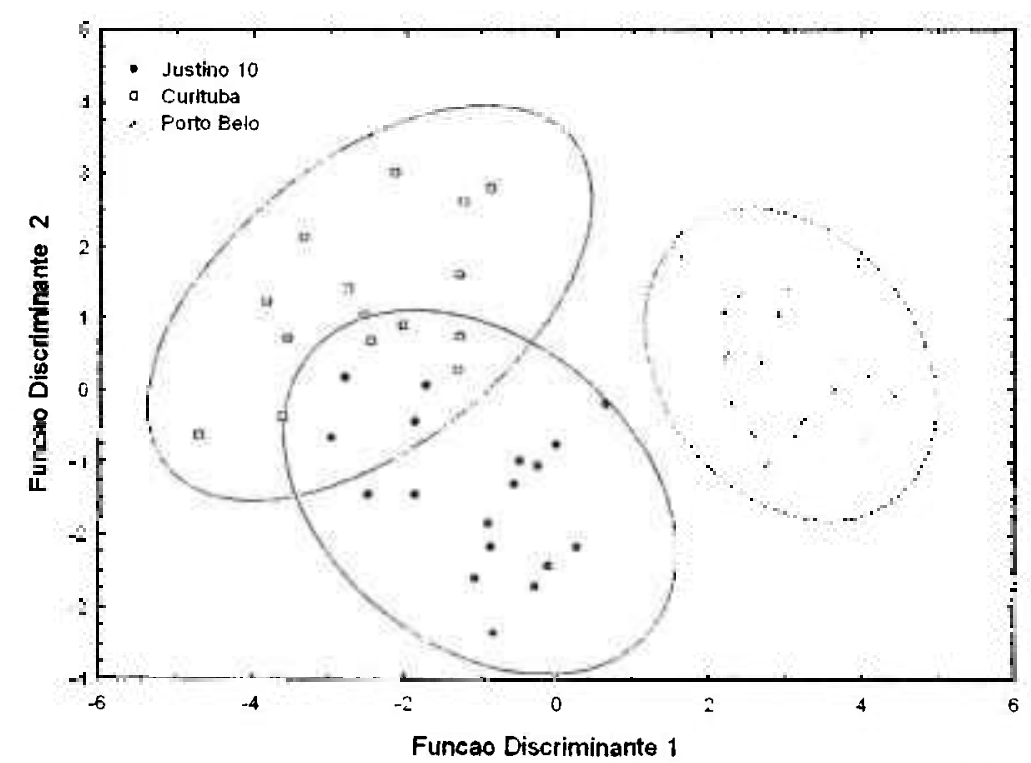

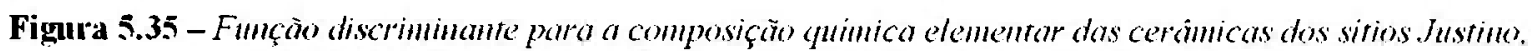



De acordo com a Figura 5.36, as diferenças mais significantes entre as composições químicas das cerâmicas dos sítios Curituba e Justino (Cemitério B) foram 
encontradas para os elementos $\mathrm{Na}, \mathrm{Lu}, \mathrm{Cs}$ e Eu. As diferenças mais notáveis na composição para as amostras dos sítios Porto Belo e Justino (Cemitério B), conforme a Figura 5.37, são em relação às concentrações de Na, Sc, Fe e Eu. Para os sítios Porto Belo e Curituba, as diferenças mais visíveis são nas concentrações de $\mathrm{Na}, \mathrm{Lu}$, Th e $\mathrm{Cr}$ (Figura 5.38).



Figura $\mathbf{5 . 3 6}$ - Diferenças padronizadas entre as composiçñes quimicas médias das cerâmicas dos sitios Justino (Cemitério B) e Curituba.

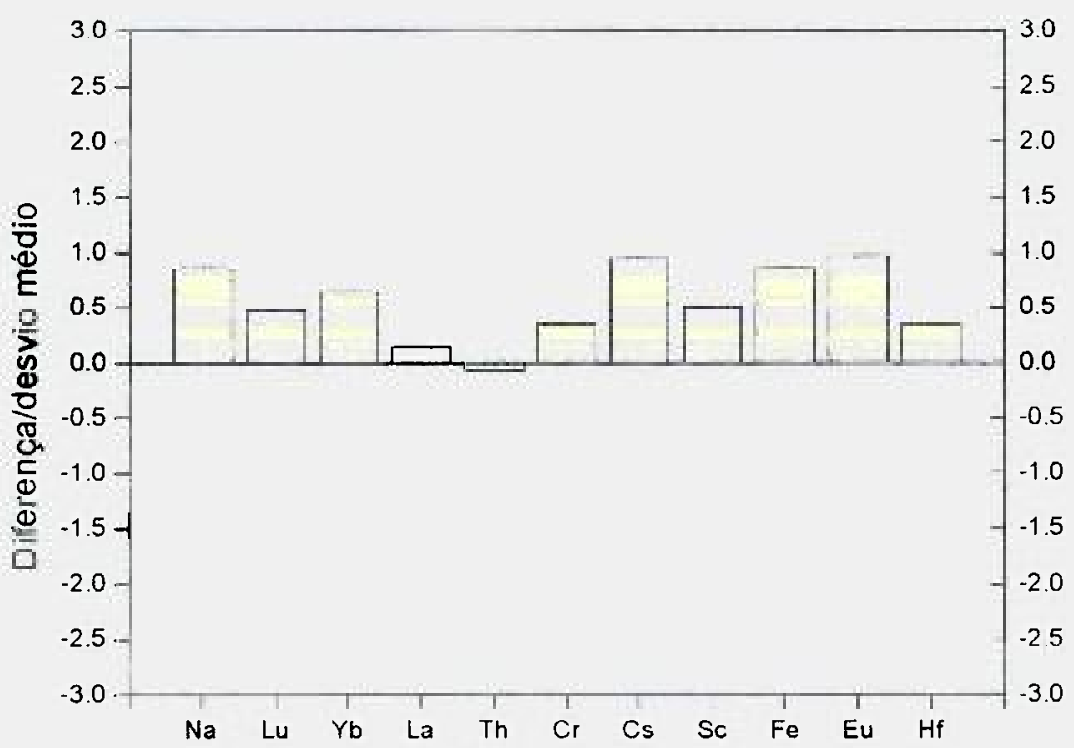

Elementos

Figura 5.37 - Diferença padronizada entre as composições quimicas médias das cerâmicas dos sitios Justino (Cemiterio Bi e P'orto Belo. 


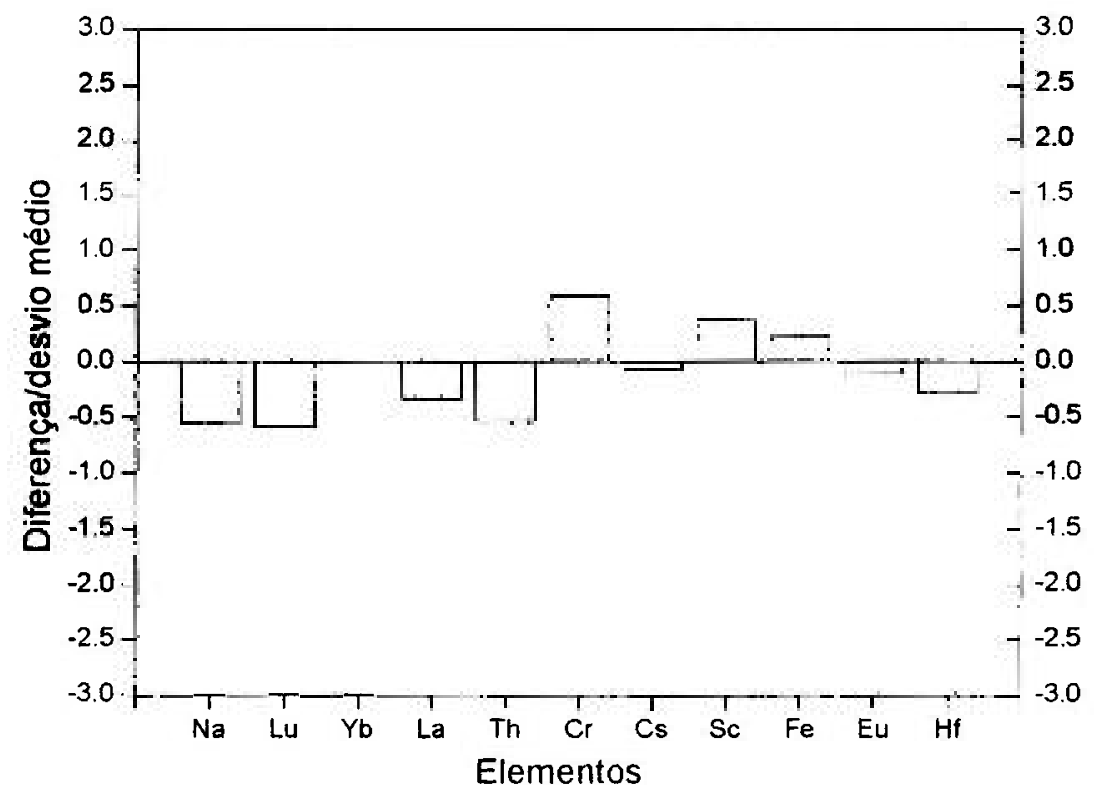

Figura 5.38 - Diferença padronizada entre as composições quimicas médias das cerämicas dos Curituba e Porto Belo.

\subsection{Datação Termoluminescente}

Para localização temporal e verificação da contemporaneidade do material cerâmico estudado, nove fragmentos cerâmicos foram datados por meio de técnicas termoluminescente: Justino (duas amostras), São José (uma amostra), Saco da Onça (uma amostra), Curituba (uma amostra), Vitória Régia (uma amostra) e Porto Belo (três amostras). O critério da escolha da amostra foi baseado na profundidade onde a amostra foi resgatada e no tamanho. Evitou-se datar as peças maiores uma vez que as mesmas serão utilizadas para reconstrução dos objetos cerâmicos no laboratório.

Nas Figuras 5.39 e 5.40 têm-se as curvas típicas de emissão TL do quartzo extraido de amostras cerâmicas dos sítios Justino e Porto Belo, tanto para o material natural quanto para o quartzo irradiado em fonte de ${ }^{90} \mathrm{Sr} /{ }^{90} \mathrm{Y}$. Os principais picos na curva de emissão TL das amostras do sítio Justino localizaram-se em $200^{\circ} \mathrm{C}$ e $320^{\circ} \mathrm{C}$ (Figura 5.39). Para as amostras do sítio Porto Belo, observou-se que os principais picos na curva de emissão são em $210^{\circ} \mathrm{C}$ e $280^{\circ} \mathrm{C}$. As outras amostras cerâmicas datadas correspondem aos sítios São José, Saco da Onça, Curituba e Vitória Régia. Essas apresentaram emissão termoluminescente nas mesmas temperaturas das amostras do sítio Porto Belo. 




Figura 5.39 - Curvas de emissões TL tipicas para amostras do sitio. Justino, natural e irradiada em ${ }^{90} \mathrm{Sr}{ }^{90} \mathrm{Y}$, com doses de $10,20,30$ e $40 \mathrm{GW}$.

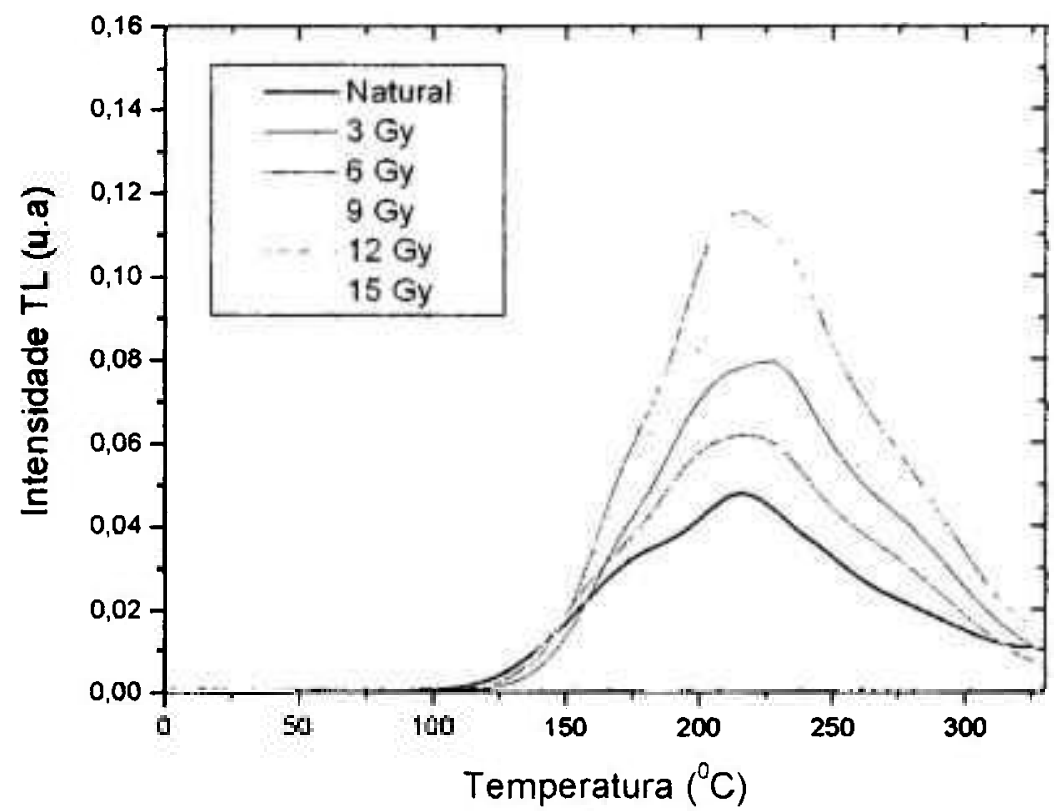

Figure 5.40 - Curvas de emissões TL tipicas para amostras do sitio Porto Belo, natural e irradiada em fonte ${ }^{90} \mathrm{Sr} /{ }^{(x)} \mathrm{Y}$, com doses de 3, 6, 9, 12 e $15 \mathrm{~Gy}$.

Para verificar os picos estáveis para datação das amostras cerâmicas, foi realizado o teste do platô (Aitken, 1985). Na Figura 5.41 é possivel visualizar que o platô se forma na curva no intervalo entre $225^{\circ} \mathrm{C}$ e $350^{\circ} \mathrm{C}$, aproximadamente. Conforme o teste, detectou-se que os picos de $320^{\circ} \mathrm{C}$ para o sítio Justino e o pico de $280^{\circ} \mathrm{C}$ para amostras dos outros sítios são estáveis para datação por técnicas TL. 


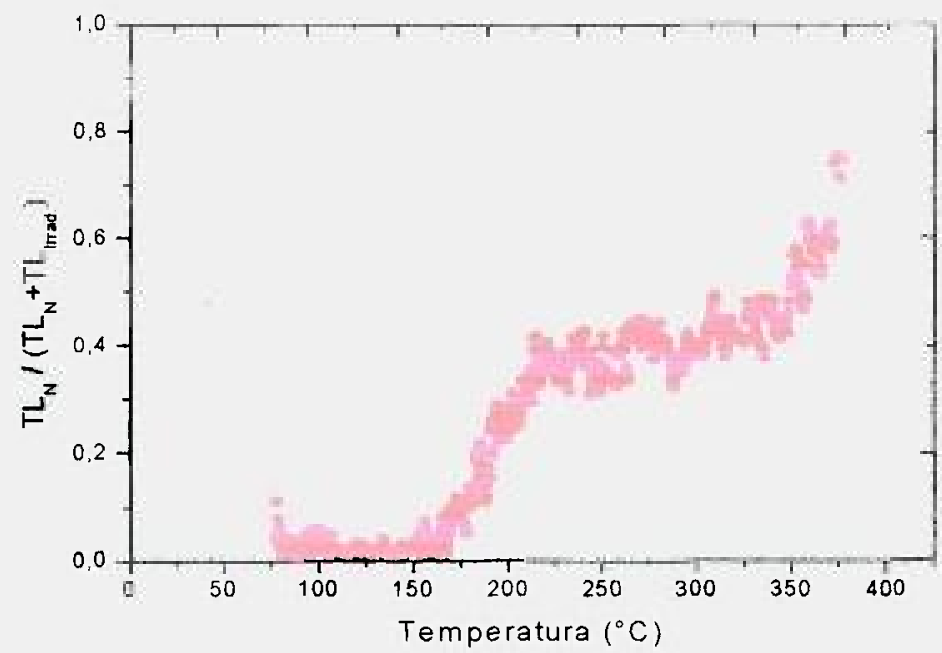

Figura 5.41 - Teste do plató para o quartzo de Xingó. Nesta cunva é traçado $T L_{N}\left(T L_{N}+T L_{\text {Irrad }}\right) X$ Temperatura, podemos observar que a partir de $225^{\circ} \mathrm{C}$ é verificada uma constancia na cuma.

A determinação das doses absorvidas pelas amostras durante o enterramento no sítio arqueológico, denominada de paleodose, foi calculada utilizando o método das doses adicionais (Wintle, 1997). Para cada amostra, foram obtidas cinco curvas de emissão para cada dose adicional. As intensidades médias das emissões termoluminescentes foram dispostas em um gráfico intensidade TL versus dose aditiva. Como exemplo, as Figuras 5.42 a 5.45 , mostram as intensidades médias da emissão TL para as amostras dos sitios Justino (Fase 15), Saco da Onça (Fase 06), Porto Belo (Fase 01) e Curituba (Fase 09).



Figura 5.42 - Resposta do pico $320^{\circ} \mathrm{C}$ TL em função das doses adicionais para o sitio Justino (Fase 




Figura 5.43 - Resposta do pico $280^{\circ} \mathrm{C}$ TL em função das doses adicionais para o sitio Saco da Onça (Fase 06)

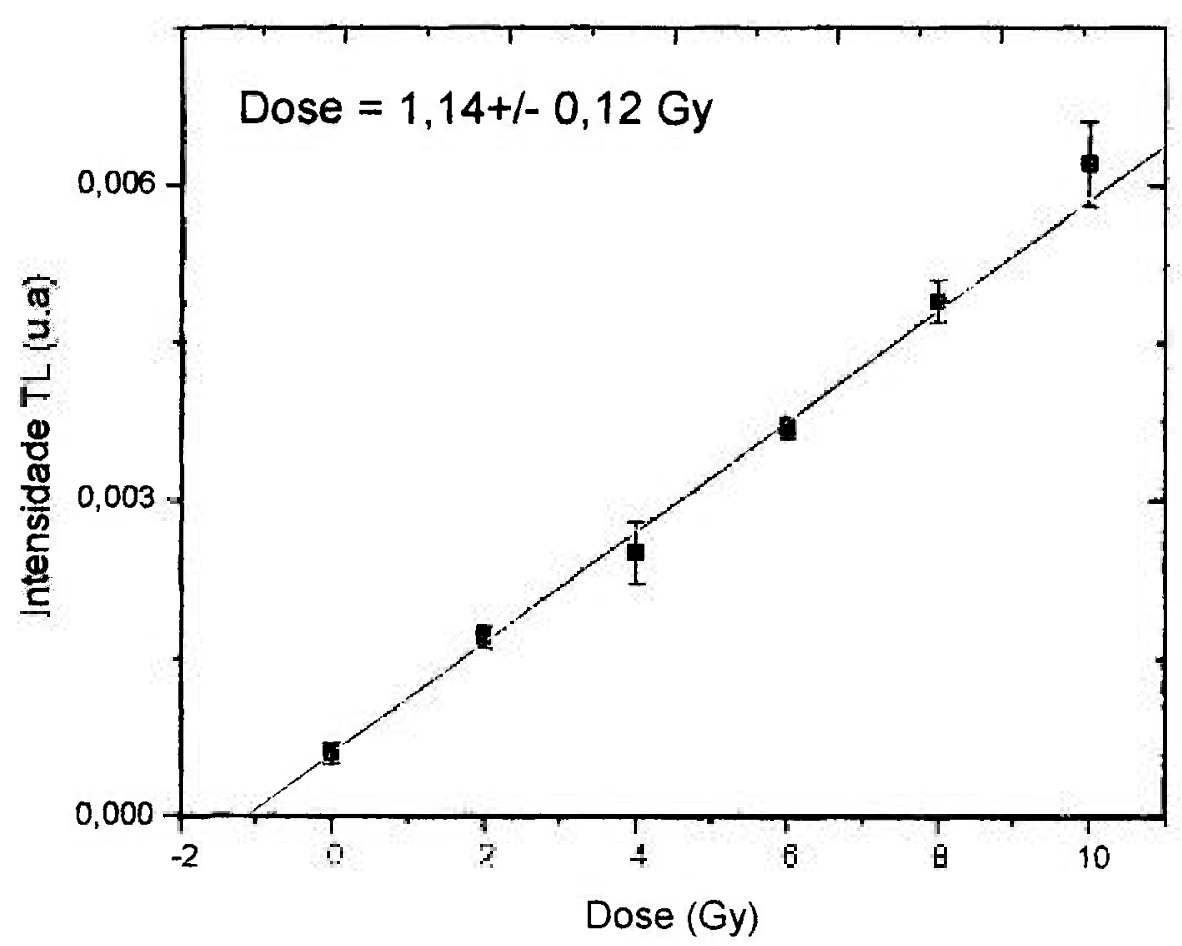

Figura 5.44 - Resposta do pico $280^{\circ} \mathrm{C}$ TL ém função das doses adicionais para o sitio Porto Belo (Fase 01) 




Figura 5.45 - Resposta do pico $280^{\circ} \mathrm{C}$ TL em função das doses adicionais para o sitio Curituba (Fase 09)

Para cada amostra, a paleodose foi determinada por meio de uma extrapolação linear da curva da intensidade TL em função da dose adicional. O ajuste linear se mostrou adequado uma vez que o coeficiente de determinação proveniente do modelo de regressão linear, para todos os casos, foi próximo de 1. Observou-se, também, a significância do coeficiente de correlação e, em todos os casos, a linearidade foi significante. Na Tabela 5.15 são mostradas as paleodoses para os sitios estudados. As incertezas associadas às paleodoses são referentes às incertezas associadas às medidas TL e às incerteza decorrentes das estimativas dos parâmetros do modelo de regressão linear. 
Tabela 5.15. Valores das paleodoses determinadas por TL.

\begin{tabular}{cc}
\hline Amostras & Paleodoses (Gy) \\
\hline Justino (Fase 15) & $10,90 \pm 0,40$ \\
Justino (Fase 04) & $5,91 \pm 0,21$ \\
Porto Belo (Fase 01) & $1,14 \pm 0,12$ \\
Porto Belo (Fase 03) & $1,75 \pm 0,04$ \\
Porto Belo (Fase 09) & $5,87 \pm 0,02$ \\
São José (Fase 04) & $3,61 \pm 0,13$ \\
Curituba (Fase 09) & $4,90 \pm 0,80$ \\
Saco da Onça (Fase 06) & $3,11 \pm 0,07$ \\
Vitória Régia (Fase 06) & $5,35 \pm 0,15$ \\
\hline
\end{tabular}

A dose anual de radiação foi determinada de acordo com Ikeya (1993), considerando-se as concentrações de ${ }^{238} \mathrm{U},{ }^{232} \mathrm{Th}$ e ${ }^{40} \mathrm{~K}$ das amostras cerâmicas e sedimentos, os que são responsáveis pela irradiação das amostras. As concentrações desses elementos nas amostras cerâmicas e sedimentos foram determinadas por meio da análise por ativação com nêutrons, e apresentadas na Tabela 5.16, juntamente com as taxas anuais de radiação. Para o cálculo das taxas anuais de radiação, considerou-se que as concentrações médias de ${ }^{238} \mathrm{U}$ e ${ }^{232} \mathrm{Th}$ no solo foram $3,25 \pm 0,95 \mathrm{ppm}$ e 1,05 $\pm 0,01 \mathrm{ppm}$, respectivamente. Considerou-se, ainda, que a contribuição da radiação cósmica para taxa anual de radiação foi de $0,25 \mathrm{mG} /$ ano. 
Tabela 5.16. Concentraçòes de ${ }^{23 x} U,{ }^{272} T h e^{4 \prime \prime} K$ nas amostras datadas neste trahalho e as taxas anuais para determinaçào das idades dos fragmentos cerâmicos.

\begin{tabular}{lllll}
\hline Amostra & Th (ppm) & U (ppm) & K (\%) & Taxa (mGy/ano) \\
\hline Justino (Fase 15) & $8,5 \pm 0,7$ & $2,4 \pm 0,5$ & $2,1 \pm 0,6$ & $2,78 \pm 0,53$ \\
Justino (Fase 04) & $11,6 \pm 0,32$ & $3,1 \pm 0,73$ & $1,68 \pm 0,33$ & $2,63 \pm 0,31$ \\
Porto Belo (Fase 01) & $16,26 \pm 0,85$ & $1,93 \pm 0,29$ & $1,86 \pm 0,20$ & $2,86 \pm 0,18$ \\
Porto Belo (Fase 03) & $9,05 \pm 0,48$ & $1,70 \pm 0,51$ & $2,36 \pm 0,60$ & $2,95 \pm 0,42$ \\
Porto Belo (Fase 09) & $5,72 \pm 0,32$ & $0,74 \pm 0,24$ & $2,55 \pm 0,30$ & $2,85 \pm 0,27$ \\
São José (Fase 04) & $8,80 \pm 0,28$ & $5,60 \pm 0,29$ & $2,15 \pm 0,53$ & $3,22 \pm 0,47$ \\
Curituba (Fase 09) & $5,47 \pm 0,64$ & $3,40 \pm 0,80$ & $2,35 \pm 0,31$ & $2,98 \pm 0,38$ \\
Saco da Onça (Fase 06) & $7,65 \pm 0,44$ & $1,79 \pm 0,20$ & $1,36 \pm 0,30$ & $2,01 \pm 0,27$ \\
Vitória Régia (Fase 06) & $9,35 \pm 0,38$ & $1,07 \pm 0,35$ & $1,73 \pm 0,45$ & $2,33 \pm 0,39$ \\
\hline
\end{tabular}

Com os valores das paleodoses e das taxas anuais de radiação, foram determinadas as idades dos fragmentos cerâmicos de acordo com a Equação 3.4. A Tabela 5.17 mostra os valores das datações das amostras. As incertezas são relacionadas às incertezas da determinação da taxa anual de radiação a da paleodose.

Tabela 5.17. Valores de idades calculadas para os fragmentos cerâmicos estudados.

\begin{tabular}{cc}
\hline Amostra & Idades (Antes do Presente - AP) \\
\hline Justino (Fase 15) & $3.865 \pm 398$ \\
Justino (Fase 04) & $2.191 \pm 276$ \\
Porto Belo (Fase 01) & $342 \pm 51$ \\
Porto Belo (Fase 03) & $537 \pm 85$ \\
Porto Belo (Fase 09) & $2.003 \pm 195$ \\
São José (Fase 04) & $1.065 \pm 164$ \\
Curituba (Fase 09) & $1.588 \pm 140$ \\
Saco da Onça (Fase 06) & $1.491 \pm 210$ \\
Vitória Régia (Fase 06) & $2.240 \pm 389$
\end{tabular}

As incertezas associadas são em média de $13 \%$ do valor idade calculada. Para reduzir essas incertezas, sugere-se a realização de uma dosimetria ambiental na área, por meio da utilização de dosímetros TL, os que devem ser fixados no solo por um período 
mínimo de um ano. Este trabalho tem sido desenvolvido em colaboração com o grupo de datação da Universidade Federal de Sergipe.

A qualidade dos resultados referentes às datações TL, pode ser testada por meio da comparação dos valores obtidos com algumas datações determinadas por meio de ${ }^{14} \mathrm{C}$ em esqueletos ou carvão de fogueira, encontrados nos mesmos niveis dos sítios estudados. Datações obtidas no sítio Justino, por exemplo, registraram 1280 445 AP (Lyon 5750) e $3270 \pm 135 \mathrm{AP}$ (Lyon 5752) para as fases 03 e 13, respectivamente, e os resultados obtidos neste trabalho para fases 04 e 15 , registraram $2191 \pm 276 \mathrm{AP}$ e $3865 \pm 398 \mathrm{AP}$.

De acordo com as datações obtidas neste trabalho, juntamente com outras datações obtidas em trabalho anterior (Sousa, et al., 2006; Santos, 2002), as que indicaram $5500 \pm 980$ AP, $4310 \pm 800$ AP, $2720 \pm 620$ AP e $2010 \pm 430$ AP para os sítios Justino, Fases 20,13, 10 e 08, respectivamente.

Os resultados das datações sugerem que a ocupação ceramista da região correspondente ao sítio Justino é uma das mais antigas do Nordeste brasileiro e a mais antiga dos sítios estudados no trabalho. A segunda ocupação mais antiga se refere ao sítio São José, uma vez que na fase 04 a datação é da ordem da idade encontrada nos mesmos níveis, e até em níveis mais profundos, de outros sítios da região. As primeiras fases do sítio Porto Belo tiveram suas cerâmicas localizadas em um período bastante recente, mas a datação da amostra resgatada em uma profundidade maior (Fase 09) mostra que este sítio teve uma ocupação anterior às ocupações dos sítios Saco da Onça e Curituba. Assim, os resultados estão corroborando com as hipóteses sugeridas por Luna (2006) a respeito da dinâmica de ocupação da área por populações ceramistas.

Entretanto, sugere-se que seja ampliado o número de amostras datadas de outros sítios da área, com amostras de várias profundidades, de forma que seja possível entender com mais precisão a dinâmica de ocupação da região no passado.

\subsection{Temperatura de queima e composição mineralógica}

Com o objetivo de estudar alguns aspectos da tecnologia de manufatura das cerâmicas produzidas pelas comunidades que ocuparam a região de Xingó, principalmente, as características da queima, neste trabalho alguns fragmentos cerâmicos foram analisados em relação à sua composição mineralógica.

Nas Figuras 5.46 a 5.49 são apresentados alguns difratogramas de amostras analisadas. Uma análise qualitativa dos difratogramas permitiu identificar que os minerais da pasta cerâmica dos sítios de Xingó são similares e, apresentam, basicamente, quartzo 
$(\mathrm{Q})$, feldspato $(\mathrm{F})$, mica $(\mathrm{M})$ e traços de outros minerais. Em alguns casos foi possível identificar a presença de caulinita $(K)$. Acredita-se que estes minerais não foram adicionados pelo ceramista durante a confecção dos objetos, uma vez que a matéria-prima da área apresenta uma fração significativa, e a adição poderia reduzir a plasticidade a tal ponto de tornar impraticável a manufatura de cerâmica (Vergne \& Fagundes, 2006).

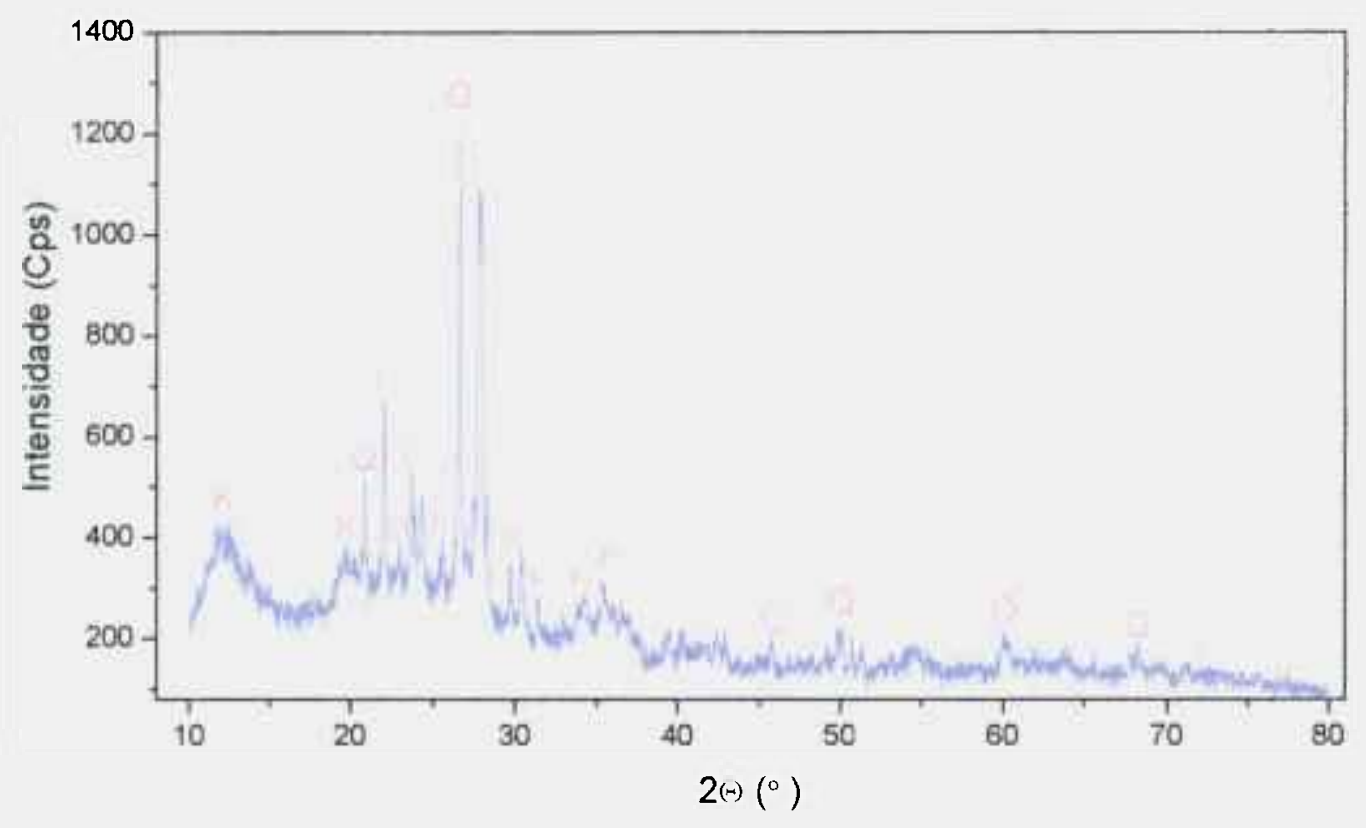

Figura 5.46 - Difratograma para amostra cerämica do sitio Justino (Cemitério B).

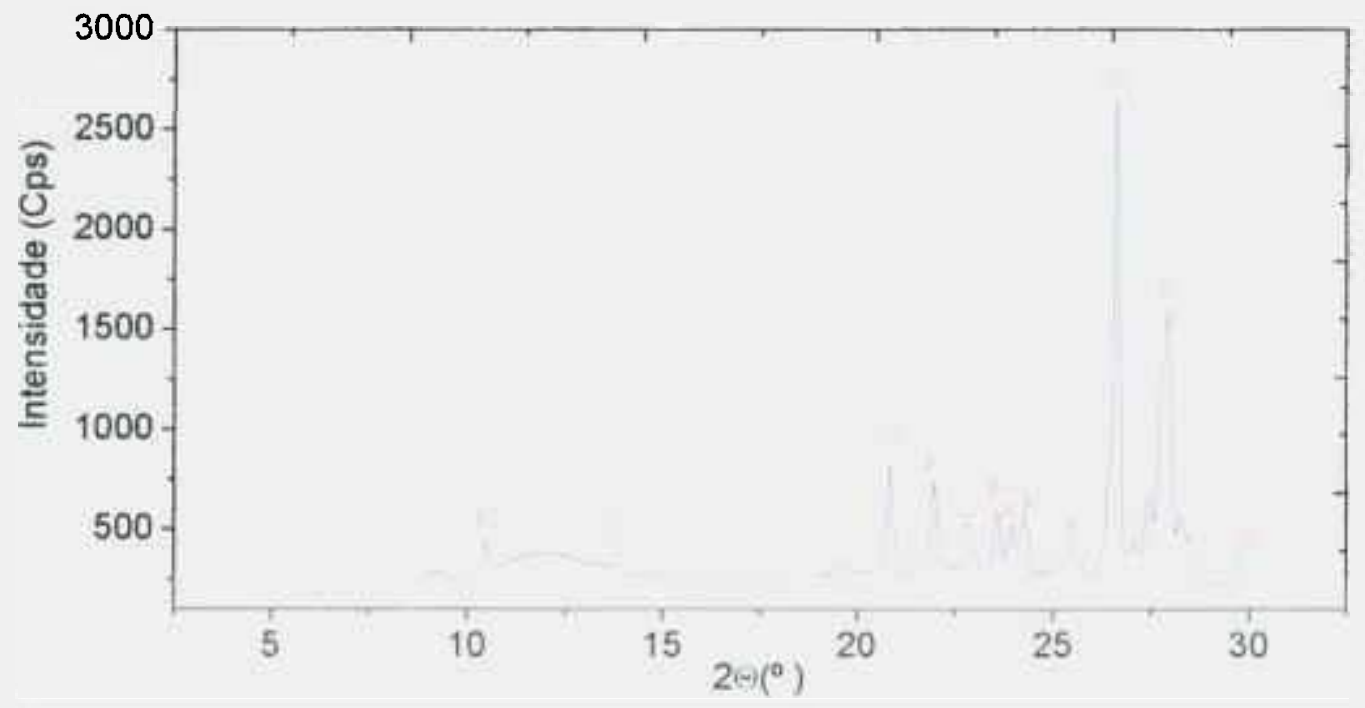

Figura 5.47-Difratograma para amostra cerâmica do sítio Justino (Cemitério C). 


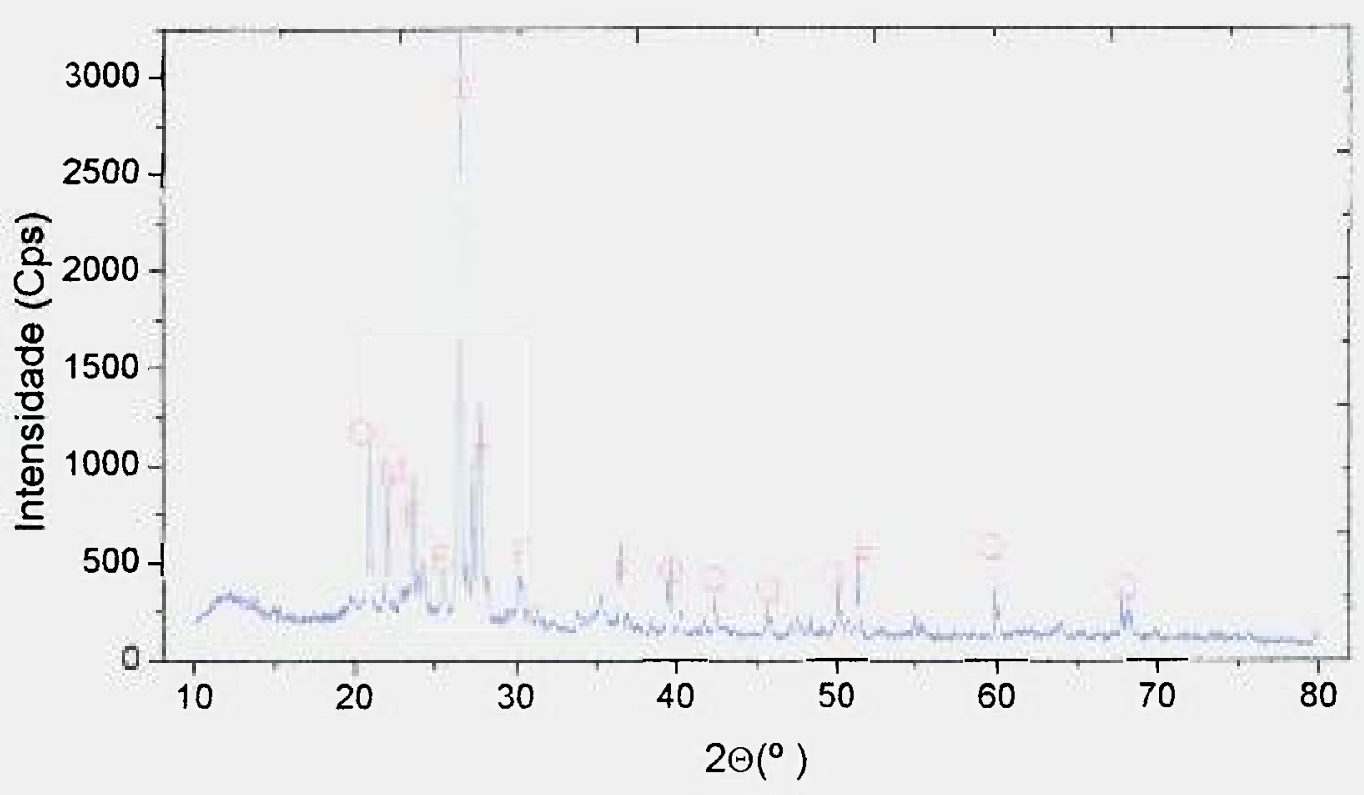

Figura 5.48 - Difratograma para amostra cerâmica do sitio São José.



Figura 5.49 - Difratograma para amostra cerâmica do sitio Curituba

A temperatura de queima da cerâmica pode ser determinada pela presença ou não de determinados minerais, tendo em vista as diversas transições das fases cristalográficas assumidas por estes minerais em função da temperatura. Por exemplo, a presença de caulinita indica que a cerâmica teve uma temperatura de queima inferior a 550 ${ }^{\circ} \mathrm{C}$ (Moropoulou et al., 1995). Logo, a ausência do pico da caulinita em vários fragmentos indica que a temperatura de queima da cerâmica em Xingó, na maioria das vezes, ultrapassou $550^{\circ} \mathrm{C}$.

Todavia, as presenças dos picos da caulinita em alguns difratogramas obtidos indicam que estes artefatos cerâmicos foram queimados em temperatura inferior a $550^{\circ} \mathrm{C}$. 
Estes fragmentos, onde se identificou caulinita, são amostras que apresentam bastante fragilidade quando sujeitos aos esforços mecânicos. Este comportamento é característico de objetos que sofreram uma queima incompleta, $\mathrm{cm}$ atmosfera parcialmente oxidante. As observações da seção transversal destes fragmentos mostram variações cromáticas bastante acentuadas, as quais reforçam as afirmações anteriores. Esta condição de queima, de uma forma geral, é encontrada em queimas processadas em fogueira a céu aberto. 


\section{CONCLUSÕES}

A qualidade analítica dos dados gerados por análise por ativação com nêutrons, referentes ao estudo composicional das cerâmicas de Xingó, foi adequada com a precisão analítica desejável para estudos das composições químicas elementares de cerâmicas arqueológicas e estudos de proveniência. Para diversos elementos, sobretudo para elementos traços, os coeficientes de variação distribuíram-se bastante próximos de $5 \%$, os quais estão abaixo de $10 \%$. Por meio dos Z-scores e da comparação dos valores obtidos neste trabalho com os obtidos por outros autores, observou-se que a metodologia empregada na análise das cerâmicas estudadas tem uma qualidade analítica comprável às publicadas na literatura.

Conforme os resultados da análise por ativação com nêutrons, verificou-se que após transformação logarítmica os dados apresentaram uma distribuição normal, isto é, a distribuição univariada dos dados é lognormal. Entretanto, observou-se que a distribuição conjunta dos resultados não é lognormal, conforme a extensão do teste de Shapiro-Wilks, o que não implica em grandes prejuízos na análise composicional de cerâmicas.

Foi possível identificar as amostras discrepantes, por sítio estudado, por meio da aplicação das distâncias Mahalanobis clássica e robusta. A distância Mahalanobis robusta mostrou-se mais adequado para a identificação das amostras aberrantes, uma vez que é um método mais restritivo. Estas amostras classificadas como aberrantes, podem se tratar de cerâmicas inclusivas, as quais indicam interações entre comunidades.

A aplicação das técnicas de estatística multivariada, tais como análise das componentes principais, análise de agrupamento e análise discriminante, permitiu a identificação de diversos grupos composicionais. No sítio Justino foram identificados dois grupos distintos, correspondentes aos Cemitérios B e C. A composição química elementar das amostras do Cemitério $\mathrm{C}$ é mais dispersa que as amostras do Cemitério B. Essta homogeneidade das amostras do Cemitério B indica uma evolução tecnológica no preparo da pasta cerâmica ao longo dos anos.

A correção das concentrações obtidas por meio do filtro Mahalanobis modificado permitiu a formação dos grupos composicionais com menor dispersão e, conseqüentemente, uma melhor resolução dos grupos cerâmicos formados. 
De uma forma geral as distinções entre os grupos composicionais estão correlacionados com os períodos de ocupação dos sítios. Esta afirmação pode ser observada, por exemplo, por meio da visualização dos resultados referentes aos sítios São José, Curituba e Saco da Onça. A distinção entre as composições dos sítios São José e Curituba é claro, enquanto que as amostras do sítio Saco da Onça dispersaram-se nos outros dois grupos. Esta dispersão confirma a hipótese que o sítio Saco da Onça se trata de um sítio de acampamento.

Conforme o teste do platô, verificou-se que os picos de $320^{\circ} \mathrm{C}$ e $280^{\circ} \mathrm{C}$ são estáveis para datação termoluminescente. Observou-se que o ajuste linear foi adequado para extrapolação da curva intensidade TL em função da dose de radiação adicional. De acordo com as concentrações de ${ }^{238} \mathrm{U},{ }^{232} \mathrm{Th}$ e ${ }^{40} \mathrm{~K}$ nas amostras cerâmicas datadas e dos sedimentos, obteve-se que as taxas anuais de radiação recebidas pelas amostras distribuemse na faixa de 2,01 - 3,22 mGy/ano. As idades obtidas para os fragmentos, mostraram que o sítio Justino corresponde a uma das mais antigas ocupações ceramistas do Nordeste brasileiro. Juntamente com outras datações obtidas pelo autor deste trabalho, verifica-se, também, a contemporaneidade de algumas das fases do sítio São José com o Justino. Os outros sítios datados mostram-se serem ocupados mais recentemente que esses dois primeiros, inclusive, com ocupações situadas em um período histórico.

Os resultados dos estudos da mineralogia dos vestígios cerâmicos mostraram que as cerâmicas de Xingó apresentam, qualitativamente, composições similares, onde os principais constituintes são quartzo, feldspato, mica, traços de outros minerais e em alguns casos caulinita. Uma vez que a matéria-prima encontrada na área apresenta bastante quantidade de antiplásticos, encontrou-se que não foram adicionados pelos ceramistas durante a confecção dos utensílios cerâmicos, sendo, portanto, de ocorrência natural. A queima da cerâmica, provavelmente, se processou à temperatura um pouco superior a 550 ${ }^{\circ} \mathrm{C}$. Diversos fragmentos dos sítios São José e Justino, associados aos enterramentos, apresentaram o pico da caulinita, indicando que a queima foi incompleta e abaixo de $550^{\circ} \mathrm{C}$.

De acordo com os resultados obtidos, foi possível realizar associações entre os materiais cerâmicos estudados neste trabalho com hipóteses da ocupação da região de Xingó, conforme considerações do ponto de vista arqueológico e, dessa forma, fornecendo contribuições significativas para esclarecimento das questões referentes à dinâmica de ocupação da região do baixo São Francisco no passado. 


\section{SUGESTÕES PARA TRABALHOS FUTUROS}

- Estudo de outras formas de normalização dos dados, por exemplo, uma transformação Box - Cox para dados multivariados;

- Aplicação completa do filtro de Mahalanobis modificado para formação de grupos composicionais, sem considerações apriorísticas de informações arqueológicas. Este procedimento visa a alocação das amostras consideradas atípicas, que será fundamental para identificar interações culturais entre as populações ceramistas da área;

- Aumentar o número de amostras analisadas por análise por ativação neutrônica, aumentado o universo amostral por sítio e inclusão de outros sítios locais de Xingó, bem como outros sítios localizados no curso do rio São Francisco. Isto permitirá auxiliar no entendimento da penetração do homem pré-histórico na região do Baixo São Francisco;

- Aplicação de métodos de inteligência artificial, como redes neurais, para classificação dos grupos composicionais. Após definição de grupos químicos de referência, este procedimento se mostra mais rápido para identificação do grupo à qual a amostra cerâmica analisada pertence;

- Estudo de parâmetros que influenciam nas datações TL, tais como supralinearidade da curva de intensidade em função da dose e taxas anuais de radiação, com o objetivo de reduzir as incertezas nas idades obtidas;

- Obtenção de uma cronologia mais completa dos sítios estudados e de outros sítios ao longo do curso do rio São Francisco, por meio de TL;

- Estudo da mineralogia por outras técnicas, tais como microscopia petrográfica e ressonância paramagnética eletrônica. 
- Ensaios mecânicos com alguns fragmentos para identificação de informações macroscópicas a respeito da produção cerâmica de Xingó, tal como resistência mecânica do utensílio e sua relação com a técnica de manufatura. 


\section{REFERÊNCIAS BIBLIOGRÁFICAS}

AB'SABER, A.N. $O$ homem dos terraços do Xingó. Documento 06, UFS/PAX/PETROBRAS/CHESF, 1997.

AGUllo-LOPEZ, F., CATLOW, C.R.A., TOWSEND, P.D. Point defects in Materials. London: Academic Press, 1998.

AITKEN, M. J. Thermoluminescence Dating. Academic Press, London, 1985.

AITKEN, M.J., TITE, M.S., REID, J. Thermoluminescence dating of ancient ceramics. Nature, 202, $1032-1033,1964$.

AITKEN, M.J., ZIMMERMAN, D.W., FLEMING, S.J. Thermoluminescence dating of ancient ceramics. Nature, 219, $442-4441968$.

ALAMIN, M. B., SPYROU, N. M. Semi-empirical determination of detector absolute efficiency in INAA of voluminous samples. Journal of Radioanalytical and Nuclear Chemistry, 215 (2), $205-209,1997$.

ALBERS, A. P. F., MELCHIADES, F. G., MACHADO, R. BALDO, J. B. BOSCHI, A. O. Um método simples de caracterização de argilominerais por difração de raios-x. Cerâmica, 48(305), 34 - 37, 2002.

AMBROSIMO, G., PINDRUS, P. Nondesctructive analysis of ancient metallic objects. Rev. Metall, 50, 136, 1953.

AYALON, A., BAR-MATTHEWS, M., GOREN, Y. Authenticity examination of the inscription on the ossuary attributed to James, brother of Jesus. Journal of Archaeological Science, 31, 1185-1189, 2004.

BAFFA, O., KINOSHITA, A., FIGUEIREDO, A.M.G., BRUNETTI, A., GINESU, S. ESR dating of an ancient goat tooth from Nouro, Sardinia, Italy. Radiation Protection Dosimetry , 118, 1-4, 2006.

BALLA, M. Provenance study of Qumran pottery by neutron activation analysis. Phd. Thesis, Technical University of Budapest, Budapest, 2005.

BALLA, M., MOLNAR, Z., KOROS, A. Uncertainty budget and validation of NAA using reference materials. Journal of Radioanalytical and Nuclear Chemistry, 259 (3), $395-400$, 2004.

BARROSO, L.P., ARTES, R. Análisc Multivariada. 1. ed. Lavras: Região Brasileira da Sociedade Internacional de Biometria, 2003. v.1. 150p. 
BAXTER, M.J., JACKSON, C.M. Variable selection in artifact compositional studies. Archaeometry, $253-268,2001$.

BAXTER, M. J. Detecting multivariate outliers in artefact compositional data. Archaeometry, 41 (2), 321 - 338, 1999.

BAXTER, M.J. Stepwise Discriminant Analysis in Archacometry: a Critique. Journal of Archaeological Science, 21, 659-666, 1994.

BECKMAN, R. J., COOK, R. D. Outlier. Technometrics, 25 (2), 119 - 163, 1983.

BEIER, T. MOMMSEN, H. Modified Mahalanobis Filters for grouping pottery by chemical composition. Archaeometry, 36(2), 287 -306, 1994.

BELISÁRIO, R. Carbono 14 não é o único método de datação. Com Ciências Arqueologia e Sítios Arqueológicos, 2003. Disponível em: $<$ http://www.comciencia.br/reportagens/arqueologia/arq06.shtml. Acessado em 07 de janeiro de 2007.

BERTElle, M., CALOGERO, S., ODDONE, M., SALERNO, R., SEGNAN, R., STIEVANO, L. Firing techniques of the impasti from the prehistoric site of Concordia Sagittaria (Venice). Journal of Cultural Heritage, 1, 261 - 279, 2000.

BISHOP, R.L., BLACKMAN, M.J. Instrumental neutron activation analysis of archacological ceramics: scale and interpretation. Accounts of Chemical Research, 35(8), $603-610,2002$.

BISHOP, R. L. RANDS, G. R. HALLEY. Ceramic compositional analysis in: archaeological perspective. In: Advances in Archaeological Method and Theory, M. B. Schiffer (ed), 5 (1982) 275, New York, Academics Press

BONA, I.A.T., SARKIS, J.E.S., SOARES, A.L.R. Assinaturas quimicas cm cerâmicas Guarani do Rio Grande do Sul. In: XIII Congresso da Sociedade de Arqueologia Brasileira, Campo Grande , 03 - 08 setembro, volume 1, 50-52, 2005.

BORONE, G., IOPPOLO, S., MAJOLINO, D., MIGLIORDO, P., TIGANO, G. $A$ multidisciplinary investigation on archaeological excavation in Messina (Sicily), a comparison of pottery findings in the "The Strati of Messina area". Journal of Cultural Heritage, 3(2) 145-153, 2002.

BROEKMANS, T., ADRIAENS, A., PANTOS, E. Analytical investigations of cooking pottery from Tell Beydar (NE-Syria). Nuclear Instruments and Methods in Physics Research Section B-Beam Interactions with Materials and Atoms, 226 (1-2), 92-97, 2004.

CALDERÓN, V. Contribuição para o conhecimento da arqueologia do Recôncavo e do Sul do Estado da Bahia. Programa Nacional de Pesquisas Arqueológicas, Resultados Preliminares do Quinto Ano 1960 - 1970. Publicações Avulsas n²6, Belém: Museu Paraense Emilio Goeldi, 141 - 154, 1974. 
CALZA, C., ANJOS, M., SOUZA, S.M.F.M., BRANCAGLION, A., LOPES, R.T. Pigments analysis in cartonage of an Egyptian mummy of the Roman period using X-ray fluorescence spectrometry. Journal of Biological Research, 80, 136-138, 2005.

CARVALHO, O.A., QUEIROZ, A.N. Informações tafônicas da coleção paleoantropológica de Xingó, Brasil, como subsídio à compreensão de processos culturais. CLIO - Série Arqueológica, 2, 148 - 174, 2005.

CHEN, U. Physicochemical compositional analysis of ceramics: A case study in Kenting, Taiwan. Archaeometry, 48(4), 565 - 580, 2006.

CULLITY, B. D. Elements of $X-$ ray diffraction. Second edition. Addison - Wesley Publishing Company: Menlo Park, 1978.

DANIELS, F., BOYD, C.A., SAUNDERS, D.F. Thermoluminescence as a Research Tool. Science, $117,343-349,1953$.

DANTAS, V.J. Pausa para um banquete: análise dos marcos de uso em vasilhames cerâmicos pré-históricos do sitio Justino, Canindé do São Francisco - Dissertação de Mestrado apresentada ao Núcleo de Pós-graduação em Geografia da UFS (2005).

DOORYHEE, E., TAMURA, N., GOUDEAW, P., SCHIAN, P. Micro scanning X-ray diffraction study of Galla Roman Terra Sigillata ceramics. Applied Physics A: Materials Science \& Processing, 83(2), 219 - 224, 2006.

ETCHEVARNE, C. Sitios dunares: contribuição à arqueologia do sub-médio São Francisco - Dissertação de Mestrado apresentada ao programa de Mestrado em Arqueologia da USP, 1991.

FARIA, D.L.A, EDWARDS, H.G.M., AFONSO, M.C. Raman spectroscopic analysis of a tembetá: a resin archaeological artifact in need of conservation. Spectrochimica Acta, 34. $189-193,2004$.

FARIA, D.L.A, EDWARDS, H.G.M., AFONSO, M.C. Espectroscopia raman: uma nova luz no estudo de bens culturais. Revista do Museu de Arqueologia e Etnologia da USP, 12, $1505,2003$.

FELICISSIMO, M.P, PEIXOTO, J,L., BARBOSA, M.S., DERMOTIER, G., , PIREAUX, J.J., RODRIGUES, U.P. PIXE and PIGE analysis of Pre-colonial pottery from pantanal MS, Brazil. Journal of Radioanalytical and Nuclear Chemistry, 209-217 (1), 2005.

FELICISSIMO, M. P., BITTENCOURT, C., HOUSSIAU, L., TOMASI, R., RODRIGUES, U. P., PIREAUX, J.J. Additive dispersion in ancient ceramics from Pantanal by SEM, EDS and ToF-SIMS: A study of shards tensile strength. In: $13^{\text {th }}$ European Microscopy Congress, August 22 - 27, Antwerp, 2004a.

FELICISSIMO, M.P, RODRIGUES, U.P, PEIXOTO, J.L., PIREAUX, J.J., TOMAS, R., AZIOUNE, A. XPS and SIMS applied to the compositional study of Pre-Colonial pottery from South Pantanal. Philosophical Magazine A - Physics of Condensed Matter Structure Defects and Mechanical Properties, 84 (32), $2004 \mathrm{~b}$. 
FELICISSIMO, M.P., PEIXOTO, J.L., PIREAUX, J., DEMORTIER, G., RODRIGUES, U.P. Estudos arqueométricos de cerâmicas indigenas pré-coloniais das lagoas do Castelò e Vermelha, localizadas no Pantanal Sul-Mato-Grossense. Revista Canindé, 4, 326-368, $2004 \mathrm{c}$.

FELICÍSSIMO, M.P., RODRIGUES, U.P., PEIXOTO, J.L. SEM and EDS mapping as a tool for the study of additives in ancient ceramics. from the South-west border of Pantanal. Acta Microscopica A, 285 -286, 2001.

FILZMOSER, P., GARRET, R. G., REIMANN, C. Multivariate outlier detection in exploration geochemistry. Computers \& Geosciences, 31579 - 587, 2005.

FITZPATRICK, S. M., DICKINSON, W. R., CLARK, G. Ceramics petrography and cultural interaction in Palau, Micronesia. Journal of Archaeology Science, 30, 1175-1184, 2003.

FROH, J. Archacological ceramics studied by scanning Electron Microscopy. Hyperfine Interactions, 154, $159-176,2004$.

FROST, R. L. The structure of the kaolinite minerals - A FT-Raman study. Clay Minerals, $32(1), 65-77,1997$.

FROST, R. L., VASSALLO, A. M. The dehydroxylation of the kaolinite clay minerals using infrared emission spectroscopy. Clays and Clay Minerals, 44 (5), 635 - 651, 1996.

GARDOLINSKI, J. E., FILHO, H. P. M., WYPYCH, F. Comportamento térmico da caulinita hidratada. Quim. Nova, 26 (1), 30 - 35, 2003.

GEBHARD, R. Materials analysis in Archaeology. Hyperfine Interactions, 150 I-5, 2003.

GLASCOCK, M. D., NEFF, H. Neutron activation analysis and provenance research in archacology. Measurement Science \& Technology, 14 (9), 1516-1526, 2003.

GLASCOCK, M. D., NABELEK, P. I., WEINRICH, D. D., COVENEY, R. M. Correcting for uranium fission in instrumental neutron-activation analysis of high-uranium rocks. Journal of Radioanalytical and Nuclear Chemistry, 99 (1), 121 - 131, 1986.

GLASCOCK, M.D. Characterization of ceramics at MURR by NAA and Multivariate Statistics. In: Chemical Characterization of Ceramic Paste in Archaeology, Monographs in World Archaeology, H. NEFF, Prehistory Press, Section 1, 11, 1992.

GLASCOCK, M.D. The status of activation analysis in archeology and geochemistry. Journal of Radiochemistry and Nuclear Chemistry, 244(3), 537 - 541, 2000.

GOUlART, E. P., ALVES, M. A., FERNANDES, S. C. G., MUNITA, C. S., PAIVA, R. P. Caracterização microestrutural e química de amostras de cerâmica pré-histórica do sítio Água Limpa, Monte Alto, São Paulo. Revista Canindé, 7, 187-196, 2006. 
GOUlART, E. P., ALVES, M. A., ZANDONADI, A. R., MUNITA, C. S., PAIVA, R. P. Caracterização microestrutural e química de amostras de cerâmica índigena. Revista Canindé, 6, $67-84,2005$.

GOULART, E.P. Técnicas Instrumentais para caracterização mineralógica $c$ microestrutural de materiais cerâmicos arqueológicos. Revista Canindé, 4, 249 - 281, 2004.

GOUVEIA, M. A., PRUDENCIO, M. I. New data on sixteen reference materials obtained by INAA. Journal of Radioanalytical and Nuclear Chemistry, 245 (1), 105 - 108, 2000.

GRIM, R. E. Clay Mineralogy. McGraw - Hill Book Company Ltda, New York, 1953.

GROGLER, N., HOUTERMANS, F.G., STOUFFER, H. Ueber die datierung von keramik und ziegel durch thermolumineszenz. Helv. Physi Acta, 33, 595-596, 1960.

GRUBBS, F. E. Sample criteria for testing outlying observations. Annals of Mathematical Statistics, 21, $27-58,1950$.

GUASC-JANÉ, M. R., ANDRÉS-LACUEVA, C., JÁURENGUI, O., LAMUELARAVENTÓS, R. M. First evidence of white wine in ancient Egypt from Tutankhamun's tomb. Journal of Archaeological Science, 33, 1075 - 1080, 2006.

GUIDON, N., SALVIA, E.S.L., MARANCA, S., WATANABE, S., AYTA, W.E.F. Some evidence of date of first humans to arrive in Brazil. Journal of Archaeological Science, 29, $1-6,2002$.

GUNNEWEG, J., PERLMAN, I., ASARO, F. A Canaanite jar from Enkomi. Israel Exploration Journal, $168-172,1987$.

HAIR JUNIOR, J.F., ANDERSON, R.E., TATHAM, R.L., BLACK, C. Análise multivariada de dados. Bookman, Porto Alegre, 2005.

HALL, M.E. Pottery production the Late Jomom period: insight from the chemical analyses of Kasomori B Pottery. Journal of Archaeological Science, 31 (10), $1439-1450$, 2004.

HARBOTTLE, G. Chemical characterization in archaeology. In contexts for Prehistoric Exchange, eds. Ericson, J. E., T. K., Academic Press, New York, 1982.

HARBOTTLE, G. Activation analvsis in archacologv. In Radiochemistry 3 (ed. G.W.A. Newton), London, 33-72, 1976.

HARDIR, J., ROCKE, D. M. Outlier detection in the multiple cluster setting using the minimum covariance determinant estimator. Computation Statistics \& Data Analysis, 44, $625-638,2004$.

HAUSLER, W. Firing of clays studied by X-ray Diffraction and Mossbauer spectroscopy. Hyperfine Interactions, 154, $121-141,2004$. 
HEDLEY, I. G. New directions in archaeomagnetism. Journal of Radioanalytical and Nuclear Chemistry, 247(3), 663-672, 2001.

HERNANDEZ, R.P.B., GONÇALVES, R. P., NEIVA, A. C., MELLO, H.G., LIMA, S.C., COSTA, V. Caracterização visual espectroscópica e por difração de produtos de corrosão de peças metálicas do MAE-USP. In: 24" Congresso Brasileiro de Corrosão, 21 -- 25 junho, Rio de Janeiro, 2004.

HEVESY, G., LEVI, H. Kgl. Danske Videnskab. Selskab. Math. Fys., 15 (5), 1936.

HEYDORN, K. INAA - Application and limitation. Fresenius Journal of Analytical Chemistry, 337 (5), $498-502,1990$.

HOSSAIN, S. M., DE CORTE, F., VANDENBERGHE, D., VAN DEN HAUTE, P. The role of $k(0)-N A A$ in the assessment of the annual radiation dose for use in TL/OSL dating of sediments. Journal of Radioanalytical and Nuclear Chemistry, 257 (3), 639-642, 2003.

ICHIKAWA, Y. Dating of ancient ceramics by thermoluminescence. Bulletin of the .Institute of Chemical Research, Kyoto, 43, 1-6, 1965.

INTERNATIONAL ATOMIC ENERGY AGENCY. Proficiency Test on Determination of Major. Minor and Trace Elements in Ancient Chinese Ceramic, IAEA/AL/168, Seibersdorf, 2006.

INTERNATIONAL ATOMIC ENERGY AGENCY. Nuclear Analytical Techniques in Archaeological Investigations, IAEA-TRS416, Vienna, 2003.

IINTERNATION ATOMIC ENERGY AGENCY. Practical aspects of operating a neutron activation analysis laboratory, IAEA-TECDOC-564, Vienna, 1990.

JAREK, S. Minormtest: A Package for normality test multivariate variables. 2001. (disponível para download em: $\underline{\text { http://cran.r- }}$ project.org/src/contrib/Descriptions/mvnormtest.html).

JOHNSON, R. A., WICHERN, D. W. Applied Multivariate Statistical Analysis (3"ed). Ed. Prentice Hall, New Jersey, pp 575- 584, 1992

JOLLIFFE, I. T. Rotation of ill-defined principal components. Applied Statistics-Journal of The Royal Statistical Society Series C, 38 (1), 139 - 147, 1989

JOLLIFFE, I. T., JONES, B., B. MORGAN, J. T. Identifing influential observations in hierarchical cluster analysis. Iournal of Applied Statistics, 22 (1), 1995.

JONES, A. Archaeometry and Materiality: Materials-based analysis in theory and practice. Archaeometry, 46 (3) 327-338, 2004.

KAISER, H. F. The varimax criterion for analytic rotation in factor analysis. Psychometrika, 35, 401-415, 1958. 
KAUFMAN, L., ROUSSEEUW, P. J. Finding groups in data: An introduction to cluster analysis. John Wiley \& Sons, New York, 1990.

KENNEDY, G.C., KNOPFF, L. Dating by thermoluminescence. Archaeology, 13. 147 $148,1960$.

KENNETT, D.J., ANDERSON, A.J., CRUZ, M.J., CLARK, G.R., SUMMERHAYES, G.R. Geochemical characterization of Lapita pottery via Inductively Coupled Plasma mass Spectrometry (ICP-MS). Archaeometry, 46(1), 35 - 46, 2004.

KLEIN, M., JESSE, F., KASPER, H.U., GOLDEN, A. Chemical characterization of ancient pottery from Sudan by $x$-ray fluorescence spectroscopy (XRF), electron microprobe analyses (EMPA) and inductively coupled plasma mass spectrometry (ICP-MS). Archaeometry, 46(3), 339-347, 2004.

KLUG, H.P. e ALEXANDER, L.E. X-Ray Diffraction Procedures for Polycrystalline and Amorphous Materials. $2^{\text {nd }}$ Ed. John Wiley, New York, 1974.

KULEFF, I., DJINGOVA, R. Activation analysis in archaeology. In: Activation Analysis, edited by Z. Alfassi, CRC Press, vol. 2, pp 431, 1990.

KULEFF, I., PERNICKA, E. INAA of some geological standard reference materials. Journal of Radioanalytical and Nuclear Chemistry, 251 (1), 139 - 143, 2002.

LAGE, M.C.S.M., MORAES, B.C. A utilização da química como indicador do uma ocupação humana pré-histórica no PARNA Serra da Capivara. CLIO - Série Arqueológica, 17, 23 - 26, 2005.

LEGODI, M.A., DE WALL, D. Raman spectroscopic study of ancient South African domestic clay pottery. Spectrochimica Acta Part A - Molecular and Biomolecular Spectroscopy, 66 (1), 135-142, 2007.

LEUTE, U. Archaeometry: A Introduction to Physical Methods in Archaeology and the History Art. New York: VCH Publishers, 1987.

LUNA, S. C. A. As pesquisas arqueológicas sobre cerâmica no Nordeste do Brasil. Revista Canindé, 8, 167-207, 2006.

LUNA, S.C.A. Os grupos pré-históricos do Baixo São Francisco. ClIO - Série Arqueológica, 2, 4-41, 2005.

LUNA, S.C.A. Sobre as origens da agricultura e da cerâmica pré-histórica no Brasil. CLIO - Série Arqueológica, 1 (16), 67 - 78, 2003.

LUNA, S. C. A. As Populações Ceramistas Pré - Históricas no Baixo São Francisco. Recife, 2001. Tese de Doutorado, Departamento de História - Universidade Federal de Pernambuco. 
MA, Q., YAN, A., HU, Z., LI, Z., FAN, B. Principal component analysis and artificial neural networks applied to the classification of Chinese pottery of neolithic age. Analytical Chimica Acta, 406, 247 - 256, 2000.

MAGAlHÃES, M.N., LIMA, A.C.P. Noções de Probabilidade e Estatística. Editora da Universidade de São Paulo. São Paulo, 2004.

MAGEE, P., BARBER, D., SOBUR, M., JASIM, S. Sourcing Iron Age softstone artifacts in southeastern Arabia: results from a programme of analysis using Inductively Coupled Plasma - Mass Spectrometry/Optical Emission Spectrometry (ICP - MS/OES). Arabian Archaeology and epigraphy, 16(2), 129 - 143, 2005.

MARDIA, K. V. Applications of some measures of multivariate skewness and kurtosis for testing normality and robustness studies. Sankhya B, 36, 115-128, 1974.

MARDIA, K. V., KENT, J. T. Rao score tests for goodness of fit and independence. Biometrika, 78, 355-363, 1991.

MARTIN, G. As pinturas rupestres do Sítio Alcobaça, Buique, no contexto da Tradição Agreste. CLIO - Série Arqueológica, 18, 27 -50, 2005.

MARTIN, G. O cemitério pré-histórico Pedra do Alexandre, em Carnaúba do Dantas, RN. . CLIO - Série Arqueológica, 11, 43 - 57, 1996.

MARTIN, G. O povoamento Pré-histórico do Vale do são Francisco. CLIO - Série Arqueológica, 1, 9-41, 1998.

MARTIN, G. Pré-história do Nordeste do Brasil. 3.ed. Recife: Editora Universitária da UFPE, 2000.

MARTIN, G., AGUIAR, A. Projeto Itaparica de salvamento arqueológico. CLIO - Série Arqueológica, 17, $127-133,1984$.

MASSART, D. L., KAUFMAN, L. The interpretation of analytical chemical data by the use of cluster analysis. John Wiley \& Sons, New York, pp 17-37, 1983.

MATSUOKA, M., TAKATOHI, U.E., WATANABE, S., NAKAJIMA, T. TL dating of fish fossil from Brazil. Radiation Protection Dosimetry, 6, 185 - 188, 1984.

MAZESS, R.B., ZIMMERMAN, D.W. Pottery dating, from thermoluminescence. Science, $152,347-348,1966$.

MAZZOCCHIN, G. A., AGNOLI, F., COLPO, I. Investigation of roman age pigments found on pottery fragments. Analytica Chimica Acta, 478, 147-161, 2003.

McKEEVER, S.W.S. Thermoluminescence of solids. London: Cambridge University Press, 1985. 
MECKLIN, C. J., MUNDFROM, D. J. An appraisal and bibliography of tests for multivariate normality. International Statistical Review, 72 (1), 123 - 138, 2004.

MEDLIN, W.L. Thermoluminescence of geological matcrials. Ed. D.J. Medougall. London: Academic Press, 1968.

MEJDAHL, V. Thermoluminescence dating of ancient Danish ceramics. Archaeometry, $11,99-104,1969$.

MIYAMOTO, M. Estudo e aplicação da dosimetria termoluminescente na datação Dissertação de Mestrado ao Instituto de Física da USP, 1973.

MOMMSEN, H. Provenance determination of pottery by trace element analysis: Problems, solutions and applications. Journal of Radioanalytical and Nuclear Chemistry, $247(3), 657-662,2001$.

MOMMSEN, H. Short Note: Provenance of Pottery - The Need for an Integrated Approach. Archaeometry, 46 (2) $267-271,2004$.

MOMMSEN, H., KREUSER, A., WEBER, J. A method for grouping pottery by chemical composition. Archaeometry, 30, 47-57, 1988.

MOROPOULOU, A., BAKOLAS, A., BISBIKOU, K. Characterization of ancient, Byzantine and later historic mortars by thermal and $X$-ray-diffraction techniques. Thermochimica Acta, 269-270, 779-795, 1995.

MONTANA, G., MOMMSEN, H., ILIOPOUlOS, I., SCHWEDT, A., DENARO, M. The petrography and chemistry of thin-walled ware from an Hellenistic - Roman site at Segesta (Sicily). Archaeometry, 45(3), 375 - 389, 2003.

MONTES, C. R., MELFI, A. J., CARVALHO, A., VIEIRA-COElHO, A. C., FORMOSO, M. L. L. Genesis, mineralogy and geochemistry of kaolin deposits of the Jari river. Amapa State, Brazil. Clays and Clay Minerals, 50 (4), 494 - 503, 2002.

MUNITA, C. S., BARROSO, L. P., OLIVEIRA, P.M.S. Stopping rule for variable selection using stepwise discriminant analysis. Journal of Radioanalytical and Nuclear Chemistry, 269(2), 335 - 338, 2006.

MUNITA, C. S., NASCIMENTO, A., SCHREIBER, S. B., LUNA, S., OLIVEIRA, P. M. S. Chemical study of some ceramics, from Brazilian Northeast. Journal of Radioanalytical and Nuclear Chemistry, 259(2), 305-309, 2004.

MUNiTA, C. S., PAIVA, R. P., ALVES, M. A., DE OliveirA, P. M. S., MOMOSE, E. F. Provenance study of archaeological ceramic. Journal of Trace And Microprobe Techniques, 21 (4), $697-706,2003$.

MUNITA, C. S., PAIVA, R. P, ALVES, M. A., OliveirA, P. M. S, MOMOSE, E. F. Major and trace element characterization of prehistoric ceramic from Rezende archacological site. Journal of Radioanalytical and Nuclear Chemistry, 248(1), 93 - 96, 2001 a. 
MUNITA, C. S., PAIVA, R. P., OlIVEIRA, P. M. S., MOMOSE, E. F., PLA, R., MORENO, M., ANDONIE, O., FALABELLA, F., MUNOZ, L., KOHNENKAMP, I. Intercomparison among three activation analysis laboratories in South America. Journal Of Trace And Microprobe Techniques, 19 (2), 189 - 197, $2001 \mathrm{~b}$.

MUNITA, C. S., PAIVA, R. P, AlVES, M. A., MOMOSE, E. F., SAIKI, M. Chemical characterization by INAA of Brazilian ceramics and cultural implications. Journal of Radioanalytical and Nuclear Chemistry, 244(3), 575 - 578, 2000.

MURAD, E., WAGNER, U. Mössbauer spectra of kaolinite, halloysite and firing products of kaolinite - new results and reappraisal of published work. Neus Fahrbuch Für Mineralogie - Abhandlungen, 162, 281 - 309, 1991.

NEFF, H. RQ - mode principal components analysis of ceramics compositional data. Archaeometry, 36 (1), $115-130,1994$.

NEIVA, A.C., DRON, J.N., MELO, H.G., LIMA, S.C. EDXRF analysis of alloys and corrosion products of metallic Pre-hispanic pieces of the Museum of Ethnology and Archaeology of the University of Sao Paulo. In: TMS 2006 - 135th Annual Meeting \& Exhibition of The Minerals, Metals \& Materials Society, March $12-16$, 2006, San Antonio, Texas. Collected Proceedings: Structure, Extraction, Processing and Properties. Warrendale, PA, USA : The Minerals, Metals \& Materials Society, 2006. p. 189-198.

NI, B. F., WANG, P. S., TIAN, W. Z. INAA Of IAEA-33I (Spinach), SRM for 40 Elements. Journal of Radioanalytical and Nuclear Chemistry, 196 (2), 387 - 392, 1995.

NíCOLI, 1. G. Estudos de Cerâmicas de Sitios Arqueológicos Circulares da Bacia Amazônica por Meio de Métodos Geoquímicos: Datação e Caracterização. Niterói, 2000. Tese de Doutorado, Instituto de Geociências - Universidade Federal Fluminense.

NYAKAIRU, G. W. A., KOEBERL, C., KURZWEIL, H. The Buwambo kaolin deposit in central Uganda: Mineralogical and chemical composition. Geochemical Journal, 35245 $256,2001$.

OKADA, K., SHIMAI, A., TAKEI, T., HAYASHI, S., YASUMORI, A., MACKENZIE, K. J. D. Preparation of microporous silica from metakaolinite by selective leaching method. Microporous and Mesoporous Materials, 21 (4-6), 289 - 296, 1998.

OLIVEIRA, C.A. Abordagens teóricas dos grupos pré-históricos ceramistas no Nordeste. Revista Canindé, 1, 1-26, 2001.

OLIVEIRA, L.C., BOMFIM, A.P.S., SOUZA, S.O. Estudo do tempo de vida dos picos termoluminescentes do quartzo de Xingó. Revista Canindé, 8, $211-214,2006$.

PAPADOPOULOU, D. N., LALIA-KANTOURU, M., KANTIRANIS, N., STRATIS, $J$. A. Thermal and mineralogical contribution to the ancient ceramics and natural clays characterization. Journal of Thermal Analysis and Calorimetry, 84, 39-45, 2006. 
PAPPALARDO, L., ROMANO, F.P., GARRAFFO, S., DE SANOIT, J., MARCHETTA, C., PAPPALARDO, G. The Improved LNS PIXE - Alpha Portable System: Archaeometric Applications. Archaeometry, 45 (2), 333 - 339, 2003.

PAVIA, S. The determination of brick provenance and technology using analytical techniques from the Physical Science. Archaeometry, 42(2), 201 - 218, 2006.

PENNY, K. I. Appropriate critical values when testing for a single multivariate outlier by using the Mahalanobis distance. Applied Statistical, 35, 153 - 162, 1987.

PERLMAN, I., ASARO, F. Pottery analysis by neutron activation. In Science and Archaeology (ed. R.H. Brill), London, 182 - 195, 1971.

PERMAN, I., ASARO, F. Pottery analysis by neutron activation. Archaometry, 1121 $52,1969$.

POSTON, W. L., MARCHETTE, D. J. Recursive dimensionality reduction using Fisher's Linear Discriminant. Pattern Recognition, 31 (7), 881 - 888, 1998.

RALPH, E.K., HAN, M.C. Dating of pottery by thermoluminescence. Nature, 210, 245 $247,1966$.

RANDAL, J.T, WILKINS, M.H.F. Phosphorescence and electron traps. Proc. R. Soc., Ser. A, 184, $366-390,1945$.

RICE, P. M. Pottery Analysis: a Sourcebook. University of Chicago Press, Chicago, pp 90 $-93,1987$.

RIZZUTTO, M. A., TABACNIKS, M. H., ADDED, N., BARBOSA, M. D.L., CURADO, J.F., SANTOS, W. A., LIMA, S. C., MELO, H. G., NEIVA, A. C. The external beam facility used to characterize corrosion products in metallic statuettes. Nuclear Instruments and Methods in Physics Research Section B: Beam Interactions with Materials and Atoms, 240(1-2), 549-553, 2005.

ROUMIÉ, M., REYNOLDS, P., ATALLAH, C., BAKRAJI, E., ZAHRAMAN, K., NSOULI, B. Provenance study of excavated pottery from Beirut using PIXE cluster analysis. Nuclear Instruments and Methods in Physics Research Section B: Beam Interactions with Materials and Atoms, 249 (1-2), 612 - 615, 2006.

ROYSTON, P. A remark on algorithm as 181: The W test for normality. Applied Statistics, $44,547-551,1995$.

ROYSTON, P. An extension of Shapiro and Wilk's $W$ test for normality to large samples. Applied Statistics, 31, 115 - 124, 1982.

SANTOS, G. M., GOMES, P. R. S., YOYAMA, Y., TADA., M. L., CRESSWELL., R. G., FIFIELD, L. K. Datação por ${ }^{14}$ C Utilizando Espectrometria de Massa com Acelerador de Particulas. Revista de Física Aplicada e Instrumentação, 14 (1) 18 - 26, 1999. 
SANTOS, J. O. Datação Arqueológica por Termoluminescência a partir de vestigios cerâmicos do Sítio Justino na Região do Baixo São Francisco - Dissertação de Mestrado apresentada ao Núcleo de Pós-graduação em Física da UFS, 2002.

SANTOS, J. O., MUNITA, C. S., VALERIO, M. E. G., VERGNE, C., OLIVEIRA, P.M.S. Determination of trace elements in archaeological ceramics and application of Kernel Density Estimates: Implications for the definition of production locations. Journal of Radioanalytical and Nuclear Chemistry, 269(2), 441 - 445, 2006.

SANTOS, P.S. Tecnologia de argilas. Ed. Edgar Blücher, São Paulo, pág. 802, 1975.

SASTRY, M.D., SUllasi, H.S.L., CAMARGO, F., WATANABE, S., PROUS, A. P.P., SILVA. Dating sediment deposits on Montalvanian carvings using EPR and TL methods. Nuclear Instruments and Methods in Physics Research B, 213, 751 - 755, 2004.

SAYRE, E.V. DODSON, R.W. Neutron activation study of Mediterranean postsherds. American Journal of Archaeology, 61, 35 - 41, 1957.

SCHORTMAN, E. M., URBAN, P. A. Modeling the roles of craft production in ancicnt political economies. Journal of Archaeological Research, 12 (2) 185 - 226, 2004.

SILVA, R. M.C., NASCIMENTO, V. F., APPOLONI, C. R., PEREZ, C. A. Fluorescência de Raios $-X$ aplicada a amostras arqueológicas. Revista do Museu de Arqueologia e Etnologia da USP, 15-16, 2005.

SIlva, R. M.C., NASCIMENTO, V. F., APPOLONI, C. R., PEREZ, C. A. Caracterização quimica de fragmentos cerâmicos arqueológicos por microfluorescência de Raios-X. Revista Brasileira de Pesquisa e Desenvolvimento, 4(3), 957-978, 2002.

SILVA, R.N. Cadeia operatória: A perspectiva tecnológica para o estudo do material lítico dos sítios não-especializados da região de Xingó - Dissertação de Mestrado apresentada ao Núcleo de Pós-graduação em Geografia da UFS (2005).

SOUZA, S.O., BARRETO, M.F.A., SANTOS, J.O., AMARAL JÚNIOR, J.F., MILITÃO, D.G., VALÉRIO, M.E.G. Datação de artẹfatos arqueológicos de Xingó por termoluminescência. Revista Canindé, 8, 139-149, 2006.

SPASSOV, S., HUS, J. Estimating backing temperatures in Roman pottery kiln by rock magnetic properties: implications of thermochemical alteration on archaeointensity determinations. Geophysical Journal Internation, 167(2), 592-604, 2006.

STANJEK, H., HAUSLER, W. Basics of X-ray diffraction. Hyperfine, 154, $107-119$, 2004.

SUZUKI, S., HIRAI, S. Multielement analysis of environmental reference materials by instrumental neutron-activation analysis. Analytical Sciences, 8 (3), 437 - 441, 1992.

SZMUK, P.E., WATANABE, S. Dating of brazilian indian pottery. TLD Publication IAEA, n²31, 1971. 
TATUMI, S.H., GOZZI, G., YEE, M., DE OLIVEIRA, V.I., SALLUN, A.E.M., SUGUIO, K. Luminescence dating of quaternary deposits in geology in Brazil. Radiation Protection dosimetry, 119 (1-4), 462 - 469, 2006.

TATUMI, S.H., KOWATA, E.A., GOZZI, G., KASSAB, L.R.P., SUGUIO, K., BARRETO, A.M.F., BEZERRA, F.H.R. Optical dating results of beachrock, eolic dunes and sediments applied to sea-level changes study. Journal of luminescence, $102,562-565,2003$.

TATUMI, S.H., MARTINS, G.R., KASHIMOTO, E.M., AYTA, W.E.F., WATANABE, S. Thermoluminescence dating of archaeological ceramics collected from state of Mato Grosso do Sul, Brazil. Radiation Effects and Defects in Solids, 146, $297-302,1998$.

TATUMI, S.H., MATSUOKA, M., WATANABE, S. Datação de estalagmite pelos métodos da DTL (Dosimetria Termoluminescente). Ciência e Cultura, 38, 297 - 297, 1986.

TITE, M. S. Pottery production, distribution, and consumption - The contribution of the physics sciences. Journal of Archaeological Method and Theory, 6 (3), 181-233, 1999.

VANDIVER, P. The role of materials research in ceramics and archaeologv. Annu. Rev. Mater. Res. 31373 - 385, 2001.

VELDE, B., DRUC, I. C. Archaeological Ceramic Materials: Origin and Utilization. Berlin: Springer, 1999.

VERGNE, M.C.S., FAGUNDES, M. Estudos tecnológico e tipológico da cerâmica arqueológica do Sítio Curituba I, Canindé de São Francisco - SE. Revista Canindé, 8, 151 $-165,2006$.

VERGNE, C. Arqueologia do Baixo São Francisco: estruturas funerárias do Sítio Justino - região de Xingó, Canindé do São Fràncisco, Sergipe. São Paulo, 2004. Tese de doutorado, Museu de Arqueologia e Etnologia - Universidade de São Paulo.

VERGNE, M.C.S., FAGUNDES, M. Atributos tecnológicos da indústria lítica do Sítio Barragem (Decapagem 01 a 06), Xingó - Alagoas. Revista Canindé, 4, 9-53, 2004.

VERGNE, M.C.S. Relatório Final do Projeto de Salvamento Arqueológico de Xingó. São Cristóvão, Universidade Federal de Sergipe/CHESF, 1998. (PAX)

VERGNE, M.C.S., CARVALHO, O.A., QUEIROZ, A.N. Estruturas funerárias do Sitio Justino:distribuição no espaço e no tempo. Revista Canindé, 4, 251 - 273, 2002.

VIEIRA JUNIOR, A.S. PALMEIRA, J.A.V. Grupos Pré-históricos de Xingó: Um estudo cranioscópio e craniométrico. Canindé do São Francisco: Museu de Arqueologia de Xingó, 2006. 
VINAGRE FILHO, U.M., LATINI, R.M., BELLIDO, A.V.B., BUARQUE, A., BORGES, A.M. Ancient ceramic analysis by activation in association with multivariate methods. Brazilian Journal of Physics, 35(3), 779-781, 2005.

WAGNER, F.E., KYEK, A. Mossbauer spectroscopy in Archaeology: Introduction and experimental consideration. Hyperfine Interactions, 154, 5-33, 2004.

WATANABE, S., MITTANI, J.C., CANO, N.F. Use of $[P b-P b] 3$ center of the amazonite for dating. Applied Radiation and Isotopes, 62, 251 - 254, 2005.

WATANABE, S., HAMAGUCHI, H., AYTA, W.E.F. Some evidence of a date of first humans to arrive in Brazil. Journal of Archaeological Science, 30, 351 - 354, 2003.

WATANABE, S., ORTEGA, N.R.S., AYTA, W.E.F., COAQUIRA, J.A.H., CORTEZÃO, S.U., ARENAS, J.S.A. Thermoluminescence dating of sands from llha deCananeia. Radiation Measurements, 27(2), 373 - 376, 1997.

WICKS, F. J., CORBEIL, M. C., BACK, M. E., RAMIK, R. A. Microbeam x-raydiffraction in the analysis of minerals and materials. Canadian Mineralogist, 33 (2), $313-$ 322, 1995.

WILKS, S. S. Multivariate statistical outliers. Sankhya, 25, 407-426, 1963.

WINTLE, A. G. Luminescence Dating: Laboratory Procedures and Protocols. Radiation Measurements, 27(5/6), $769-817,1997$. 